\title{
The Probability of
}

Containment Failure by
Direct Containment Heating

\section{in Surry}

Prepared by

M. M. Pilch, M. D. Allen/SNL

B.W. Spencer/ANL

K. D. Bergeron/SNL

K. S. Quick, D. L. Knudson/INEL

E. E. Tadios, D. W. Stamps/SNL

Sandia National Laboratories

Argonne National Laboratory

Idaho National Engineering Laboratory

Prepared for

U.S. Nuclear Regulatory Commission 


\section{AVAILABILITY NOTICE \\ Availability of Reference Materials Cited in NRC Publications}

Most documents cited in NRC publications will be available from one of the following sources:

1. The NRC Publlc Document Room, 2120 L Street, NW., Lower Level, Washington, DC 20555-0001

2. The Superintendent of Documents, U.S. Government Printing Office, P. O. Box 37082, Washington, DC 20402-9328

3. The National Technical Information Service, Springfield, VA 22161-0002

Although the llsting that follows represents the majority of documents clted in NRC publications, it is not intended to be exhaustive.

Referenced documents available for inspection and copying for a fee from the NRC Public Document Room include NRC correspondence and internal NRC memoranda; NRC bulletins, circulars, information notices, inspection and investigation notices; licensee event reports; vendor reports and correspondence: Commission papers; and applicant and ilcensee documents and correspondence.

The following documents in the NUREG series are avallable for purchase from the Government Printing Office: formal NRC staff and contractor reports, NRC-sponsored conference proceedings. international agreement reports, grantee reports, and NRC booklets and brochures. Also available are regulatory guides, NRC regulations in the Code of Federal Regulations, and Nuclear Regulatory Commission Issuances.

Documents avallable from the National Technical Information Service include NUREG-series reports and technical reports prepared by other Federal agencies and reports prepared by the Atomic Energy Commission. forerunner agency to the Nuclear Regulatory Commission.

Documents avallable from public and special technical libraries include all open literature items, such as books, Journal articles, and transactions. Federal Register notices. Federal and State legislation, and congresslonal reports can usually be obtalned from these libraries.

Documents such as theses, dissertations, foreign reports and translations, and non-NRC conference proceedings are available for purchase from the organization sponsoring the publication cited.

Single coples of NRC draft reports are available free, to the extent of supply, upon written request to the Offlce of Administration, Distribution and Mail Services Section, U.S. Nuclear Regulatory Commission, Washington, DC 20555-0001.

Copies of industry codes and standards used in a substantive manner in the NRC regulatory process are maintained at the NRC Library. Two White Flint North. 11545 Rockville Pike, Rockville, MD 20852-2738, for use by the public. Codes and standards are usually copyrighted and may be purchased from the originating organization or, if they are American National Standards, from the American National Standards Institute, 1430 Broadway. New York, NY 10018-3308.

\section{DISCLAIMER NOTICE}

This report was prepared under an international cooperative agreement for the exchange of technical information. Neither the United States Government nor any agency thereof, nor any of their employees, makes any warranty, expressed or implied, or assumes any legal liability or responsibility for any third party's use, or the results of such use, of any information, apparatus, product, or process disclosed in this report, or represents that its use by such third party would not infringe privately owned rights. 


\section{DISCLAIMER}

Portions of this document may be illegible in electronic image products. Images are produced from the best available original document. 
NUREG/CR-6109

SAND93-2078

\section{The Probability of Containment Failure by Direct Containment Heating in Surry}

Manuscript Completed: February 1995

Date Published: May 1995

Prepared by

M. M. Pilch, M. D. Allen/SNL

B.W. Spencer/ANL

K. D. Bergeron/SNL

K. S. Quick, D. L. Knudson/INEL

E. L. Tadios, D. W. Stamps/SNL

Sandia National Laboratories

Albuquerque, NM 87185-1137

Argonne National Laboratory

9700 South Cass Avenue

Argonne, IL 60439

Idaho National Engineering Laboratory

P.O. Box 1625

Idaho Falls, ID 83415

\section{Prepared for}

Division of Systems Technology

Office of Nuclear Regulatory Research

U.S. Nuclear Regulatory Commission

Washington, DC 20555-0001

NRC Job Code J6027 


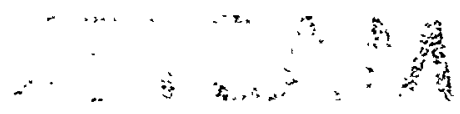




\begin{abstract}
This report uses the methodology and scenarios described in NUREG/CR-6075 and its supplement to address the direct containment heating (DCH) issue for the Surry nuclear power plant (NPP). Consistency of the initial condition distributions has been ensured by using insights from system-level codes, specifically SCDAP/RELAP5 and CONTAIN. The most useful insights are that the reactor coolant system (RCS) pressure is low at vessel breach, metallic blockages in the core region do not melt and relocate into the lower plenum, and melting of upper plenum steel is correlated with hot leg failure. The SCDAP/RELAP5 output was used as input to CONTAIN to assess the containment conditions at vessel breach.

The load evaluations for Surry showed no intersections of the load distributions with the containment strength distribution, and thus the DCH issue for Surry can be resolved based on containment loads alone. However, the likelihood of high RCS pressures at vessel breach was evaluated for Surry for a limited number of sequences. The probability of RCS pressures greater than 1.38 $\mathrm{MPa}$ for all station blackout scenarios without power recovery or operator intervention was found to be low $(\simeq 0.077)$. This probability could have been factored into the containment failure probability for Surry if there had been intersections of the load and strength distributions.
\end{abstract}





\section{CONTENTS}

$\underline{\text { Page }}$

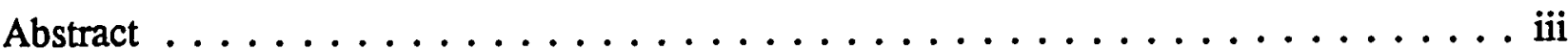

Foreword $\ldots \ldots \ldots \ldots \ldots \ldots \ldots \ldots \ldots \ldots \ldots \ldots \ldots \ldots \ldots \ldots \ldots \ldots \ldots \ldots$

Acknowledgments $\ldots \ldots \ldots \ldots \ldots \ldots \ldots \ldots \ldots \ldots \ldots \ldots \ldots \ldots \ldots \ldots \ldots$

Acronyms $\ldots \ldots \ldots \ldots \ldots \ldots \ldots \ldots \ldots \ldots \ldots \ldots \ldots \ldots \ldots \ldots \ldots$

Executive Summary $\ldots \ldots \ldots \ldots \ldots \ldots \ldots \ldots \ldots \ldots \ldots \ldots \ldots \ldots \ldots$

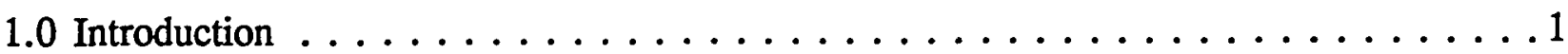

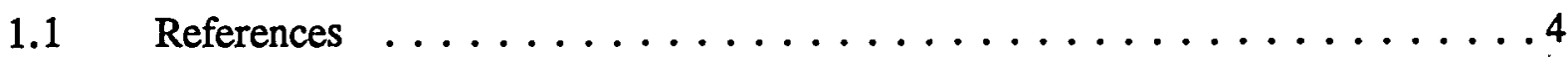

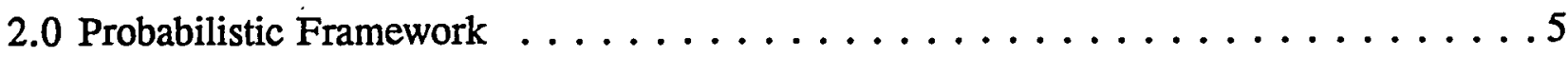

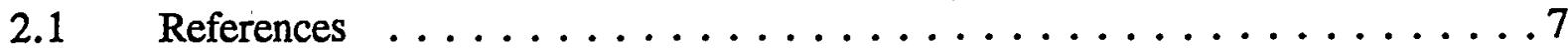

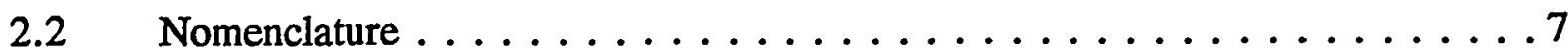

3.0 Quantification of Initial Conditions $\ldots \ldots \ldots \ldots \ldots \ldots \ldots \ldots \ldots \ldots \ldots \ldots \ldots$

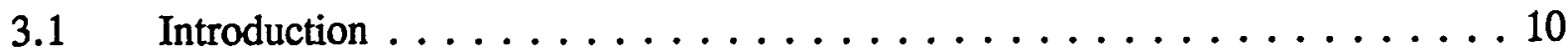

3.2 Splinter Scenarios . . . . . . . . . . . . . . . . . 11

3.3 Summary of SCDAP/RELAP5 and CONTAIN Insights $\ldots \ldots \ldots \ldots 14$

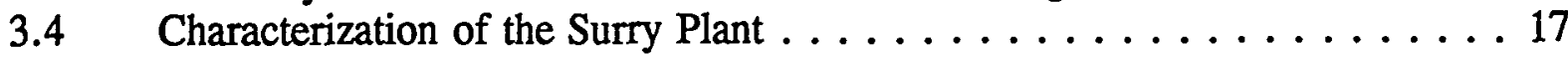

3.5 Definition of Probability Levels . . . . . . . . . . . . . . . . . . . . 19

3.6 Scenario V - SBLOCA with Repressurization of the RCS by

Operator Intervention . . . . . . . . . . . . . . 20

3.7 Scenario VI - SBLOCA under Wet Core Conditions . . . . . . . . 28

3.8 Summary Melt Masses and Compositions . . . . . . . . . . . 30

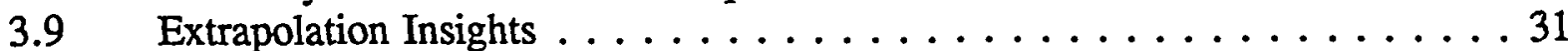

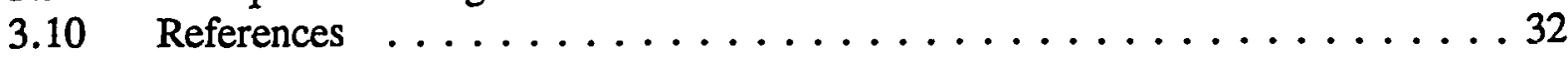

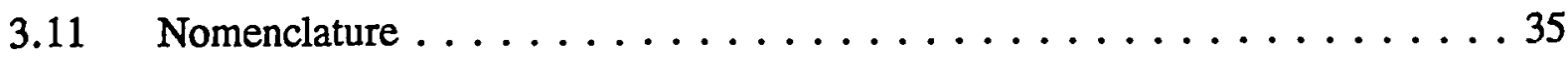

4.0 Quantification of the DCH Phenomenon $\ldots \ldots \ldots \ldots \ldots \ldots \ldots \ldots \ldots \ldots \ldots \ldots$

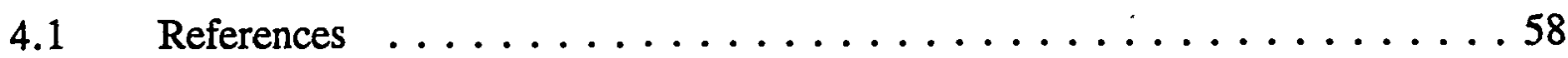

4.2 Nomenclature . . . . . . . . . . . . . . . . . . 59

5.0 Quantification of Containment Fragility $\ldots \ldots \ldots \ldots \ldots \ldots \ldots$

5.1 Fragility Curve Selected for DCH Evaluation . . . . . . . . . . 69

5.2 References ....................... 71 


\section{CONTENTS (concluded)}

\section{$\underline{\text { Page }}$}

6.0 Results and Sensitivities . . . . . . . . . . . . . . . 74

$6.1 \quad$ Results ........................ 74

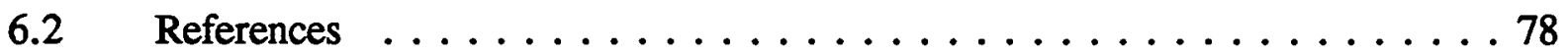

7.0 Conclusions and Recommendations $\ldots \ldots \ldots \ldots \ldots \ldots$. . . . . 87

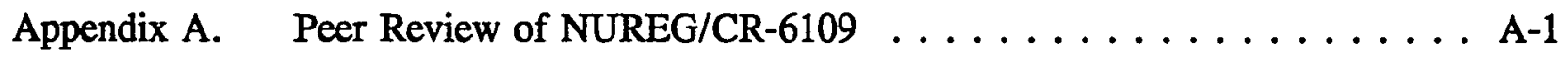

Appendix B. Summary of DCH Experiments and Insights $\ldots \ldots \ldots \ldots$ B-1

Appendix C. Tools for Quantification of DCH Containment Loads . . . . . . . . C-1

Appendix D. CONTAIN Calculations and Hydrogen Combustion Analyses for the

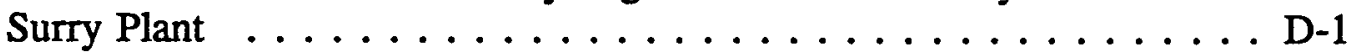

Appendix E. A SCDAP/RELAP5 Analysis Supporting DCH Issue Resolution for the Surry PWR $\ldots \ldots \ldots \ldots \ldots \ldots \ldots \ldots \ldots \ldots \ldots \ldots$

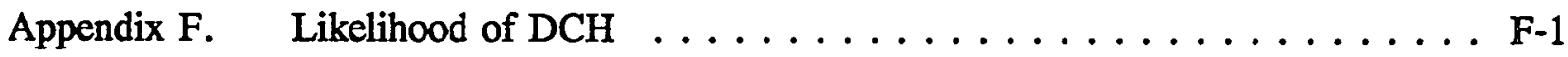

Appendix G. Comparison of CONTAIN and TCE Calculations . . . . . . . . G-1 


\section{LIST OF FIGURES}

Figure

Page

2.1 The probabilistic framework for containment failure under direct containment

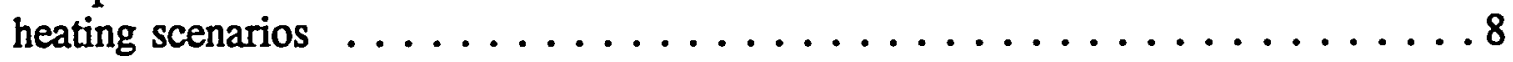

2.2 Illustration of the probabilistic framework in terms of schematic depiction of

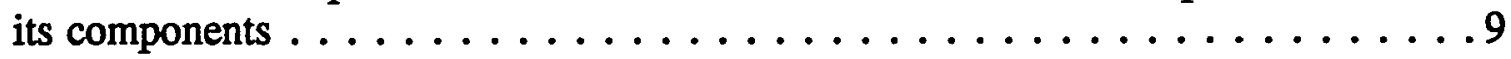

3.1 Splinter DCH scenarios used in NUREG/CR-6075 . . . . . . . . . . . . . 42

3.2 Splinter DCH scenarios reflecting working group recommendations $\ldots \ldots . \ldots 43$

$3.3 \quad$ Surry nuclear power plant $\ldots \ldots \ldots \ldots \ldots \ldots$

3.4 Distribution for fraction of $\mathrm{Zr}$ oxidized (core-wide) in Scenarios V and VI . . . 45

3.5 Crucible formation in a flooded RPV - Scenario V . . . . . . . . . . 46

3.6 Distribution for $\mathrm{UO}_{2}$ release from the crucible in Scenario $\mathrm{V} \ldots \ldots . \ldots$

3.7 Distribution for molten $\mathrm{UO}_{2}$ in the lower plenum at the time of vessel rupture

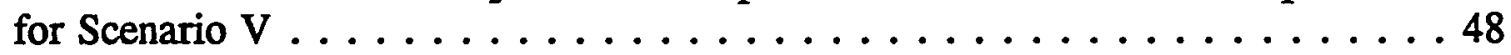

3.8 Crucible formation in wet core scenario with partial operator intervention Scenario VI ............................. . . . . . . . . . . . .

3.9 Distribution for $\mathrm{UO}_{2}$ release from the crucible in Scenario VI . . . . . . . . . 50

3.10 Distribution for molten $\mathrm{UO}_{2}$ in the lower plenum at the time of vessel rupture

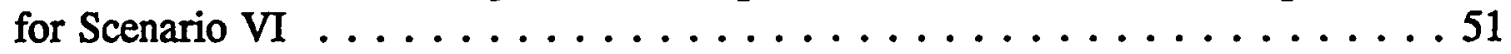

4.1 Validation of the two-cell equilibrium model against all experiments with

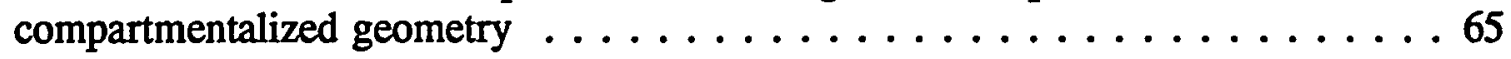

4.2 Validation of the coherence ratio for Surry-like cavity designs for scenarios

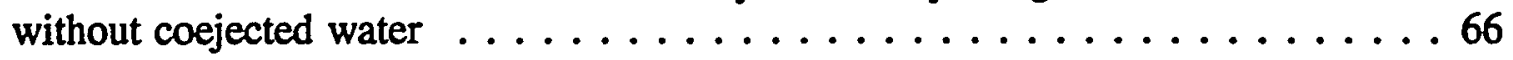

$4.3 \quad$ Validation of the hole ablation model ................... 67

$5.1 \quad$ Cumulative failure probabilities $\ldots \ldots \ldots \ldots \ldots \ldots$

6.1 Calculated distribution for the hole size $\ldots \ldots \ldots \ldots \ldots$

6.2 Calculated distribution for the coherence ratio $\ldots \ldots \ldots . \ldots . \ldots$ 


\section{LIST OF FIGURES (continued)}

Figure

6.3 Calculated distribution for the containment temperature $\ldots \ldots \ldots$. . . 84

6.4 Calculated distribution for the containment pressure $\ldots \ldots \ldots$. . . . 85

6.5 Scenario $\mathrm{V}$ with TMI-like containment conditions $\ldots \ldots \ldots 6$

C.1 Experimental validation of TCE model $\ldots \ldots \ldots \ldots \ldots \ldots \ldots$ C-9

C.2 CONTAIN predictions versus experimental results for (a) $\Delta \mathrm{P}$, and

(b) scaled $\mathrm{H}_{2}$ production for the standard input prescription $\ldots \ldots \ldots \ldots$ C-10

D.1 Schematic of containment design and nodalization for Surry power plant $\ldots$ D-12

D.2 Hydrogen source flow rates $\ldots \ldots \ldots \ldots \ldots \ldots \ldots \ldots \ldots \ldots \ldots \ldots$

D.3 Steam source flow rates $\ldots \ldots \ldots \ldots \ldots \ldots \ldots \ldots$ D-13

D.4 Gas temperature at source locations $\ldots \ldots \ldots \ldots \ldots \ldots \ldots \ldots \ldots \ldots$

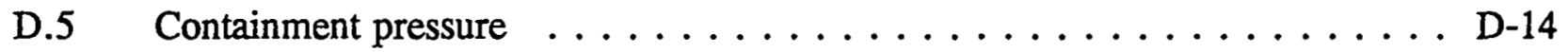

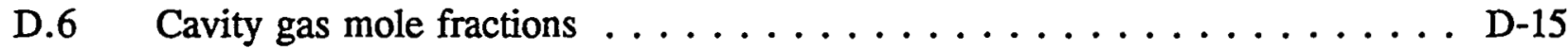

D.7 Cavity gas temperature $\ldots \ldots \ldots \ldots \ldots \ldots \ldots \ldots \ldots \ldots \ldots \ldots \ldots \ldots \ldots$

D.8 Steam generator room gas mole fractions $\ldots \ldots \ldots \ldots \ldots \ldots \ldots$ D-16

D.9 Steam generator room gas temperature $\ldots \ldots \ldots \ldots \ldots \ldots \ldots \ldots$ D-16

D.10 Annulus gas mole fractions $\ldots \ldots \ldots \ldots \ldots \ldots \ldots \ldots \ldots \ldots \ldots \ldots \ldots$

D.11 Annulus gas temperature $\ldots \ldots \ldots \ldots \ldots \ldots \ldots \ldots \ldots \ldots \ldots \ldots \ldots \ldots$

D.12 Dome gas mole fractions $\ldots \ldots \ldots \ldots \ldots \ldots \ldots \ldots \ldots$ D-18

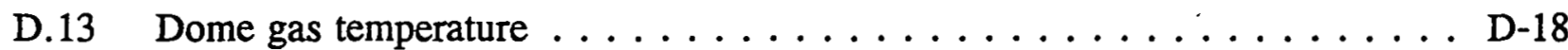

D.14 Autoignition temperature data for hydrogen-steam jets $\ldots \ldots \ldots \ldots$ D-19

D.15 Jet hydrogen concentration and temperature of the gases released from the PORV . . . . . . . . . . . . . . . . . . D 19 
List of Figures (continued)

Figure

Page

D.16 Jet hydrogen concentration and temperature of the gases released from the reactor coolant pump 1 seal leak $\ldots \ldots \ldots \ldots \ldots \ldots \ldots \ldots$ D-20

D.17 Jet hydrogen concentration and temperature of the gases released from the reactor coolant pump 2 seal leak $\ldots \ldots \ldots \ldots \ldots \ldots \ldots \ldots$ D-20

D.18 Jet hydrogen concentration and temperature of the gases released from the reactor coolant pump 3 seal leak $\ldots \ldots \ldots \ldots \ldots \ldots \ldots \ldots$ D-21

D.19 Jet hydrogen concentration and temperature of the gases released from the reactor coolant pump 3 seal leak $\ldots \ldots \ldots \ldots \ldots \ldots \ldots \ldots \ldots$ D-21

D.20 Jet hydrogen concentration and temperature of the gases hot leg break .... D-22

D.21 Jet hydrogen concentration and temperature of the gases hot leg break . . . D-22

E.1 Surry reactor vessel nodalization with provisions for in-vessel natural

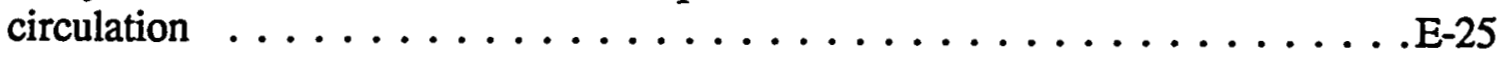

E.2 Pressurizer coolant loop nodalization for the Surry PWR without provisions for hot leg countercurrent natural circulation $\ldots \ldots \ldots \ldots \ldots \ldots \ldots$ E-26

E.3 Pressurizer coolant loop nodalization for the Surry PWR with provisions for hot leg countercurrent natural circulation $\ldots \ldots \ldots \ldots \ldots \ldots \ldots$ E-27

E.4 Nodalization detail showing the surge line connection to the split hot leg $\ldots$ E-28

E.5 Cross section of the five channel core with assembly and channel relative power levels . . . . . . . . . . . . . . . . . . . E 28

E.6 Cross section of the five channel core with CRA (control rod assembly) locations . . . . . . . . . . . . . . . . . . . . . . E-29

E.7 COUPLE mesh representing the lower reactor vessel head of the Surry PWR . E-30

E.8 Pressure in the reactor vessel lower head $\ldots \ldots \ldots \ldots \ldots \ldots \ldots$ E-31

E.9 Reactor vessel collapsed liquid level $\ldots \ldots \ldots \ldots \ldots \ldots \ldots \ldots \ldots$ E-31

E.10 Volume-averaged temperatures of pressurizer loop piping $\ldots \ldots \ldots \ldots$ E-32

E.11 Lower head debris depth (referenced to the bottom inside surface of the head) . E-32 


\section{List of Figures (concluded)}

Figure

E.12 Lower head maximum debris temperature $\ldots \ldots \ldots \ldots \ldots \ldots \ldots$. . . . . . . . .

E.13 Mass of liquid in the reactor vessel $\ldots \ldots \ldots \ldots \ldots \ldots \ldots$ E-33

E.14 Total hydrogen generated $\ldots \ldots \ldots \ldots \ldots \ldots \ldots \ldots$ E-34

E.15 Total hydrogen vented to containment $\ldots \ldots \ldots \ldots \ldots \ldots \ldots$ E-34

F.1, RCS pressure response for various sequences $\ldots \ldots \ldots \ldots \ldots \ldots \ldots$

F.2 Approach taken to arrive at probability of high-pressure melt ejection . . . . F F-31

F.3 RCS pressure in the Surry base case $\ldots \ldots \ldots \ldots \ldots \ldots \ldots \ldots$ F-32

F.4 Volume-averaged structure temperatures in the Surry base case $\ldots \ldots \ldots \ldots$ F-33

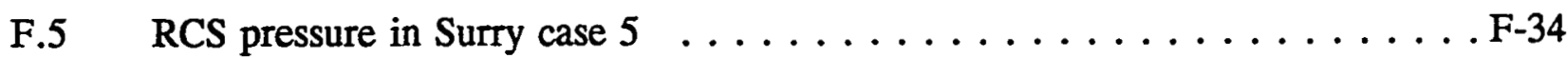

F.6 Event tree for assessing HPME probability for Surry $\ldots \ldots \ldots \ldots \ldots$ F-35

G.1 Peak pressures from CONTAIN and TCE calculations of the Surry plant . . . G-17

G.2 CONTAIN results for hydrogen mass burned $\ldots \ldots \ldots \ldots \ldots \ldots$ G-18

G.3 CONTAIN results for containment pressure $\ldots \ldots \ldots \ldots \ldots \ldots$. . . . . . . . .

G.4 CONTAIN results for containment dome temperatures $\ldots \ldots \ldots \ldots \ldots$ G-20 


\section{LIST OF TABLES}

$\underline{\text { Table }}$

Page

3.1 Characterization of the Surry plant $\ldots \ldots \ldots \ldots \ldots$

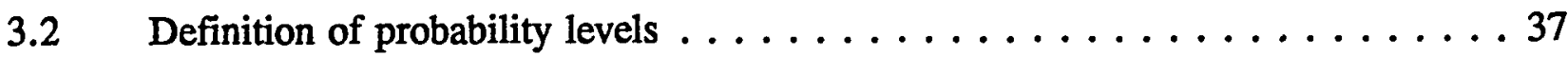

3.3 Summary of initial condition quantification $\ldots \ldots \ldots \ldots$

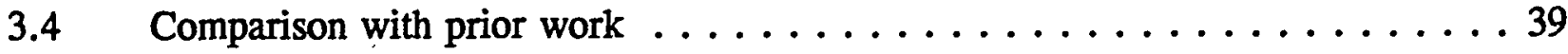

3.5 Potentially important differences between Zion and Surry . . . . . . . . . 40

3.6 Scaling of the melt mass distributions with core power . . . . . . . . . 41

$4.1 \quad$ Survey of DCH-relevant experiments $\ldots \ldots \ldots \ldots 1$

$4.2 \quad$ Applicability of the database to reactors $\ldots \ldots \ldots \ldots$

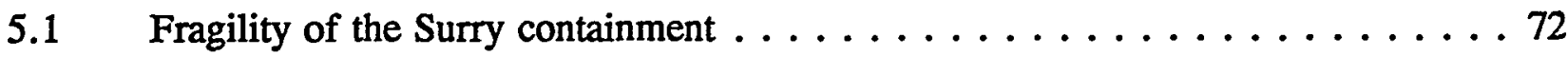

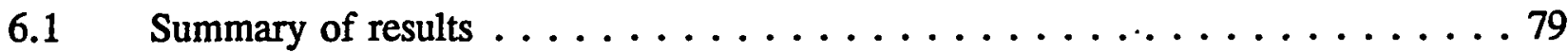

6.2 Comparison of TCE and CONTAIN results $\ldots \ldots \ldots \ldots$

6.3 HPME probabilities for Surry for all station blackout accidents . . . . . . 81

B.1 Survey of DCH-relevant experiments .................... B-20

C.1 Summary of major NRC-developed DCH analysis methodologies and codes . . C-8

D.1 SCDAP/RELAP5 calculations sequence of events $\ldots \ldots \ldots \ldots \ldots \ldots$

D.2 Surry plant nodalization $\ldots \ldots \ldots \ldots \ldots \ldots \ldots \ldots \ldots \ldots \ldots \ldots$

D.3 Initial conditions $\ldots \ldots \ldots \ldots \ldots \ldots \ldots \ldots \ldots \ldots \ldots \ldots \ldots \ldots$

E.1 SCDAP/RELAP5 model elevations relative to the lower reactor vessel head . . E-20

E.2 Comparison of countercurrent flow parameters with values calculated by SCDAP/RELAP5 ........................... E-20

E.3 $\quad \operatorname{SCDAP}$ core damage input $\ldots \ldots \ldots \ldots \ldots \ldots \ldots \ldots \ldots \ldots$

E.4 Surry UFSAR steady state parameters compared to values calculated by

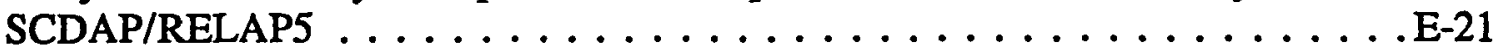




\section{LIST OF TABLES (concluded)}

Table

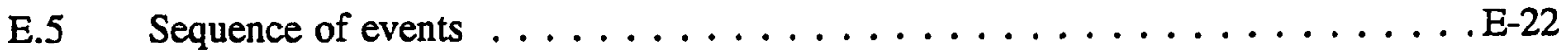

E.6 DCH parameters at selected times $\ldots \ldots \ldots \ldots \ldots \ldots \ldots \ldots \ldots$ E-24

F.1 Summary of pressures for each Surry plant damage state $\ldots \ldots \ldots \ldots \ldots$ F-26

F.2 Relative contribution of each plant damage state to core damage frequency for internal events . . . . . . . . . . . . . . . . . . F-27

F.3 Summary of Surry SCDAP/RELAP5/MOD3 results (in minutes) $\ldots \ldots \ldots \ldots$ F-28

F.4 Probabilities for a surge line or hot leg failure with RCS depressurization . . F F-28

F.5 Probabilities for being at low, intermediate, and high RCS pressure at the time of reactor vessel breach . . . . . . . . . . . . . . . . . . . . F-29

F.6 HPME probabilities for Surry $\ldots \ldots \ldots \ldots \ldots \ldots \ldots \ldots \ldots \ldots$. . . . . . . . . . .

G.1 DCH calculations for Surry initial and boundary conditions $\ldots \ldots \ldots \ldots$ G-11

G.2 Base case and sensitivity study modeling assumptions $\ldots \ldots \ldots \ldots \ldots$ G-12

G.3 Comparison of CONTAIN and TCE Surry DCH results $\ldots \ldots \ldots \ldots \ldots$ G-13

G.4 CONTAIN DCH Surry analysis $\ldots \ldots \ldots \ldots \ldots \ldots \ldots$ G-14 


\section{FOREWORD}

NUREG/CR-6109 assesses the direct containment heating (DCH) issue for the Surry nuclear power plant (NPP) using the methodology and assumptions consistent with those developed in NUREG/CR-6075 and its supplement for the Zion NPP. The preliminary draft of NUREG/CR6109 had a broader scope than the current version, and a different title: "Integrated Report on DCH Issue Resolution for PWRs." However, the initial peer review suggested that attempting to define an extrapolation methodology to resolve the $\mathrm{DCH}$ issue for all PWRs was premature. Consequently, the scope of NUREG/CR-6109 was redefined to be a second demonstration of the methodology (based on comparisons of containment loads with containment strength) developed in NUREG/CR-6075 and its supplement. For Surry, there were no intersections of the load distributions with the containment strength distribution, and thus the $\mathrm{DCH}$ issue for Surry can be resolved on containment loads alone. NUREG/CR-6109 also explores DCH resolution from the perspective that high-pressure melt ejection (HPME) events are unlikely (i.e., had there been intersections of the load and strength distributions, the HPME probability could have been integrated with the containment failure probability to resolve the DCH issue for Surry). The current version of NUREG/CR-6109 focuses specifically on the Surry NPP and does not directly propose any broad approach for extrapolating resolution of the $\mathrm{DCH}$ issue to other NPPs. The first version of NUREG/CR-6109 was reviewed by a group of 13 experts who provided extensive comments. In the current version of NUREG/CR-6109, we have accounted for comments that pertained specifically to Surry and will address their comments on extrapolation in future reports; however, we will not respond to each comment individually as we did in NUREG/CR-6075 since many of the comments no longer apply to the new version of NUREG/CR-6109.

NRC's plan for resolving DCH for other plants is to address groups of plants individually in separate reports. They have asked Sandia National Laboratories to prepare reports on three groups of NPPs: ice condenser (IC) plants, Combustion Engineering (CE) plants, and Westinghouse/Babcock and Wilcox (B\&W) plants. The purpose of the IC and CE reports is to identify important DCH issues, both probabilistic and those of complex phenomena, and to make recommendations on how to proceed on resolving the $\mathrm{DCH}$ issue. The purpose of the Westinghouse/B\&W report is to define a technically defensible extrapolation methodology that can be used to bring the DCH issue for those types of PWRs to closure. 


\section{ACKNOWLEDGMENTS}

The original version of NUREG/CR-6109 was prepared by a team of individuals from Sandia National Laboratories (SNL), Idaho National Engineering Laboratory (INEL), Argonne National Laboratory (ANL), and Purdue University. The following people from SNL contributed to the original report: Susan Dingman, Michael Allen, Michael Bohn, Allen Camp, Frederick Harper, John Ludwigsen, Martin Pilch, Kenneth Washington, and Robert Watson. The following people from INEL helped prepare the original report: Daryl Knudson, Paul Bayless, Charles Dobbe, and Joy Rempe. In addition, Bruce Spencer from ANL and Mamoru Ishii from Purdue University helped write the section on the "Summary of DCH Experimental Programs" for the original version of NUREG/CR-6109, which is included in this version as Appendix B. We acknowledge the contributions of all of these individuals since many of the words and ideas in the original version of NUREG/CR-6109 have been used in the current version.

Much of the successful resolution of the DCH issue is the result of an extensive experimental program. The DCH experiments were reviewed as part of a Nuclear Regulatory Commission (NRC)-sponsored effort known as the Severe Accident Scaling Methodology (SASM) Program that was chaired by Novak Zuber (NRC). As a result of SASM recommendations, the NRC-sponsored experimental programs were redirected toward performing integral counterpart experiments at two different physical scales at Sandia National Laboratories and Argonne National Laboratory. These experiments included detailed (geometrically scaled) simulations of the Zion and Surry subcompartment structures and had initial conditions closely tied to postulated accident scenarios.

Additional guidance for the experiment programs was provided by a five-member $\mathrm{DCH}$ Experiment Technical Review Group (TRG) who were all members of the original SASM program. They included R.E. Henry, M. Ishii, F.J. Moody, B.R. Sehgal, and T.G. Theofanous. The $\mathrm{DCH}$ working group for the experimental program consisted of representatives of the sponsor (NRC), universities and industry (TRG), and the national laboratories (SNL and ANL), and met periodically to discuss new results and decide future directions. 
NUREG/CR-6075 and the original version of NUREG/CR-6109 were reviewed by a panel of 13 experts representing national laboratories, universities, and industry. The reviewers identified two areas of unresolved concerns: initial conditions and model validity. Two working groups were formed to address these concerns. The first meeting, on initial conditions, included Robert Henry, Sal Levy, and Mohammed Modarres. The second meeting, on model validity, included Joe Shepherd, Mamoru Ishii, Sal Levy, Fred Moody, and Robert Henry. The authors would like to thank these reviewers for their guidance on NUREG/CR-6075 and its supplement.

David Williams, John E. Kelly, Nestor Ortiz, Richard Griffith, Walter von Riesemann, Ken Bergeron, Ken Washington, Fred Harper, Allen Camp, and Michael Bohn have contributed significantly to the process of resolving the DCH issue. Russell Smith and Randall Gauntt reviewed the report, providing numerous helpful comments. Mary Lou Garcia and Ellen Walroth prepared the manuscript, including the difficult task of consolidating the various author inputs.

SCDAP/RELAP5 calculations in Appendix E were performed by Daryl Knudson with consultation from Chris Allison and management support from Ed Harvego. The CONTAIN calculations in Appendices D and G were performed by David Stuart and Ken Washington.

This work was sponsored by the Accident Evaluation Branch of the Office of Research of the U.S. Nuclear Regulatory Commission. Input and valuable guidance were supplied by Farouk Eltawila, Charles Tinkler, and Richard Lee. 
. 


\section{ACRONYMS/INITIALISMS}

$\begin{array}{ll}\text { AC } & \text { Alternating current } \\ \text { ANL } & \text { Argonne National Laboratory } \\ \text { ANS } & \text { American Nuclear Society } \\ \text { CCFP } & \text { Conditional containment failure probability } \\ \text { CFP } & \text { Containment failure probability } \\ \text { CLCH } & \text { Convection limited containment heating } \\ \text { COV } & \text { Coefficient of variation } \\ \text { CR } & \text { Causal relation } \\ \text { CRA } & \text { Control rod assembly } \\ \text { CWTI } & \text { Corium, water thermal interaction } \\ \text { DBA } & \text { Design basis accident } \\ \text { DCH } & \text { Direct containment heating } \\ \text { DPD } & \text { Discrete probability distribution } \\ \text { ECC } & \text { Emergency core coolant } \\ \text { ECCS } & \text { Emergency core cooling system } \\ \text { ERI } & \text { Energy Research, Inc. } \\ \text { GPM } & \text { Gallons per minute } \\ \text { HIPS } & \text { High pressure streaming } \\ \text { HPME } & \text { High-pressure melt ejection } \\ \text { IET } & \text { Integral effects test } \\ \text { INEL } & \text { Idaho National Engineering Laboratory } \\ \text { IPE } & \text { Individual plant examination } \\ \text { LFL } & \text { Lower flammability limit } \\ \text { LFP } & \text { Limited flight path } \\ \text { LHS } & \text { Latin hypercube sampling } \\ \text { NPP } & \text { Nuclear power plant } \\ \text { NRC } & \text { Nuclear Regulatory Commission } \\ \text { PDS } & \text { Plant damage state } \\ \text { PDF } & \text { Probability density function } \\ \text { PORV } & \text { Pilot-operated relief valve } \\ \text { PRA } & \text { Probabilistic risk assessment } \\ \text { PWR } & \text { Pressurized water reactor } \\ \text { RCB } & \text { Reactor containment building } \\ \text { RCP } & \text { Reactor coolant pump } \\ \text { RCS } & \text { Reactor coolant system } \\ \text { RHR } & \text { Residual heat removal } \\ \text { RPV } & \text { Reactor pressure vessel } \\ \text { SASM } & \text { Severe accident scaling methodology } \\ \text { SBLOCA } & \text { Small break loss-of-coolant accident } \\ \text { SBO } & \text { Station blackout accident } \\ \text { SG } & \text { Steam generator } \\ \text { SNL } & \text { Sandia National Laboratories } \\ \text { Safety relief valve } \\ \text { Two-cell equilibrium } \\ \end{array}$




\section{ACRONYMS/INITIALISMS (concluded)}

TDS Technology development tests

TPG Technical Program Group

UCSB University of California at Santa Barbara

UFSAR Updated final safety analysis report

WC Water cavity 


\section{EXECUTIVE SUMMARY}

In a light-water reactor core melt accident, if the reactor pressure vessel (RPV) fails while the reactor coolant system (RCS) is at high pressure, the expulsion of molten core debris may pressurize the reactor containment building $(\mathrm{RCB})$ beyond its failure pressure. A failure in the bottom head of the RPV, followed by melt expulsion and blowdown of the RCS, will entrain molten core debris in the high-velocity steam blowdown gas. This chain of events is called a high-pressure melt ejection (HPME). Four mechanisms may cause a rapid increase in pressure and temperature in the reactor containment: (1) blowdown of the RCS, (2) efficient debris-to-gas heat transfer, (3) exothermic metal-steam and metal-oxygen reactions, and (4) hydrogen combustion. These processes, which lead to increased loads on the containment building, are collectively referred to as direct containment heating $(\mathrm{DCH})$. It is necessary to understand factors that enhance or mitigate DCH because the pressure load imposed on the RCB may lead to early failure of the containment.

NUREG/CR-6075, "The Probability of Containment Failure by Direct Containment Heating in Zion," was the first step in resolving the $\mathrm{DCH}$ issue. It was intended to evaluate the probability of containment failure by DCH for the Zion Nuclear Power Plant (NPP). It underwent an extensive review by a panel of 13 experts representing national laboratories, universities, and industry. The reviewers provided written comments; the authors responded to these comments; and finally, the reviewers wrote rebuttals to the authors' responses. From the peer review process, two areas of residual concern were identified: initial conditions and the validity of the model. Two working group meetings addressed these unresolved issues. A supplement to NUREG/CR-6075 was written to document the peer review process, address residual concerns about initial conditions and model validity, and document modeling enhancements.

Four new splinter scenarios were proposed for Zion in the working group meetings. The new scenarios either bound the scenarios in NUREG/CR-6075 or stress greater consistency in the conditions at vessel breach; thus, the new scenarios are intended to replace those in NUREG/CR-6075. Two high-pressure scenarios resulting from operator intervention were defined. One (16 MPa) is characterized by coejection of large quantities of water $(75 \mathrm{mt})$ because of operator action to reflood the RCS, and the other ( $8 \mathrm{MPa})$ is characterized by

coejection of $10 \mathrm{mt}$ of water. The expected melt composition is predominantly oxidic. Two 
low-pressure scenarios were also defined. These are characterized by melts with a larger metallic component and small amounts of coejected water.

In order to ensure consistent initial conditions for each scenario, the working group members stressed the use of insights from system-level codes, specifically SCDAP/RELAP5 and CONTAIN. Existing SCDAP/RELAP5 calculations for short-term station blackout scenarios for Zion and Surry indicate that failure of the hot leg or surge line and resulting depressurization of the primary system occur well before core relocation and lower head failure in all cases analyzed. Calculations were continued until lower head failure and showed that only a small amount of metallic debris relocates to the lower plenum. Little or no melting of upper plenum steel was observed, and there was very little relocation of metallic core blockages into the lower plenum. In addition, these analyses showed that RCS pressure could remain high only if the vessel was reflooded by operator intervention. These insights were used to develop the distributions for the four new scenarios defined in the supplement to NUREG/CR-6075.

NUREG/CR-6109 uses the methodology (based on comparisons of containment loads with containment strength) developed for NUREG/CR-6075 and its supplement to assess the conditional containment failure probability for the Surry NPP. The scenarios described in the NUREG/CR-6075 supplement were considered in NUREG/CR-6109. The methodology used for NUREG/CR-6075 to quantify initial conditions was repeated here with specific input from Surry and with the insights gained from existing SCDAP/RELAP5 calculations for the Surry NPP.

There are several tools for calculating DCH loads. In NUREG/CR-6075, the two-cell equilibrium (TCE) model and the convection-limited containment heating (CLCH) model were used. These models were validated against the extensive DCH experimental database and gave similar results because the basic modeling assumptions are the same. Only the TCE model was used to compute containment loads in NUREG/CR-6109. However, the CONTAIN code has also been used extensively to calculate DCH loads. For comparison, load calculations were performed for specific sets of input parameters with the CONTAIN code and with the TCE model in NUREG/CR-6109. The calculations were performed for Scenarios V, Va, and VI at the upper end of the mass distributions and with likely hydrogen concentrations. The loads computed with CONTAIN were comparable to or less than the loads calculated with the TCE model with identical input parameters. 
The conditional (on core damage) containment failure probability (CCFP) can be divided into two components: (1) the likelihood of being at high pressure at vessel failure, and (2) the probability that the containment will fail given DCH. NUREG/CR-6075 and its supplement resolved the DCH issue based on containment loads only, i.e., the load distributions were compared with the containment strength distribution to calculate containment failure probabilities without regard to the likelihood of being at high pressure at vessel breach. The conclusion in NUREG/CR-6075 for Zion was that there were no intersections of the load distributions and the containment strength distributions, and thus the $\mathrm{DCH}$ issue was considered to be resolved for the Zion NPP. The results of the load evaluations for Surry were similar to those for Zion: there were no intersections of the load distributions with the containment strength distribution, and thus the DCH issue for Surry can be resolved on containment loads alone. However, the likelihood of high RCS pressures at vessel breach was evaluated for Surry for a limited number of sequences. The probability of RCS pressures greater than $1.38 \mathrm{MPa}$ for all station blackout scenarios without power recovery or operator intervention was found to be low $(p \sim 0.077)$. This probability could have been factored into the containment failure probability for Surry if there had been intersections of the load and strength distributions.

We recognize that there is some uncertainty in our understanding of in-vessel core melt progression and direct containment heating, and in the tools used to model these phenomena; however, at this point, the analyses and conclusions in this report represent our current best estimate. 


\subsection{INTRODUCTION}

In a light-water reactor core melt accident, if the reactor pressure vessel (RPV) fails while the reactor coolant system (RCS) is at high pressure, the expulsion of molten core debris may pressurize the reactor containment building (RCB) beyond its failure pressure. A failure in the bottom head of the RPV, followed by melt expulsion and blowdown of the RCS, will entrain molten core debris in the high-velocity steam blowdown gas. This chain of events is called a high-pressure melt ejection (HPME). Four mechanisms may cause a rapid increase in pressure and temperature in the reactor containment: (1) blowdown of the RCS, (2) efficient debris-to-gas heat transfer, (3) exothermic metal-steam and metal-oxygen reactions, and (4) hydrogen combustion. These processes, which lead to increased loads on the containment building, are collectively referred to as direct containment heating (DCH). It is necessary to understand factors that enhance or mitigate DCH because the pressure load imposed on the RCB may lead to early failure of the containment.

DCH is a prominent severe accident issue because of its potential for early containment failure. The Nuclear Regulatory Commission (NRC) has identified DCH as a major issue for resolution in the Revised Severe Accident Research Plan (NRC, 1992) and has sponsored programs at Sandia National Laboratories (SNL) to resolve the DCH issue.

The NRC-sponsored experimental program has played a major role in developing an understanding of the key physical processes in DCH. The technical basis for these scaled experiments was developed by the Severe Accident Scaling Methodology Technical Program Group (SASM-TPG) (Zuber et al., 1991) and by Pilch et al. (1992). The extensive database from counterpart experiments by Sandia National Laboratories and Argonne National Laboratory (ANL) has allowed the development and validation of simple analytical models for predicting the containment loads. In particular, the two-cell equilibrium (TCE) model is based on insights from the experimental program and is used in the analyses presented here. The TCE model takes into account the coherence between the entrained debris and the RCS blowdown steam. Any noncoherence in the entrainment process limits the interactions that result in debris-to-gas heat transfer and in chemical reactions that produce hydrogen.

The first step in the DCH issue resolution process was writing NUREG/CR-6075 (Pilch et a1., 1994a): "The Probability of Containment Failure by Direct Containment Heating in Zion." 
NUREG/CR-6075 assesses the probability of containment failure by DCH for the Zion nuclear power plant (NPP) and establishes the basic methodology that will be used to address DCH for all NPPs. The report was extensively reviewed by a panel of 13 experts representing national laboratories, universities, and industry (see Appendix A, Pilch et al., 1994b). The review process included written comments by the reviewers, responses by the authors, and rebuttals by the reviewers. Following this process, two working group meetings of selected members of the original peer review group were held to resolve two residual concerns: initial conditions and validity of the model.

Supplement 1 of NUREG/CR-6075 (Pilch et al., 1994b) was written in response to the peer review process to close the $\mathrm{DCH}$ issue for the Zion plant. It contains the additional analyses that the working groups indicated were necessary to strengthen the original conclusions. The working groups defined four new scenarios for analysis using the methodology in NUREG/CR6075 and suggested using system-level codes to ensure consistency of the DCH initial conditions. They recommended using insights from core melt progression analyses performed by the Idaho National Engineering Laboratory (INEL) with SCDAP/RELAP5. For the NUREG/CR-6075 supplement, INEL analyzed three short-term station blackout cases for the Surry plant with different leak rates. In all three cases, failure of the hot leg or surge line resulting in depressurization of the primary system was observed well before core relocation and lower head failure. However, the calculations were continued until the lower head failed in order to gain insights about conditions at lower head failure, such as the melt mass and composition, reactor coolant system pressure, melting of upper plenum steel, and relocation of metallic core blockages into the lower plenum. These insights were applied in developing the distributions for the new scenarios. In addition, uncertainties in these calculations were examined in order to derive the probability of HPME.

SCDAP/RELAP5 is the NRC's best tool for performing integrated analyses of core melt progression and as such, it attempts to embody the most current information available. The peer review of SCDAP/RELAP5 noted that models and the existing database for late-phase core melt progression are often inadequate. Consequently, we anticipate that continued research will significantly improve our understanding and capabilities in this area. Nonetheless, an integrated perspective of core melt progression is useful in guiding the selection of melt mass and composition distributions (Section 3). In addition, SCDAP/RELAP5 has been used to establish 
the probability of HPME (Appendix F) for short-term station blackouts by using intentionally biased calculations and by factoring in uncertainties in key event timing.

NUREG/CR-6109 has two purposes. The first is to apply the methodology for overpressure failure of the containment (based on load and strength evaluations) developed in NUREG/CR-6075 and its supplement to the Surry plant. The probabilistic framework for these analyses is described in Section 2 of this report. The working groups suggested four new possible scenarios for analysis using the methodology in NUREG/CR-6075. The scenarios are described and justified in Section 3. Quantification of the DCH phenomenon with the TCE model is discussed in Section 4, and quantification of the Surry containment fragility is described in Section 5. The probabilistic synthesis is carried out using a Monte Carlo sampling method in the TCE/Latin Hypercube Sampling (LHS) code. Section 6 contains the results of the calculations for the splinter scenarios. The second purpose is to show how the probability of HPME can be assessed (Appendix F) and the results integrated into the DCH resolution process. This integration is also addressed in Section 6. Conclusions and recommendations are summarized in Section 7.

In the Surry resolution process, a conditional (on core damage) containment failure probability (CCFP) of less than 0.1 was applied as a figure of merit to be used as a success criterion for resolving the DCH issue. The CCFP can be decomposed into the product of two probabilities:

1. The probability (given an HPME) of containment overpressure failure based on load and fragility comparisons, and

2. The probability that vessel failure will occur while the RCS is still sufficiently pressurized to lead to an HPME and DCH (i.e., the probability of HPME).

DCH is resolved here for Surry and for Zion in NUREG/CR-6075, Supplement 1, from the first perspective.. In addition, the second perspective is explored in Appendix F for Surry. The demonstration here was not intended to be all inclusive, and it is limited to station blackout accidents without operator intervention. A complete demonstration of $\mathrm{DCH}$ resolution by the second approach was not necessary because the issue was adequately resolved by the first approach based on load to strength evaluations. Either approach is acceptable for resolution of 
$\mathrm{DCH}$, and the best estimate would involve integrating both components in a complete demonstration. This report does not address potential steam explosions, potential liner meltthrough, or potential damage to equipment resulting from HPME or DCH.

\subsection{References}

NRC (1992). Severe Accident Research Program Plan Update, NUREG-1365, Rev. 1, U.S. Nuclear Regulatory Commission, Washington, DC.

Pilch, M.M., M.D. Allen, and J.L. Binder (1992). "Counterpart and Replicate DCH Experiments Conducted at Two Different Physical Scales: The SNL/IET-1, 1R and the ANL/IET-1R, 1RR Experiments," Letter Report to the NRC, Sandia National Laboratories, Albuquerque, NM.

Pilch, M.M., H. Yan, and T.G. Theofanous (1994a). "The Probability of Containment Failure by Direct Containment Heating in Zion, " NUREG/CR-6075, SAND93-1535, Sandia National Laboratories, Albuquerque, NM.

Pilch, M.M. et al., (1994b). "The Probability of Containment Failure by Direct Containment Heating in Zion, "NUREG/CR-6075, Supplement 1, Sandia National Laboratories, Albuquerque, NM.

Zuber, N. et al. (1991). An Integrated Structure and Scaling Methodology for Severe Accident Technical Issue Resolution, Draft for Comment, NUREG/CR-5809, EGG-2659, EG\&G Idaho, Inc., Idaho Falls, ID. 


\subsection{PROBABILISTIC FRAMEWORK}

The basic understanding upon which this approach to resolving the DCH issue is based (and confirmed in repeated experiments) is that the intermediate (or steam generator) compartment traps most of the debris dispersed from the reactor cavity and that the thermal-chemical interactions during this dispersal process are limited by the incoherence in the steam blowdown and melt entrainment processes. To put it simply, for blowdowns that are sufficient to cause entrainment and significant thermal-chemical interactions, the entrainment time is short compared with the blowdown time so that the molten debris is exposed to only a small fraction of the steam from the primary system. Because this steam is the principal medium for carrying the melt energy and the hydrogen produced by steam-metal interactions to the main containment volume, this incoherence is a crucial mitigating factor. With this understanding, it is possible to reduce most of the complexity of the $\mathrm{DCH}$ phenomena to a single parameter: the ratio of the melt entrainment time constant to the system blowdown time constant $\left(R_{r}=\tau_{d} / \tau_{\mathrm{b}}\right.$ in the TCE model). For simplicity, $R_{r}$ is referred to as a coherence ratio.

Besides these modeling factors, the $\mathrm{DCH}$ loads depend on parameters that characterize the system initial conditions; that is, primary system pressure, temperature and composition (i.e., hydrogen mole fraction), melt quantity and composition (zirconium and stainless steel mass fractions), initial containment pressure and composition (hydrogen mole fraction), and geometry (containment volume and the size of the breach). The key component of the framework, therefore, is the causal relation (CR1) between these parameters and the resulting containment pressure (and temperature) under the influence of the uncertainty in the coherence ratio, $R_{r}$. Of these parameters, some are fixed, some vary only over a narrow range, and some are so uncertain that they can be approached only in a very bounding sense. The following features were considered in coming up with the final choice of a framework:

1. Geometry. The specific geometry is fixed for a given plant; however, the basic features are that there is an intermediate compartment between the cavity and the main containment volume and that the lower head fails by rupture in a local (rather than global) manner. In addition, the geometry is characterized by the free volume of the containment and the primary system volume. 
2. Containment Conditions. Typically, high-pressure scenarios evolve with significant primary system venting prior to vessel breach (see Section 3); this venting increases the containment pressure to $\sim 0.25 \mathrm{MPa}$ with temperatures near saturation. This pressure will be somewhat lower for a subatmospheric plant such as Surry and can be considerably lower if any of the active containment heat removal systems are operational. The containment atmosphere will also contain hydrogen at a concentration of a few mole percent. Preexisting hydrogen is limited by the quantity of zirconium available to react in the core, and thus there is a constrained relationship between preexisting hydrogen in the containment and the hydrogen produced by steam-zirconium reactions in the DCH event.

3. Primary System Conditions. We emphasize here the reasonable consistency between reactor coolant system pressure (and temperature) and melt mass and composition. Model predictions indicate that $\mathrm{DCH}$ loadings are insensitive to the temperature of the frimary system (see Appendix D, NUREG/CR-6075), and accident analyses indicate that the primary system pressure can be enveloped rather than predicted (Section 3 ). This leaves only the expelled melt parameters in need of quantification. These are melt quantity, composition, and temperature and are the variables that drive the $\mathrm{DCH}$ process; however, they are highly uncertain. They depend on the complex interactions and the scenario variations in the core meltdown, relocation, and lower head failure processes and are hence in need of very careful quantification. This is done in Section 3.

The probabilistic framework can be structured in the manner illustrated in Figures 2.1 and 2.2. As shown in these figures, the initial melt parameters are to be quantified as independent probability density functions, representing modeling uncertainty in the parameters (variations from stochastic processes are assessed as insignificant relative to modeling uncertainty). These functions are formed into a joint probability density function and then combined with CR1, under the parameter distribution function that represents model uncertainty for the DCH processes, coherence ratio $\left(R_{\tau}\right)$, to obtain a probability density function for the peak containment pressure. This distribution function is combined with the set of containment fragility curves 
(probabilistically distributed themselves ${ }^{1}$ ) to obtain a probability distribution of containment failure frequency. ${ }^{2}$

Sandia has developed software to perform either traditional Monte Carlo sampling or stratified Monte Carlo sampling. The software, called LHS, is user friendly and has an established quality assurance pedigree, including code assessment and verification. Sandia chose to use this numerical tool based on LHS to propagate distributions through the probabilistic framework. The resulting software was applied in NUREG/CR-6075, Supplement 1 (Pilch et al. 1994), where it is described more fully in Appendix B. The same software is used here without modification.

\subsection{References}

Pilch, M.M. et al. (1994). The Probability of Containment Failure by Direct Containment Heating in Zion, NUREG/CR-6075, Supplement 1, Sandia National Laboratories, Albuquerque, NM.

\subsection{Nomenclature}

$\begin{array}{ll}\mathrm{F}_{\mathrm{f}} & =\text { failure frequency } \\ \mathrm{M}_{\mathrm{ss}} & =\text { mass of steel } \\ \mathrm{M}_{\mathrm{UO2}} & =\text { mass of } \mathrm{UO}_{2} \\ \mathrm{P}_{\mathrm{f}} & =\text { failure probability } \\ \mathrm{R}_{\mathrm{r}} & =\text {. coherence ratio } \\ \mathrm{X}_{\mathrm{Zr}} & =\text { mass fraction } \mathrm{Zr}\end{array}$

${ }^{1}$ In the current assessments, only a single fragility curve is available, but the discussion here has been generalized to accommodate desired improvements in information.

${ }^{2}$ Note here that each fragility curve is expressed in terms of failure frequency, and this frequency expresses the statistically meaningful variations (based on actual experience) in containment strength that are due to variations in material and workmanship; that is, the fraction that failed in a nominally similar population of structures subjected to the same load. On the other hand, the probability assigned to each fragility curve expresses a subjective degree of belief as to the appropriateness of it in meeting the intended task. 


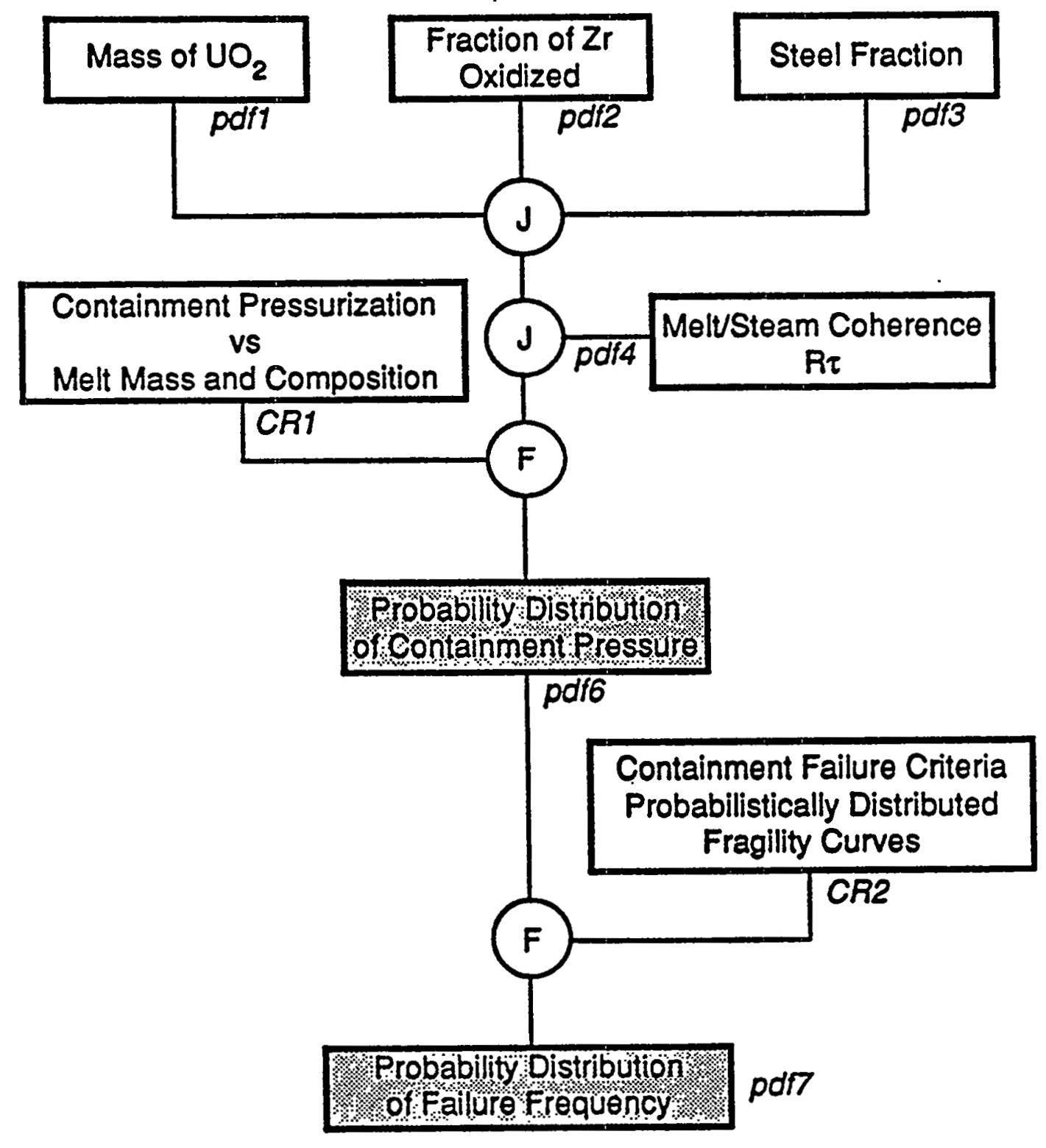

Figure 2.1. The probabilistic framework for containment failure under direct containment heating scenarios. The $(J)$ and $(F)$ are the "joint" and "function" operations, respectively, as described in the text. 


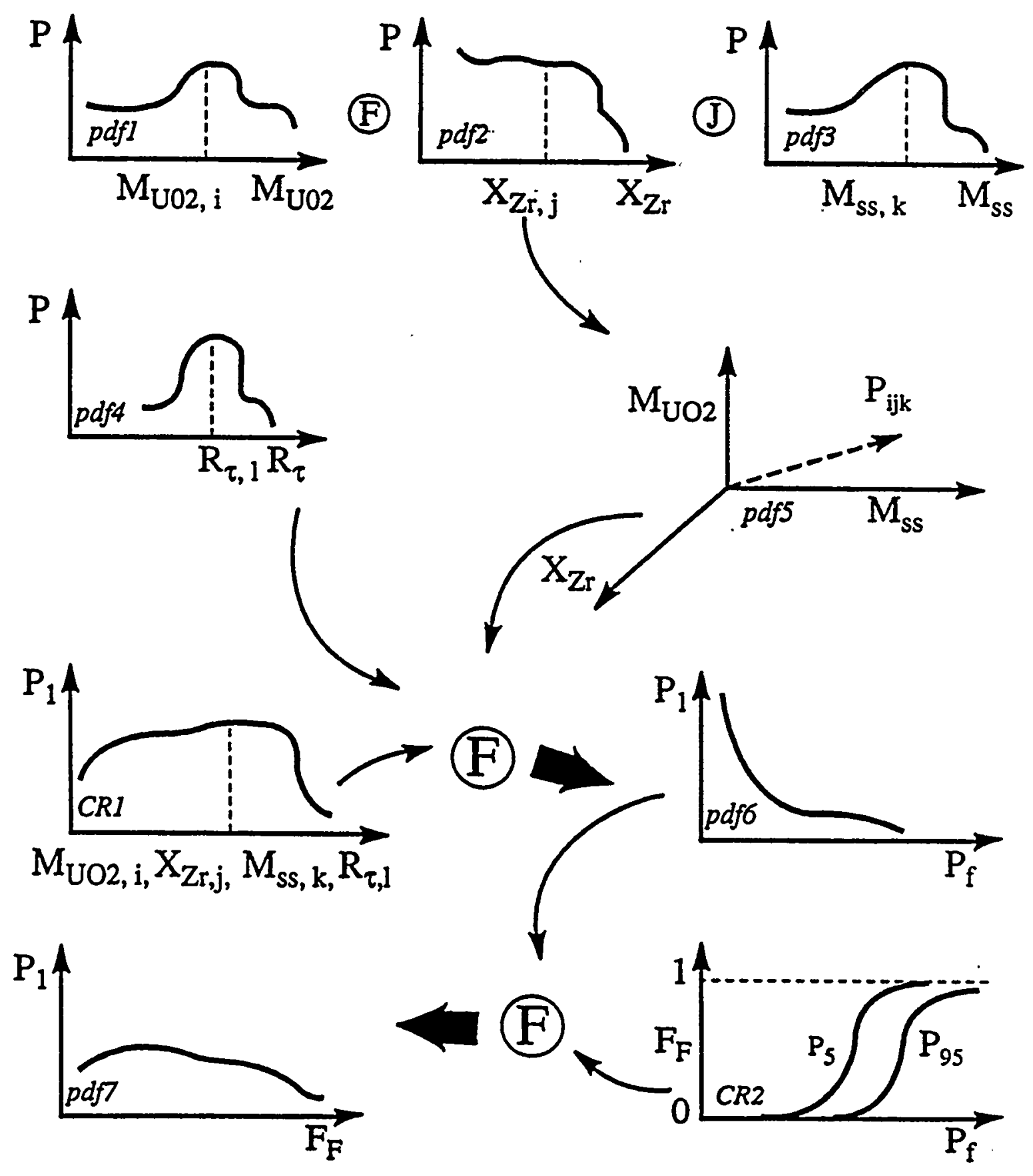

Figure 2.2. Illustration of the probabilistic framework in terms of schematic depiction of its components. 


\subsection{QUANTIFICATION OF INITIAL CONDITIONS}

\subsection{Introduction}

DCH has traditionally been examined for a rather narrow range of hypothesized severe accident conditions: unmitigated station blackout at full system pressure; formation of a metallic blockage with an overlying ceramic crust in the core that contains a large fraction of core in a molten state; sudden failure of this blockage and crust, resulting in a massive relocation of the melt into the lower plenum; failure of a penetration passing through the lower head of the reactor pressure vessel; rapid ablation of the resulting hole in the RPV from 5 to about $40 \mathrm{~cm}$ (Pilch and Tarbell, 1985); and high-pressure melt ejection from the single hole followed by highpressure steam blowdown. In attempts to address the DCH issue from either a systems point of view or an accident management point of view, intentional depressurization of the primary system has been examined (Hanson et al., 1990). Experiments have shown that the pressure must be very low (less than $1 \mathrm{MPa}$ ) to preclude the onset of dispersal from the cavity and to prevent the possibility of DCH (Tutu et al., 1988). Bounding calculations (Pilch and Tarbell, 1986) suggest that as little as 20 percent of the core (participating in $\mathrm{DCH}$ ) could pose a threat for the containment. With this traditional understanding, containment-threatening loads from DCH can only be precluded if the RCS is almost fully depressurized. However, based on the understanding developed in NUREG/CR-6075 (Pilch et al. 1994a, b), a substantial reduction of DCH loads is achieved without having to rely upon nearly complete depressurization of the RCS.

Quantification of melt release conditions was developed by attempting to envelop physically possible behavior in a comprehensive and systematic manner. This means that we needed to examine all reasonably conceivable severe accident scenarios, identify key aspects of their phenomena and respective ranges of behavior, and establish the few scenarios that envelop the DCH challenge to the containment.

Reviewers raised the following questions (Appendix A in Pilch et al. 1994b) regarding the completeness of the splinter scenarios considered in NUREG/CR-6075 (Pilch et al. 1994a) for the Zion application:

1. Can full-system pressure cases be ruled out? 
2. Should operator intervention scenarios be analyzed?

3. Can dry core scenarios lead'to melting and relocation of the metal $(\mathrm{Zr})$ blockage from the core to the lower plenum?

Generally, the reviewers characterized initial condition quantifications in NUREG/CR-6075 (Pilch et al. 1994a) for Zion as "optimistic." Specifically, they expressed concern that $\sim 8 \mathrm{MPa}$ RCS pressure might not be adequately bounding, that the melt mass distributions were too narrow, and that the melt composition did not contain sufficient metallics ( $\mathrm{Zr}$ and steel). The reviewers also stressed that SCDAP/RELAP5 analyses should be performed and used in -a consistent manner in establishing initial conditions.

The NRC convened a working group to make recommendations on how to resolve these concerns for Zion. Their minutes are included in Appendix A of Pilch et al. (1994b) and summarized in Section 3.2, where additional splinter scenarios are defined, Residual concerns were fully resolved for Zion (Appendix A in Pilch et al. 1994b) and it is our intent to follow the prescription for quantifying initial conditions for Surry. SCDAP/RELAP5 calculations were cited and some additional calculations were performed to provide confirmatory insight into the working group recommendations for Surry. These calculations are discussed in Appendix E and the relevant insights are summarized in Section 3.3. Quantifications for the new scenarios are presented in Sections 3.6 and 3.7.

\subsection{Splinter Scenarios}

Figure 3.1 depicts the four splinter scenarios analyzed in NUREG/CR-6075. The complex phenomena of severe accidents lead to the possibility of two divergent scenarios: one concerned with the quantity of melt that accumulates in the core region prior to its release and relocation into the lower plenum, and the other concerned with the mode and timing of lower head failure. Analysis of the first considers crucible formation or failure versus gradual relocation (no crucible) as the mechanism for melt relocation into the lower plenum. Analysis of the second considers a localized penetration failure of the lower head versus rupture.

Working group recommendations focused on four new splinter scenarios as shown in Figure 3.2. The intent was to place greater reliance on systems-level codes (SCDAP/RELAP5) in order 
to achieve better consistency between RCS pressure at vessel breach with melt mass and composition. Specifically, the working group emphasized that high RCS pressures and oxidic melts are correlated predominantly with operator intervention and that metallic melts are correlated with reduced RCS pressures associated with pump seal leaks of sufficient magnitude that hot leg failure does not occur. The working group minutes (Appendix A in Pilch et al. 1994b) refer to the new splinters as Scenarios II, IIa, IIb, and III; however, to avoid confusion with the scenarios already analyzed in NUREG/CR-6075, we refer to the new splinters in this report as Scenarios V, VI, VII, and VIII. The new scenarios either bound the scenarios in NUREG/CR-6075 or stress greater consistency in the conditions at vessel breach; thus, the new scenarios are intended to replace those in NUREG/CR-6075. The rationale leading to these new splinter scenarios is discussed next.

The working group felt that there was no compelling need to further analyze scenarios with penetration failures. The INEL lower head failure analysis (Rempe et al., 1993) and the OECDNEA-TMI-2 vessel investigation project (Stickler et al., 1993) both concluded that rupture was much more likely than a penetration-type failure. Marshall (1988) performed some scoping experiments on tube ejection. Specifically, he confirmed that binding caused by differential thermal expansion could prevent ejection of a penetration from the lower head (for the conditions and materials tested); however, ballooning of the lower head, which could induce ejection of a penetration as a precursor to rupture, was not modeled in these experiments. Fauske and Associates, Inc. (FAI) (Hammersley et al., 1993), under the sponsorship of the Electric Power Research Institute (EPRI), has examined melt penetration into in-core instrument guide tubes. Pressure-driven melt was observed to travel approximately $2 \mathrm{~m}$, which is far enough to carry it well beyond the lower head. However, the melt mass is too small to threaten the integrity of the guide tube. These limited experiments confirm INEL and OECD conclusions that penetration-type failures are unlikely. NUREG/CR-6075 (Pilch et al., 1994a) showed that a penetration failure followed by ablation of the lower head would produce a hole about the same size as would be expected for a local rupture of the lower head. Finally, work reported in NUREG/CR-6075 (Pilch et al., 1994a) showed that predicted loads for rupture scenarios bound predicted loads for penetration failure scenarios; consequently, penetration failures need not be considered further in the supplement assessments for Surry or in any extrapolation activities.

Scenario VI is very similar to Scenario II in NUREG/CR-6075. Here, the working group wanted to emphasize the presence of water in the lower head. They recommended the addition 
of a new TMI-like scenario (Scenario V) characterized by reflooding and repressurization ( $\sim 16 \mathrm{MPa})$ of the RCS as a result of operator actions. Scenarios V and VI were envisioned as having water in the core (at least covering the bottom) during much of the core melt progression; consequently, slumping core material would form a crucible which could fail only locally. The melt composition would be largely oxidic, with most unoxidized $\mathrm{Zr}$ permanently retained as a metal blockage in the core. Scenarios V and VI envelop those scenarios in which operators attempt to manage or recover an accident but fail to prevent severe core damage, which then leads to failure of the RPV lower head.

The working group then recommended consideration of scenarios in which core melting would proceed without water in the core region and largely without water in the lower plenum. It was their expectation that these scenarios would evolve to much lower RCS pressures at vessel failure for typical small break loss-of-coolant accidents (SBLOCAs). At the lower pressures, the possibility of the upper plenum steel melting without also failing the hot leg becomes possible; thus, both scenarios VII and VIII augment the oxidic melt with large quantities of upper plenum steel. Scenario VIII is distinguished from Scenario VII in that the metal blockage is also assumed to remelt, allowing large quantities of unoxidized $\mathrm{Zr}$ to relocate to the lower plenum.

NUREG/CR-6075 (Scenario IV) considered a gradual relocation that progressed under high pressure ( $~ 8 \mathrm{MPa})$ with complete melting of upper plenum steel. Working group discussions pointed out that this scenario is overly conservative and that melting of upper plenum steel is strongly correlated with hot leg failure: In fact, gradual relocation has been predicted in only one MELPROG calculation for the Surry plant (Heames and Smith, 1987); and even here, hot leg failure was predicted to occur before core relocation into the lower plenum. Should a gradual relocation occur, working group members believed that it would look like Scenario VIII at the time of vessel failure.

SCDAP/RELAP5 calculations have been performed (based on working group recommendations) to confirm the basic features of Scenarios VII and VIII for Zion (Appendix $\mathrm{C}$ in Pilch et al. 1994b). Three cases (representing short-term station blackout accidents) were run with SCDAP/RELAP5 representing the full spectrum of expected pump seal LOCAs: no leaks, $250 \mathrm{gpm} / \mathrm{pump}$, and $480 \mathrm{gpm} / \mathrm{pump}$. The key conclusion for Zion, however, is that hot leg failure will occur before core relocation for all pump seal LOCAs, leading to complete 
depressurization of the RCS before lower head failure. Earlier SCDAP/RELAP5 calculations for Surry (Knudson and Dobbe, 1993) also predicted that hot leg failure would occur before core relocation for these cases except for the 480-gpm/pump RCP leak. The earlier Surry calculations, however, were intentionally biased to accelerate core melt progression and lower head failure. Consequently, the NRC asked INEL to perform a best-estimate SCDAP/RELAP5 calculation for a 480-gpm/pump RCP leak at Surry. This best-estimate calculation also led to hot leg failure and complete depressurization of the RCS before lower head failure. Appendix E presents these calculations in detail, and the results are summarized in Section 3.3. Since pressure between the RCS and the containment equilibrates after hot leg failure, there is no mechanism to oxidize the high metallic content of the melt; consequently, Scenarios VII and VIII are not further analyzed in this report.

\subsection{Summary of SCDAP/RELAP5 and CONTAIN Insights}

The initial and boundary conditions for the scenarios analyzed in this supplement are based in part on insights from SCDAP/RELAP5 and CONTAIN calculations. These system code calculations are used to justify the initial and boundary conditions for the dry core splinter scenarios discussed in Section 3.2. In this report, "dry core" implies that the RPV water level is below the bottom of the core so that the potential exists for metallic blockages to relocate to the lower plenum. All of the cases analyzed produced "dry core" conditions. However, SCDAP/RELAP5 calculations did not predict any significant relocation of metallic blockages in any of the dry core cases that were analyzed.

Surry is a three-loop Westinghouse nuclear steam supply system that does not have the core by-pass feature found in Zion. Existing SCDAP/RELAP5 calculations (Knudson and Dobbe, 1993), which were intentionally biased to accelerate core melt progression and lower head failure, were examined for insights on core melt progression. Three different RCP leak rates were examined: (1) no leaks, (2) 250 -gpm/pump leaks, and (3) 480 -gpm/pump leaks. In addition, a best-estimate calculation for the $480-\mathrm{gpm} /$ pump case was run for this study. These calculations provide insight into melt mass, melt composition, and RCS pressure at the time of lower head failure. The flow of steam, water, hydrogen, and nitrogen into the containment for the best-estimate 480 -gpm/pump case was provided to Sandia by INEL for use in CONTAIN to determine containment conditions at the time of lower head failure. A number of important insights were obtained from these calculations. 
First, the existing SCDAP/RELAP5 calculations indicated that hot leg or surge line failure occurred prior to melt relocation into the lower plenum in all but the $480-\mathrm{gpm} / \mathrm{pump}$ case. The existing calculations were intentionally biased to accelerate core melt progression and lower head failure in order to bound the likelihood that lower head failure could occur while the RCS was still at elevated pressure. Consequently, the NRC asked INEL to perform a best-estimate calculation of the $480-\mathrm{gpm} /$ pump case, which is documented here as Appendix E. This best estimate also led to hot leg failure. These conclusions are fully consistent with those reached for Zion.

Sensitivity studies were performed for the biased SCDAP/RELAP5 calculations (Appendix F) in order to assess the potential impact of uncertainties on these conclusions. The probability that the RCS pressure would exceed 1.38 MPa (200 psig) is -1.1 percent conditional on a short-term station blackout accident. This insensitivity occurs because of the significant amount of time between hot leg failure and lower head failure. As a result, we conclude that the probability of an HPME is small for a station blackout accident, without operator intervention or recovery.

A second insight is related to the amount of metallic debris present in the melt in the lower plenum. We noted that the degree of upper plenum steel melting is limited in all cases and is strongly correlated with hot leg failure. The maximum amount of upper plenum steel that was predicted to melt was much less than $1 \mathrm{mt}$. We also noted that lower plenum steel was assumed to melt in all cases, representing an additional $\sim 5 \mathrm{mt}$ of steel. Hence, the amount of steel in the melt is limited to $\sim 5 \mathrm{mt}$.

With respect to zirconium in the melt, SCDAP/RELAP5 indicates that very little zirconium is predicted to relocate into the lower plenum. The maximum amount of zirconium in the lower plenum melt is $\sim 0.13 \mathrm{mt}$ for any of the calculations. This implies that meltout of the metallic blockage in the core region is not predicted, even in dry core scenarios.

The reason for this behavior can be seen by a careful review of the calculations. In all cases, the melt that relocated into the lower plenum is predicted to quench, but not all of the available water is vaporized. This is most likely due to displacement of water from the lower plenum as the melt relocates. The water eventually settles back into the lower plenum, but a stratified condition exists, i.e., the water overlies the debris residing on the lower head. Owing 
to inefficient heat transfer between the debris and the water, the water is vaporized slowly and, in all cases, water remains in the lower plenum at the time of lower head failure. The presence of water and its slow vaporization appears to be sufficient to prevent meltout of the in-core blockages. Hence, we conclude that the amount of zirconium in the melt in the lower plenum will be very limited. We acknowledge uncertainties in modeling of late-phase core melt progression; consequently, additional $\mathrm{Zr}$ will be treated in our melt composition quantifications as discussed in Sections 3.6 and 3.7.

A third insight is related to the amount of hydrogen generated, which ranged from $\sim 20$ to 60 percent. We observed that about 60 percent of the hydrogen in some sensitivity studies is generated by oxidation of zirconium. Our expectation is that the 60 percent level is a likely upper bound since much of the remaining zirconium is contained in metallic blockages that are difficult to oxidize.

The fourth insight is related to the amount of molten material at the time of lower head failure. We noted that the maximum amount of oxide material that relocated into the lower plenum was $\sim 75 \mathrm{mt}$. The biased SCDAP/RELAP5 calculations indicate that virtually all of the core debris relocated in the lower plenum is solid at the time of lower head failure. This is a consequence of attempts to accelerate lower head rupture. The best-estimate Surry calculation indicates that $\sim 13 \mathrm{mt}$ of relocated material will be solidified at the time of lower head failure.

The CONTAIN calculations were used to provide insights into the containment conditions at the time of lower head failure. The Surry containment was represented by seventeen cells. The SCDAP/RELAP5 predictions of the temperature and mass flow rates of water, steam, hydrogen, and nitrogen from the RCS were used as inputs to the CONTAIN calculations. Because of the complexity of the hydrogen combustion issues, CONTAIN was run with all burn models disabled. This allows the maximum accumulation of hydrogen at the time of RPV failure. Several insights were obtained from the CONTAIN calculations.

The CONTAIN calculations showed that the containment pressure at the time of lower head failure was $\sim 0.15 \mathrm{MPa}$ for the best-estimate $480-\mathrm{gpm} / \mathrm{pump}$ case. These values are somewhat lower than similar assessments for Zion $(\sim 0.22 \mathrm{MPa})$ primarily because Surry is a subatmospheric plant. Condensation on internal structures and containment walls had a significant influence on the steam concentration in the containment atmosphere prior to vessel 
breach. It was predicted that the gases would not accumulate in the steam generator compartments or in the containment annulus.

Hydrogen combustion during venting from the RCS or combustion of hydrogen in the atmosphere prior to the DCH event was evaluated only for the best-estimate $480 \mathrm{gpm}$ case. The SCDAP/RELAP5 predictions were analyzed to determine what fraction, if any, of the hydrogen injected into the containment would be consumed as an autoigniting jet. Furthermore, since the scenario analyzed was a station blackout scenario, the autoigniting jets were considered to be the only possible ignition source for deflagrations in the containment. The analyses indicated that autoignition would occur in the hot leg, but that this case would depressurize so quickly that it would not be a DCH threat. The analyses also indicate the gases venting from the third RCP might also autoignite, but that only a negligible amount $(-6 \mathrm{~kg})$ of jet hydrogen would be consumed if the jet did autoignite. The atmosphere composition in the steam generator rooms were flammable at the time when the RCP pump might autoignite; however, only $\sim 6$ percent of the premixed hydrogen in the containment at that time would be consumed. We conclude that global mixtures in the dome were nonflammable during the period when hydrogen was injected into the containment. It was determined that the only possibility of jet autoignition would occur at the hot leg break in the case of $480 \mathrm{gpm} /$ pump leaks, and this case would depressurize so quickly that they would not be a DCH threat. Lastly, the possibility of autoigniting jets does little to alter the composition of the containment atmosphere prior to vessel breach.

\subsection{Characterization of the Surry Plant}

Surry Power Station, Unit 1 is a 2441-MWt pressurized water reactor, designed and built by Westinghouse. A second unit which is essentially identical to this unit is also located on the site. Some systems are shared between the two units, which is reflected in the dominant core damage sequences discussed in Appendix F.

In the sequences of concern for DCH, no emergency core coolant (ECC) except accumulator injection is available. The accumulator setpoint is $4 \mathrm{MPa}(600)$ psi for Surry. In some station blackout sequences (loss of all off-site and on-site ac power), dc power is provided through batteries. It is expected that these batteries would be depleted within 4 hours after accident initiation. 
The auxiliary feedwater system has three pumps; two are driven by electric motors, the third is driven by a steam turbine. Only the turbine-driven pump would be available in station blackout sequences. The turbine-driven pump requires batteries to operate, so in an accident would cease to function after the batteries are depleted.

The RCS has three U-tube steam generators and three reactor coolant pumps. Protecting against overpressure in the reactor coolant system is provided by three code safety valves and two power-operated relief valves (PORVs). With the U-tube steam generator design, countercurrent natural circulation between the RPV and steam generators is possible. This has been shown to have a large impact on the potential for temperature-induced failures during an accident, as discussed in Appendix F. The pumps contain the older design of Westinghouse O-rings, which have a high probability of leaking during an accident involving loss of pump cooling (and it is our understanding that the plant has not committed to replacing the O-rings with the newer design).

In an emergency, containment heat is removal by spray systems. There is no connection between the sump and the reactor cavity at a low elevation in the Surry containment. Water from a pipe break in containment will flow to the sump. The reactor cavity will remain dry unless the containment sprays operate.

The Surry containment is a cylinder with a dome roof. Both the cylinder and the roof are constructed of reinforced concrete. The foundation is a reinforced concrete slab. The containment is lined with welded 0.25 -in. plate steel. During operation, the interior of the containment is maintained about 5 psig below ambient atmospheric pressure.

Quantification of initial conditions for analyzing containment loads is based on the plant characteristics shown in Table 3.1. It is worth noting that approximately 30 percent of the core is within one fuel assembly from the edge of the core. This material, owing to its low decay power and high heat transfer to the core barrel, is difficult to melt, and it is an unlikely contributor to core melt (in the lower plenum) at vessel breach. Although the core contains little steel, the upper and lower plenums contain large quantities of steel that might be added to the core melt, depending on the scenario. Here, we have restricted ourselves to relatively thin steel that has no substantial inertia to thermal loads that might be imposed on the structure. 
Figure 3.3 depicts the Surry NPP. Debris ejected from the reactor pressure vessel first enters the reactor cavity, where high-pressure blowdown gases can disperse the debris into the containment by one of two possible paths. The first is an annular gap around the RPV, which would allow debris to disperse directly to the upper dome. This annular gap is partially filled with reflective insulation and is blocked by neutron shielding and the six nozzles near the top of the RPV. The SNL integral effects test (IET)-11 (Blanchat et al., 1994) experiment showed that if gas can carry debris into the gap, then the insulation can melt and be swept clear of the gap. Such a situation cannot be precluded at Surry; consequently, this potential flow path is explicitly bounded in the evaluation of containment loads.

As shown in Figure 3.3, the major dispersal path (by virtue of its large flow area) is through a tunnel leading from under the RPV, which exists so that in-core instrument guide tubes can have access to the lower head. Debris dispersed from the cavity through this path will enter the lower compartmentalized regions of the containment. In particular, a significant amount of debris will be captured and retained in the residual heat removal (RHR) platform region; which represents an insignificant volume of the containment. The TCE model treats this subcompartment room as part of its basic formulation, but it is found that DCH interactions are dominated by the interaction with the blowdown gas rather than any gas initially in the subcompartment. Consequently, this room plays no real role in DCH except to confine debris to an insignificant portion of the containment atmosphere. However, hydrogen produced in the cavity and basement during the $\mathrm{DCH}$ event will be pushed to the upper dome through vent paths by blowdown steam.

The seal table room sits above the RHR platform region over the cavity exit. Experiments have shown that some dispersed debris can reach the upper dome through this room.

\subsection{Definition of Probability Levels}

Our approach here recognizes that variability (i.e., statistical variations for nominally similar conditions) will probably be smaller than uncertainties in the phenomena themselves. We chose to use artificial probabilities as a tool to demonstrate relative variations in the probabilities of different outcomes. The numbers themselves have no quantitative value; they are important only in a relative sense. We used a physically based probability scale (Table 3.2 ) to quantify inputs and used the same scale to convert bottom-line results to a physical interpretation. The physical 
interpretations have been selected for the case of $\mathrm{DCH}$ within the context of the entire risk picture. We recognize that a probability of 0.01 might be considered very high in another context.

Empirically, it can be shown that the physical interpretation of the probability calculation is invariant relative to the numbers assigned to the judgmental degrees of belief, as long as the same geometrical progression is preserved. With our recommended assignment, the product of two "edge of spectrum" events $\left(p \sim 10^{-1}\right)$ is $10^{-2}$, which should be interpreted as an "upper bound." The interpretations in Table 3.2 might be given the alternative assignments: 1, 1/3, 1/9. Once again, the product of two "edge of spectrum" events $(p \sim 1 / 3)$ is $1 / 9$, which should be interpreted physically as an "upper bound" with the new assignments. Therefore, the specific value of a judgmental degree of belief has no intrinsic meaning; it is only meaningful when measured against the physical assignment.

Our judgmental degree of belief for any process can be characterized as likely $(p \sim 1)$, as unlikely $\left(p \sim 10^{-2}\right)$, or as something in between $\left(p \sim 10^{-1}\right)$. As a practical matter, we assign $p \sim 1$ to our best estimate and $p \sim 10^{-2}$ to our estimate of a reasonable upper bound (assuming we have a reasonable expectation that the upper bound is unlikely). The working group for NUREG/CR6075, Supplement 1 concurred with this interpretation.

\subsection{Scenario V - SBLOCA with Repressurization of the RCS by Operator Intervention}

Scenario $\mathrm{V}$ represents a core melt accident that progresses with water still present in the lower portions of the core. Such conditions lead to formation of a crust within the core followed by a massive release of melt when the crust fails. Accumulation of core material on the lower head of the RPV causes the lower head to heat up, eventually to the point where its structural strength is so degraded it can no longer withstand the stresses induced in the lower head by elevated RCS pressures. Thus, creep rupture of the lower head is the expected failure mechanism. The distinguishing feature of Scenario $\mathrm{V}$ is that operator actions are assumed to refill the RPV with water and to fully repressurize the RCS. Analysis of DCH for a repressurized RCS is deemed conservative because we expect operators to depressurize the RCS in a core damage accident. 
Table 3.3 summarizes the initial conditions for this scenario. Operator actions are assumed to repressurize the RCS to $16 \mathrm{MPa}$. Operator intervention refills the RPV with water $(\sim 75 \mathrm{mt})$ to the hot leg nozzles and quenches any steam remaining in the RCS to near saturation $(\sim 700 \mathrm{~K})$. Recall that at TMI-II a noncondensible gas bubble prevented operators from refilling the entire RCS. The RPV lower head must be heated by accumulated core material to the point that steel loses its strength $(\sim 1000 \mathrm{~K})$, which leads to rupture of the lower head. The initial hole diameter is $\sim 0.40 \mathrm{~m}$ (Pilch et al., 1994a) because of the likely presence of hot spots and because of stress concentrations associated with the existence and spacing of lower head penetrations. This rupture size is in accordance with working group recommendations (Appendix A in Pilch et al. 1994b) for Zion; experiments (Allen et al., 1991) and models have not shown a strong sensitivity to the initial hole size. The final hole size $(\sim 0.46 \mathrm{~m}$ at the upper bound) is computed with the ablation model, Eq. (4.2); however, ablation is not important for the large initial hole sizes associated with rupture of the lower head.

Oxidation of $\mathrm{Zr}$ occurs predominantly before significant core degradation, as demonstrated in various calculations. In earlier two-dimensional MELPROG calculations performed by Kelly et al. (1987), 80 percent of the $\mathrm{Zr}$ oxidation occurred prior to formation of a molten pool. SCDAP/RELAP5 calculations (Appendix C in Pilch et al. 1994b) performed for Zion confirm these early assessments and show that nearly 100 percent of the hydrogen is produced before core slump. SCDAP/RELAP5 predicts similar behavior for Surry (Appendix E and Knudson and Dobbe 1993). Furthermore, most $\mathrm{Zr}$ will be permanently retained in core blockages, with any $\mathrm{Zr}$ remaining in the melt existing as a eutectic with the other (mainly oxidic) constituents. Little of this $\mathrm{Zr}$ is expected to oxidize during massive relocations. To a first order then, $\mathrm{Zr}$ oxidation is independent of the core melt progression that follows the main oxidation event; and since oxidation occurs predominantly before formation of the molten pool, existing system-level computer codes are technically adequate to assess the range of possible oxidation.

Referring then to SCDAP/RELAP5 calculations (Knudson and Dobbe, 1993; Knudson, 1993; Appendix C in Pilch et al. 1994b, and Appendix E), MELPROG/PWR-MOD1 calculations (Kelly et al., 1987), and CORMLT calculations (Denny and Sehgal, 1983), we find that the fraction of $\mathrm{Zr}$ oxidized ranges from 20 to 60 percent, with a mean around 40 percent. MAAP calculations cited in the Surry individual plant examination (IPE) for a short-term station

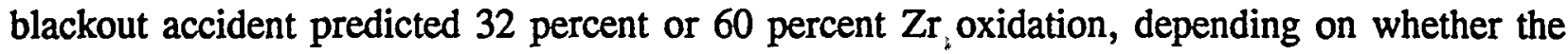
core blockage model was turned on or off. Consistent with NUREG-1150 expert elicitations, 
the extremes of the distributions are considered unlikely $(p \sim 0.01)$. The distribution is shown in Figure 3.4. The calculations cited were chosen because of their explicit treatment of recirculating flow patterns in the core.

Consistent with TMI-II, the potential release of molten material to the lower head is controlled by the formation of a hemispherical crucible that excludes only the outer assemblies of the core (Figure 3.5). The outer assemblies are generally not expected to be in a severely degraded state because the RPV is flooded. Asymmetries in crucible growth ensure that localized penetration of the outer assembly and the core barrel would most likely occur when the crucible has grown (on average) to the outer assembly. This is consistent with the observed end state at TMI-II.

The maximum volume of such a crucible is $4.6 \mathrm{~m}^{3}$ and it would be filled with a predominantly oxidic melt with a density of $\sim 10,000 \mathrm{~kg} / \mathrm{m}^{3}$. This means that the crucible can hold a maximum of $\sim 46 \mathrm{mt}$ of molten material. The amount of melt released from the crucible is a function of where the crucible fails, with downward and sideward representing the two extremes. Recent studies by Schmidt and Humphries (1994), which consider only conduction processes, suggest that bottom failure of a crucible is very unlikely. Natural convection patterns (which produce edge-peaked heat flux distributions) in the molten pool, should they develop, would only reinforce the prediction of side failure of the crucible. The MP-2 experiment (Gasser et al., 1994) tends to confirm that downward failure of an oxidic crust is unlikely, even in the absence of active cooling. To establish an upper bound $(p \sim 0.01)$ on the $\mathrm{UO}_{2}$ mass that relocates to the lower plenum, it was assumed that the crucible could fail at the bottom, releasing the entire $\sim 46 \mathrm{mt}$ of material to the lower plenum head. ${ }^{3}$

To fix the composition a little more closely, we note that $\sim 80-90$ percent of $46 \mathrm{mt}$ $(0.85 \times 46 \sim 40 \mathrm{mt})$ is $\mathrm{UO}_{2}$. As a best estimate, and consistent $\mathrm{u}$ ith TMI-II observations and working group recommendations, side failure of the crucible is expected to release about half of the material ( $\sim 23 \mathrm{mt}$ total) to the lower head. Likewise, the best estimate on the amount of relocated $\mathrm{UO}_{2}$ is $\sim 20 \mathrm{mt}$. On this basis, the distribution for the amount of $\mathrm{UO}_{2}$ released from the crucible can be constructed as in Figure 3.6.

3 As an upper bound, NUREG/CR-6075 assumed that 75 percent of the molten material bottled up in the crucible would relocate. The initial condition working group for Zion (Pilch et al. 1994b) recommended that 100 percent relocation should be used as the upper bound. 
It should be noted that the amount of $\mathrm{UO}_{2}$ released from the crucible exceeds the amount of molten material available to participate in $\mathrm{DCH}$ at the time of vessel failure. First, not all material released from the TMI-II crucible reached the lower head. Some froze between the core former plate and the core barrel and some additional material froze on other structures as it drained into the lower plenum. Second, some molten material will quench and freeze as it flows through the water in the lower plenum. Calculations using the THIRMAL code (Rempe et al., 1993) suggest that as much as $\sim 50$ percent might freeze during this process if the water is subcooled. Experiments (Spencer et al., 1994) tend to confirm this number if the water is subcooled, but suggest that only $\sim 10$ percent will quench if the water is saturated. Third, some of the molten material accumulated on the lower head will form an upper crust resulting from heat transfer to the overlying water. Finally, some of the molten material will freeze as it transfers heat to the lower head and drives it to failure.

The extent to which these solidified materials persist to vessel rupture is coupled to generation of decay heat within the debris and the time required to heat the vessel to rupture. SCDAP/RELAP5 calculations for Zion (Appendix $C$ in Pilch et al. 1994b) indicate that $\sim 20-25 \mathrm{mt}$ of material are frozen on the lower head at the time of vessel breach. The SCDAP/RELAP5 calculations are themselves a lower bound since they do not account for water intruding into the melt through cracks in the overlying crust or gaps along the vessel wall. These additional cooling mechanisms were identified as part of the TMI-II vessel investigation program (Stickler et al., 1993).

As a bound, we consider only melt freezing in the process of heating the lower head to rupture. Boucheron (referenced in Zuber et al., 1991) shows that $\sim 10-15 \mathrm{mt}$ of oxide will freeze (with decay heat coupling) in order to heat the lower head to a point where it loses its strength and ruptures. With this in mind, we shift the $\mathrm{UO}_{2}$ distribution in Figure 3.6 an additional $10 \mathrm{mt}$ to the left. The distribution of molten $\mathrm{UO}_{2}$ at the time of vessel breach is then given by Figure 3.7. The best estimate is then centered at $10 \mathrm{mt}$, with an upper bound of $30 \mathrm{mt}$. We emphasize the conservative nature of this distribution given the additional quenching mechanisms that have been ignored.

We acknowledge that some of the $\sim 10 \mathrm{mt}$ of solid material may be ejected with the melt into the reactor cavity and that this solid material may participate in DCH. The solids, however, are oxidic, and sensitivity studies (Pilch et al., 1994b, Appendix A, Response H19) indicate that 
DCH loads are not sensitive to the total quantity of oxides in the melt. Furthermore, Griffith (Appendix $\mathrm{H}$ in Zuber et al., 1991) indicates that complete ejection of the solid material is not expected even if it exists as loose debris particles. The extent to which ejected solids can participate in DCH may be further limited by the particle size, since fragmentation to $\sim 1 \mathrm{~mm}$ is necessary for efficient DCH interactions. Consequently, the impact of solid debris on DCH loads is judged to be insignificant and is neglected in these evaluations.

The amount of molten $\mathrm{ZrO}_{2}$ in the melt is controlled by the amount of oxidation that occurs prior to core melt. The amount of molten $\mathrm{ZrO}_{2}$ can be estimated from

$$
M_{\mathrm{zroz}}=\frac{M_{\mathrm{vo2}}(\text { melt })}{M_{\mathrm{vo} 2}(\text { core })} M_{\mathrm{zr}}^{0} f_{\mathrm{zr}} \frac{123}{91} \text {. }
$$

This expression assumes that $\mathrm{ZrO}_{2}$ is contained in the melt in the same fraction to which the core is degraded $M_{\mathrm{UO} 2}$ (degraded) $/ M_{\mathrm{UO} 2}$ (core) and that $\mathrm{ZrO}_{2}$ relocates to the lower plenum in the same manner as the $\mathrm{UO}_{2}$, that is, $M_{\mathrm{UO} 2}$ (melt) $/ M_{\mathrm{UO} 2}$ (degraded).

The relocation of $\mathrm{Zr}$ metal within the core plays a key role in the ultimate formation of core blockages. Upon melting, most of the $\mathrm{Zr}$ metal and $(\mathrm{U}, \mathrm{Zr}) \mathrm{O}_{2}$ relocates downward until it freezes in cooler portions of the core, forming partial or complete blockages, depending on the amount of relocating material. The subsequent melting of $\mathrm{UO}_{2}$ and $\mathrm{ZrO}_{2}$ allows molten oxides (at least initially) to settle and refreeze on top of the metallic blockages. In this way, the accumulating melt forms a crucible on top of the metallic blockage. This picture is consistent with SCDAP/RELAP5 calculations. This separation of molten oxides from the blockage, which consists of unoxidized clad and dissolution products, ensures that little metal enters the melt, except possibly through some additional formation of $(\mathrm{U}, \mathrm{Zr}) \mathrm{O}_{2}$ eutectics, dripping of $\mathrm{Zr}$ from fuel stubs above the degraded region, or when the crust fails. However, SCDAP/RELAP5 predicts only negligible additional formation of eutectics, and dripping is not predicted even in scenarios in which the core is completely dry. As observed in TMI-II, the crust is expected to fail locally (from inhomogeneities in the crust and asymmetries in crucible growth), carrying only small quantities of metal from the blockage into the lower plenum. The flooded core scenario precludes melting out of the blockage. Thus, little or no $\mathrm{Zr}$ is expected in the melt.

We note that SCDAP/RELAP5 calculations predict little or no $\mathrm{Zr}$ in the melt. However, to account for uncertainties in eutectic formation and crucible failure (and consistent with the 
working group recommendations), we assume that the molten $\mathrm{Zr}$ mass is proportional to the mass of molten $\mathrm{UO}_{2}$. Thus, the amount of molten $\mathrm{Zr}$ can be computed from

$$
M_{\mathrm{Zr}}=0.029 M_{\mathrm{Uo2}} \text {. }
$$

The constant of proportionality, as estimated for Zion (Pilch et al. 1994b), is assumed to be applicable to Surry also. We conservatively assume that any $\mathrm{Zr}$ that relocates with the melt does not oxidize as it falls through the water pool. Additional perspectives on this formulation are discussed in Section 3.7.

In a wet core scenario such as this, the control rod material will be an initial contributor to the metal blockage in the core and the flooded core scenario precludes melting out of the blockage. Consequently, only trivial quantities $(\sim 0 \mathrm{mt})$ of control rod will be present in the melt at the time of vessel breach.

Melting of upper plenum steel is strongly correlated with failure of the surge line or hot leg nozzle at high system pressures ( $\sim 8 \mathrm{MPa})$. Specifically, gas temperatures that are hot enough to melt upper plenum steel $(\sim 1700 \mathrm{~K})$ are also hot enough to induce rupture (under pressure) of the hot leg or surge line. Upper plenum steel is a potential contributor to melt mass and composition only in those scenarios (Scenarios VII and VIII) that proceed to relatively low pressures at the time of vessel breach; and even then, SCDAP/RELAP5 predicts failure of the hot leg. In any case, melting of upper plenum steel cannot be important when operators reflood the RPV as they did in TMI-II. The small amount of steel initially in the core, like cladding and control rod material, is largely retained in core blockages, which cannot melt out in a flooded core scenario.

The melting of lower plenum steel by relocated core material is the only source of molten steel of potential importance in a DCH event. SCDAP/RELAP5 calculations show that some water is always present in the lower plenum, so the core debris cannot radiate to structures. Only thin lower plenum steel (e.g., nozzles) that is submerged in the accumulating core material is assumed to melt. The quantity of submerged steel depends on the volume of core material in the lower plenum and can be computed from 


$$
M_{s}=M_{s, L P} \frac{\frac{M_{U O 2}}{\rho_{U O 2}}+\frac{M_{Z \mathrm{Z} O 2}}{\rho_{Z \mathrm{Z} O 2}}+\frac{10 \times 10^{3}}{\rho_{U O 2 / Z \mathrm{ZrO} 2}}+\frac{M_{\mathrm{Zr}}}{\rho_{\mathrm{Zr}}}+\frac{M_{C R M}}{\rho_{C R M}}}{V_{L P}}
$$

where the densities $\left(\mathrm{kg} / \mathrm{m}^{3}\right)$ are $\rho_{\mathrm{UO2}}=10,400, \rho_{\mathrm{Zro2}}=5,900, \rho_{\mathrm{Uoz} / \mathrm{Zr} 02}=9,660, \rho_{\mathrm{Zr}}=6,500$, and $\rho_{\mathrm{CRM}}=9,250$. Note that the quenched $10 \mathrm{mt}$ must be taken into account because it is part of the volume of core material. We note that submerged nozzles at TMI-II did not all melt; consequently, Eq. (3.3) gives a conservative result.

Consideration of natural convection in volumetrically heated pools (Theofanous, 1988; Epstein and Fauske, 1989) indicates that the melt superheat cannot exceed $-200 \mathrm{~K}$ under steady-state conditions. These assessments are also consistent with SCDAP/RELAP5 analyses. The $\mathrm{UO}_{2} / \mathrm{ZrO}_{2}$ eutectic melts at about $2800 \mathrm{~K}$, so the maximum temperature on relocation is about $3000 \mathrm{~K}(\sim 2900 \mathrm{~K}$ has been estimated for TMI-II), but some cooling on relocation is expected. Thus, we believe that a conservative bounding value of $\sim 2800 \mathrm{~K}$ is appropriate for Scenario $V$.

Surry is a subatmospheric plant so the containment pressure at vessel breach could be somewhat lower than the $\sim 0.25 \mathrm{MPa}$ estimate for Zion (Pilch et al. 1994b). Supporting documentation for NUREG-1150 (NUREG/CR-4551) lists the containment pressure as $\sim 0.18$ MPa. MAAP calculations in support of the Surry IPE range from $\sim 0.19 \mathrm{MPa}$ to $\sim 0.25 \mathrm{MPa}$, depending on the sequence. The most recent CONTAIN calculations, using sources from SCDAP/RELAP5 for a 480-gpm/pump RCP leak case, yield $\sim 0.15$ at the time of vessel breach. As a result, $\sim 0.18 \mathrm{MPa}$ was chosen as representative of cases where active containment cooling is not operational. Appendix D in NUREG/CR-6075 (Pilch et al., 1994a) concludes that DCH loads are insensitive to reasonable choices of initial containment pressure (assuming fan coolers or sprays are not operational). The Surry containment is initially subatmospheric, so approximately $0.069 \mathrm{MPa}(360 \mathrm{~K} / 314 \mathrm{~K}) \approx 0.079 \mathrm{MPa}$ of the pressure at vessel breach is air. Consequently, the initial steam concentration is $\sim 56$ percent.

The containment conditions discussed above assume that active containment cooling systems (i.e., fan coolers or sprays) are not operational. We note that fan coolers were operational at TMI-II and that containment conditions were $\mathrm{P} \sim 0.11 \mathrm{MPa}, \mathrm{T} \sim 326 \mathrm{~K}, \mathrm{X}_{\mathrm{STM}} \sim 0.035$, and $X_{\mathrm{H} 2} \sim 0.079$. Thus, there was little steam in the containment. This situation will also be 
analyzed as Scenario $\mathrm{Va}$ in Section 6 to better envelop the range of containment conditions. We note that the Surry IPE does not take into account fan coolers, but some sequences will involve spray operation at the time of vessel failure. The potential impact of containment sprays will be addressed in Section 6.

The core-wide oxidation of $\mathrm{Zr}$ also controls the amount of preexisting hydrogen that can exist in the containment building at the time of vessel breach. The RCS retains very little of this hydrogen because it is produced early in the accident and most is vented to the containment. This is supported by earlier SCDAP/RELAP5 calculations (Knudson, 1993) where more than 90 percent of the $\mathrm{H}_{2}$ was released to the containment. Recent SCDAP/RELAP5 calculations performed for Zion (Appendix C in Pilch et al. 1994b) indicate that essentially all the hydrogen produced in-vessel will be released to the containment. Steam and $\mathrm{H}_{2}$ sources from SCDAP/RELAP5 are sometimes very hot (Appendix D in Pilch et al. 1994b) and there is a possibility that hydrogen will burn as it enters the containment. However, recent CONTAIN assessments for Zion (Pilch et al. 1994b) using SCDAP/RELAP5 sources suggest that this effect is minimal except in the event of a hot leg failure, which precludes a DCH event. Consequently, we assume that all hydrogen produced in-vessel will be released to containment, where it will not burn prior to vessel breach. The moles of preexisting hydrogen in the containment are given by:

$$
N_{H 2}(g \cdot \text { mole })=\frac{2}{0.091} f_{z r} M_{z r}^{0}(\text { core })
$$

or alternatively, a concentration can be specified

$$
X_{H 2}=\frac{N_{H 2}}{N_{A T M}^{0}} .
$$

We note that at TMI-II there was $\sim 7.9$ percent $\mathrm{H}_{2}$ in the atmosphere and essentially no steam. Even though these conditions are in the flammable regime, we cannot guarantee that a random ignition source (unless intentional) will burn off the hydrogen prior to vessel failure if the flammability limits are exceeded. 


\subsection{Scenario VI - SBLOCA under Wet Core Conditions}

Table 3.3 also summarizes the initial conditions for Scenario VI. In the absence of any RCS leaks, SCDAP/RELAP5 (Appendix E) predicted surge line failure long before bottom head failure. These cases fully depressurize and are of no interest for $\mathrm{DCH}$. We then sought SBLOCAs of just the right size to depressurize sufficiently that natural circulation degrades to the point that surge line or hot leg failure is not assured. Such an intermediate state was not found (Appendices E, F). In fact, SCDAP/RELAP5 predicts hot leg failure before core relocation for the full spectrum of SBLOCAs; consequently, Scenario VI can only exist as the consequence of partial operator intervention. Owing to the similarity in Scenarios V and VI, we emphasize only the differences in RCS temperature, melt mass, and composition, with all other parameters developed in a manner similar to that for Scenario V.

The RCS gas at the time of vessel breach clearly must be superheated. In conjunction with the pressure and volume, the moles of gas in the RCS can be computed with the RCS temperature. The gas temperatures in each region of the RCS are estimated from SCDAP/RELAP5 output (Appendix E). Given this assessment, a lower bound of $\sim 1000 \mathrm{~K}$ is assigned to this scenario.

The potential release of molten material to the lower head is again controlled by the formation and failure of a crucible in the core region. Water occupies only the lowest regions of the core, so radial cooling of a growing crucible is reduced in this situation, and consistent with SCDAP/RELAP5 predictions, the crucible could take on the bounding shape of an upright cylinder as depicted in Figure 3.8. We note that SCDAP/RELAP5 conservatively assumes that the melt pool must grow to the core boundary as a condition for core relocation, thus SCDAP/RELAP5 shows some localized involvement of the outer assemblies. We expect, however, that asymmetries in crucible growth ensure that localized penetration of the outer assembly and core barrel would likely occur when the crucible has grown (on average) to the outer assembly. Consequently, the outer assemblies are excluded from our assessments.

In the extreme of this geometry, -80 percent of the core can be contained in the crucible. The upper bound to the $\mathrm{UO}_{2}$ distribution is then $0.8 \times 79.8 \mathrm{mt}$ or $\sim 65 \mathrm{mt}$ if the crucible fails on the bottom. Again, the calculations of Schmidt and Humphries (1994) favor side failure before the crucible obtains these extreme proportions. As a best estimate we assume $\sim 32.5 \mathrm{mt}$ 
of $\mathrm{UO}_{2}$ can be released. With this in mind, the distribution of $\mathrm{UO}_{2}$ released from the crucible can be constructed as indicated in Figure 3.9. Again allowing $(\sim 10 \mathrm{mt})$ only for melt freezing in order to heat the lower head to rupture, the distribution of molten $\mathrm{UO}_{2}$ at the time of vessel failure is given by Figure 3.10.

Scenario VI is envisioned as having water in the lower plenum, but not to the extent that it submerges the bottom of the core. Under such circumstances, it is possible for low melting point control rod material to relocate to the lower plenum. SCDAP/RELAP5 calculations (Knudson and Dobbe, 1993; Quick and Knudson, Appendix E) suggest that $\sim 2 \mathrm{mt}$ of control rod material may relocate into the lower plenum when the core is not submerged. Although this material will quench in lower plenum water or on the lower head, we conservatively assume that the subsequent relocation of large quantities of oxide material will remelt all the control rod material and heat it to the oxide temperature $(\sim 2800 \mathrm{~K})$ ?

We note that SCDAP/RELAP5 calculations predict little or no $\mathrm{Zr}$ in the melt. However, to account for uncertainties in eutectic formation and crucible failure, we assume that the molten $\mathrm{Zr}$ mass is 2.9 percent of the molten $\mathrm{UO}_{2}$ mass. Although SCDAP/RELAP5 does not predict relocation of the metallic blockage, we acknowledge that scenarios where the bottom of the core is not submerged in water have an increased potential for partial melting and relocation of the metallic blockage into the lower plenum. We note, however, that complete oxidation of the $\mathrm{Zr}$ in prototypic core melts was observed in a FARO experiment involving melt drainage into a pressurized water pool. More importantly, however, are SCDAP/RELAP5 predictions that the RCS will be depressurized in those scenarios that have the greatest potential for relocation of the metallic blockage.

It is useful to examine the recommended $\mathrm{Zr}$ content of the melt from alternative perspectives. The recommended formulation is equivalent to a hypostoichiometry of urania, which can be expressed as $\mathrm{UO}_{2-x}$, where $\mathrm{x} \sim 0.17$. One can also perform a mass balance on the $\mathrm{Zr}$ inventory. For instance, the core contains $16.5 \mathrm{mt}$ of $\mathrm{Zr}$ in Surry. On a core-wide basis, $\sim 40$ percent of $\mathrm{Zr}$ is oxidized, so $\sim 9.9 \mathrm{mt}$ of $\mathrm{Zr}$ metal remains. About 26 percent of the initial $\mathrm{Zr}$ inventory resides in the cooler outer assemblies, which are not part of the degraded core debris. Assuming only 20 percent oxidation in the outer assemblies, about $3.4 \mathrm{mt}$ of $\mathrm{Zr}$ will remain in the outer assemblies and the remaining $6.5 \mathrm{mt}$ will be retained in the core blockage. At the upper end of the Scenario $\mathrm{VI} \mathrm{UO}_{2}$ distribution, $\sim 1.6 \mathrm{mt}$ of $\mathrm{Zr}$ will relocate to the lower 
plenum. This represents -25 percent of the $\mathrm{Zr}$ inventory in the metal blockage. These perspectives on possible $\mathrm{Zr}$ relocation coupled with the likelihood of complete oxidation on relocation and low RCS pressures, support the bounding nature of our assessments, even in scenarios where the core is not submerged in water.

The fraction of $\mathrm{Zr}$ oxidized remains unchanged. This, in conjunction with the causal relations (Eqs. 3.1 - 3.4) developed in Section 3.6, defines the remaining melt constituents and atmosphere compositions.

\subsection{Summary Melt Masses and Compositions}

Because many of the melt constituents are correlated, it is useful to tabulate the lower bound, best-estimate, and upper bound masses for a more direct comparison and to compare these quantifications with prior work. This is done in Table 3.6. The lower and upper bounds are taken at the $\sim 1$ percent probability level.

Consider first the comparison of Scenarios $\mathrm{V}$ and $\mathrm{VI}$ by composition. The $\mathrm{ZrO}_{2}$ values are a function of both the $\mathrm{UO}_{2}$ mass and the fraction of $\mathrm{Zr}$ oxidized. For this comparison, the three $\mathrm{UO}_{2}$ masses are used in conjunction with the best estimate for the fraction of $\mathrm{Zr}$ oxidized. This ensures that lower and upper bounds to the $\mathrm{ZrO}_{2}$ values are also at the -1 percent probability level. This prescription is not unique. For instance, it is possible to use the best estimate for the $\mathrm{UO}_{2}$ mass in conjunction with the lower, best-estimate, and upper bound values for the fraction of $\mathrm{Zr}$ oxidized. This procedure, however, gives somewhat less $\mathrm{ZrO}_{2}$ mass for the bestestimate and upper bound value.

At the outset, we should state that no potential comparisons are fully consistent with the plant and scenarios discussed in this report, so some compromise is necessary to make suitable comparisons. Prior summary efforts (i.e., NUREG-1150 and SASM) are therefore the most useful for comparison (see Table 3.4) since these activities employed panels of knowledgeable experts who were able to synthesize the experimental and analytical information available at the time. Since the time of these summary efforts, new information has become available and these new data are reflected in our current quantifications. 
NUREG-1150 was the first summary assessment of core melt progression parameters and addressed only the core fraction that is molten and the fraction of cladding oxidized. NUREG1150 assessments were largely based on MARCH, early MAAP, and preliminary MELPROG calculations. The distribution of the molten core fraction in Scenario VI is in good agreement with the expert elicitation results in NUREG-1150.

SASM (Zuber et al., 1991) is the most recent of the summary assessments, and it was focused specifically on the DCH issue. The SASM recommendations for molten oxides are enveloped by the current quantifications; however, the metals are outside the current assessments. Asssessment of steel mass in the SASM effort was largely based on a MELPROG calculation (Kelly et al., 1987) of a station blackout accident in which significant upper plenum melting was predicted. Melting of upper plenum steel is strongly correlated with surge line or hot leg failure, which in fact was predicted in the MELPROG calculation. Specifically, gases hot enough to melt upper plenum steel are also hot enough to rupture the surge line or hot leg. This is also consistent with the current SCDAP/RELAP5 assessments. The large quantities of $\mathrm{Zr}$ and CRM in the SASM assessment are traceable to a MELPROG modeling assumption that crucible failure occurs as a massive event carrying most of the metallic blockage into the lower plenum. Thus, the SASM assessment of metals in the melt is not consistent with our current understanding of core melt progression under wet core conditions.

Table 3.4 also summarizes the melt mass predicted by SCDAP/RELAP5 at the time of vessel failure for a 250 -gpm/pump case. Current quantifications (Scenarios V and VI) for oxide mass are in general agreement with the system code predictions, which are interpreted as upper bounds because SCDAP/RELAPS assumes complete drainage of the in-core molten pool. SCDAP/RELAP5 predicts essentially no $\mathrm{Zr}$ in the melt while our quantifications chose to bound the amount with $\sim 1.3 \mathrm{mt}$. The amount of lower plenum steel predicted by SCDAP/RELAP5 is also in agreement with the current assessment.

\subsection{Extrapolation Insights}

The methodology for establishing initial conditions has now been completed for two plants, Zion and Surry, so it would be useful to examine the results for some trends and possible insights that could be used for extrapolation. Table 3.5 summarizes some potentially important differences between Zion and Surry. 
SCDAP/RELAP5 calculations predict that accident-induced failure of the surge line or hot leg is expected before core relocation and bottom head failure. This result is significant given the difference in power density and downcomer by-pass geometry, both of which lead to 1-hour differences in core melt progression.

The methodology for quantifying the melt mass distributions has now been completed for two plants of significantly different core size: Surry and Zion (Pilch et al. 1994b). Table 3.6 explores whether the melt mass distributions scale with core mass. For hemispherical crucibles (Scenario V), the melt mass distribution does not scale with core power while for cylindrical crucibles (Scenario VI) the melt mass is nearly in scale with core size. These observations are consistent with the assumed geometries. More important, however, the melt mass distributions reasonably envelop SCDAP/RELAP5 predictions of melt mass at vessel breach for both Zion and Surry. SCDAP/RELAP5 predicts that dissolution products and clad material will be permanently retained in core blockages and that the amount of $\mathrm{Zr}$ in the melt at vessel breach will be negligible. The SCDAP/RELAP5 calculations also predict that conditions leading to melting of upper plenum steel will also lead to hot leg failure. Steel enters the melt only to the extent that debris submerges thin structures in the lower plenum.

In the absence of active containment cooling, CONTAIN calculations with sources from SCDAP/RELAP5 show that the containment pressure is $-0.20-0.25 \mathrm{MPa}$ at the time of vessel breach for Zion and $\sim 0.15 \mathrm{MPa}$ for Surry. Much of this difference results from the fact that Surry is a subatmospheric plant.

\subsection{References}

Allen, M.D. et al. (1990). A Demonstration Experiment of Steam-Driven, High-Pressure Melt Ejection: The HIPS-10S Test, NUREG/CR-5373, SAND89-1135, Sandia National Laboratories, Albuquerque, NM.

Allen, M.D. et al. (1991). Experiments to Investigate the Effect of Flight Path on Direct Containment Heating (DCH) in the Surtsey Test Facility: The Limited Flight Path (LFP) Tests, NUREG/CR-5728, SAND91-1105, Sandia National Laboratories, Albuquerque, NM.

Allen, M.D. et al. (1993). Experiments to Investigate the Effects of Fuel/Coolant Interactions on Direct Containment Heating, The IET-8A and IET-8B Experiments, SAND92-2849, Sandia National Laboratories, Albuquerque, NM. 
Allen, M.D. et al. (1994a). Experiments to Investigate Direct Containment Heating Phenomena with Scaled Models of the Zion Nuclear Power Plant in the Surtsey Test Facility, NUREG/CR6044, SAND93-1049, Sandia National Laboratories, Albuquerque, NM.

Allen, M.D., T.K. Blanchat, and M.M. Pilch (1994b): Test Results on Direct Containment Heating by High Pressure Melt Ejection into the Surtsey Vessel: The TDS Test Series, SAND911208, Sandia National Laboratories, Albuquerque, NM.

Blanchat, T.K. et al. (1994). Experiments to Investigate Direct Containment Heating Phenomena With Scaled Models of the Surry Nuclear Power Plant, NUREG/CR-6152, SAND932519, Sandia National Laboratories, Albuquerque, NM.

Denny, V.E., and B.R. Sehgal (1983). "Analytical Prediction of Core Heatup/Liquefaction/ Slumping," Proceedings International Meeting on Light Water Reactor Severe Accident Evaluation, Aug. 28-Sept. 1, Cambridge, MA.

Epstein, M., and H.K. Fauske (1989). "The Three Mile Island Unit 2 Core Relocation -- Heat Transfer Mechanisms," Nuclear Technology, Vol. 87, p. 1021.

FAI (1991). Zion IPE Position Paper on Direct Containment Heating, FAI/91-18, submitted to Commonwealth Edison Co., Chicago, IL.

Gasser, R.D. et al. (1994 draft). Late Phase Melt Progression Experiment--MP-2, Results and Analysis, NUREG/CR-6167, SAND93-3931, Sandia National Laboratories, Albuquerque, NM.

Ginsberg, T., and N.K. Tutu (1988). Progress in Understanding Direct Containment Heating Phenomena in Pressurized Light Water Reactors, BNL-NUREG-41751, Brookhaven National Laboratory, Upton, NY.

Hammersley, R.J., M. Merilo, and R.E. Henry (1993). "Experiments to Address Lower Plenum Response Under Severe Accident Conditions," Proceedings of the International Topical Meeting on Probabilistic Safety Assessment (PSA93), Clearwater Beach, FL.

Hanson, D.J. et al. (1990). Depressurization as an Accident Management Strategy to Minimize the Consequence of DCH, NUREG/CR-5447, U.S. Nuclear Regulatory Commission, Washington, DC.

Heames, T.J., and R.C. Smith (1987). "Integrated MELPROG/TRAC Analyses of a PWR Station Blackout," Nuclear Engineering and Design, Vol. 125, pp. 175-188.

Kelly, J.E., R.J. Henninger, and J.F. Dearing (1987). MELPROG-PWT/MODI Analysis of a TMLB' Accident Sequence, NUREG/CR-4742, SAND86-2175, Sandia National Laboratories, Albuquerque, NM.

Knudson, D.L. (1993). Transmittal of SCDAP/RELAP5/MOD3 Results for the Zion Power Station, Letter Report to NRC. 
Knudson, D.L., and C.A. Dobbe (1993). Assessment of the Potential for High Pressure Melt Ejection Resulting from a Surry Station Blackout Transient, NUREG/CR-5949, EGG-2689, EG\&G Idaho, Inc., Idaho Falls, ID.

Marshall, B.W. (1988). Reactor Safety Research Semi-annual Report July-December 1987, NUREG/CR-5039, SAND87-2411, Vol. 2, p. 244, Sandia National Laboratories, Albuquerque, NM.

Pilch, M., and W.W. Tarbell (1985). High Pressure Ejection of Melt from a Reactor Pressure Vessel: The Discharge Phase, NUREG/CR-4383, SAND85-0012, Sandia National Laboratories, Albuquerque, NM.

Pilch, M., and W.W. Tarbell (1986). Preliminary Calculations on Direct Heating of a Containment Atmosphere by Airborne Core Debris, NUREG/CR-4455, SAND85-2439, Sandia National Laboratories, Albuquerque, NM.

Pilch, M.M., H. Yan, and T.G. Theofanous (1994a). The Probability of Containment Failure by Direct Containment Heating in Zion, NUREG/CR-6075, SAND93-1535, Sandia National Laboratories, Albuquerque, NM.

Pilch, M.M. et al. (1994b). The Probability of Containment Failure by Direct Containment Heating in Zion, NUREG/CR-6075, Supplement 1, Sandia National Laboratories, Albuquerque, NM.

Rempe, J.L. et al. (1993). Light Water Reactor Lower Head Failure Analysis, NUREG/CR5642, EGG-2618, Idaho National Engineering Laboratory, Idaho Falls, ID.

Schmidt, R.L., and L.L. Humphries (1994). Late Phase Melt Progression Scoping and Sensitivity Studies, Draft, SAND92-2831, Sandia National Laboratories, Albuquerque, NM.

Spencer, B.W. et al. (1994). Fragmentation and Quench Behavior of Corium Melt Streams in Water, NUREG/CR-6133, ANL-93/32, Argonne National Laboratory, Argonne, IL.

Stickler, L.A. et al. (1993). Calculations to Estimate the Margin to Failure in the TMI-2 Vessel, TMI V(93)EG01, Idaho National Engineering Laboratory, EG\&G Idaho, Inc., Idaho Falls, ID.

Theofanous, T.G. (1988). "Some Considerations of Severe Accidents at Loviisa," Report Prepared for Imatron Voima 04, Helsinki, Finland.

Tutu, N.K., T. Ginsberg, and L. Fintrok (1988). "Low Pressure Cutoff for Melt Dispersal from Reactor Cavities," in Fourth Proceedings of Nuclear Thermal Hydraulics, p. 29-37.

Zuber, N. et al. (1991). An Integrated Structure and Scaling Methodology for Severe Accident Technical Issue Resolution, NUREG/CR-5809, EFF-2659, EG\&G Idaho, Inc., Idaho Falls, ID. 


\subsection{Nomenclature}

$$
\begin{array}{ll}
\mathrm{f}_{\mathrm{Zr}} & =\text { fraction of } \mathrm{Zr} \text { oxidized core-wide } \\
\mathrm{M}_{\mathrm{CRM}} & =\text { mass of control rod material in melt at vessel failure } \\
\mathrm{M}_{\mathrm{Zr}}^{0} & =\text { mass of } \mathrm{Zr} \text { initially in core } \\
\mathrm{M}_{\mathrm{s}} & =\text { mass of steel in melt at vessel failure } \\
\mathrm{M}_{\mathrm{r}, \mathrm{LP}} & =\text { mass of steel in lower plenum } \\
\mathrm{M}_{\mathrm{UO2}} & =\text { mass of } \mathrm{UO}_{2} \text { in melt at vessel failure } \\
\mathrm{M}_{\mathrm{Zr}} & =\text { mass of } \mathrm{Zr} \text { in melt at vessel failüre } \\
\mathrm{M}_{\mathrm{Zr} 02} & =\text { mass of } \mathrm{ZrO} \text { in melt at vessel failure } \\
\mathrm{N}_{\mathrm{ATM}}^{0} & =\text { atmosphere moles in containment just prior to vessel failure } \\
\mathrm{N}_{\mathrm{H} 2} & =\text { mole of hydrogen produced from } \mathrm{Zr} \text { oxidation } \\
\mathrm{P}_{\mathrm{RCS}}^{0} & =\text { initial } \mathrm{RCS} \text { pressure } \\
\mathrm{T}_{\mathrm{RCS}}^{0} & =\text { initial } \mathrm{RCS} \text { temperature } \\
\mathrm{V}_{\mathrm{LP}} & =\text { volume of lower plenum } \\
\mathrm{X}_{\mathrm{H} 2} & =\text { hydrogen concentration in the containment atmosphere }
\end{array}
$$

\section{Greek}

$$
\begin{array}{ll}
. \rho_{\mathrm{CRM}} & =\text { mass density of control rod material } \\
\rho_{\mathrm{UO2}} & =\text { mass density of } \mathrm{UO}_{2} \\
\rho_{\mathrm{UO2} \mathrm{ZrO2}} & =\text { mass density of } \mathrm{UO}_{2} / \mathrm{ZrO}_{2} \text { eutectic } \\
\rho_{\mathrm{Zr}} & =\text { mass density of } \mathrm{Zr} \\
\rho_{\mathrm{ZrO} 2} & =\text { mass density of } \mathrm{ZrO}_{2}
\end{array}
$$


Table 3.1 Characterization of the Surry plant

\begin{tabular}{||l|c|}
\hline \multicolumn{1}{|c|}{ Parameter } & Value \\
\hline \hline Thermal power (MW) & 2441 \\
\hline Number of fuel assemblies & 157 \\
\hline Number of fuel assemblies at edge of core & 52 \\
\hline Fuel assembly dimensions (m) & 0.214 \\
\hline RCS volume $\left(\mathrm{m}^{3}\right)$ & 238 \\
\hline Lower head ID (m) & 4.0 \\
\hline Lower head thickness $(\mathrm{m})$ & 0.127 \\
\hline Core inventory (mt) & 79.8 \\
UO & 16.5 \\
Zr & 3.8 \\
Steel & 2.7 \\
CRM & 102.8 \\
\hline Total & 16 \\
\hline Thin upper plenum steel $(\mathrm{mt})$ & 7.8 \\
\hline Thin lower plenum steel $(\mathrm{mt})$ & 26.6 \\
\hline Lower plenum volume $\left(\mathrm{m}^{3}\right)$ & $51.0 \times 10^{3}$ \\
\hline Containment volume $\left(\mathrm{m}^{3}\right)$ & 800 \\
\hline Subcompartment volume $\left(\mathrm{m}^{3}\right)$ & 290 \\
\hline Cavity volume $\left(\mathrm{m}^{3}\right)$ & 0.069 \\
\hline Containment pressure $\left(\mathrm{MPa}^{3}\right)$ & 314 \\
\hline Containment temperature $(\mathrm{K})$ & $=$ \\
\hline
\end{tabular}


Table 3.2 Definition of probability levels

\begin{tabular}{|c|l|}
\hline Process Likelihood & \multicolumn{1}{c|}{ Process Characteristics } \\
\hline \hline$\sim 1$ & Behavior is within known trends - best estimate. \\
\hline $10^{-1}$ & $\begin{array}{l}\text { Behavior is within known trends but obtainable only } \\
\text { at the edge of spectrum parameter. }\end{array}$ \\
\hline $10^{-2}$ & Behavior cannot be positively excluded - upper bound. \\
\hline
\end{tabular}


Table 3.3 Summary of initial condition quantification

\begin{tabular}{|c|c|c|c|}
\hline \multirow[b]{2}{*}{ Parameter } & \multicolumn{3}{|c|}{ SCENARIO } \\
\hline & $\mathrm{V}$ & $\mathrm{Va}$ & VI \\
\hline RCS pressure (MPa) & 16 & 16 & 8 \\
\hline RCS temperature (K) & 700 & 700 & 1000 \\
\hline RPV water (mt) & 75 & 75 & 10 \\
\hline RPV temperature (K) & 1000 & 1000 & 1000 \\
\hline Initial hole dia. (m) & 0.4 & 0.4 & 0.4 \\
\hline Final hole dia. $(\mathrm{m})$ & Eq. 4.3 & Eq. 4.3 & Eq. 4.3 \\
\hline Fraction $\mathrm{Zr}$ oxidized & Fig. 3.4 & Fig. 3.4 & Fig. 3.4 \\
\hline $\mathrm{UO}_{2}$ mass $(\mathrm{mt})$ & Fig. 3.7 & Fig. 3.7 & Fig. 3.10 \\
\hline $\mathrm{Zr}$ mass $(\mathrm{mt})$ & Eq. 3.2 & Eq. 3.2 & Eq. 3.2 \\
\hline $\mathrm{ZrO}_{2}$ mass (mt) & Eq. 3.1 & Eq. 3.1 & Eq. 3.1 \\
\hline Steel mass (mt) & Eq. 3.3 & Eq. 3.3 & Eq. 3.3 \\
\hline CRM mass (mt) & 0.0 & 0.0 & 2.0 \\
\hline Melt temp. (K) & 2800 & 2800 & 2800 \\
\hline Fraction of $\mathrm{Zr}$ blockage relocated & 0.0 & 0.0 & 0.0 \\
\hline Containment pressure (MPa) & 0.18 & 0.069 & 0.18 \\
\hline Containment temperature $(\mathrm{K})$ & 360 & 316 & 360 \\
\hline Preexisting $\mathrm{H}_{2}$ & Eq. 3.4 & Eq. 3.4 & Eq. 3.4 \\
\hline Autoignition temperature (K). & 950 & 950 & 950 \\
\hline Melt fraction ejected into cavity & 1.0 & 1.0 & 1.0 \\
\hline Ejected fraction dispersed from cavity & 1.0 & 1.0 & 0.85 \\
\hline Fraction dispersed through gap & 0.16 & 0.16 & 0.16 \\
\hline $\begin{array}{l}\text { Fraction dispersed through seal table } \\
\text { room and SG vents }\end{array}$ & 0.05 & 0.05 & 0.05 \\
\hline Coherence ratio & Eq. 4.2 & Eq. 4.2 & Eq. 4.2 \\
\hline
\end{tabular}


Table 3.4 Comparison with prior work

\begin{tabular}{||l|c|c|c|c|c||}
\hline \multicolumn{1}{|c|}{ Parameter } & Scenario V & Scenario VI & NUREG-1150 & $\begin{array}{c}\text { SASM } \\
\text { NUREG/CR-5809 }\end{array}$ & $\begin{array}{c}\text { SCDAP/RELAP5 } \\
\text { Appendix E }\end{array}$ \\
\hline \hline $\mathrm{UO}_{2}$ mass (mt) & $0 / 10 / 30$ & $0 / 23 / 55$ & & 15.7 & 38.1 \\
\hline $\mathrm{ZrO}_{2}$ mass (mt) & $0 / 1.1 / 3.3$ & $0 / 2.5 / 5.9$ & & 4.45 & 9.7 \\
\hline $\mathrm{Zr}$ mass (mt) & $0 / 0.3 / 0.9$ & $0 / 0.7 / 1.6$ & & 6.35 & 0.0 \\
\hline Steel mass (mt) & $0.3 / 0.6 / 1.3$ & $0.3 / 1.1 / 2.3$ & & 13.8 & 5.4 \\
\hline CRM mass (mt) & 0 & 2 & & 2.7 & 1.9 \\
\hline Total melt mass (mt) & $0.3 / 12.0 / 35.5$ & $2.3 / 29.3 / 66.8$ & & 4.3 & 55.1 \\
\hline Core fraction molten & $0.003 / 0.1 / 0.33$ & $0.02 / 0.29 / 0.65$ & $0 / 0.28 / 0.60$ & 0.42 & 0.54 \\
\hline Fraction Zr oxidized & $0.15 / 0.40 / 0.65$ & $0.15 / 0.40 / 0.65$ & $0.08 / 0.32 / 0.76$ & $0.40-050$ & 0.53 \\
\hline
\end{tabular}


Table 3.5 Potentially important differences between Zion and Surry

\begin{tabular}{|l|c|c|}
\hline \multicolumn{1}{|c|}{ Parameter } & Zion & Surry \\
\hline \hline Thermal power $(\mathrm{MW})$ & 3238 & 2441 \\
\hline Core mass (mt) & 125 & 102.8 \\
\hline Average power density $(\mathrm{kW} / \mathrm{l})$ & 232 & 204 \\
\hline RCS loops & 4 & 3 \\
\hline Downcomer by-pass & yes & no \\
\hline Containment volume $\left(\mathrm{m}^{3}\right)$ & $76.9 \times 10^{3}$ & $51 \times 10^{3}$ \\
\hline RCS volume & 353 & 238 \\
\hline
\end{tabular}


Table 3.6 Scaling of the melt mass distributions with core power

\begin{tabular}{||l|c|c|c|c|c||}
\hline \multirow{2}{*}{ Plant } & \multirow{2}{*}{ Core Mass (mt) } & \multicolumn{2}{|c|}{ Scenario V } & \multicolumn{2}{c|}{ Scenario VI } \\
\cline { 3 - 6 } & & BE Mass (mt) & UB Mass (mt) & BE Mass (mt) & UB Mass (mt) \\
\hline \hline Surry & 103 & 12.0 & 35.5 & 27.3 & 64.7 \\
\hline Zion & 125 & 23.9 & 59.3 & 36.0 & 84.1 \\
\hline Ratio Size & 0.82 & 0.50 & 0.60 & 0.76 & 0.77 \\
\hline
\end{tabular}




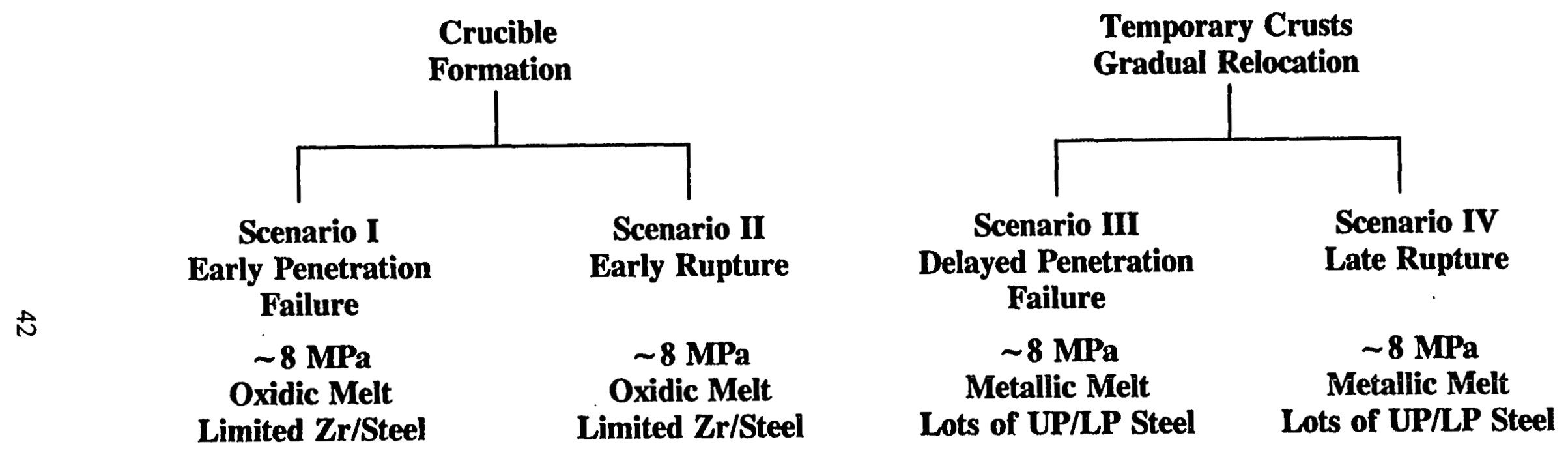

Figure 3.1. Splinter DCH scenarios used in NUREG/CR-6075. 
CRUCIBLE

FORMATION/FAILURE

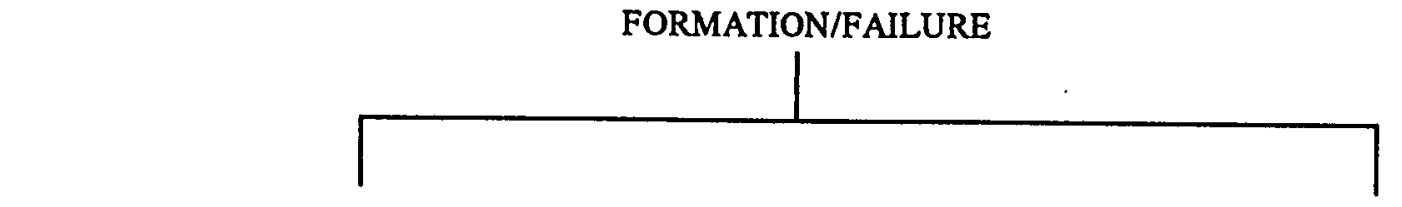

GRADUAL

RELOCATION

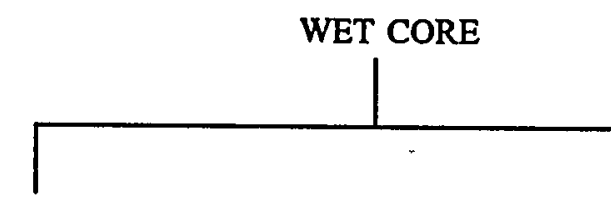

SCENARIO $\mathrm{V}$

SCENARIO VI

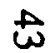

TMI-Like

Operator Action

RCS Press. (16 MPa)

RPV Reflooded

Oxidic Melt

Limited $\mathrm{Zr} /$ Steel

Rupture of LH

\section{RCS Press. (8 MPa)}

Lower Plenum Water

Oxidic Melt

Limited $\mathrm{Zr} /$ Steel

Rupture of LH

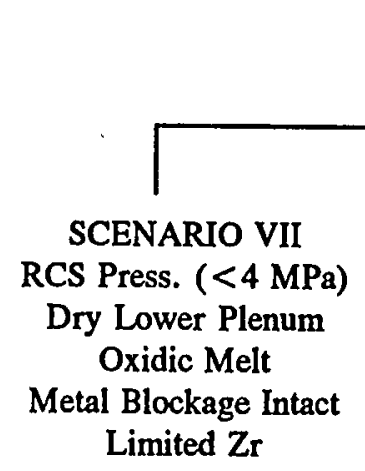

Limited Zr

Large Amt. Upper Plenum Steel

Bigger Rupture of $\mathrm{LH}$
DRY CORE

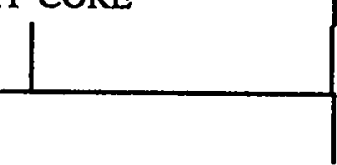

SCENARIO VIII RCS Press. ( $<3 \mathrm{MPa}$ )

Oxidic Melt

Relocate Metal Blockage

Lots of $\mathrm{Zr}$

Large Amt. Upper Plenum Steel

Bigger Rupture of LH

Figure 3.2. Splinter DCH scenarios reflecting working group recommendations. 


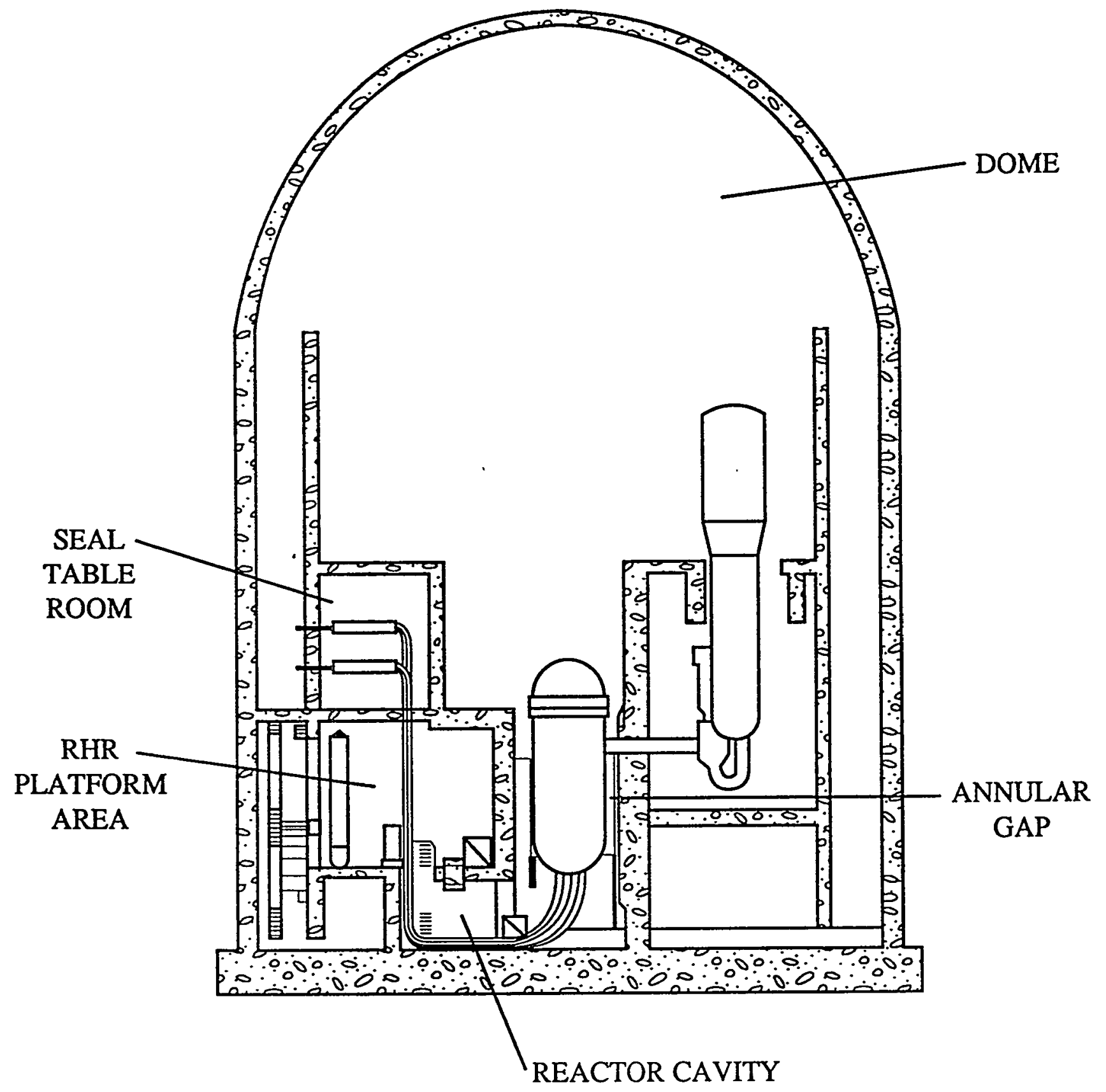

Figure 3.3. Surry nuclear power plant. 


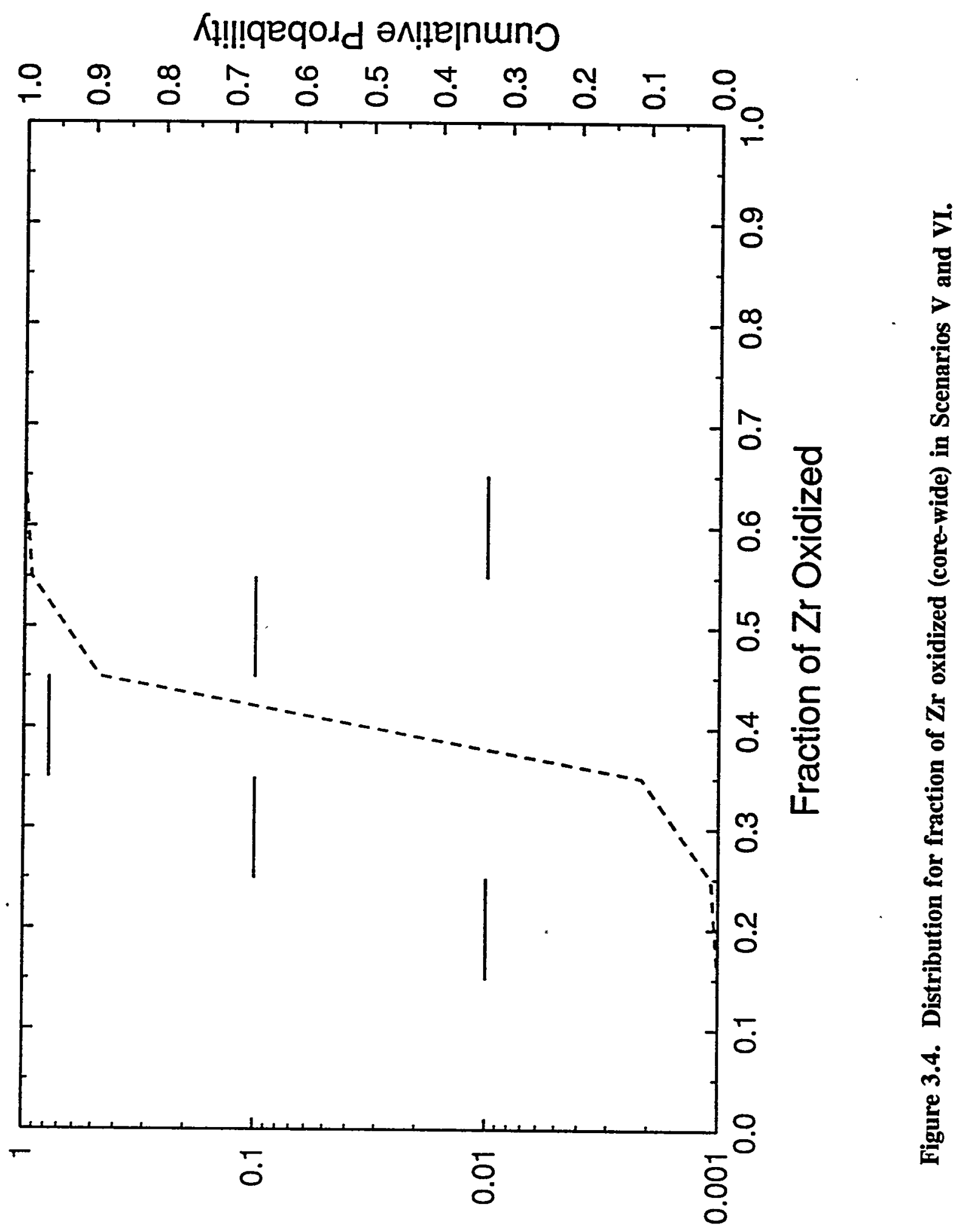

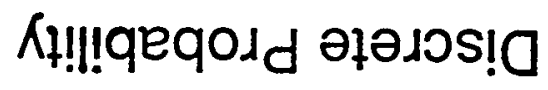




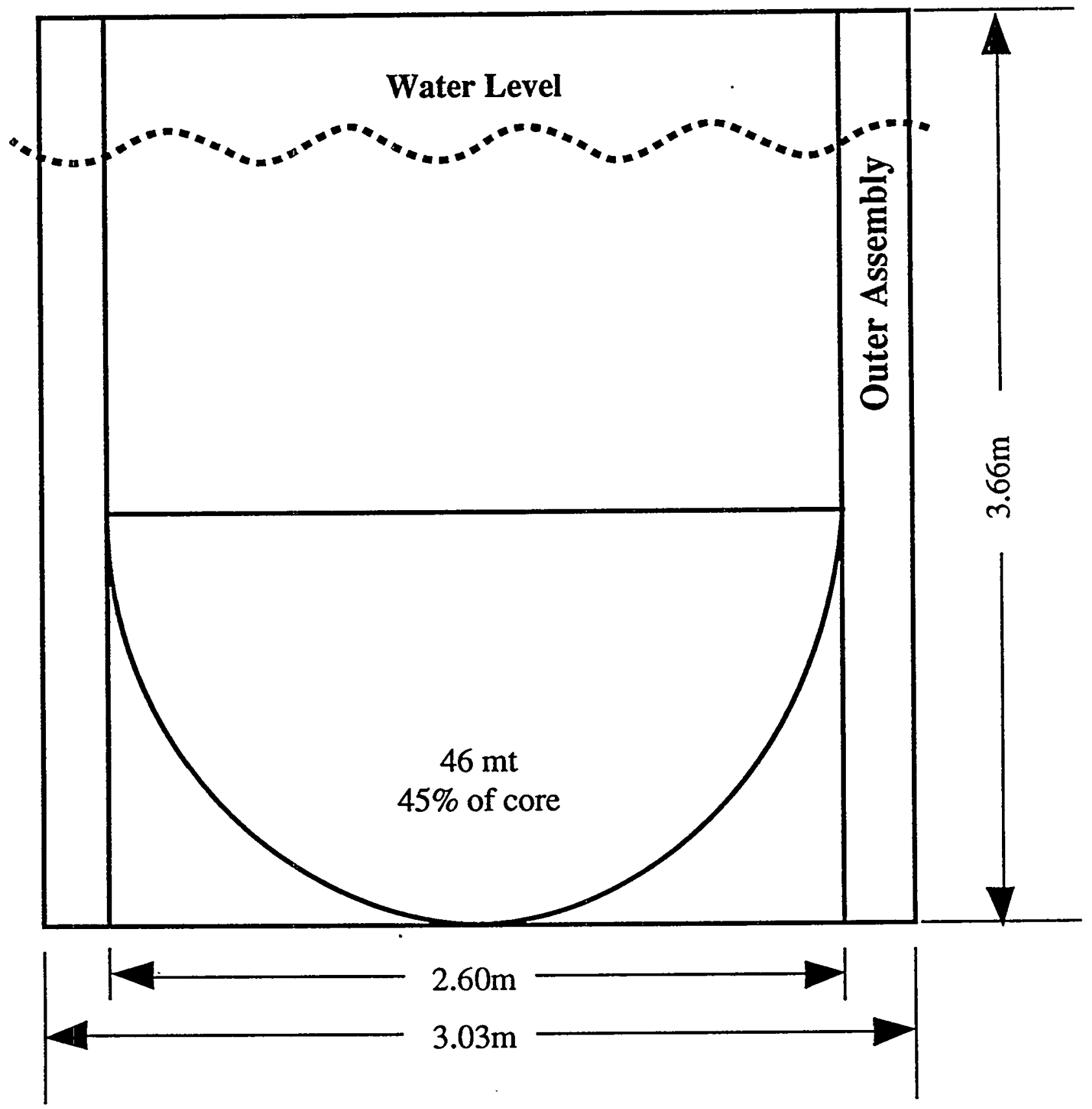

Figure 3.5. Crucible formation in a flooded RPV - Scenario V. 


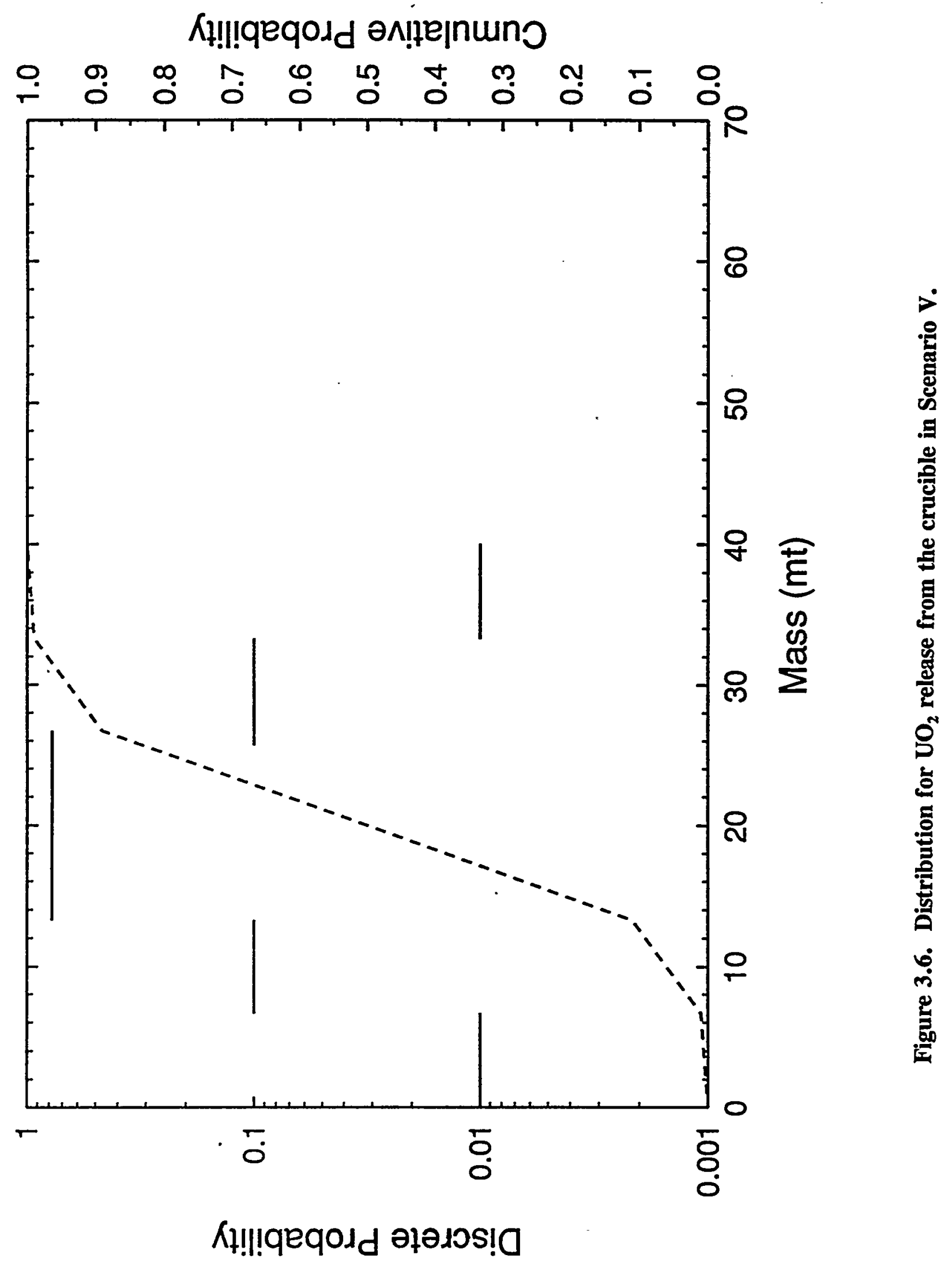




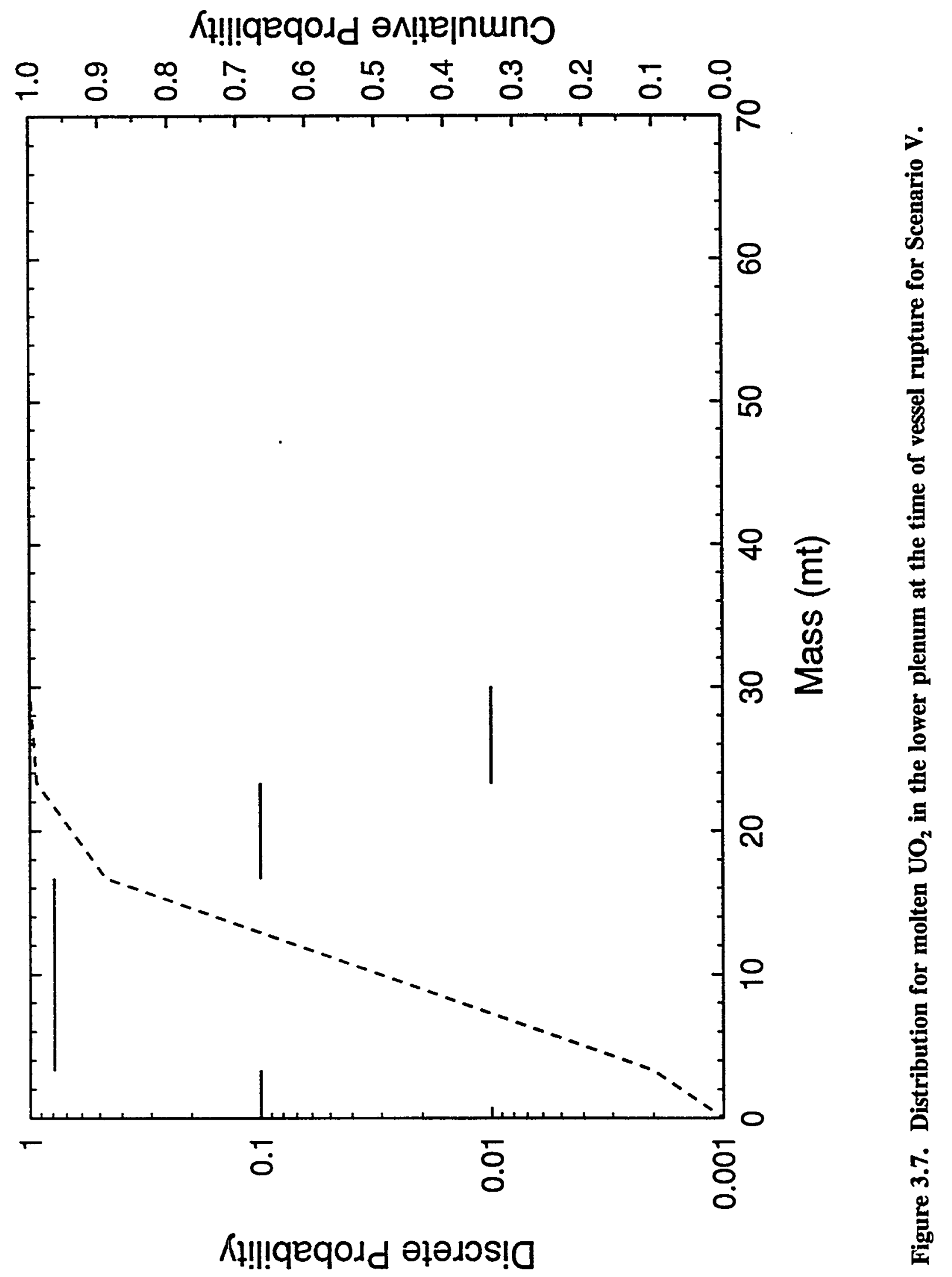




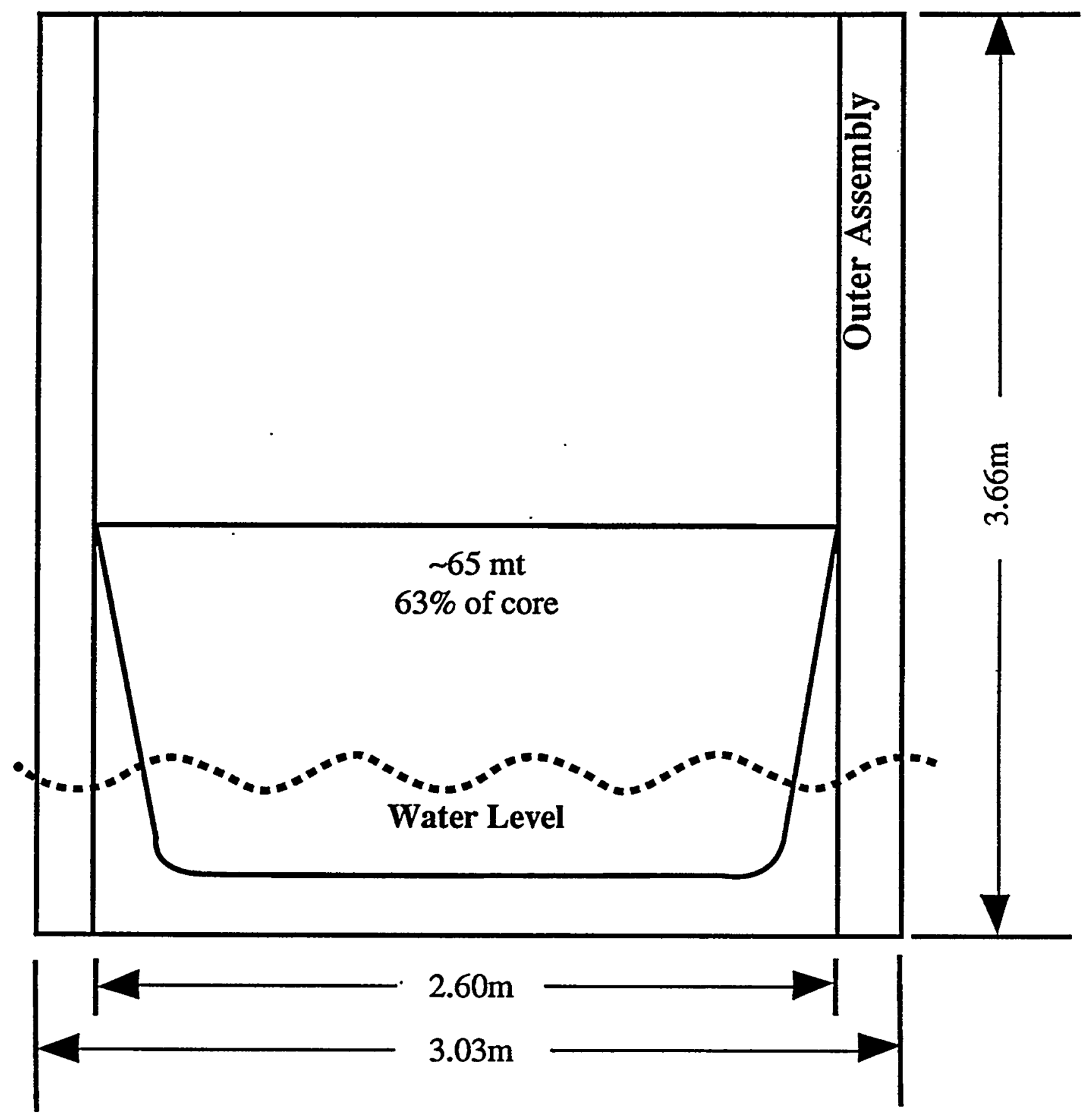

Figure 3.8. Crucible formation in wet core scenario with partial operator intervention Scenario VI. 


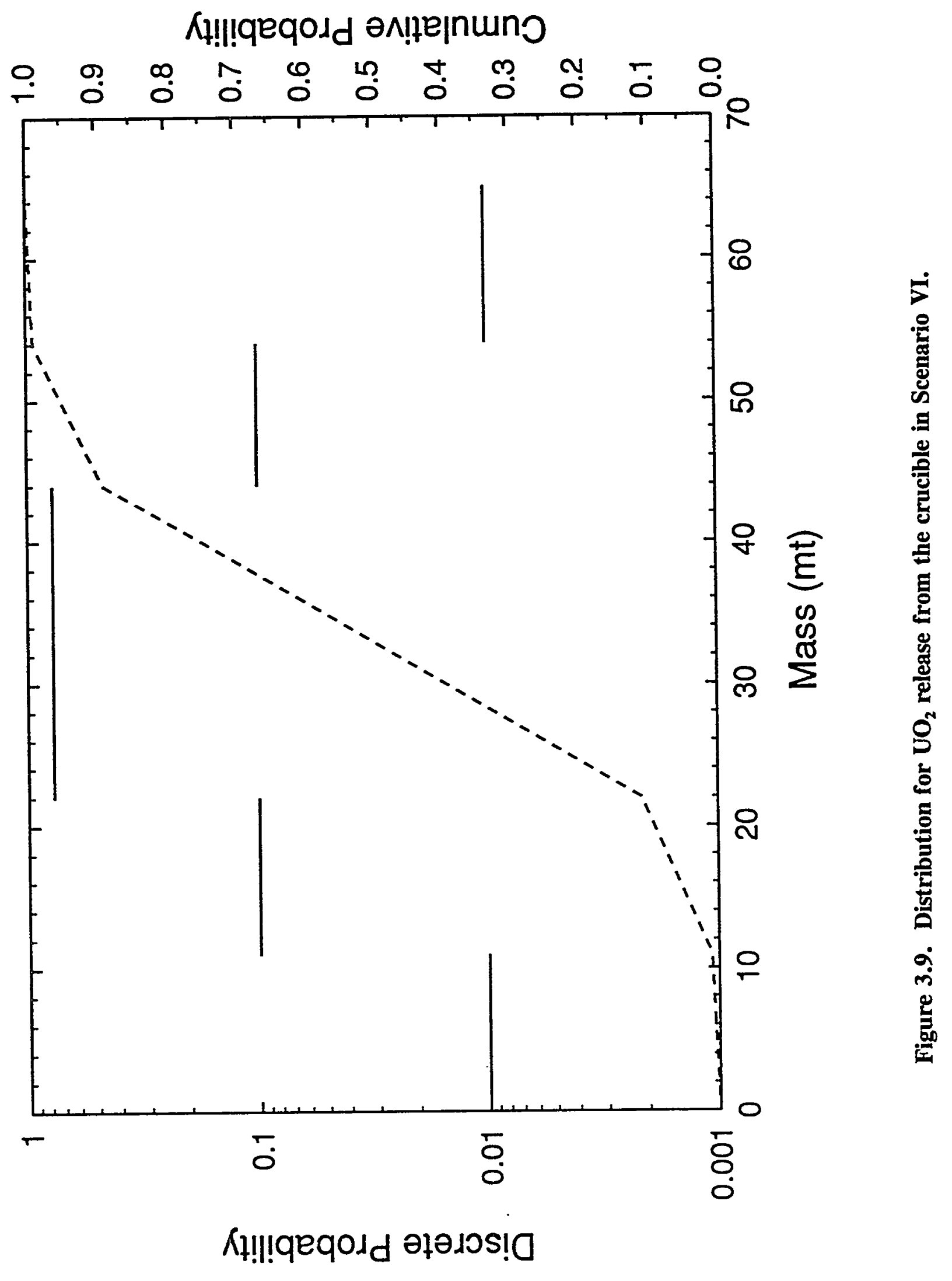




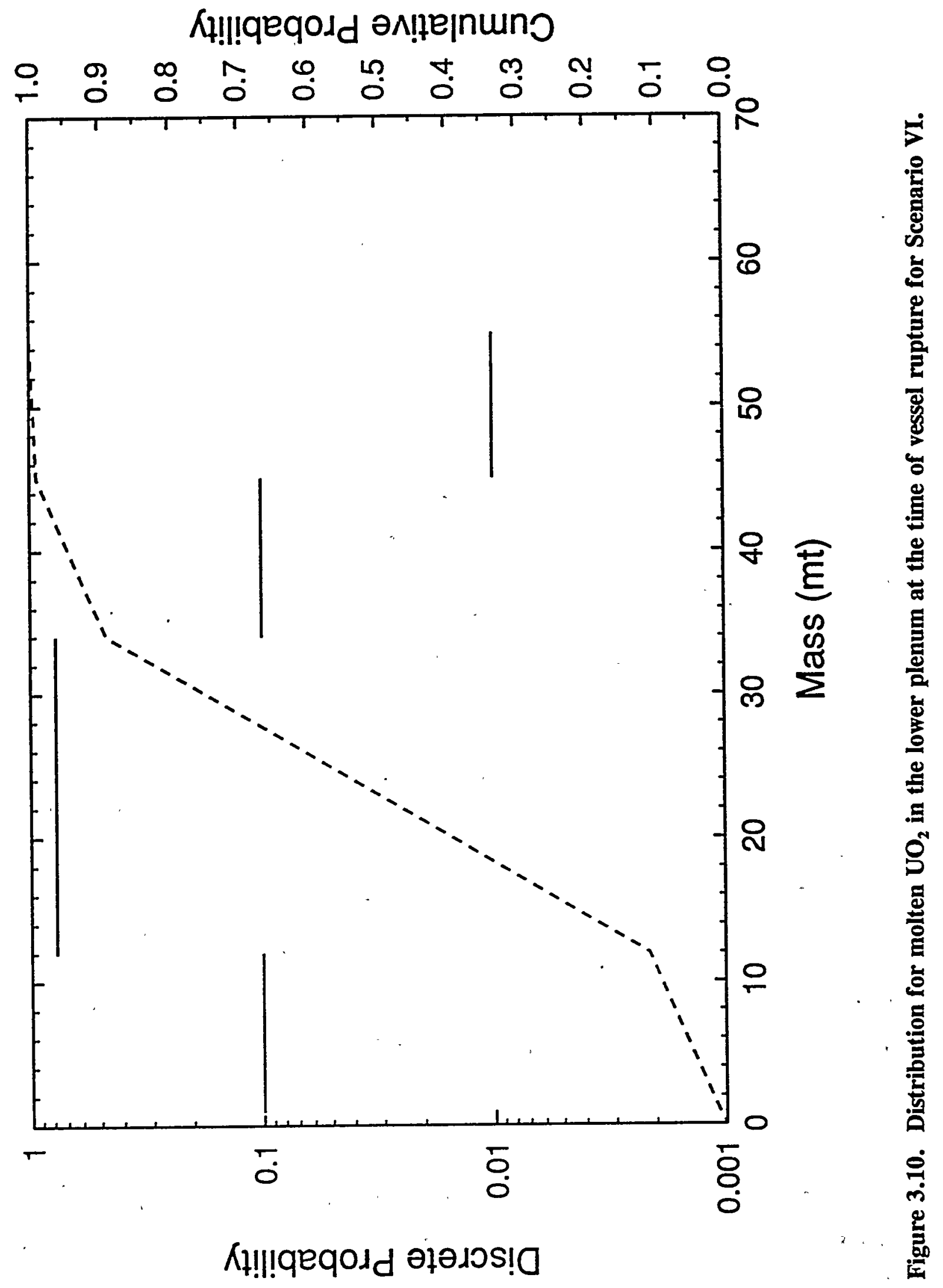




\subsection{QUANTIFICATION OF THE DCH PHENOMENON}

The quantification of the $\mathrm{DCH}$ phenomenon is carried out by means of a causal relation (CR1) for the containment load. CR1 is fulfilled here by the two-cell equilibrium model, which is developed in Appendix E of NUREG/CR-6075 (Pilch et al. 1994a). In the TCE model, the containment pressurization can be written in terms of the various energy sources (blowdown, latent and sensible heat of debris, oxidation of metallic debris constituents, and hydrogen combustion) that can contribute to DCH,

$$
\frac{\Delta P}{P_{C}^{0}}=\eta \frac{\sum \Delta E_{i}}{U^{0}(1+\psi)},
$$

where $\eta$ is an efficiency of containment pressurization due to the combined processes of blowdown, heating of the atmosphere, and hydrogen combustion. The efficiency accounts for compartmentalized geometry of the containment and accounts for mitigation that is due to the noncoherence of debris dispersal and blowdown processes. The TCE model has been validated against the extensive database that is summarized in Table 4.1. Figure 4.1 compares model predictions with the relevant database.

Appendix $\mathrm{C}$ gives an overview of other available models that have been used to predict DCH loads. In particular, the convection limited containment heating (CLCH) model (Yan and Theofanous, Appendix D in Pilch et al. 1994a) has been used (along with TCE) in resolution of the DCH issue for Zion, where TCE and CLCH gave similar results. The CONTAIN code has also been used extensively in DCH analysis of containment loads. Appendix G compares CONTAIN and TCE predictions for conditions near the upper end of our distributions. CONTAIN predicts loads comparable to or less than the TCE model. Consequently, we do not expect different modeling approaches to yield significantly different loads for the same input conditions.

The working group discussions from NUREG/CR-6075, Supplement 1 (Appendix A in Pilch et al. 1994b) defined two new scenarios ( $V$ and VI) which involve significant quantities ( $\sim 10-75$ $\mathrm{mt}$ ) of nearly saturated water that would be coejected with the melt into the reactor cavity. This is a situation that has not been addressed by the existing database; however, the working group (Appendix A in Pilch et al. 1994b) expressed an opinion that water in the primary system at 
vessel breach is expected to mitigate the impact of $\mathrm{DCH}$. We note that a related experiment involving large quantities of cavity water (Allen et al. 1993; 1994a) suggests that DCH energies went entirely into vaporizing water, pressurizing the containment to levels comparable to containment pressures observed in (essentially) dry DCH tests. RPV water (unlike cavity water) will partially flash to steam during isentropic blowdown. The contribution to containment pressure from this mechanism is less than $\sim 0.075 \mathrm{MPa}$ for $\sim 75 \mathrm{mt}$ of water. The calculations and results presented here are performed by ignoring any impact of coejected water. The margins to a significant DCH threat are high enough for Surry so that the impact of coejected water can be ignored in these analyses; however, it may become necessary to address this phenomenon explicitly in the extrapolation effort.

We note that the Surry reactor cavity is not likely to be deeply flooded in station blackout scenarios. The walls of the Surry cavity rise from the basement floor so that the cavity cannot act as a sump for the plant. Consequently; we expect only condensate levels of water in the cavity at the time of vessel failure in station blackout scenarios. The Surry IPE, however, notes that containment sprays could deeply flood the cavity in those accidents that progress with plant power (e.g., TMI-II) or have power restored prior to vessel failure. Such deeply flooded situations could preclude lower head failure, but this is an area of ongoing NRC research.

Most input parameters in the TCE model are related to initial conditions and material properties. The key modeling parameter in the TCE model is the melt-to-steam coherence ratio. Because the entrainment time is short compared with the blowdown time, molten debris is exposed to a small fraction of the primary system steam during the dispersal process. Since this steam is the medium for carrying the melt energy and the hydrogen produced by steam-metal interactions to the main containment volume, this incoherence is a crucial mitigating factor. With this understanding, it is possible to reduce most of the complexity of cavity phenomena to the coherence ratio $\left(\mathrm{R}_{r}=\tau_{\mathrm{e}} / \tau_{\mathrm{b}}\right.$ in the TCE model). We now focus on the coherence ratio and its quantitative representation in the calculations (i.e., pdf4, see Figures 2.1 and 2.2).

Appendix E in NUREG/CR-6075 (Pilch et al., 1994a) develops a correlation for the coherence ratio based on experiment values obtained by a procedure best suited to the TCE model. For this application, the Surry data are best correlated by 


$$
R_{\tau}=12.2 f_{d}\left(\frac{T_{R C S}^{0}}{T_{d}^{0}}\right]^{\frac{1}{4}}\left[C_{d} \frac{M_{d}^{0}}{M_{g}^{0}} \frac{A_{h} V_{c a v}^{\frac{1}{3}}}{V_{R C S}}\right]^{\frac{1}{2}}
$$

It is assumed that $R_{r}$ values are distributed normally about the mean given by Equation 4.2 with a relative standard deviation of 18 percent as indicated by the database. A comparison of the correlation against the Surry database is shown in Figure 4.2. The correlation has also been successfully developed for the Zion database, the differences being that the lead constant should be replaced by 9.661 and the relative standard deviation is 29 percent. Although modeling uncertainty is accounted for directly in $R_{\tau}$, additional uncertainty in computer values of $R_{\tau}$ arise because the causal relation (Equation 4.2) is evaluated for a distributin of melt masses.

The database for the coherence ratio largely overlaps the range of individual parameters that are of interest to reactor applications (Table 4.2). However, the database does not include all possible combinations of parameters for each of the potential applications; consequently, the correlation for the coherence ratio is required to fill gaps in the database. It is significant that this process is one of interpolation rather than extrapolation.

Rapid ejection of hot melt through a breach in the RPV leads to ablation, which increases the initial hole size. Appendix J in NUREG/CR-6075 (Pilch et al. 1994a) develops a model for hole ablation. The final hole size can be computed from

$$
\frac{\Delta D_{h}}{D_{h}^{0}}=\frac{\frac{\tau_{M}}{\tau_{D}}}{1+0.6934\left(\frac{\tau_{M}}{\tau_{D}}\right)^{2 / 3}}
$$

where

$$
\tau_{M}=\frac{M_{d}^{0}}{\dot{M}_{d}}=\frac{M_{d}^{0}}{\rho_{d} C_{d} \frac{\pi\left(D_{h}^{0}\right)^{2}}{4}\left[\frac{2}{\rho_{d}}\left(P_{R C S}^{0}-P_{c}^{0}\right)\right]^{1 / 2}}
$$

is the characteristic time to eject all the melt from the RPV in the absence of ablation and where 


$$
\tau_{D}=\frac{D_{h}^{0}}{\dot{D}_{h}}=\frac{D_{h}^{0}}{\left[\frac{2 h_{d, w}\left(T_{d}^{0}-T_{m p, w}\right)}{\rho_{w}\left[C_{p, w}\left(T_{m p, w}-T_{w}\right)+h_{f, w}\right]}\right]}
$$

is the characteristic time to double the initial hole size by ablation. Figure 4.3 validates the model against the existing database. This figure also illustrates that ablation increases the hole size only slightly for initial hole sizes characteristic of lower head rupture; consequently, ablation will not have a strong influence on the calculations performed for this report. Although a point estimate of the initial hole size is specified in this report, a distribution of final hole sizes results because the causal relation (Equation 4.3) is evaluated for a distribution of melt masses.

A second phenomenological uncertainty concerns hydrogen combustion during $\mathrm{DCH}$. The working group for Zion resolution (Appendix A in Pilch et al. 1994a) emphasized that hydrogen combustion should be treated in a manner consistent with the expected conditions in the containment. Appendix E (Pilch et al. 1994b) addresses the issue of jet combustion, entrainment into a jet, stratification, global mixing, and volumetric combustion phenomenology in more detail. Our conclusions regarding hydrogen combustion during DCH events can be summarized as follows:

1. DCH-produced hydrogen (plus some entrainment of $\mathrm{H}_{2}$ from the preexisting atmosphere) can burn as a jet in the dome and contribute to peak containment pressures. These burning jets would represent an adequate ignition source for deflagrations if flammable conditions exist in the containment.

2. Stratification of hot jet combustion products will occur in the dome, thus impeding the mixing of combustion products with the cooler preexisting atmosphere. Thus, we picture hot nonflammable gases accumulating in the upper dome and the cooler, potentially flammable, preexisting atmosphere displaced downward in the lower dome regions.

3. Flame propagation is difficult to achieve in stratified containment atmospheres with $\sim 50$ percent steam, and the burning process is too slow and inefficient to contribute to peak loads except possibly at the upper end of $\mathrm{H}_{2}$ distribution. Explicit treatment of deflagrations to better define and bound uncertainties in hydrogen combustion was 
included in the Zion supplement (Pilch et al. 1994b) and our current analyses. The fraction of the preexisting hydrogen that can burn on $\mathrm{DCH}$ time scales and contribute to peak loads is given by

$$
f_{p r e}=\eta_{c}\left[1-\frac{\dot{E}_{H T}}{\ddot{E_{H 2}}}\right] .
$$

Even for finite combustion completeness $\left(\eta_{c}\right)$, heat transfer to structures can exceed the energy release rate that is due to the deflagration so that the deflagration does not contribute to peak DCH loads. The deflagration model also handles the continuum of cases where deflagrations can contribute to peak $\mathrm{DCH}$ loads depending on atmosphere composition and temperatures induced by the $\mathrm{DCH}$ event itself. Deflagration-enhanced DCH loads are predicted for a TMI-like scenario with essentially no steam in the atmosphere, but the increased pressure is offset by the lower initial pressure in the containment.

4. Slow volumetric combustion of preexisting hydrogen can occur in parallel with potential deflagrations, but slow volumetric combustion does not contribute to peak loads.

5. Sudden volumetric combustion (autoignition) of preexisting hydrogen is essentially impossible in a stratified atmosphere because heating of the containment atmosphere is limited by mixing. However, to better bound uncertainties in hydrogen combustion phenomena, we recommend an autoignition temperature of $950 \mathrm{~K}$ based on separate effects data.

6. Combustion initiated by mixing of hot gases with the preexisting atmosphere is too slow to contribute to peak pressure. This is because the mixing time scale of the atmosphere is long compared with the time scale for structure heat transfer. Here, we refer to global mixing of the atmosphere, not entrainment into a burning jet, which is already accounted for in item 1 above. This mixing limited combustion occurs in parallel with potential deflagrations and volumetric combustion.

These insights and recommendations are consistent with peer review comments for NUREG/CR-6075 (Pilch et al. 1994a) concerning the autoignition temperature and the need to 
consider partial combustion of the preexisting hydrogen. These recommendations have been factored into the calculated results presented in Section 6.

The amount of material participating in DCH is typically less than the melt mass on the lower head at the time of bottom head failure. Experiments show melt retention in both the crucible (scaled to the bottom head of the RPV) and the reactor cavity below the RPV. On average, 99 percent of the melt was ejected into the cavity in Surry experiments (IET-9, 11, 12; Blanchat et al. 1994). A conservative upper bound of 100 percent is used for all the scenarios in the supplement. These same Surry counterpart experiments (conducted at $\sim 11 \mathrm{MPa}$ driving pressure) have also shown that only $80 \pm 7.7$ percent of the melt in the cavity is dispersed into the containment. Other experiments (Allen et al. 1991, 1994b) with Surry cavities, but at lower driving pressures $(\sim 4 \mathrm{MPa})$ have resulted in $\sim 63$ percent dispersal. Consequently, debris dispersal increases with increasing RCS pressure. We assign a dispersal fraction of 85 percent to our $8 \mathrm{MPa}$ scenarios and 100 percent to the $16 \mathrm{MPa}$ scenarios.

In Zion geometry, numerous experiments have shown that debris dispersed from the cavity through the instrument tunnel (not the annular gap) will enter the upper dome, some through the seal table room (located directly over the cavity exit) and some through vents above the reactor coolant pumps. The Zion experiments, however, did not model the seal table that blocks access into the seal table room because the experiments did not model the "penthouse" over the cavity exit (a steel enclosure with blowout panels intended to deny unauthorized personnel access to the cavity) and because the experiments did not model the vast array of in-core instrument guide tubes that will be dispersed from the cavity with the debris. Minimal transport to the dome is supported by additional scoping experiments using water (FAI 1991; Ginsberg 1988).

Debris transport through the seal table room to the dome is also expected in Surry geometry, but the database is limited to only three experiments: SNL IET-9, 10, and 11 (Allen et al. 1994a). The seal table (which was simulated in two of the experiments) failed in IET-10, allowing transport through the seal table room to the dome. The seal table, however, remained intact in IET-11, blocking transport through the seal table room. An important difference in the tests is that the annular gap around the RPV (which exists in the plant) was modeled in IET-11 but not in IET-10. For the evaluations in this report, we assume 5 percent transport through the seal table room to the upper dome. Such treatment, however, is deemed conservative because the Surry experiments did not model the steel hatch (which restricts personnel access to the 
cavity), which will be blown upward, because the seal table may not fail, and because the experiments did not model the vast array of in-core instrument guide tubes that will be dispersed from the cavity with the debris.

A second possible flow path to the upper dome is the annular gap around the RPV. The SNL IET-11 experiment showed that the melt-laden gas will melt the insulation and sweep it from the gap. The SNL HIPS-8C experiment also simulated the gap without insulation. Analysis of these two experiments indicates that the fraction of dispersed debris that goes through the gap is equivalent to the minimum flow area (without insulation) through the gap divided by the sum of the minimum gap and tunnel flow areas (see Appendix I in Pilch et al. 1994a for more development of the phenomena involved and validation against a database for Zion and Surry designs). The HIPS-10S experiment (Allen et al., 1990) showed that the incore instrument tubes and their supports are forcibly ejected from the cavity; consequently, the minimum tunnel flow area is evaluated without the presence of these structures. For Surry, the minimum tunnel flow area is $-6.4 \mathrm{~m}^{2}$ and the minimum gap flow area (at the level of the nozzles) is $-1.0 \mathrm{~m}^{2}$. Consequently, $\sim 16$ percent of all dispersed debris will be transported through the gap to the dome. This assessment of gap transport may be conservative because the experiments did not model the neutron shields or other structures in the gap, because water is expected to be coejected from the RPV with the melt, and because $\sim 10-40$ percent of the melt could be intercepted by the missile shield, Bertodano (1993). Transport through the gap can be added to the $\sim 5$ percent transport through the seal table room, so that 21 percent of all dispersed debris will enter the dome. This bounds all observations in the Surry experiments (Blanchat et al. 1994), and we expect this quantification to reasonably bound the expected behavior in the plant. Nonetheless, containment loads are not sensitive to reasonable variations in dome transport of debris because hydrogen combustion is the dominant contributor to loads.

\subsection{References}

Allen, M.D. et al. (1991). Experiments to Investigate the Effect of Flight Path on Direct Containment Heating (DCH) in the Surtsey Test Facility: The Limited Flight Path (LFP) Tests, NUREG/CR-5728, SAND91-1105, Sandia National Laboratories, Albuquerque, NM.

Allen, M.D. et al. (1993). Experiments to Investigate the Effects of Fuel/Coolant Interactions on Direct Containment Heating, The IET-8A and IET-8B Experiments, SAND92-2849, Sandia National Laboratories, Albuquerque, NM. 
Allen, M.D. et al. (1994a). Experiments to Investigate Direct Containment Heating Phenomena with Scaled Models of the Zion Nuclear Power Plant in the Surtsey Test Facility, NUREG/CR6044, SAND93-1049, Sandia National Laboratories, Albuquerque, NM.

Allen, M.D., T.K. Blanchat, and M.M. Pilch (1994b). Test Results on Direct Containment Heating by High Pressure Melt Ejection into the Surtsey Vessel: The TDS Test Series, SAND911208, Sandia National Laboratories, Albuquerque, NM.

Bertodano, M. Lopez de (1993). Direct Containment Heating DCH Source Term Experiment for Annular Reactor Cavity Geometry, Ninth Proceedings of Nuclear Thermal Hydraulics, 1993 ANS Winter Mtg., Nov. 14-18, 1993, San Francisco, CA, p. 111-120.

Blanchat, T.K. et al. (1994). Experiments to Investigate Direct Containment Heating Phenomena With Scaled Models of the Surry Nuclear Power Plant, NUREG/CR-6152, SAND932519, Sandia National Laboratories, Albuquerque, NM.

FAI (1991). Zion IPE Position Paper on Direct Containment Heating, FAI/91-18, submitted to Commonwealth Edison Co., Chicago, IL.

Ginsberg, T., and N.K. Tutu (1988). Progress in Understanding Direct Containment Heating Phenomena in Pressurized Light Water Reactors, BNL-NUREG-41751, Brookhaven National Laboratory, Upton, NY.

Pilch, M.M., H. Yan, and T.G. Theofanous (1994a). The Probability of Containment Failure by Direct Containment Heating in Zion, NUREG/CR-6075, SAND93-1535, Sandia National Laboratories, Albuquerque, NM.

Pilch, M.M. et al. (1994b). The Probability of Containment Failure by Direct Containment Heating in Zion, NUREG/CR-6075, Supplement 1, Sandia National Laboratories, Albuquerque, NM.

\subsection{Nomenclature}

$\mathrm{A}_{\mathrm{h}}=$ breach area in RPV

$\mathrm{C}_{\mathrm{d}}=$ discharge coefficient (0.6)

$\mathrm{C}_{\mathrm{p}, \mathrm{w}} \quad=$ heat capacity of RPV steel

$\mathrm{D}_{\mathrm{h}}^{0} \quad=$ initial hole diameter

$\dot{\mathrm{D}}_{\mathrm{h}} \quad=$ characteristic ablation rate

$\dot{\mathrm{E}}_{\mathrm{HT}} \quad=$ characteristic heat transfer rate to structure

$\dot{\mathrm{E}}_{\mathrm{H} 2}=$ energy release rate from combustion of preexisting hydrogen

$\mathrm{f}_{\mathrm{d}} \quad=$ fraction dispersed

$\mathrm{f}_{\mathrm{pre}} \quad=$ fraction of preexisting hydrogen burned on DCH timescales 
$\mathrm{h}_{\mathrm{d}, \mathrm{w}}=$ debris/wall heat transfer coefficient during ablation (see Appendix J, NUREG/CR-6075)

$\mathrm{h}_{\mathrm{f}, \mathrm{w}} \quad=$ heat of fusion for RPV steel

$\mathbf{M}_{\mathfrak{d}}^{0} \quad=$ initial melt mass

$\mathbf{M}_{\mathrm{g}}^{0} \quad=$ initial RCS gas mass

$\mathbf{P}^{0} \quad=$ initial containment pressure

$\mathrm{P}_{\text {RCS }}^{0} \quad=$ initial $\mathrm{RCS}$ pressure

$\mathrm{R}_{\tau} \quad=$ coherence ratio

$\mathrm{T}_{\mathrm{d}}^{0} \quad=$ debris temperature

$\mathrm{T}_{\text {RCS }}^{0}=$ RCS gas temperature

$\mathrm{T}_{\text {mp,w }}=$ melting temperature of RPV steel

$\mathrm{T}_{\mathrm{w}} \quad=$ temperature of RPV lower head at vessel failure

$\mathrm{U}^{0}=$ total internal energy of containment atmosphere

$\mathrm{V}_{\mathrm{cav}} \quad=$ cavity volume

$\mathrm{V}_{\mathrm{RCS}}{ }^{\prime}=\mathrm{RCS}$ volume

Greek

$\Delta \mathrm{D}_{\mathrm{h}} \quad=$ change in hole diameter

$\Delta \mathrm{E}_{\mathrm{i}} \quad=$ energy contribution of $\mathrm{DCH}$ process

$\triangle \mathrm{P} \quad=$ pressure increase in containment due to $\mathrm{DCH}$

$\rho_{\mathrm{d}} \quad=$ mass density of debris

$\rho_{\mathrm{w}} \quad=$ mass density of RPV steel

$\sigma_{\text {bis }} \quad=$ relative bias

$\sigma_{\mathrm{rms}} \quad=$ relative (root mean squared) standard deviation

$\tau_{\mathrm{D}}=$ characteristic time to double the initial hole size by ablation

$\tau_{\mathrm{M}} \quad=$ characteristic time to eject melt from RPV in the absence of ablation

$\psi=$ total heat capacity of dispersed debris divided by total heat capacity of the atmosphere

$\eta \quad=$ pressurization efficiency

$\eta_{\mathrm{c}} \quad=$ combustion efficiency 
Table 4.1 Survey of DCH-relevant experiments

\begin{tabular}{|c|c|c|c|c||}
\hline Experiment Series & $\begin{array}{c}\text { Number } \\
\text { of Tests }\end{array}$ & $\begin{array}{c}\text { Nominal } \\
\text { Scale }\end{array}$ & $\begin{array}{c}\text { Cavity } \\
\text { Type }\end{array}$ & Water \\
\hline \hline SNL/DCH & 4 & $1: 10$ & Surry & None \\
\hline SNL/TDS & 7 & $1: 10$ & Surry & None \\
\hline SNL/LFP & 6 & $1: 10$ & Surry & None \\
\hline SNL/WC & 3 & $1: 10$ & Surry & $\begin{array}{c}\text { None } \\
\text { Cavity }\end{array}$ \\
\hline SNL/IET-Surry & 9 & $1: 10$ & Surry & $\begin{array}{c}\text { Cavity } \\
\text { Cavity/basement }\end{array}$ \\
\hline SNL/IET-Surry & 3 & $1: 5.75$ & Surry & $\begin{array}{c}\text { None } \\
\text { Cavity/basement }\end{array}$ \\
\hline ANL/CWTI & 2 & $1: 30$ & Surry-like & Cavity/basement \\
\hline ANL/IET & 6 & $1: 40$ & Surry & $\begin{array}{c}\text { None } \\
\text { Cavity }\end{array}$ \\
\hline ANL/U & 3 & $1: 40$ & Surry & \begin{tabular}{c} 
None \\
\hline FAI/DCH
\end{tabular} \\
\hline
\end{tabular}


Table 4.1 (continued)

Survey of DCH-relevant experiments

\begin{tabular}{||c|c|c|c|c|c||}
\hline $\begin{array}{c}\text { Experiment } \\
\text { Series }\end{array}$ & $\begin{array}{c}\text { Driving } \\
\text { Gas }\end{array}$ & $\begin{array}{c}\text { Driving } \\
\text { Pressure } \\
(\mathrm{MPa})\end{array}$ & $\begin{array}{c}\text { Melt Mass } \\
(\mathrm{kg})\end{array}$ & $\begin{array}{c}\text { Melt } \\
\text { Composition }\end{array}$ & $\begin{array}{c}\text { Hole } \\
\text { Size }\end{array}$ \\
\hline SNL/DCH & $\mathrm{N}_{2}$ & $2.6-6.7$ & 20,80 & $\mathrm{Fe} / \mathrm{Al}_{2} \mathrm{O}_{3}$ & 0.06 \\
\hline SNL/TDS & $\mathrm{H}_{2} \mathrm{O}$ & $3.7-4.0$ & 80 & $\mathrm{Fe} / \mathrm{Al}_{2} \mathrm{O}_{3} / \mathrm{Cr}$ & 0.065 \\
\hline SNL/LFP & $\mathrm{H}_{2} \mathrm{O}$ & $2.5-3.6$ & 50,80 & $\mathrm{Fe} / \mathrm{Al}_{2} \mathrm{O}_{3} / \mathrm{Cr}$ & $0.04-0.09$ \\
\hline SNL/WC & $\mathrm{H}_{2} \mathrm{O}$ & $3.8-4.6$ & 50 & $\mathrm{Fe} / \mathrm{Al}_{2} \mathrm{O}_{3} / \mathrm{Cr}$ & $0.04-0.10$ \\
\hline $\begin{array}{c}\text { SNL/IET } \\
\text { Surry }\end{array}$ & $\mathrm{H}_{2} \mathrm{O}$ & $5.9-7.1$ & 43 & $\mathrm{Fe} / \mathrm{Al}_{2} \mathrm{O}_{3} / \mathrm{Cr}$ & 0.04 \\
\hline $\begin{array}{c}\text { SNL/IET } \\
\text { Surry }\end{array}$ & $\mathrm{H}_{2} \mathrm{O}$ & 12 & 158 & $\mathrm{Fe} / \mathrm{Al}_{2} \mathrm{O}_{3} / \mathrm{Cr}$ & $0.072-0.098$ \\
\hline ANL/CWTI & $\mathrm{N}_{2}$ & $4.7-5.0$ & 4.1 & $\mathrm{UO}_{2} / \mathrm{ZrO}_{2} / \mathrm{SS}$ & 0.13 \\
\hline ANL/IET & $\mathrm{H}_{2} \mathrm{O}$ & $5.7-6.7$ & $0.72,0.82$ & $\mathrm{Fe} / \mathrm{Al}_{2} \mathrm{O}_{3} / \mathrm{Cr}$ & 0.011 \\
\hline ANL/U & $\mathrm{H}_{2} \mathrm{O}$ & $3.0-6.0$ & 1.13 & $\mathrm{UO}_{2} / \mathrm{Zr}^{2} / \mathrm{ZrO}_{2} / \mathrm{SS}$ & 0.011 \\
\hline FAI/DCH & $\mathrm{N}_{2}$, & $2.4-3.2$ & 20 & $\mathrm{Fe} / \mathrm{Al}_{2} \mathrm{O}_{3}$ & 0.025 \\
\hline
\end{tabular}


Table 4.1 (concluded)

Survey of DCH-relevant experiments

\begin{tabular}{|c|c|c|c|c|}
\hline $\begin{array}{l}\text { Experiment } \\
\text { Series }\end{array}$ & $\begin{array}{l}\text { Containment } \\
\text { Pressure } \\
\text { (MPa) }\end{array}$ & $\begin{array}{c}\text { Annular } \\
\text { Gap Around } \\
\text { RPV }\end{array}$ & $\begin{array}{l}\text { Atmosphere } \\
\text { Composition }\end{array}$ & $\begin{array}{l}\text { Containment } \\
\text { Structures }\end{array}$ \\
\hline SNL/DCH & 0.08 & No & Air, Ar & Open containment \\
\hline SNL/TDS & $0.09-0.23$ & No & Air, Ar & Open containment \\
\hline SNL/LFP & 0.16 & No & $\mathrm{Ar}$ & $\begin{array}{c}\text { Compartmentalized } \\
\text { by slab }\end{array}$ \\
\hline SNL/WC & 0.16 & No & $\mathrm{Ar}$ & Essentially open \\
\hline $\begin{array}{l}\text { SNL/IET } \\
\text { Surry }\end{array}$ & 0.2 & No & $\begin{array}{c}\mathrm{N}_{2}, \mathrm{~N}_{2} / \mathrm{Air} \\
\mathrm{N}_{2} / \mathrm{Air} / \mathrm{H}_{2}, \\
\mathrm{CO}_{2} / \mathrm{Air} / \mathrm{H}_{2} \\
\end{array}$ & $\begin{array}{c}\text { Surry } \\
\text { subcompartment } \\
\text { structures }\end{array}$ \\
\hline $\begin{array}{l}\text { SNL/IET } \\
\text { Surry }\end{array}$ & $0.13-0.19$ & $\begin{array}{c}\text { No } \\
\text { partial } \\
\text { insulation }\end{array}$ & $\mathrm{Air} / \mathrm{H}_{2} \mathrm{O} / \mathrm{H}_{2}$ & $\begin{array}{c}\text { Surry } \\
\text { subcompartment } \\
\text { structures }\end{array}$ \\
\hline ANL/CWTI & 0.1 & Nio & $\mathrm{Ar}$ & $\begin{array}{c}\text { Compartmentalized } \\
\text { by baffle }\end{array}$ \\
\hline ANL/IET & 0.2 & No & $\begin{array}{c}\mathrm{N}_{2}, \mathrm{~N}_{2} / \mathrm{Air} \\
\mathrm{N}_{2} / \mathrm{Air} / \mathrm{H}_{2}, \\
\mathrm{H}_{2} \mathrm{O} / \mathrm{Air} / \mathrm{H}_{2} \\
\end{array}$ & $\begin{array}{c}\text { Surry } \\
\text { subcompartment } \\
\text { structures } \\
\end{array}$ \\
\hline $\mathrm{ANL} / \mathrm{U}$ & 0.2 & No & $\mathrm{N}_{2} / \mathrm{Air} / \mathrm{H}_{2}$ & $\begin{array}{c}\text { Surry } \\
\text { subcompartment } \\
\text { structures }\end{array}$ \\
\hline FAI/DCH & 0.1 & $\begin{array}{c}\text { No } \\
\vdots\end{array}$ & $\mathrm{N}_{2}$ & $\begin{array}{l}\text { Surry (Like) } \\
\text { subcompartment } \\
\text { structures }\end{array}$ \\
\hline
\end{tabular}


Table 4.2 Applicability of the database to reactors

\begin{tabular}{|c|c|c|c|c|c|}
\hline & CAVITY & $f_{\text {dap }}$ & $\mathbf{T}_{d_{d}}^{0} / \mathbf{T}^{0}{ }_{\text {RCS }}$ & $\mathbf{M}_{\mathrm{d}}^{*} / \mathbf{M}_{\mathrm{z}}$ & $A_{h} V^{1 / 3} / V_{R C S}$ \\
\hline Complete database & Surry, Surry & $0.6-1.0$ & $3.0-11.0$ & $2.8-21.4$ & $0.001-0.014$ \\
\hline $\begin{array}{l}\text { SNL/ANL IET Surry tests } \\
\mathrm{P}_{\mathrm{RCS}}^{0}=6 \mathrm{MPa}\end{array}$ & Surry & $0.6-0.9$ & 4.2 & $3.9-6.0$ & 0.0027 \\
\hline $\begin{array}{l}\text { SNL/IET Surry tests } \\
\mathrm{P}_{\mathrm{RCS}}^{0}=13 \mathrm{MPa}\end{array}$ & Surry & 0.9 & 3.2 & 2.9 & 0.0033 \\
\hline $\begin{array}{l}\mathrm{NPP} \\
\quad \mathrm{P}_{\mathrm{RCS}}^{0}=8 \mathrm{MPa} \\
\mathrm{D}_{\mathrm{h}}^{0}=0.4 \mathrm{~m} \\
\mathrm{~T}_{\mathrm{RCS}}^{0}=1000 \mathrm{~K} \\
\mathrm{M}_{\mathrm{d}}^{0}=50 \mathrm{mt} \\
\end{array}$ & Surry & $\sim 1$ & 3.5 & 6.2 & 0.002 \\
\hline 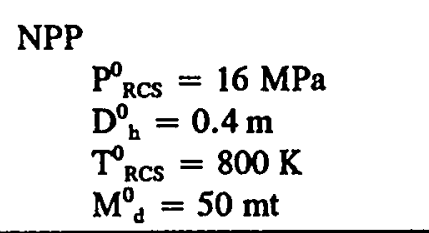 & Surry & $\sim 1$ & 2.8 & 3.9 & 0.002 \\
\hline
\end{tabular}



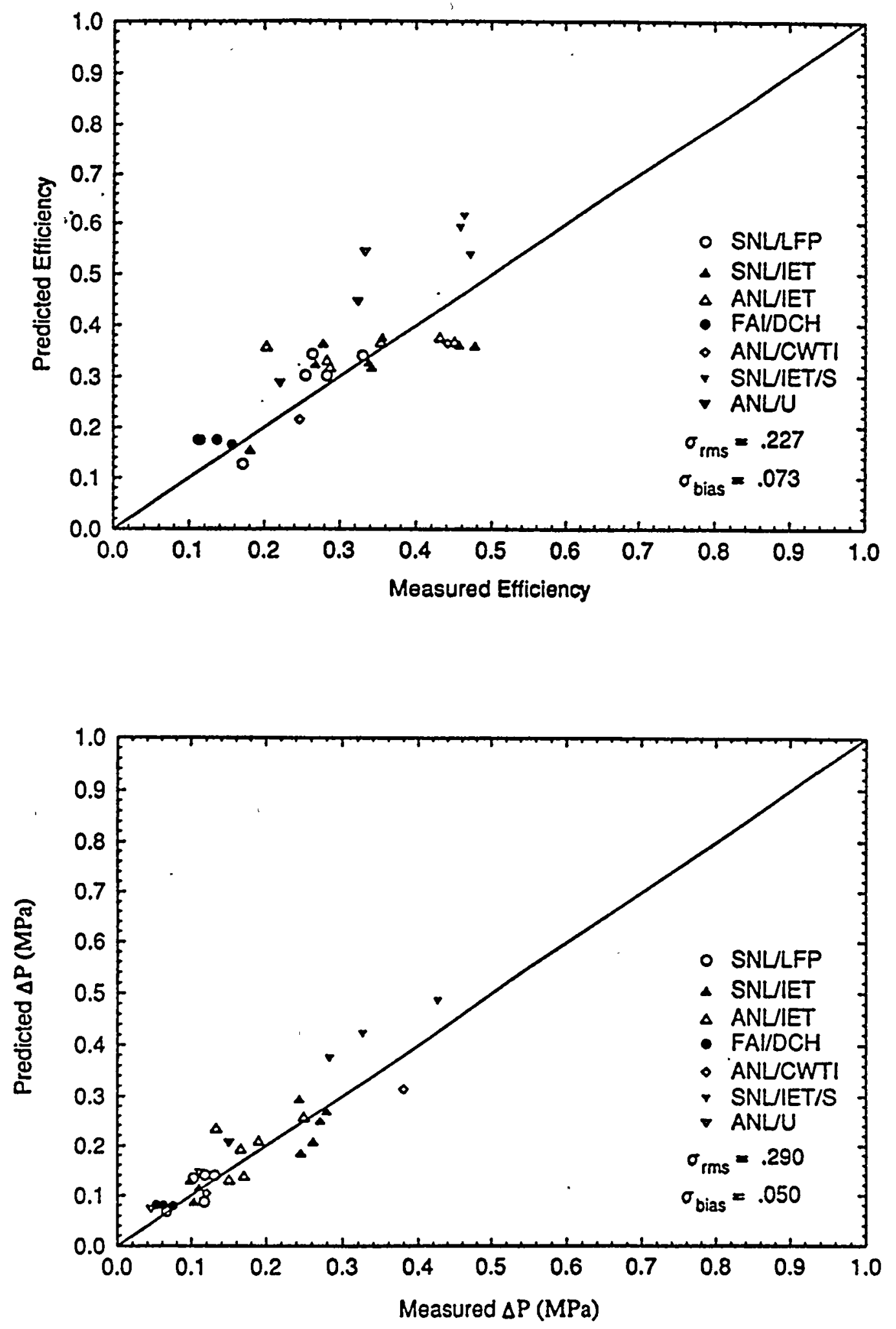

Figure 4.1. Validation of the two-cell equilibrium model against all experiments with compartmentalized geometry. 


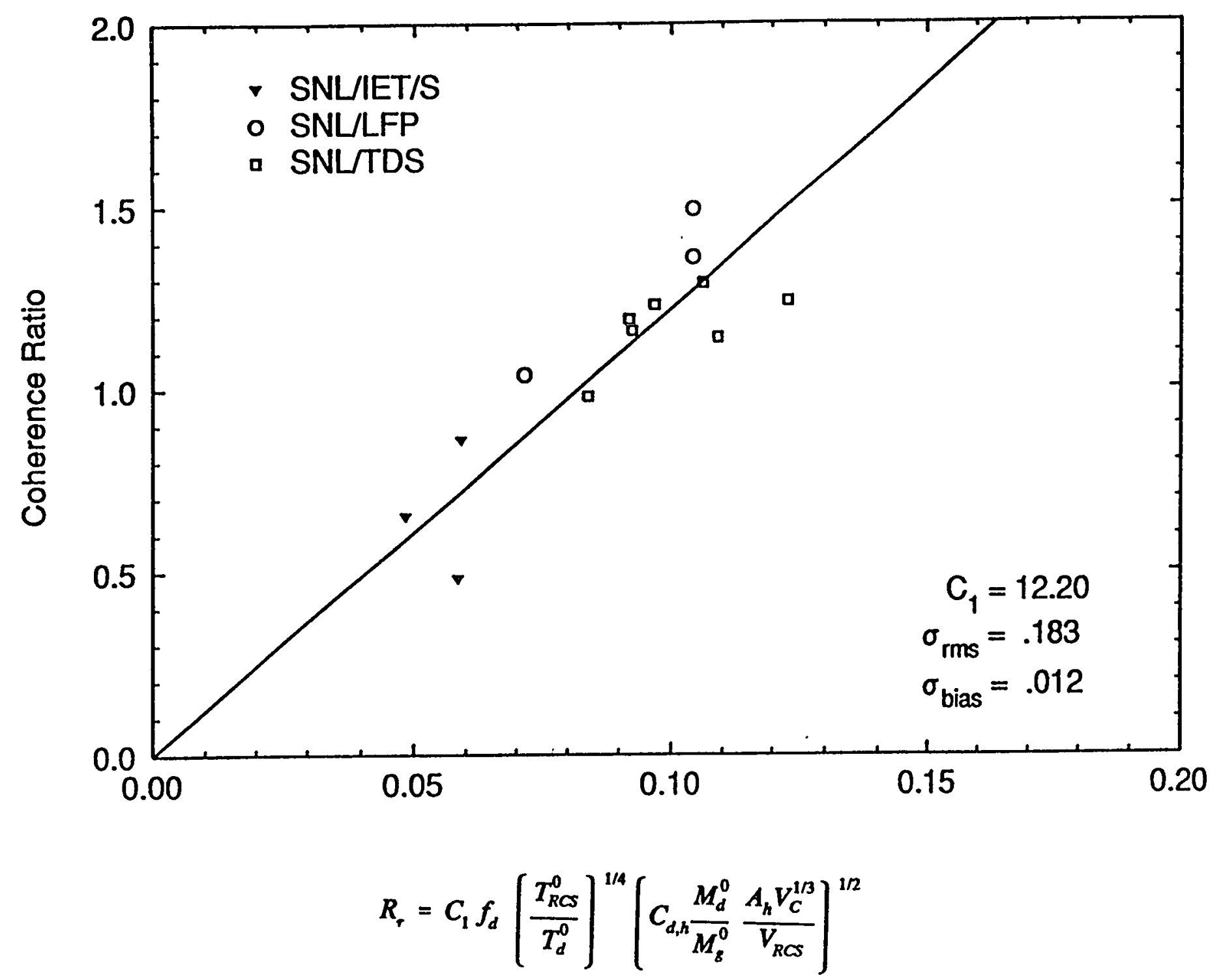

Figure 4.2. Validation of the coherence ratio for Surry-like cavity designs for scenarios without coejected water. 


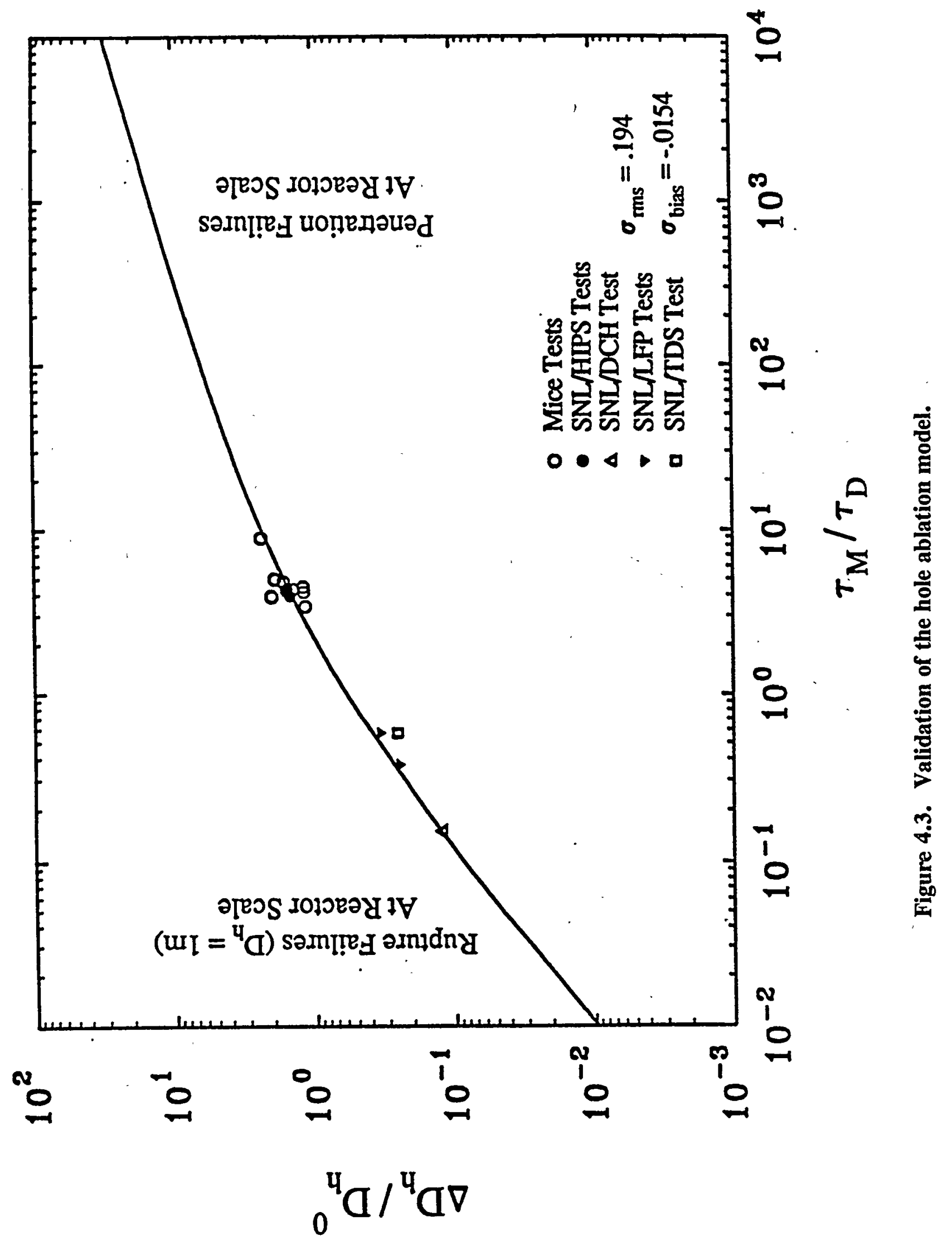




\subsection{QUANTIFICATION OF CONTAINMENT FRAGILITY}

This section characterizes the strength of the Surry containment in probabilistic terms. The pressure capacity of the Surry containment is treated as a random variable because of the variability in material properties, of unknown differences between the as-built and design conditions, and modeling uncertainties. The probability that the containment failure pressure is less than a specified pressure is known as the containment overpressure fragility curve.

Fragility curves represent a probabilistic estimate of the capacity of the containment. In general, the fragility curve could be derived from data and full-scale experiments. However, the containment fragility curves are dependent on site-specific detail and, without detailed model tests, they must be derived from analysis. As a practical matter, the fragility curves are derived from a combination of material property data, tolerances in dimensions from drawings, and judgment of the analyst. Judgment is used in determining what level of analysis is required and what failure mechanisms are considered to govern the containment capacity. Typically, adequate material property data exist to characterize variability in material properties. Finally, analyst judgment is used to assign "modeling" uncertainty to the models to characterize the analyst's confidence in the ability of the selected models to represent the actual failure mechanisms involved. Modeling uncertainty could, in principle, be reduced with further analysis or testing. Funding constraints, however, usually require the analyst to exercise his or her judgment to reflect the uncertainty involved.

In addition, it should be noted that a containment fragility curve is, in fact, a plant- specific entity. It is to be anticipated that the fragility curves derived for a specific containment are sensitive to local design details, tolerances, and the design philosophy used for that particular containment. While it is likely that various submodels representing different local containment failure modes may be applicable to a variety of containments of a given type, it is also true that the combination of failure mechanisms existing in a given containment is unique. Thus, the reader is cautioned against reading any generic applicability into the fragility curves developed for any specific containment. 


\subsection{Fragility Curve Selected for DCH Evaluation}

The containment building is constructed of reinforced concrete and rests on an unexcavated bed of stiff, silty clay. There is a waterproof membrane beneath the bottom of, and outside of, the containment walls below grade. The inside of the structure is lined with steel plate to form a gas-tight barrier. The containment structure is designed for a leakage rate not to exceed onetenth weight percent per day at the design pressure of $0.41 \mathrm{MPa}$-abs (45 psig).

The number of points at which the gas-tight liner is penetrated is limited in order to minimize the potential for leakage. The penetrations include:

1. a personnel air lock,

2. an equipment hatch,

3. piping penetrations,

4. electrical penetrations, and

5. the fuel transfer tube.

All penetrations are leak-tight assemblies welded to the steel liner.

The containment foundation mat is a 3-m (10-ft) deep cylinder. The containment foundation mat, walls, and dome are heavily reinforced with steel bars (rebars) and other steel inserts. The rebars in the bottom part of the mat are placed in a grid pattern. The top part of the mat contains rebars laid in concentric circles with radial spokes.

The containment cylinder wall has rebars placed in identical patterns near the inside and outside wall faces. Each pattern consists of vertical and horizontal members. The two patterns are connected by rebars inclined at $45^{\circ}$ diagonal angles to resist seismic stresses. Set at $45^{\circ}$ inclines near the base mat are shear assemblies to resist the loads associated with the containment pressurization resulting from a design basis accident (DBA).

The containment dome is a hemisphere with an inside radius of $19.2 \mathrm{~m}(63 \mathrm{ft})$. Rebars are placed in a pattern of arced spokes extending in two layers from the center of the dome outward to connect with the rebars in the cylinder wall. The concrete dome is only $0.762 \mathrm{~m}(2.5 \mathrm{ft})$ thick rather than $1.37 \mathrm{~m}(4.5 \mathrm{ft})$ thick as in the cylinder wall. 
The liner completely envelops the interior of the concrete structure to form a gas-tight membrane. It is constructed of carbon steel. The liner is anchored at close intervals to the inside of the concrete structure for support and for transfer of loads. The anchors are designed so that failure will occur at the anchor and liner integrity will not be affected. The liner thicknesses are as follows:

1. $63.5 \mathrm{~mm}(0.25 \mathrm{in}$.) on the containment foundation mat,

2. $69.8 \mathrm{~mm}(0.375 \mathrm{in}$.) on the cylinder wall,

3. $127 \mathrm{~mm}(0.5 \mathrm{in}$.) on the dome, and

4. $190 \mathrm{~mm}(0.75 \mathrm{in}$.) under the in-core instrumentation area and sump area.

The containment fragility curve used for this study (Figure 5.1) is taken from the Surry IPE (Surry 1992), which in turn adopted the aggregate fragility curve from the NUREG-1150 study (Breeding et al. 1992). This curve reflects the most recent judgment of the licensee of the plant. As described by the licensee, the Surry IPE fragility was derived as follows. The Surry IPE fragility curve was based on the input of four experts (from Sandia National Laboratories, Anatech Research Corporation, United Engineering \& Constructors, and Sargent \& Lundy), who were asked to determine what distribution characterizes the failure pressure for static loading of the Surry containment and what conditional probabilities describe the failure modes at each pressure. The failure modes were determined by the break size assumed. A large hole or rupture was defined as an opening greater than $0.046 \mathrm{~m}^{2}\left(0.5 \mathrm{ft}^{2}\right)$ which resulted in containment depressurization in less than 2 hours. A small leak was anything smaller than $0.046 \mathrm{~m}^{2}\left(0.5 \mathrm{ft}^{2}\right)$. Finally, the failure mode of "catastrophic rupture," denoted CR, was considered; this implied the complete failure of a substantial portion of the containment pressure boundary, with possible disruption of the piping systems that penetrate the containment wall. (No similar gross structural failure was implied by the rupture failure mode.) Each expert worked independently, but had access to a variety of past reports and analyses as well as the containment drawings for Surry. The containment fragility curve based upon the three limiting failure modes and their associated uncertainties is shown in Figure 5.1.

Three pressure rise cases were described in the original definition of the issue for the experts:

1. Pressure spike at vessel breach, 
2. Late deflagration, and

3. Late, gradual pressure rise.

Typical rise times for cases 1 and 2 would be on the order of a few seconds. Typical rise times for case 3 would be on the order of an hour. While very high atmospheric temperatures might be observed for a fraction of a minute in case 1 , the bulk temperature of the steel liner which forms the pressure boundary is not expected to exceed 300 to $350^{\circ} \mathrm{F}$.

\subsection{References}

Breeding, R.J. et al. (1992). Evaluation of Severe Accident Risks: Quantification of Major Input Parameters, NUREG/CR-4551, SAND86-1309, Vol. 2, Rev. 1, Part 3, Sandia National Laboratories, Albuquerque, NM.

Stewart, W.L. (1991). Probabilistic Risk Assessment of Surry Nuclear Power plant Units 1\&2 for Individual Plant Exams in response to Generic Letter 88-20, Suppl. l: Final Report, Vols. I-V, Virginia Electric and Power Company, NRC Docket \#05000280 (Unit 1), \#05000281 (Unit 2). 
Table 5.1 Fragility of the Surry containment

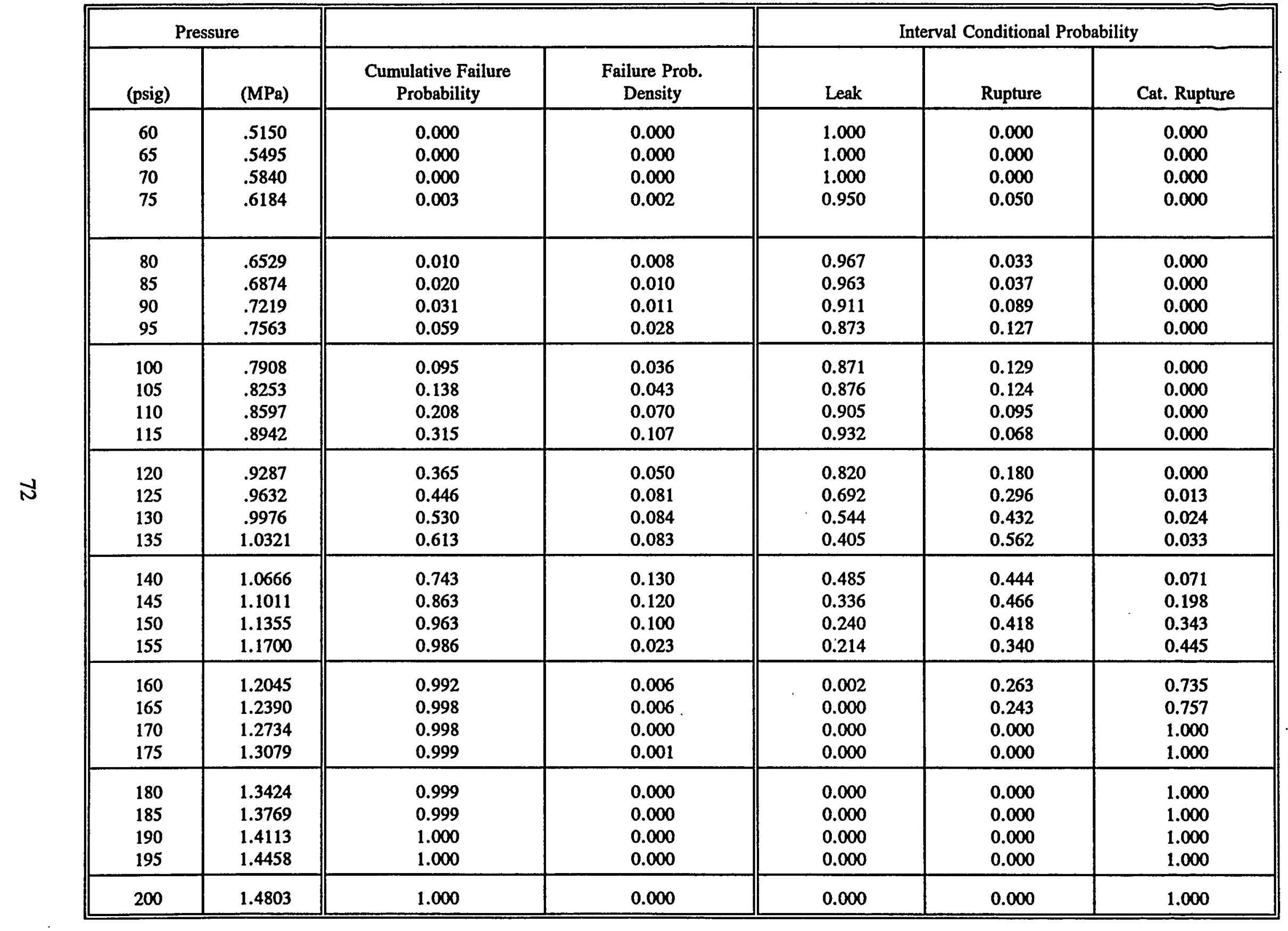




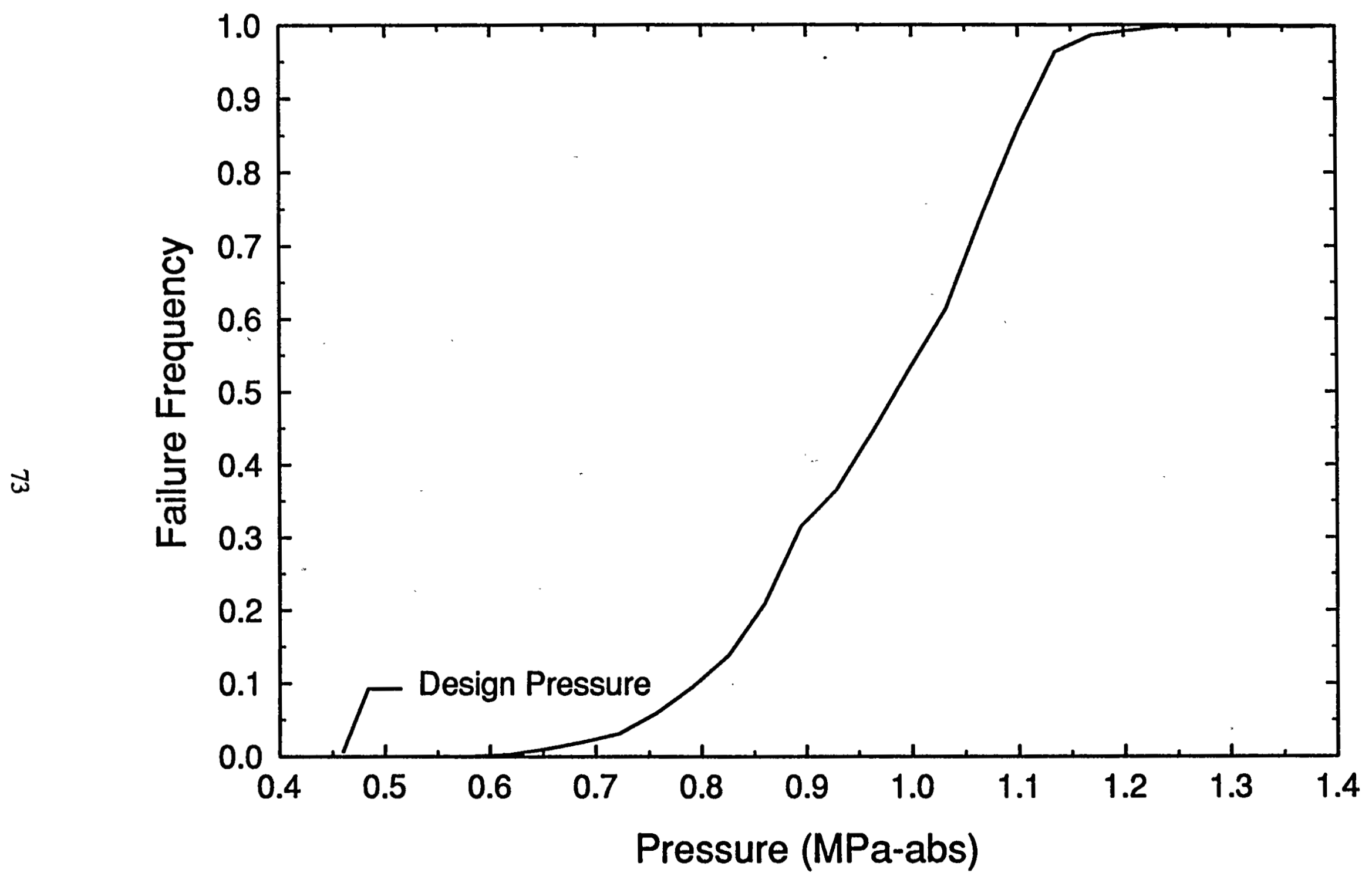

Figure 5.1. Cumulative failure probabilities. 


\subsection{RESULTS AND SENSITIVITIES}

\subsection{Results}

Each scenario identified in Section 3, supplemented by the respective coherence ratio distribution as discussed in Section 4 and the fragility curve of Section 5, was run through the arithmetic defined by the probabilistic framework of Section 2 to produce probability distributions for the final hole size, coherence ratio, containment temperature, and containment pressure. Finally, the containment failure probability was computed. The calculations were carried out using the computer code TCE/LHS as listed in Appendix B of NUREG/CR-6075, Supplement 1 (Pilch et al. 1994b) with 200 samples.

SCDAP/RELAP5 calculations were performed (based on working group recommendations) to confirm the basic features of Scenarios VII and VIII. Three cases were run with SCDAP/RELAP5 to represent the full spectrum of expected pump seal LOCAs: no leaks, 250-gpm/pump, and 480-gpm/pump. Appendix E presents these calculations in detail, and the results are summarized in Section 3.3. The key conclusion, however, is that hot leg failure is predicted to occur before core relocation for all SBLOCAs that proceed without operator intervention. Consequently, Scenarios VII and VIII are not further analyzed in this report.

Table 6.1 provides a concise summary of where to find each of the calculated distributions and the range of the calculated parameter organized as lower bound (LB), best estimate (BE), and upper bound (UB). The distributions for hole size, coherence ratio, and containment temperature are provided so the reader can see firsthand the range over which these key intermediate parameters vary. No intersection of the load distribution with containment fragility is predicted; therefore, we conclude that probability of containment failure by DCH in the Surry plant is zero for the scenarios analyzed.

Examination of the results led to the following observations:

1. Scenario VI produces the higher load even though the RCS pressure is lower, because of a bigger hydrogen combustion contribution resulting from metals in the melt (simply because there is more melt). 
2. The calculated final breach diameters are well within the scaled range used in the experiments.

3. The debris interacts with only a fraction of the blowdown gas, as indicated by the coherence ratio.

Scenario $\mathrm{V}$ is an operator intervention accident with features roughly similar to the TMI-II accident. The TMI-II accident differs from Scenario V in that fan coolers were operational so that there was essentially no steam in the reactor building (compared with $\sim 60$ percent steam in Scenario V). To examine this scenario, we ran a TMI-like case with no steam in the containment atmosphere. We refer to this as Scenario Va, and the initial conditions are listed in Table 3.3.

A hydrogen burn occurred at TMI-II when the hydrogen concentration in the dome was $\sim 7.9$ percent, which was above the local flammability limit of $\sim 4.0$ percent. Consequently, we cannot guarantee an ignition source, which would burn off the hydrogen in the containment prior to the DCH event. Deflagrations, which contribute to peak containment pressure, are expected in this scenario because of the high hydrogen concentration and the low steam concentration in the atmosphere. The deflagration model developed in Appendix E (Pilch et al. 1994b) adequately handles this situation.

Figure 6.5 shows the results of Scenario Va with TMI-like containment conditions. The upper bound pressure is $0.580 \mathrm{MPa}$, which is below the threshold ( $-0.61 \mathrm{MPa}$ ) for Surry's containment fragility. The predicted pressure for TMI-like conditions is only slightly lower than for Scenario VI, which had much more steam in the building. This is because the increased pressures resulting from the deflagration in the TMI-like case are offset by the lower initial containment pressure.

The operation of fan coolers was responsible for the low steam concentrations in the TMI-II atmosphere. The Surry IPE does not credit fan coolers in its containment analysis; however, some accident sequences leading to vessel failure will have containment sprays operational. Spray operation has the effect of reducing the steam concentration just like fan coolers while raising the question of whether it will significantly mitigate DCH loads. The following brief 
discussion shows that heat transfer to containment sprays is not rate limited, but that not enough water is held in the atmosphere to significantly affect peak DCH loads.

There are three separate containment spray systems at Surry which can supply a total of 1.1 $\mathrm{m}^{3} / \mathrm{s}$ of water to the atmosphere with a Sauter mean diameter of $0.2 \mathrm{~mm}$. At any given instant, the suspension of water in the atmosphere is given by

$$
V_{S P R A Y}=\dot{V}_{S P R A Y} \frac{H}{v}-2.5 m^{3}
$$

where $H(-50 \mathrm{~m})$ is the height of the building and $v(\sim 20 \mathrm{~m} / \mathrm{s})$ is the vector sum of the terminal drop velocity $(\sim 3 \mathrm{~m} / \mathrm{s})$ and the downward convective flow $(\sim 17 \mathrm{~m} / \mathrm{s}$, Marx 1988) in the atmosphere induced by the spray operation. The transient time of a water drop in the atmosphere is $\sim 2.5 \mathrm{~s}$ and the DCH time scale to peak pressure is $\sim 5 \mathrm{~s}$; consequently, we might reasonably assume that $\sim 5 \mathrm{~m}^{3}(5 \mathrm{mt})$ of water can interact during the $\mathrm{DCH}$ event. Heating and vaporizing this amount of water represents an energy sink of $\sim 13.3 \times 10^{\circ} \mathrm{J}$, which can be compared to

$$
E \sim \frac{V \Delta P}{\gamma-1} \sim 64 \times 10^{9} \mathrm{~J}
$$

added to the atmosphere by DCH (TCE model). Therefore, the potential energy sink afforded by the spray is only 20 percent of that necessary to quench the DCH event. Even then, water vaporization will add moles to the atmosphere so the potential impact of containment pressurization is less than 20 percent.

The DCH energy is added to the containment over $\sim 5 \mathrm{~s}$ so the rate is $\sim 12.9 \times 10^{9} \mathrm{~J} / \mathrm{s}$. At any given instant, there are $N=V_{\mathrm{SPRAY}} / V_{\mathrm{DROP}}$ or $\sim 6.57 \times 10^{11}$ drops suspended in the atmosphere. TCE predicts a peak atmosphere temperature of $\sim 1300 \mathrm{~K}$ (ignoring the spray) so heat transfer to the drops is dominated by radiation; consequently, the suspended water drops can absorb energy at the rate of $70 \times 10^{9} \mathrm{~J} / \mathrm{s}$, which is large compared with the energy addition rate that is due to DCH. Consequently, heat transfer to containment sprays is not rate limited. In summary, containment sprays represent a heat sink for $\mathrm{DCH}$ that might reduce loads only marginally. 
The TCE model was used to quantify containment loads in our analyses. The CONTAIN code has attempted a more complete kinetic representation of $\mathrm{DCH}$ processes. Point calculations have been performed with the CONTAIN code for initial conditions selected near the upper end of our mass distributions. The calculations are documented in Appendix $G$ and compared with predictions using the TCE model.

The TCE/CONTAIN comparisons are summarized in Table 6.2. The CONTAIN results (loads in particular) are comparable to or less than TCE results. The CONTAIN results for Scenario $\mathrm{Va}$ are noticeably lower than TCE predictions. This is because the containment temperatures are sufficiently high that CONTAIN's more complete treatment of heat losses makes a noticeable difference. Recognizing modeling differences between TCE and CONTAIN, the comparison is significant because the different modeling approach represented by CONTAIN equally supports resolution of the DCH issue for Surry.

The figure of merit for DCH resolution is based on a conditional (on core damage) containment failure probability. DCH is considered resolved if the CCFP is less than 0.1 . The CCFP can be decomposed into the product of two probabilities: the probability (conditional on core damage) that the RCS pressure at vessel breach is high enough such that DCH cannot be precluded (i.e., the probability of HPME), and the probability that DCH will fail containment given an HPME event.

The resolution approach taken for Surry in the main body of this report and for Zion (Pilch et al. 1994a, b) is to define a small number of splinter scenarios that envelop the expected core melt progression behavior for the accident sequences with the potential for leading to HPME and DCH. However, we stop short of assigning probabilities to the various splinter scenarios. Consequently, this approach has focused solely on the probability that DCH will fail the containment given an HPME event. On this basis alone, the DCH issue is resolved for both Surry and Zion because there was no intersection of the load distribution and the fragility distribution.

Resolution of the DCH issue, however, can be approached from a complimentary perspective that looks at the probability (conditional on core damage) of an HPME. If this probability is sufficiently small, then DCH can be resolved from the likelihood perspective without recourse to load or fragility evaluations. 
DCH has been examined from this perspective for a limited number of sequences for Surry in Appendix F. PRA studies show that station blackout accidents dominate those core damage accidents that have the potential of leading to high-pressure melt ejection. Table 6.3 shows the probability of being in various pressure ranges for all station blackout accidents. The combined probability (for all station blackouts) that vessel breach will occur with the RCS exceeding 1.38 MPa is $\sim 0.077$. Consequently, the likelihood of HPME in Surry is low for those station blackout accidents without power recovery or operator intervention. For a short-term station blackout, there is a high likelihood that accident-induced failure of the surge line or hot leg will occur as energy is redistributed from the core region to the components by natural circulation. Uncertainties are larger for long-term station blackouts because we lack a fully integrated bestestimate calculation. Uncertainty estimates in these probabilities are beyond the scope of this effort. The likelihood of HPME for accidents that proceed with power (e.g., TMI-II) or proceed to vessel breach following power recovery is also beyond the scope of the current effort.

The DCH issue is not resolved solely on the basis of HPME probabilities; however, the trends clearly support resolution of this issue for Surry. It is likely that additional analyses could resolve DCH for Surry solely from the perspective of HPME probabilities. This is not necessary for Surry and we recommend that no further analyses be performed. However, when attempting to resolve DCH for other plants, it may be necessary to focus on HPME probabilities or combine HPME probabilities with containment failure (given HPME) probabilities to achieve adequate resolution.

\subsection{References}

Marx, K.O. (1988). Analysis and Computer Simulation of Confined Ring Vortices Driven by Falling Sprays, Phys. Fluids, 31 (2), P. 263-277. 
Table 6.1 Summary of results

\begin{tabular}{|c|c|c|c|c|}
\hline \multirow{2}{*}{ Distribution/Result } & \multicolumn{2}{|c|}{ Scenario V } & \multicolumn{2}{|c|}{ Scenario VI } \\
\hline & $\begin{array}{c}\text { Figure } \\
\text { Location }\end{array}$ & Range * & $\begin{array}{c}\text { Figure } \\
\text { Location }\end{array}$ & Range * \\
\hline Hole size $(\mathrm{m})$ & Fig. 6.1 & $\begin{array}{l}0.405 \mathrm{LB} \\
0.420 \mathrm{BE} \\
0.438 \mathrm{UB}\end{array}$ & Fig. 6.1 & $\begin{array}{l}0.407 \mathrm{LB} \\
0.440 \mathrm{BE} \\
0.469 \mathrm{UB}\end{array}$ \\
\hline Coherence ratio & Fig. 6.2 & $\begin{array}{c}0.07 \mathrm{LB} \\
0.259 \mathrm{BE} \\
0.503 \mathrm{UB}\end{array}$ & Fig. 6.2 & $\begin{array}{c}0.147 \mathrm{LB} \\
0.604 \mathrm{BE} \\
1.13 \mathrm{UB}\end{array}$ \\
\hline Containment temperature (K) & Fig. 6.3 & $\begin{array}{l}420 \mathrm{LB} \\
488 \mathrm{BE} \\
582 \mathrm{UB}\end{array}$ & Fig. 6.3 & $\begin{array}{l}455 \mathrm{LB} \\
587 \mathrm{BE} \\
980 \mathrm{UB}\end{array}$ \\
\hline Containment pressure $(\mathrm{MPa})$ & Fig. 6.4 & $\begin{array}{l}0.294 \mathrm{LB} \\
0.341 \mathrm{BE} \\
0.408 \mathrm{UB}\end{array}$ & Fig. 6.4 & $\begin{array}{l}0.276 \mathrm{LB} \\
0.356 \mathrm{BE} \\
0.595 \mathrm{UB}\end{array}$ \\
\hline $\begin{array}{l}\text { Containment failure } \\
\text { probability }\end{array}$ & & 0 & & 0 \\
\hline
\end{tabular}

* LB, lower bound $(p=0.01)$; BE, best estimate $(p=0.50)$; UB; upper bound $(p=0.99)$. 
Table 6.2 Comparison of TCE and CONTAIN results

\begin{tabular}{||l|c|c|c||}
\hline & Scenario V & Scenario Va & Scenario VI \\
\hline TCE Results & & & \\
\hline $\mathrm{P}_{\max }(\mathrm{Pa})$ & 0.474 & 0.492 & 0.456 \\
\hline $\mathrm{T}_{\max }(\mathrm{K})$ & 686 & 1279 & 774 \\
\hline $\mathrm{H}_{2}$ Produced $(\mathrm{kg})$ & 101.40 & 101.40 & 120.69 \\
\hline $\begin{array}{l}\text { Preexisting } \mathrm{H}_{2} \text { burned on DCH time } \\
\text { scale }(\mathrm{kg})\end{array}$ & 34.85 & 212.47 & 41.53 \\
\hline $\mathrm{H}_{2}$ burned on DCH time scale $(\mathrm{kg})$ & 136.25 & 313.87 & 162.22 \\
\hline Carryover fraction (\%) & $21.00 \%$ & $21.00 \%$ & $21.00 \%$ \\
\hline CONTAIN Results & & & \\
\hline \hline $\mathrm{P}_{\max }(\mathrm{Pa})$ & 0.486 & 0.366 & 0.458 \\
\hline $\mathrm{T}_{\max }(\mathrm{K})$ & 689 & 1230 & 705 \\
\hline Time at $\mathrm{P}_{\max }(\mathrm{s})$ & 5.4 & 8 & 6.8 \\
\hline $\mathrm{H}_{2}$ Produced (kg) & 104.01 & 103.65 & 147.38 \\
\hline $\begin{array}{l}\text { Preexisting } \mathrm{H}_{2} \text { burned on DCH time } \\
\text { scale (kg) }\end{array}$ & 39.39 & 205.78 & 43.39 \\
\hline $\mathrm{H}_{2}$ burned on DCH time scale $(\mathrm{kg})$ & 143.40 & 309.43 & 190.77 \\
\hline Carryover fraction (\%) & $20.02 \%$ & $19.58 \%$ & $11.64 \%$ \\
\hline $\begin{array}{l}\text { Note: } \\
\text { The CONTAIN value of preexisting } \mathrm{H}_{2} \text { burned on a DCH time scale is the } \\
\text { CONTAIN is the time before } \mathrm{P}_{\max }\end{array}$ & & & \\
\hline
\end{tabular}


Table 6.3 HPME probabilities for Surry for all station blackout accidents

\begin{tabular}{|l|c|}
\hline Pressure Range & Probability \\
\hline System setpoint' $(16 \mathrm{MPa})$ & 0.00500 \\
High $(6.89-16 \mathrm{MPa})$ & 0.01490 \\
Intermediate $(1.38-6.89 \mathrm{MPa})$ & 0.05678 \\
Low $(<1.38 \mathrm{MPa})$ & 0.92332 \\
\hline
\end{tabular}




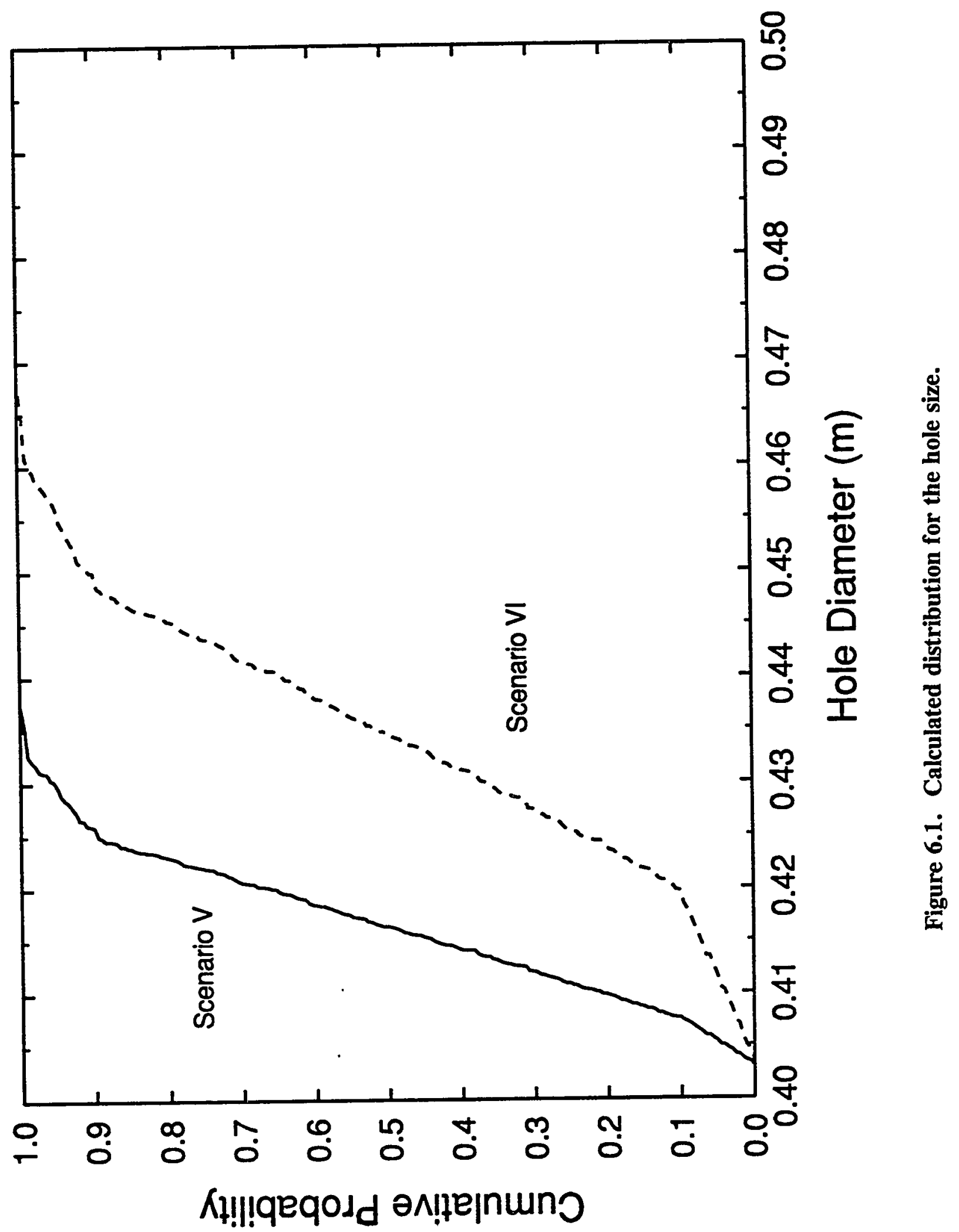




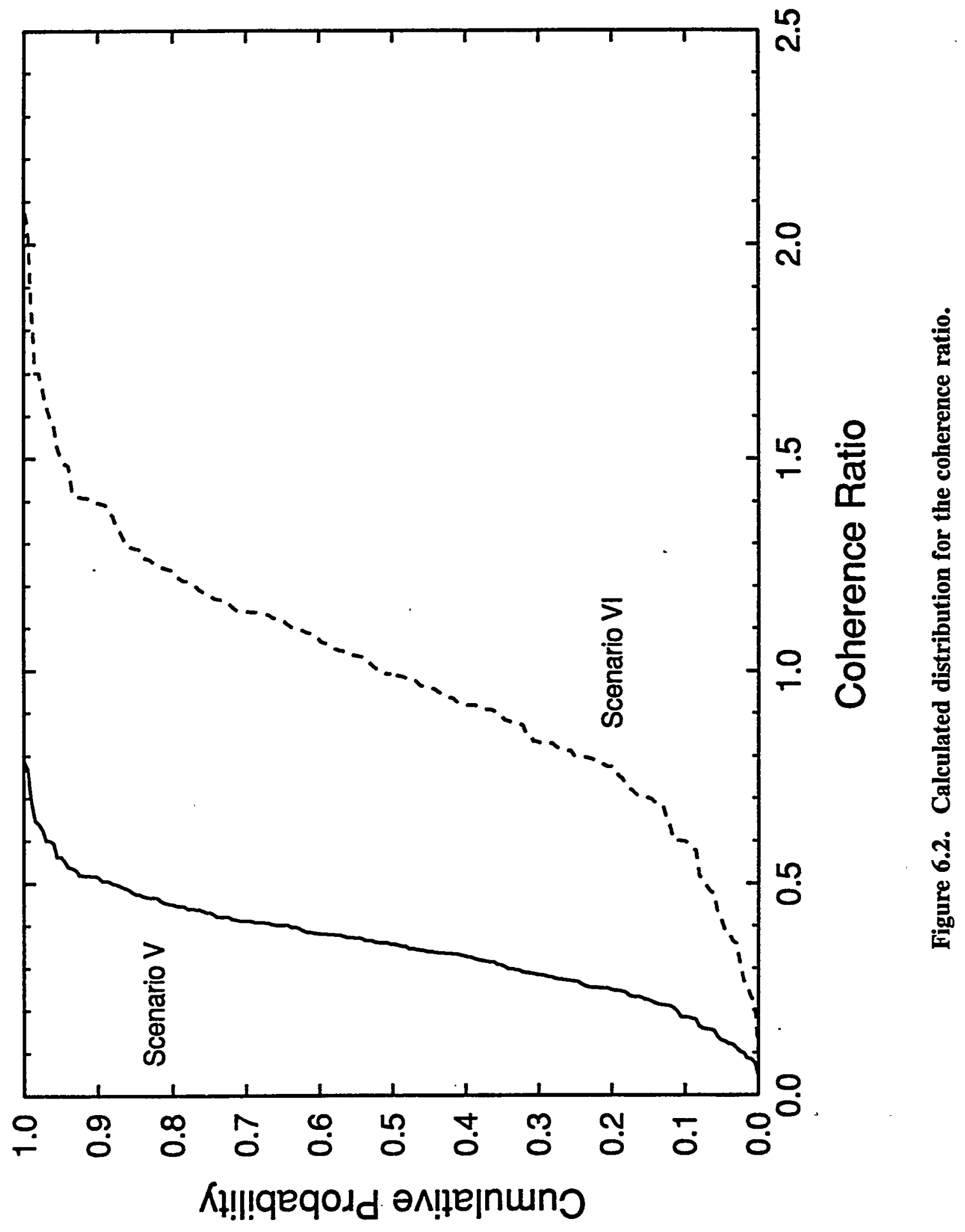




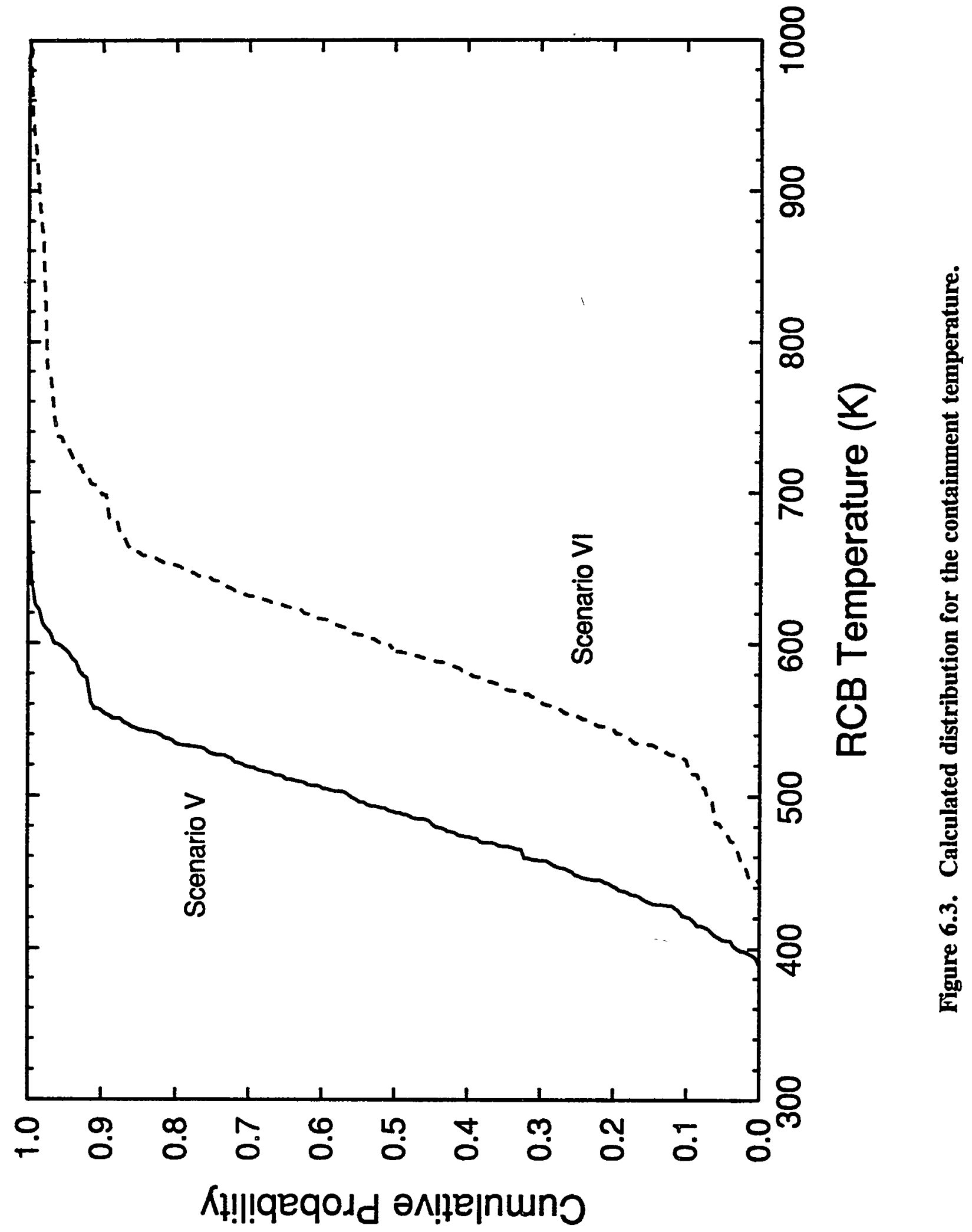




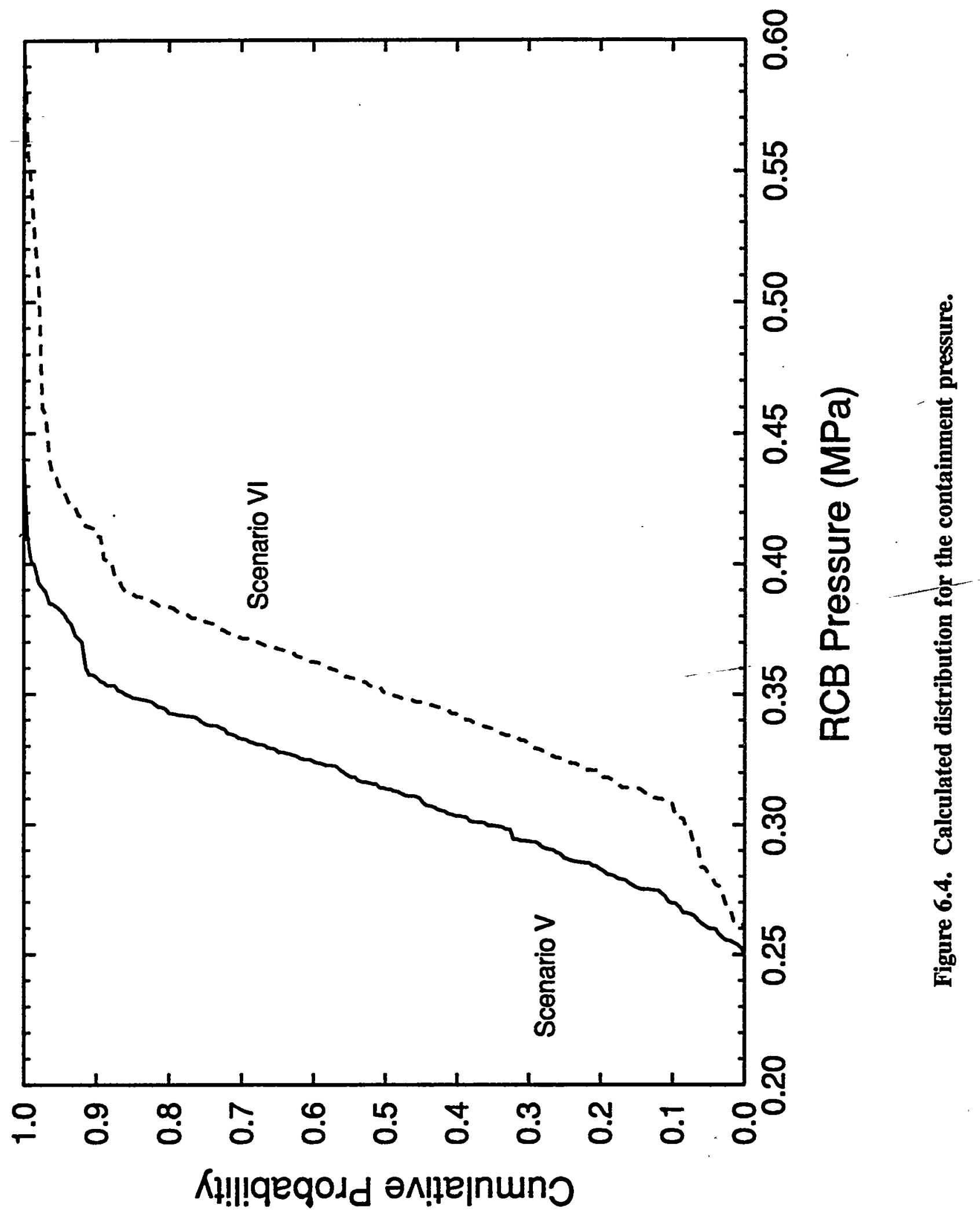



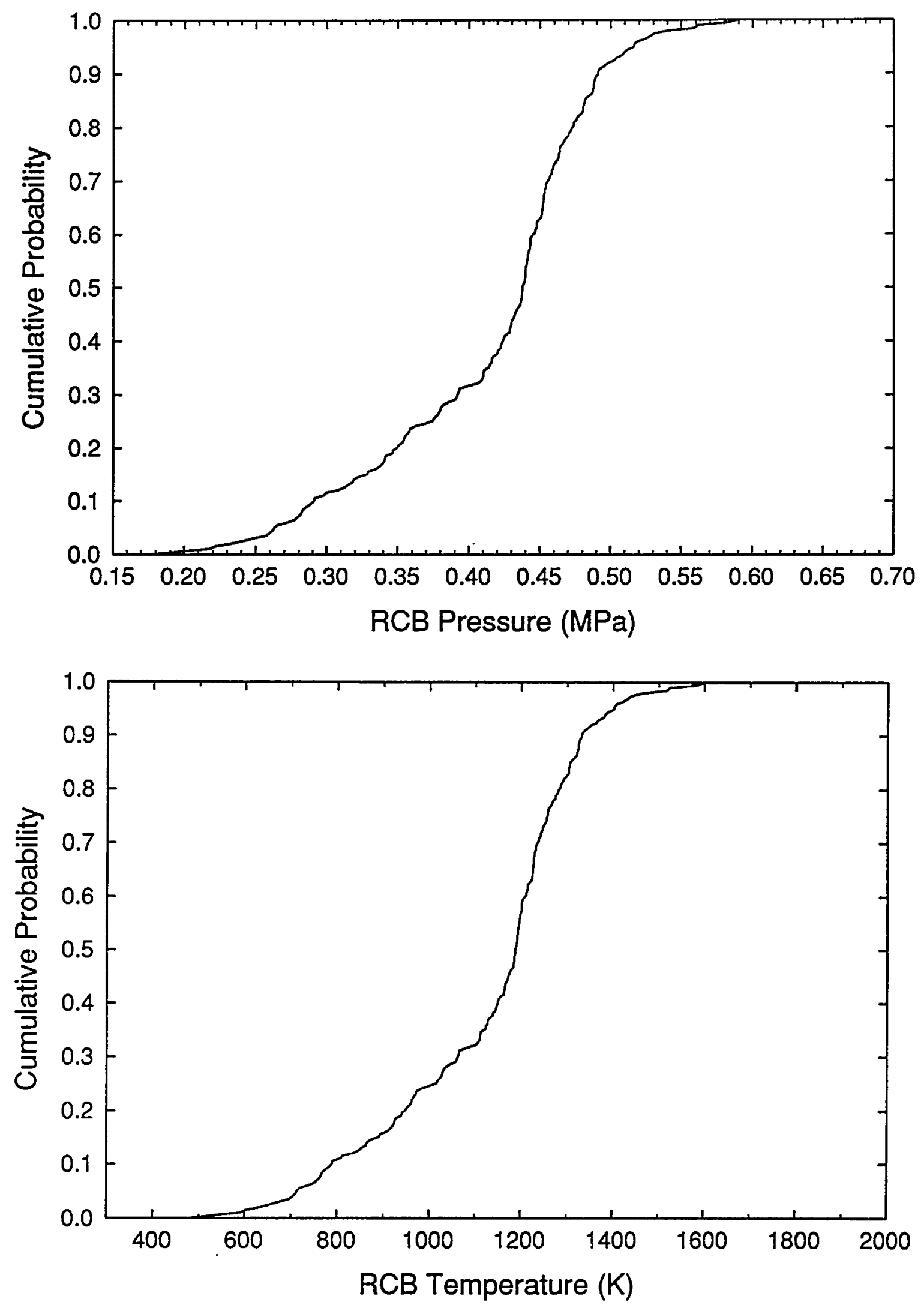

Figure 6.5. Scenario $\mathrm{V}$ with TMI-like containment conditions. 


\subsection{CONCLUSIONS AND RECOMMENDATIONS}

The conclusions listed below are the result of insights from SCDAP/RELAP5 and CONTAIN analyses and of analyses of splinter scenarios defined in working group meetings using the methodology previously developed in NUREG/CR-6075. We recognize that there is some uncertainty in our understanding of in-vessel core melt progression and direct containment heating and in the tools used to model these phenomena; however, at this point, the analyses and conclusions in this report represent our current best estimate.

1. Existing and new SCDAP/RELAP5 were examined for a short-term station blackout scenario with no recovery or operator intervention with three different pump seal leak rates: (1) no leaks, (2) $250 \mathrm{gpm}$ per pump, and (3) $480 \mathrm{gpm}$ per pump. In all cases analyzed, the RCS depressurized to roughly containment pressure well before lower head failure.

2. SCDAP/RELAP5 analyses indicate that only a very small amount of metallic debris relocates to the lower plenum. In-core metallic blockages tend to stay in place, i.e., they do not relocate to the lower plenum. The amount of metallics in the lower plenum at vessel breach predicted by SCDAP/RELAP5 were $\sim 0.1 \mathrm{mt} \mathrm{Zr}, \sim 5 \mathrm{mt}$ lower plenum steel, and no upper plenum steel.

3. The methodology developed in the Zion resolution effort for quantifying melt mass distributions was applied to Surry with Surry-specific input. SCDAP/RELAP5 calculations were used to guide the development of the melt mass distributions. SCDAP/RELAP5 predictions of $\mathrm{Zr}$ content in the melt were broadened to account for likely uncertainties in late-phase core melt progression. The melt mass distributions and melt compositions envelop SCDAP/RELAP5 predictions for Surry.

4. CONTAIN calculations using input from SCDAP/RELAP5 for a 480-gpm/RCS pump case resulted in containment conditions $(\mathrm{P} \sim 0.15 \mathrm{MPa}$ ) somewhat lower than those found for Zion, primarily because Surry is a subatmospheric plant.

5. The new splinter scenarios defined in the working group meetings for Zion were analyzed for Surry using the methodology developed in NUREG/CR-6075. There were no load-to- 
strength intersections and, thus, the containment failure probabilities were zero for the scenarios analyzed. Therefore, the primary conclusion is that DCH is resolved for Surry.

6. Point calculations of DCH loads have been performed with the CONTAIN code for initial conditions selected near the upper end of our mass distributions. The CONTAIN predictions of containment loads were comparable to or less than similar predictions using the TCE model.

7. The probability of HPME is low for Surry. Consideration of uncertainties in SCDAP/RELAP5 analyses for station blackout accident (without power recovery or operator intervention) indicates that the probability of vessel failure with the RCS exceeding 1.38 $\mathrm{MPa}(200 \mathrm{psi})$ is $\sim 0.077$ for all station blackout accidents. 


\section{APPENDIX A \\ Peer Review of NUREG/CR-6109}

NUREG/CR-6109 uses the methodology developed in NUREG/CR-6075 and its supplement for the Zion nuclear power plant (NPP) to assess the direct containment heating (DCH) issue for the Surry NPP. The preliminary draft of NUREG/CR-6109 had a broader scope than the current version, and a different title: "Integrated Report on DCH Issue Resolution for PWRs." However, the initial peer review suggested that attempting to define an extrapolation methodology to resolve the DCH issue for all PWRs was premature. Consequently, the scope of NUREG/CR-6109 was redefined to be a second demonstration of the methodology (based on comparisons of containment loads with containment strength) developed in NUREG/CR-6075 and its supplement. NUREG/CR-6109 also explores DCH resolution from the perspective that high-pressure melt ejection events are unlikely. The current version of NUREG/CR-6109 focuses specifically on the Surry NPP and does not directly propose any broad approach for extrapolation that could resolve the DCH issue for other NPPs. The first version of NUREG/CR-6109 was reviewed by a group of 13 experts who provided extensive comments. In the current version of NUREG/CR-6109, we have accounted for comments on the original version of NUREG/CR-6109 that pertained specifically to Surry and will address their comments on extrapolation in future reports; however, we have not provided a response to each comment as we did in NUREG/CR-6075 since many of the comments no longer apply to the new version of NUREG/CR-6109.

This version of NUREG/CR-6109 was reviewed by six members of the working group on NUREG/CR-6075. Their comments are included here for completeness, and we have revised the report to address their concerns. 
<smiles>[IH3]</smiles> 


\section{位}

Fauske \& Associates, Inc.

January 20, 1995

Dr. Mohsen Khatib-Rahbar

Energy Research, Inc.

6110 Executive Boulevard, Suite 502

Rockville, Maryland 20852

Dear Mohsen:

As requested, I have reviewed draft NUREG/CR-6109 entitled, "The Probability of Containment Failure by Direct Containment Heating in Surry". This report provides a logical extension of the peer reviewed approach used for the Zion reactor documented in NUREG/CR-6075 and Supplement 1 of NUREG/CR-6075. I find that the report is consistent application of the previous methodology and.is documented in a manner consistent with the previous approach. In addition, I find that the authors have been responsive to comments from the peer review committee with respect to dry scenarios and the potential for hot leg creep rupture, as well as for "wet scenarios" that could result from operator actions.

I agree with the approach taken in the report and the conclusions presented. Furthermore, these conclusions have the support of a well controlled experimental program and the approach used in this draft NUREG is consistent with the experimental program and the scaling methodologies laid out in the SASM process. Of course, there are some differences which have evolved from an improved understanding from additional studies with respect to hot leg creep rupture, the character of the molten mass as a result of the downward melt progression, etc. These differences are adequately discussed in the draft NUREG.

I have reviewed this report as requested with the material from Appendices D and E missing. I have assumed that the results from these analyses are consistent with those performed for the Zion assessment and therefore have no surprises. Obviously these represent an important part of the justification for the fundamental conclusions in this study. Therefore, my acceptance of this draft NUREG is predicated upon the fact that these analyses that will be supplied in the final report and are consistent with the discussion in the report. Given the results of the Zion study, this is a logical extrapolation but the reviewers should be made aware of the character of analytical results before the final NUREG is printed. 
Lastly, I have some minor comments that the authors should address in the final version.

- Equation 4.1 on page 51 includes an $\eta$ which is defined as "an efficiency that accounts for mitigation of $\mathrm{DCH}$ due to compartmentalization geometry of the containment...". It should be clearly noted that this $\eta$ is an efficiency of containment pressurization due to the combined processes of blowdown, net steam generation, heating of the atmosphere and hydrogen combustion. In other words, this is not an efficiency of $\mathrm{DCH}$, or the mitigation of $\mathrm{DCH}$ by itself. Even if there was no potential for direct containment heating, this parameter would not be zero.

- Equation 4.6 on page 55 includes an $\eta$ which is defined as the fraction of combustion completeness. To avoid confusion for the different uses of $\eta$, this value should be given a unique characterization, such as $\eta_{\mathrm{cc}}$.

- In the middle of page 73 there is a reference to Appendix $C$ discussing the results of SCDAP/RELAP5. I believe this should be Appendix E.

- On page 75 there is a reference to Marx (1988). I do not find this reference at the end of this section. This should be added in the final version.

Thank you for giving me the opportunity to review this important application of the issue resolution process for direct containment heating. I hope that my comments have been constructive and should there be any questions, please feel free to give me a call.

Sincerely yours,

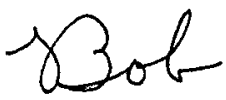

Robert E. Henry

Senior Vice President

REH:jal 


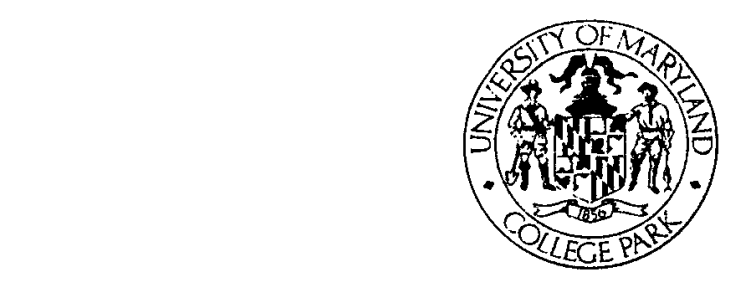

\section{UNIVERSITY OF MARYLAND AT COLLEGE PARK}

RELLABILITY ENGINEERING

MATERIALS AND NUCLEAR ENGINEERING

\section{Dr. Mohsen Khatib-Rahbar}

January 16,1995

Energy Research, Inc.

P.O. Box 2034

Rockville, MD 20847

Dear Dr. Khatib-Rahbar:

I have completed my review of NUREG/CR-6109. I have concluded that the authors have adequately considered and addressed important points related to the Surrey $\mathrm{DCH}$ issue. Accordingly, I concur with the conclusion of the report that suggests closure of the $\mathrm{DCH}$ issue for the Surry plant.

In reviewing NUREG/CR-6109, I have generated some comments and corrections for improving the report. I have listed them below:

\section{General Comment:}

This report addresses two distinct and somewhat disjoint probabilistic approaches: one to estimate the probability of DCH given HPME, and another to assess the probability of HPME given a core damage. While the Surry DCH issue may be resolved based on the probability of $\mathrm{DCH}$ alone, the report also calculates the conditional probability of HPME. However, the report fails to discuss how these two probabilities should be used together for the plants that cannot be resolved based on one of these probabilities. As it stands in this report, discussions about HPME probability (e.g., Appendix F) are superfluous and should be eliminated. However, if the purpose is to provide an example of a resolution based on both probabilities when applied to other plants, then it is important to discuss the integration of these two probabilities.

\section{page 3 (3rd Paragraph):}

I don't recall that the 0.1 "figure of merit" being used in NUREG/CR-6075. Anyhow, the figure of merit does not play a role in Zion and Surry closures. However, it deserves a more careful evaluation, especially if it is playing a role in the $\mathrm{DCH}$ resolution of other plants (or plant categories). I disagree with the statement that this figure of merit is consistent with the NRC safety goals. A value of 0.01 is more consistent (based on

BUILDING 090 - COLLEGE PARK, MARYLAND 20742-2115 • (301) 454-1951 FAX \# (301) 454-4741 
the $10^{-4}$ per year for core damage probability and the $10^{-6}$ per year for catastrophic containment failure and environmental release).

page 40-50 (Figures 3.4, 3.6, 3.7, 3.9, 3.10):

In my reviews of NUREG/CR-7075, I suggested using a PDF instead of a DPD. This allows a better visualization of the relative frequencies. In these figures, besides the DPD form, a cumulative probability distribution function (CPDF) is also shown. This is another way of displaying the relative frequencies, but I believe PDFs are superior for this purpose.

\section{Appendix F}

In this appendix probability of HPME is based or the NUREG-1150 data. However, the fragility data for containment failure are taken from Surry IPE. Since the results of the internal sequences in NUREG-1150 and IPE are different (e.g., in NUREG-1150, station blackout constitutes $67.5 \%$ of the total core damage frequency, whereas in IPE this is $42.8 \%$ ), it makes sense to use the IPE results for calculating the probability of HPME.

\section{Tables F.1 and F.2:}

Mean frequency values of LOCAs for NUREG-1150 results are inconsistent in these two tables.

\section{Table F.6 and Figure F.6}

The data shown in this table includes all sequences in the event tree of Figure F.6, but excluding the first event in the tree (i.e., it excludes "Type of Station Blackout" event). To make them consistent, and to easily calculate the probability of 0.077 from this tree, I suggest the authors quantify the event tree in Figure F.6 by including all of the events in the tree.

Figure F.6

I suggest changing the second event "RCS Failure Before Core Damage" to "Stuck Open PORV or Pump Leak Before Core Damage". This makes this event consistent with the next event in the tree.

\section{Figure F.6}

While the discussions provided in the text of Appendix F covers the SCDAP/RELAP5 calculations for some discrete RCS seal leaks, it fails to address why the two leak rates of $250 \mathrm{gpm}$ and $480 \mathrm{gpm}$ covers all ranges of leaks. Also, from a probabilistic 
view point, the leak rate is a continuous random variable, and its probability cab be found for "ranges" of leak rates as opposed to exact leak rates. For example, it is possible to have a probability for leak rates of $250 \mathrm{gpm}$ and below, or $250-480 \mathrm{gpm}$, but a probability for exactly $250 \mathrm{gpm}$ or $480 \mathrm{gpm}$ may not exist.

In conclusion, I would like commend the authors of NUREG/CR-6109 for their work and their cooperation with peer reviewers. Please don't hesitate to call me at (301)405-5226, if there are any questions.

Sincerely yours,

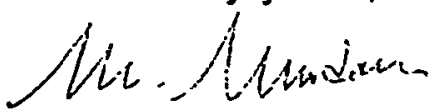

Mohammad Modarres

Professor of Nuclear

Engineering 


\section{Purdue University}

SCHOOL OF NUCLEAR ENGINEERING

January 19,1995

Dr. M. Wayne Hodges, Director

Division of Systems Research

U.S. Nuclear Regulatory Commission

Washington, D.C. 20555-0001

Dear Dr. Hodges:

Subject: Comments on Draft NUREG/CR-6109, "The Probability of Containment Failure by Direct Containment Heating in Surry"

The Surry Nuclear Power Plant has basically similar DCH characteristics as the Zion Nuclear Power Plant. Based on this observation, the methodology developed in NUREG/CR-6075 for the analysis of the Zion NPP was applied to the Surry NPP by SNL. As indicated in my earlier comments on NUREG/CR-6075 and its supplement, this methodology and the TCE model are sound when they are applied to a containment geometry with a significant subcompartment structures and a moderate vessel break size $(\leq 40 \mathrm{~cm})$. The DCH initial conditions were chosen based on the expert recommendations and SCDAP/RELAP5 sample calculations. These initial conditions used in NUREG/CR-6109 are within the bound of the model limitations, therefore, the results and conclusions have similar validity as those for the Zion NPP.

The Appendix $E$ is missing from the report at this time. Therefore, the input from the SCDAP/RELAP5 calculations and the uncertainty of the initial conditions cannot be evaluated in detail. However, it appears that SCDAP/RELAP5 calculations are consistent with the expert recommendations.

In Section 6, the probability distributions of the hole size, coherency ratio and others are given. The authors stated that the arithmetic defined by the probabilistic framework of Section 2 lead to these results. However, this process has not been clearly demonstrated. For example, in the case of the hole size, there should be some mechanistic prediction of the rupture break size and its uncertainty or range due to the difference in melt progression. Before performing the arithmetic, these predictions should be clearly stated with references such that we can distinguish between what we can predict and what we are estimating.

Sincerely,

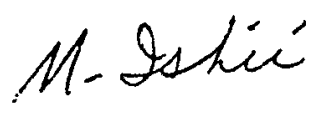

M. Ishii

Professor of Nuclear Engineering 


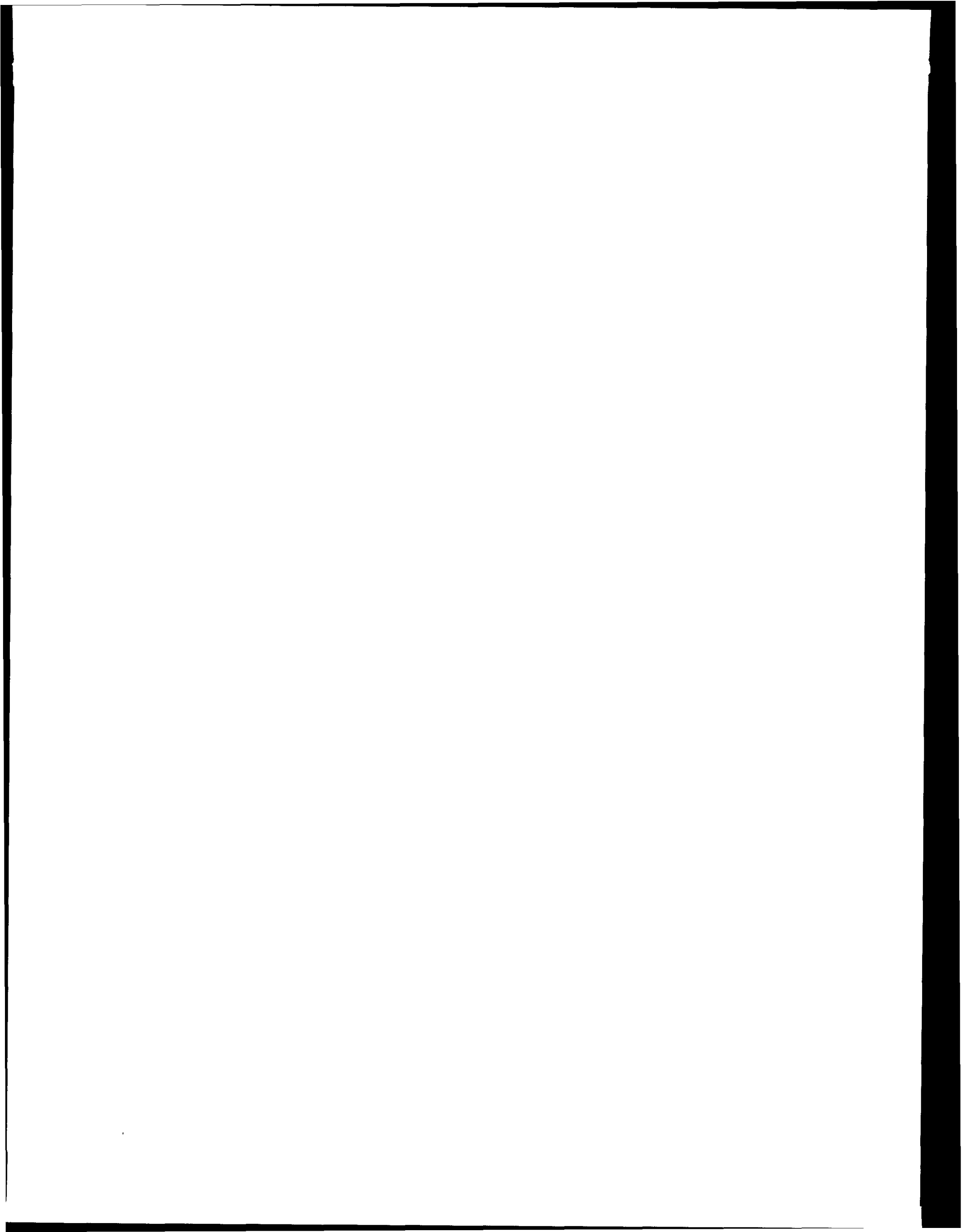


Graduate Aeronautical Laboratories

C $_{\text {alifornia }}$ Institute of $_{\text {echnology }}$

PASADENA, CALIFORNIA 91125

GUGGENHEIM AERONAUTICAL LABORATORY

\author{
Mail Stop: $\quad 105-50$ \\ Telephone: $\quad 8183953283$ \\ Fax: $\quad 8184492677$ \\ E-mail: Jeshep@galcit.caltech.edu
}

February 3, 1995

M. Wayne Hodges

Division of Systems Research

Office of Nuclear Regulatory Research

U. S. Nuclear Regulatory Commission

Washington, DC 20555-0001

RE: Review of NUREG/CR-6109

Dear Mr Hodges:

I have examined this report, "The Probability of Containment Failure by Direct Containment Heating in Surry" although I have not yet been sent Appendix D. I have paid particular attention to the those aspects of the report that deal with the mechanisms of mixing and combustion, since I feel most qualified to discuss those issues.

Substantial effort has already been expended on reviewing the previous report NUREG/CR-6075 which covers many of the generic DCH issues in addition to the specifics for Zion. It appears that the lessons learned from that exercise have been incorporated into the present report. By and large, there are no surprises and the outcome of this exercise are consistent with findings for Zion.

Several notable points:

1. Experimentation on the Surry geometry is much more limited than for the Zion configuration.

2. Most experiments have apparently been carried out without the in-core instrument guide tubes or associated support structures. It is not clear how this has been factored into the analysis of the flow areas and percentage of debris as summarized on pp. 55-57 and pp. B-4 and B-5. Does the quoted minimum tunnel flow area (p. 57) of $6.4 \mathrm{~m}^{2}$ 
include the obstructions or not? In addition, how is the flow restriction of the seal table and the steel hatch incorporated into the flow area analysis?

This is an important issue since a key element the TCE model (and indeed in any control volume model which specifies the flow paths) is the trapping of debris in the subcompartment connected to the reactor cavity. As discussed in several places (e.g., p. B-5), the debris can also pass through the annular gap directly into the upper dome of the containment, bypassing the subcompartment. The flow losses due to the potential area restrictions, seal table, steel hatch and guide tubes are clearly the key issue in determining the fraction of material dispersed through the two paths.

In the HIPS-10S tests, the guide tube and support structure models were forcibly ejected (p. B-5). How is this result used and is it reasonable to extrapolate it to reactor scale? The implication is that the guide tubes and supports will always be ejected under DCH conditions. Is there a threshold RCS pressure at which this is expected to always occur and if so, will this result in a qualitative change in the $\mathrm{DCH}$ process that could affect the conclusions of this report?

3. Hydrogen combustion is a key factor in determining the peak overpressure. Despite the conflicting experimental results on ignition and combustion during $\mathrm{DCH}$, all of the experiments and simulations indicate that the peak overpressures do not pose a threat to the containment since "the load curves do not intersect the fragility curve". I think that this conclusion is correct although I do not believe that all of the conclusions on p. 54 and 55 are supported by the experimental data and analyses on hydrogen combustion that have been carried out over the last 15 years.

In conclusion 3 of p. 54, I do not understand Eqn (4.6) or the blanket statement that "Flame propagation is difficult to achieve in a stratified containment atmosphere". What is the physical basis for this conclusion and what sort of stratification (density, compositional or both) and ignition sources are being considered here?

Conclusion 6 of p. 55 states that combustion initiated by hot gases is too slow because it is mixing limited and the mixing is slow. I think that this is incorrect since the hot gases are likely to be in the form of burning jet of hydrogen/steam/debris as observed visually in many of the SNL experiments. Such a jet is an extremely efficient ignition source of a very large and distributed nature. If a flammable mixture preexist; in the containment, only a small fraction of the atmosphere has to be mixed into the jet for ignition to take place and a propagating flame (deflagration) to occur. This type of behavior has been observed in jet ignition experiments at RPI.

Regarding the relative magnitude of the combustion and heat transfer time scales, this is a very sensitive function of the pre-existing hydrogen concentration. Almost all of the previous considerations on DCH have focused on mixtures with high concentrations of steam (50\%) and very lean hydrogen concentrations (less than $4 \%$ ). But at somewhat higher concentrations and lower amounts of steam, hydrogen combustion can apparently 
be an effective contributor to overpressure. CONTAIN results presented in Appendix G, indicate that the combustion of preexisting hydrogen can contribute up to $0.1 \mathrm{MPa}$ (p. G7) of the total pressure rise.

However, none of these issues apparently makes any real impact on the overall conclusions since even the most extreme cases fail to threaten containment integrity.

3. In my opinion, the key distinction of this report is in the application of CONTANN computations, the sensitivity study and the comparisons with the TCE model. This effort provides valuable points of comparison and a means of examining the validity of various assumptions used in developing the TCE model.

Sincerely,

rseph E. Shepherd

Associate Professor of Aeronautics 


\section{LEVY \& ASSOCIATES}

\section{S. Boscom Ave., Suite 112 \\ San Jose, CR 95124 \\ $408 / 369 / 6500$ \\ FAX 408/369-8720}

\section{Dr. Richard Lee}

Accident Evaluation Branch

Office of Nuclear Regulatory Research

Nuclear Regulatory Commission

Washington, D.C. 20555-001

Dear Richard:

I have reviewed the proposed corrections to NUREG/CR-6109 in response to the comments in my letter of January 16, 1995 to M. Wayne Hodges of NRC and I find the revisions to be generally responsive.

Sincerely Yours,

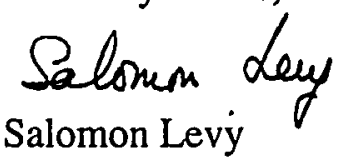


January 16,1995

M. Wayne Hodges, Director

Division of Systems Research

Office of Nuclear Regulatory Research

Nuclear Regulatory Commission

Washington, D. C. 20555-001

Dear Mr. Hodges:

As per your request of December 14, 1994, I have reviewed NUREG/CR-6109, "The Probability of Containment Failure by Direct Containment Heating in Surry". My comments which follow, were prepared without Appendices D and $\mathrm{E}$ and may have to be supplemented after their receipt:

1. NUREG/CR-6109 makes a good case that DCH is not an issue for Surry by showing that the $\mathrm{DCH}$ calculated loads are below the containment strength capability. This finding is strengthened further by establishing a relatively low probability for high pressure in the pressure vessel at the time of vessel breach.

2. NUREG/CR-6109 is well written and several of the appendices are useful in explaining and supporting the conclusions.

3. In my view, quantification of initial conditions remains the issue with the most uncertainties in the resolution of DCH. The primary reason is the lack of information and validated models to predict core melt progression particularly in the latter stages of a severe accident. In spite of my participation in the peer comments and subsequent working group for NUREG/CR-6075, I was surprised to find that my review of NUREG/CR-6109 identified two new concerns in initial conditions which may deserve comments, if not evaluations in NUREG/CR-6109.

- Table 3.4 shows that the scenarios employed in NUREG/CR-6109 assume no control rod material (CRM) in the molten material at vessel breach while both SASM (NUREG/CR-5809) and SCDAP/RELAP5, Case 5 include 2 to 2.7 metric tons of CRM. While there is a consensus that the control rod materials will melt first, it is apparent that in SCDAP/RELAP5 the molten CRM materials reach the bottom of the vessel while in NUREG/CR-6109 they are presumed to be trapped in the crust at the bottom of the reactor core. Because a definite selection among these two approaches is difficult at this time, it is recommended that sensitivity studies be performed with 50 percent and 100 percent of the CRM materials added to the molten corium in the bottom of the reactor vessel.

- $\quad$ SASM (NUREG/CR-5809) highlighted the presence of solids in the corium material at the bottom of the vessel. In NUREG/CR-6109, about 50 
percent of the corium is presumed to be solid and to not participate in the ejected materials. Also, it should be noted that in Appendix B of NUREG/CR-6109 no test with ejection of a solid-liquid mixture was ever carried out and it is not clear that some solids will not be entrained with the liquid melt during ejection from the vessel. Such solids could contribute to the energy transported to the containment if they are in the form of small particles. Additional comments about this possibility should be provided in NUREG/CR-6109. Reasons should be given for the neglect of solid materials or a prescribed fraction of the solids included in the calculations.

4. Uncertainties continue to prevail in the last stages of melt progression, particularly just before the failure of the reactor vessel. The following are typical examples:

In NUREG/CR-6109 the outer most row of fuel assemblies is assumed to not participate in the ejected material and that presumption is applied to all scenarios. As noted in NUREG/CR-6109, some of those outer most assemblies underwent melting in the SCDAP-RELAP5 evaluations (see page 28) and on page F-6 it is noted that "core damage progression is coupled to the natural circulation flow patterns" and these patterns are known to be influenced by the ballooning of the fuel rod cladding and the downwards movement of molten core materials. It is suggested that particularly in dry core scenario cases, a fraction of the outermost fuel assemblies be incorporated in the melt.

- $\quad$ Another uncertainty area is whether there will be significant relocation of metallic blockages in any of the scenarios considered. Present SCDAP-RELAP5 calculations do not predict any remelt of the metallic blockages but that result is not surprising because of the assumptions embedded in the SCDAP-RELAP5 molten pool model at the bottom of the reactor vessel. On page 15 , it is noted that this is due to inefficient heat transfer between the molten debris and the overlying water because of an oxidic crust separating them. On the same page, it is reported that the bottom molten pool contains 3 to 4 metric tons of stainless steel. However, the possibility of this molten steel rising to the top of the pool is not considered. As it rises, the molten steel will interfere with the formation of an oxidic crust to separate the water from the debris and it will reach the water while being considerably superheated and above the melting temperature of the molten oxides. This could lead to much faster heat transfer to the water and possibly high radiation from the top of the pool to the rnetallic blockages. (The MP-2 experiment is cited on page 22 to support that downward failure of an oxidic crucible is unlikely. However, that crucible test was not subjected to radiation from below as well as heat generation from above). I continue to suggest sensitivity studies with respect to the content of metallic in the melt. It was disappointing that in the sensitivity of parameters on Zion DCH loads (letter of $11 / 2 / 94$ from M. W. Hodges to S. Levy), the metallic content was not varied because it may have the greatest impact on DCH loads.

5. The probability for high pressure in the pressure vessel at the time of vessel breach was obtained from only station blackout scenarios in NUREG/CR-6109. Yet, in Appendix F, several other scenarios are listed which might lead to high pressure ejection, e. g. ATWS and SGTRs, and they need to be considered or their contribution estimated if 
such probability methodology is to be used to support increased loadings beyond those reported in the Surry plant.

6. In Appendix B, the occurrence of steam-explosions in the cavity tests is noted. It is necessary to ascertain that if such steam explosions occur in the plants that they will not destroy the cavities and allow an increased amount of ejected molten material to enter the dome directly.

7. The size of the hole assigned to a local rupture of the lower head needs to be revisited and so does the statement on page 15 that "the likelihood of HPME events with operator intervention is outside the scope of this work"

I hope that these comments are helpful. They are not meant to imply that DCH is not a resolved issue for the Surry plant but to insure defendable extrapolation of NUREG/CR6109 methodology to other plants.

Sincerely yours,

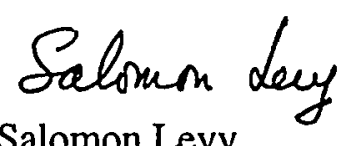

Salomon Levy 
- 
M. Wayne Hodges, Director

January 13,1995

Division of Systems Research

Office of Nuclear Regulatory Research

Washington, D.C. 20555-0001

Dear Dr. Hodges,

I have reviewed the revised draft of NUREG-CR-6109, "The Probability of Containment Failure by Direct Containment Heating in Surry," by M. M. Pilch, et. al.

It is my opinion that the report provides information which is sufficient to resolve the $\mathrm{DCH}$ issue for the SuI"ry, plart. I support the steps described in showing that the loads and containment strength distributions have no intersections.

The authors of the report have done an outstanding job of communicating the fundamental aspects of $\mathrm{DCH}$ phenomena and accident scenarios. The level of understandability should make it possible for both new and older workers in the field to realize the depth of technology which it contains, and on which its conclusions are based.

The use of existing experimental work, computational models, and supportable engineering judgements provide a convincing process for closing the issue of DCH in Surry. Moreover, applicable peer review wisdom, obtained from the $\mathrm{zion}$ DCH resolution, is incorporated in the surry study. The overall result is a consistent argument which appears credible from multiple viewpoints.

Even though additional technical opinions could lead to some shifting of probability distributions and causal relationships, I think that the authors have been careful to employ conservative bounding limits where arguments may still exist. That leads me to believe that even as more DCH phenomenological and system understanding is gained, refinements in the study described will not change the conclusions reached for the Surry DCH issue.

Yours truly,

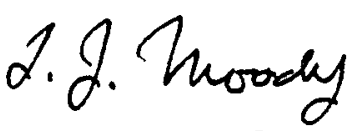

F. J. Moody

GE Nuclear Energy

Mail Code 747

175 Curtner Avenue

San Jose, CA 95125

(408) 925-6434 phone

cc. Dr. Richard Lee

$$
2790 \mathrm{fax}
$$




\title{
APPENDIX B \\ Summary of DCH Experiments and Insights
}

\author{
B.W. Spencer, Argonne National Laboratory \\ M. Pilch and M.D. Allen, Sandia National Laboratories
}

The experiment database for DCH has been accumulating since the early 1980s. Work in the United States has been sponsored by the Nuclear Safety Analysis Center (NSAC), Electric Power Research Institute (EPRI), and particularly by the Nuclear Regulatory Commission (NRC). Essentially all the work performed to date has been conducted in the United States. Some work has been performed in the United Kingdom in support of Sizewell B licensing.

The experimental work performed to date falls into two major categories:

- Essentially isothermal tests with low-temperature, simulant material, in which the objectives have been primarily to gain insights about the hydrodynamic aspects of the various phenomena associated with $\mathrm{DCH}$, and

- Tests involving use of high-temperature core melt simulants, particularly iron-aluminabased thermites and $\mathrm{UO}_{2} / \mathrm{ZrO}_{2} / \mathrm{Zr} /$ stainless steel melts, addressing separate effects as well as the integral effects of $\mathrm{DCH}$ processes.

The experiment programs have provided insights regarding $\mathrm{DCH}$ phenomena and have supported development of physical models of DCH-related processes. Such models have been developed for stand-alone purposes, for adaptation into computer codes such as CONTAIN, and for use in scaling methodologies. The severe accident scaling methodology (SASM) study (Technical Program Group 1991) focused attention on the possibility of a direct scaleup of DCH integral-effects tests if the conduct of those tests is based on applicable scaling laws, i.e., based on a knowledge of the dominant physical mechanisms and scaling approach to preserve those mechanisms. With such an approach, the results of integral, well-scaled DCH tests could be directly scaled up to the reactor system, offering a complementary approach to reliance on computer codes for the scaleup.

The SASM scaling approach recognized the difficulty of scaling up DCH because of the many processes involved in multiple regions of the nuclear power plant (NPP). In particular, 
they recognized a need to distinguish physical phenomena relevant to $\mathrm{DCH}$ occurring in four separate regions of the NPP, namely:

- The reactor pressure vessel, containing corium melt on the vessel lower head plus steam and hydrogen, and possibly water, at elevated pressure;

- The reactor cavity region beneath the vessel where, upon breach of the vessel lower head, the corium melt is ejected, spreads, and momentarily collects on the floor; vessel blowdown ensues as the breach clears of liquid, and the core materials become entrained and dispersed from the cavity by the high-velocity steam blowdown;

- The subcompartment region at the basement level of the containment where the ejected corium melt is initially dispersed and may largely collect; and

- The dome region of the containment where the ejected corium plume may penetrate if not intercepted by the subcompartment structures.

In general, the simulant material tests have examined the DCH phenomena primarily in the reactor cavity and subcompartment regions, whereas nonisothermal separate-effects tests and integral-effects tests have examined phenomena in all the regions in scaled experiments. The remainder of this section is organized roughly around DCH phenomena by region, followed by a discussion of integral experiments.

DCH experimental programs have concentrated on a limited number of NPP configurations (principally Zion and Surry). Simulant-material work addressing cavity interactions has been performed for Sizewell B (Macbeth and Trenberth 1987; Macbeth et al. 1988), Grand Gulf boiling water reactor (BWR) (Spencer et al. 1984), and a combustion engineering (CE) plant without bottom head penetrations (Sharon et al. 1992).

\section{B.1 Melt Ejection Stage}

Experiments have been performed in which the melt simulant initially resided at the bottom of a pressurized vessel, then was ejected into a scaled cavity. These melt ejection tests have revealed the following: 
- Ejection flow regime: The melt is typically ejected through the breach by expansion of the overlying pressurized gas. Initially, the melt flows out predominantly as a single-phase liquid. Subsequently, the melt depth decreases so that the depression in its surface above the opening causes "punchthrough" (Pilch and Griffith 1992) of the overlying gas. Hence a period of combined melt and gas two-phase ejection ensues. Eventually the melt is largely depleted and a single-phase gas blowdown follows until pressure equilibration between the vessel and the containment atmosphere is reached. This three-stage melt ejection process has been observed using both low-temperature simulants (Spencer et al. 1983a) and hightemperature melts (Spencer et al. 1987; Pilch and Tarbell 1985).

- Breach enlargement: During the melt ejection process, the high-velocity melt ablates the sides of the vessel breach, causing it to enlarge (Pilch et al. 1994). This enlargement of the opening has occurred during tests with high-temperature melts (Pilch and Tarbell 1985) unless it was specifically precluded by apparatus design (Spencer et al. 1987). The vessel blowdown occurs following the melt ejection-induced enlargement, and therefore occurs through the final breach size rather than the initial size. The approach in recent experimental programs (Pilch and Allen 1991) has been to design the apparatus to preclude breach enlargement (since it is difficult to control), and to use a hole size based on the final ablated size (from analyses). This approach is consistent with the SASM recommendations.

- Effervescence: Early melt ejection tests using iron-alumina thermite were performed using different inert gases to see if the selection of gas played any role (Tarbell et al. 1983). Gases were selected for their high calculated solubility $\left(\mathrm{N}_{2}\right)$ versus low solubility $\left(\mathrm{CO}_{2}\right)$ in the melt. Photographs of the ejected melt stream showed that the stream driven by the soluble $\mathrm{N}_{2}$ gas largely atomized as it exited the pressure vessel, which is attributed to effervescence, whereas the stream driven by low-solubility $\mathrm{CO}_{2}$ remained largely intact. A steam-hydrogen mixture was expected to behave more like the soluble $\mathrm{N}_{2}$ gas.

\section{B.2 Cavity Interactions}

Debris dispersal from the reactor cavity has been the focus of many programs since the Zion Probabilistic Safety Study (ZPSS 1981). Analyses (Spencer et al. 1982, 1983a) showed that the threshold for dispersal from the Zion reactor cavity is reasonably predicted by the Kutateladze criterion proposed in the Zion Probabilistic Safety Study. IDCOR (Fauske and Associates 1985) 
categorized existing cavity geometries into 14 classes and provided a subjective assessment of the dispersive or nondispersive qualities of each class. The IDCOR notion that cavity geometry influences debris dispersal has been confirmed only partially by more recent experiments. Separate-effect experiments using low-temperature simulant fluids in the Zion, Surry, and Watts Bar geometry (Tutu et al. 1988a; 1988b; Tutu and Ginsberg 1990; Tutu 1990), in the Sizewell B geometry (Macbeth and Trenberth 1987; Macbeth et al. 1988; Rose 1987), and in Korean designs (Chun et al. 1991; Kim et al. 1992), all show that cavity geometry is important only at low RCS pressures where dispersal is incomplete. However, correlations proposed by those authors and independent correlations (Technical Program Group 1991) based on some of the same data suggest that debris dispersal is nearly complete at reactor scale for RCS pressures in excess of about $4 \mathrm{MPa}$, regardless of the cavity geometry. Typical dispersal fractions of greater than 60 percent have been observed in recent large-scale integral-effects $\mathrm{DCH}$ experiments at Sandia National Laboratories (SNL) (Allen et al. 1992c, 1992d, 1992e, 1992f, 1992g, 1992h) and smaller scale counterparts at Argonne National Laboratory (ANL) (Binder et al. 1992a, 1992b, 1992c, 1992d, 1992e, 1992f). Henry et al. (1991) analyzed the dispersal process and concluded that only a portion of the dispersed material is finely fragmented, with the remaining material pushed from the cavity as a film. Henry's predictions have been confirmed by recent separate-effects tests conducted at Purdue (Ishii et al. 1993) using water as a simulant for molten core material.

Experiments by Macbeth et al. (1988) suggest that the fraction of melt swept from the cavity is independent of physical scale. Correlations by Tutu and Ginsberg (1990) for the Zion and Surry cavities [based on 1/42 scale experiments conducted at Brookhaven National Laboratory (BNL) and unpublished 1/10 scale experiments conducted at (SNL)] suggest that the extent of dispersal is nearly independent of physical scale. The correlations of Levy (Technical Program Group 1991) based on the same data suggest that dispersal increases with physical scale. Other experiments (Kim et al. 1992; Binder et al. 1992c) also show that the extent of dispersal is nearly independent of physical scale. More recently, the large-scale (1/40) experiments at ANL (Binder et al. 1992a, 1992b, 1992c, 1992d, 1992e, 1992f) show that the extent of melt dispersal is independent of physical scale.

The annular gap around the reactor pressure vessel (RPV) is a potentially important pathway for debris dispersal. Debris dispersed from the cavity through this pathway enters the upper dome of the containment, where DCH processes are most efficient. The HIPS-8C experiment 
(Pilch et al. 1988) demonstrated that significant debris can be dispersed through the annular gap (Zion-like geometry) when insulation and nozzles are not present. More prototypic experiments (Blanchat et al. 1994) have been conducted with nozzles and insulation in the gap. A closer look at all these data (Pilch et al. 1994) indicates that the fraction of debris dispersed through the gap is given by

$$
f=\frac{A_{g}}{\left(A_{g}+A_{\vartheta}\right)}
$$

where $A_{g}$ and $A_{t}$ are the minimum flow areas in the annular gap and the instrument tunnel, respectively.

Reactor cavities normally exist so in-core instrument guide tubes can have access to the lower head of the RPV. Most dispersal experiments have been conducted without these structures in the cavity. Rose (1987) found that modeling the guide tubes and their supports dramatically reduced dispersal of low-temperature simulant fluids from a model of the Sizewell B cavity. The support structures are much more massive in the Sizewell reactor than typical U.S. reactors. Allen et al. (1990) found that the guide tubes and their supports were forcibly ejected from a model of the Surry cavity during the dispersal process. The distinguishing feature here is that a high-temperature melt cut the supports free from the anchors in the floor of the cavity (by ablation).

In summary, it appears that no cavity design can be considered retentive at the high RCS pressures of interest. Significant mitigation of DCH cannot be found in current cavity designs or the structures typically found in reactor cavities.

\section{B.3 Subcompartment Region}

Early low-temperature visualization tests were performed at 1:40 scale of the Zion NPP to address the likely disposition of debris ejected from the cavity (Spencer et al. 1983c). These tests revealed that the dispersed plume was largely intercepted by seal table structures. Fifty to 70 percent of the dispersed mass was retained in the subcompartment volume in the immediate vicinity of the seal table. Most of the rest of the debris was dispersed onto the basement floor, and only a few percent escaped to the region above the subcompartments. Hence it became an 
important feature of integral tests to model this subcompartment geometry because of the potential it had to limit the plume transport to the dome.

High-temperature melt ejection tests were performed specifically to examine the effect of the plume path length on energy transfer. The limited flight path (LFP) tests were performed in the Surtsey facility at 1:10 scale (Allen et al. 1991b) with steam as the driving gas. In these tests, containment compartmentalization was crudely simulated by placing a simple concrete slab above the cavity exit. This slab divided the vessel into a subcompartment and upper dome region. The key finding was that the $\mathrm{DCH}$ heating and metal-steam reactions were almost entirely limited to the cavity and subcompartment regions and did not involve the "dome" region above the concrete slab. Hence the importance of compartment geometry was reaffirmed by these tests as well as the new importance of cavity interactions (oxidation heat source-hydrogen generation). These early findings have been confirmed in more recent experiments conducted with fully prototypic models of the Zion or Surry subcompartment structures (Allen et al. 1992c, 1992d, 1992e, 1992f, 1992g, 1992h, 1993, 1994a; Binder et al. 1992a, 1992b, 1992c, 1992d, 1992e, 1992f; Henry et al. 1991; Blanchat et al. 1994).

In all accident scenarios, water will be present on the subcompartment floor and may also spill into the cavity for some scenarios in some plants. Experiments have been conducted to address the role that water may play in DCH. Experiments show that water on the subcompartment floor has an insignificant impact on DCH loads, although melt/water interactions on the floor may continue to produce hydrogen, but on a time scale too long to contribute to peak DCH loads. A small amount of water in the cavity, from steam condensation, for example, is a trivial heat sink for the corium and will have negligible effect on DCH loads. If the water depth becomes of the order of half the tunnel height or greater, however, then its presence is significant because of the potential for enhanced quenching of corium and because of the potential for steam explosions.

Caution should be observed, however, when extrapolating experiment observations of steam explosion phenomena to plant scale because steam explosions are potentially sensitive to melt composition and physical scale. An exhaustive treatment of steam explosion phenomena has not been the focus of the $\mathrm{DCH}$ program. We note that many plants have cavities that are excavated from the soil and bedrock beneath the plant foundation (e.g., Zion). Excavated cavities are not easily damaged by steam explosions. Surry, however, is one of several plants that have cavity 
walls built up from the basement floor. Such cavities typically have a design pressure of $\sim 1.5$ MPa. Energetic steam explosions will likely fail the cavity walls and disperse debris into the basement where the debris cannot participate significantly in DCH. Steam explosions in the cavity have the potential to damage structures in the vicinity of the cavity exit; however, most plants would require damage to multiple structures before significant new debris transport to the dome is possible.

Isothermal visualization tests have revealed that the corium stream channels through the depth of water onto the floor, where it spreads (Spencer et al. 1983b). A water slug involving the mass of water initially present in the tunnel is then accelerated out the tunnel and shaft. After the slug is ejected, the vigorous entrainment and dispersal process in the cavity involves both the water and the core debris (i.e., they are essentially coentrained and codispersed). In tests with high-temperature simulants, water was found to increase the debris fraction dispersed (Spencer et al. 1983b), which is presumably due to a combination of quenching, augmented steam flow, and liquid dynamic pressure. Tests performed at 1:20 scale with iron-alumina thermite produced steam explosions. These pressurization events destroyed the cavity models (Tarbell et al. 1991). However, no attempt was made to match the structural strength of the prototypes. Tests performed at large scale (1:10) but with relatively little water in the cavity indicated there was little difference in debris dispersal or containment pressure increase, but that slightly more hydrogen was generated when water was present (Allen et al. 1992a).

Tests performed at 1:30 scale using $\mathrm{UO}_{2} / \mathrm{ZrO}_{2} /$ stainless steel corium simulant did not produce steam explosions, although the transient cavity pressure was very high during the cavity clearing time (Spencer et al. 1988). Tests with water in the cavity have typically shown increased hydrogen production (especially when inert blowdown gas was used); similar or somewhat less DCH pressurization compared with the dry case (steam generation substitutes for atmosphere heatup); and have resulted in a lower atmosphere temperature. In the CWTI tests using appreciable cavity water, the temperature of the atmosphere remained at saturation, such that the DCH heating-related pressurization load was transformed to a melt quench-steam generation pressurization load, i.e., "steam spike" (Spencer et al. 1988). A similar conclusion was drawn from SNL/IET-8B (Allen et al. 1993), which used prototypic 1:10 linear scale structures of Zion and a cavity one-half full of water. 


\section{B.4 Integral-Effects Tests}

DCH experiments have been conducted at SNL and ANL and by Fauske and Associates (FAI). Of interest here are experiments employing high-temperature chemically reactive melts, driven under pressure into a simulated reactor cavity, with the whole system confined in a vessel so that containment pressure could be measured. A brief survey of these experiments is presented in Table B.1. Experiments have been conducted at four different physical scales, with two different cavity designs, with and without subcompartment structures, with reactive and nonreactive blowdown gases, and with reactive and nonreactive atmospheres.

\section{B.4.1 SNL DCH Tests}

Four DCH-series tests were performed in the Surtsey facility (1:10 linear scale) (Tarbell et al. 1987, 1988; Allen et al. 1991a). They addressed the effects of melt mass, plume disruption, and air versus inert atmosphere. The corium melt simulant was $\mathrm{Fe} / \mathrm{Al}_{2} \mathrm{O}_{3}$ thermite with a mass scaled to 65 percent of the total core mass in Zion. However, energy was scaled to -100 percent of the core. There was no water or steam in any of these tests. The melt generatorcavity assembly was inside the Surtsey vessel and there were no subcompartment structures. The gas used to drive the melt was nitrogen.

Results showed containment pressurization ranging from 0.10 to $0.22 \mathrm{MPa}$ for the four tests. The lowest pressure was attained with a reduced melt mass. The highest pressure was attained when the debris-gas plume was ejected onto the side of the vessel, apparently enhancing its breakup and energy exchange with the atmosphere. Cavity sweepout in these tests ranged from 52 to 97 percent of the ejected melt. Oxidation of the iron ranged from 35 to 100 percent. The use of an inert atmosphere in $\mathrm{DCH}-4$ did not significantly lessen the pressurization since the lower available energy was apparently compensated for by the smal'er specific heat of the argon gas compared with the air atmosphere.

\section{B.4.2 ANL CWTI Tests}

Five CWTI-DCH tests were performed in the COREXIT facility (1:30 linear scale) (Spencer et al. 1988). These tests addressed the effects of subcompartment structures, presence of water (in the cavity and on the subcompartment floor), and air versus inert atmosphere. The tests 
featured the use of a reactor material corium $\left[60 \% \mathrm{UO}_{2}, 16 \% \mathrm{ZrO}_{2}, 24 \%\right.$ SSt (stainless steel)], and a melt mass that scales to $\sim 70$ percent of the Zion core mass. However, the scaled energy is equivalent to $\sim 60$ percent of the core energy. The orifice size was scaled to $38-$ or $76-\mathrm{cm}$ penetration failures. The initial driving pressure was $-5 \mathrm{MPa}$ of argon gas. The containment atmosphere was air or argon at $0.1 \mathrm{MPa}$ absolute. The cavity was constructed of steel (rather than concrete as in the SNL DCH tests); the use of steel promoted retention of debris in the cavity through a crust.

The results showed containment atmosphere pressurization ranging from 0.12 to $0.42 \mathrm{MPa}$. Corium sweepout ranged from 9 to 61 percent. The lowest pressure was attained in two tests that employed the subcompartment structure and no water in the cavity. In both of these cases, the peak pressure rise was $0.12 \mathrm{MPa}$, despite the fact that one was performed in an inert atmosphere and the other in an air atmosphere. A hydrogen burn occurred in the latter test from hydrogen produced by reactions between metal and water on the subcompartment floor. The two tests with water resulted in the highest system pressure rises. The water essentially filled the cavities in these tests up to the top of the horizontal tunnel. These two tests produced considerable hydrogen generation amounting to 77-79 percent complete oxidation. Interestingly, the containment atmosphere remained at water saturation temperature for these tests, indicating the energy had gone into generating steam rather than heating the atmosphere.

The largest heating of the atmosphere occurred for the test with water in neither the cavity nor the subcompartment structure. The pressure rise peaked at $0.22 \mathrm{MPa}$ despite the fact that only 9 percent of the melt mass was swept from the cavity. With this small plume and no structure, the energy transfer to the atmosphere was very effective, as was oxidation in air (67 percent oxidation).

These tests showed the large oxidation possible with steam present, the possibility of hydrogen combustion without steam inerting, the importance of subcompartment structures to lessen pressurization, and the role of cavity water in preventing atmosphere heatup and rendering DCH a "steam spike." 


\section{B.4.3 SNL/ANL Counterpart IET-Zion Tests and the ANL U Tests}

A series of counterpart tests (SNL/ANL IET) has been performed under nominally identical conditions and an identical scaling approach, differing only in physical scale (Allen et al. 1994a; Binder et al. 1994). The purpose was to assess the successfulness of the scaling approach insofar as it correctly permitted scaleup of test results between 1:40 and 1:10 scales. These tests utilized the Zion NPP geometry.

The corium melt simulant was $\mathrm{Fe} / \mathrm{Al}_{2} \mathrm{O}_{3}$ thermite doped with about $10 \mathrm{wt} . \% \mathrm{Cr}$ to increase the release of oxidation energy. When they were adjusted to scale, the melt masses were 34 percent of the total core mass in Zion. However, the scaled energy is equivalent to 43 percent of the core energy. Steam was used to drive the melt dispersal in these tests. The initial steam pressure was specified to be $6.2 \mathrm{MPa}$ to correspond to a pump seal LOCA initiated by a station blackout sequence. The RPV volume was adjusted to give a vessel blowdown that was to scale. The orifice size was scaled to a final, ablated hole diameter of $40 \mathrm{~cm}$ in the RPV lower head. A very small amount of water was on the cavity floor, representing steam condensate, but it had essentially no influence on the tests. The initial pressure of the containment atmosphere was $\mathbf{0 . 2}$ $\mathrm{MPa}$ absolute. Its composition was the key variable for the three counterpart tests.

The first counterpart tests were performed with an inert (nitrogen) atmosphere. The measured peak dome pressure rises were 0.11 and $0.15 \mathrm{MPa}$ for 1:10, and 1:40 scale respectively. The metal oxidation was 100 percent of $\mathrm{Al}$ and $\mathrm{Cr}$ and 10 percent of iron. The second counterpart tests were performed with 1 atm air plus $1 \mathrm{~atm}$ nitrogen atmosphere. The peak pressure rises were higher, measuring 0.25 and $0.19 \mathrm{MPa}$, respectively for the $1: 10$ and 1:40 scale facilities. Metal oxidation corresponded to 100 percent $\mathrm{Al}$ and $\mathrm{Cr}$ plus 21 percent Fe. Test visualization showed a burn occurring as the corium plume exited the cavity. The third counterpart tests were performed with an air/nitrogen atmosphere plus initial hydrogen corresponding to $\sim 50$ percent in-vessel zircaloy oxidation. It amounted to $\sim 2$ vol. $\%$ hydrogen in the containment atmosphere. The peak pressure rises were 0.28 and $0.25 \mathrm{MPa}$, respectively, for the 1:10 and 1:40 scale tests. It was deduced that the early-time hydrogen generation involved in the burn at the cavity exit was about the same as the previous test, and that additional long-term oxidation occurred after the $\mathrm{DCH}$ processes were completed. The final metal oxidation corresponds to 100 percent $\mathrm{Al}$ and $\mathrm{Cr}$ and 26 percent of the iron. Also, it was 
deduced that the preexisting hydrogen played essentially no role since all the burning occurred in the plume as it left the cavity.

In general, these counterpart tests show that scale has practically no effect on pressurization when only debris-gas heat transfer and oxidation are involved. When hydrogen burning is significant, there is some increase with scale. This independence of scale may be explained by the dominant role of heat transfer and chemical interaction processes occurring in the cavity. Test measurements indicated that the gas temperature had increased to nearly that of the debris at the exit of the cavity. Moreover, gas sampling indicated that hydrogen made up 30-60 vol. \% of the noncondensible gases at the cavity exit, indicating a large amount of oxidation in the cavity. Hence, a major portion of the DCH load is attributable to thermal and chemical interaction in the cavity which appears to be essentially insensitive to scale over the range of counterpart scales employed.

Test results also showed that debris dispersion was very similar for the two scales. In all cases, $>90$ percent of available melt was ejected from the vessel into the cavity. The percent sweepout from the cavity ranged from 70 to 80 percent at 1:40 scale and from 60 to 80 percent at 1:10 scale. Essentially all the sweptout debris was retained in the subcompartments. Only 4-18 percent reached the dome region at 1:40 scale versus 9-14 percent at 1:10 scale. Representative particle sizes were $0.4-1.0 \mathrm{~mm}$ at $1: 40$ scale versus $0.4-1.7 \mathrm{~mm}$ at $1: 10$ scale.

Other tests in the IET series demonstrated that using $\mathrm{CO}_{2}$ in the initial atmosphere $(0.05$ $\mathrm{MPa}$ air, $0.15 \mathrm{MPa} \mathrm{CO}_{2}$ at 1:10 scale) prevented hydrogen from burning, and that small amounts of water on the subcompartment floor had little impact on DCH loads (1:10 scale).

The ANL $U$ tests were run as a counterpart to the ANL IET tests. The ANL U tests employed a fully prototypic uranium-based melt instead of the more commonly used $\mathrm{Fe} / \mathrm{Al}_{2} \mathrm{O}_{3}$ thermite. The efficiency of DCH interactions was found to be insensitive to differences in melt composition.

\section{B.4.4 SNL TDS Tests}

The technology development tests (TDS) were performed by SNL to perfect experimental techniques employing steam as a driving gas for high-pressure melt ejection (Allen et al. 1994b). 
Seven tests were conducted with 1:10 scale mockups of the Surry cavity. Tests were conducted in the Surtsey facility without any attempt to model subcompartment structures.

The efficiency of DCH processes showed a weak dependence on the initial atmosphere pressures in the range of $0.09-0.23 \mathrm{MPa}$. Measurements of hydrogen production during the DCH event are particularly useful because the atmosphere was inert, the prototypic melt simulants were ejected by steam driving gas, and there was no water in the system.

\section{B.4.5 SNL LFP Tests}

The SNL LFP tests were conducted in the Surtsey facility and included a 1:10 scale mockup of the Surry reactor cavity (Allen et al. 1991b). The distinguishing feature here is that containment compartmentalization was approximated by placing. a simple concrete slab over the cavity exit. The slab divided the Surtsey vessel into an upper dome and a subcompartment. Flow paths around the edge of the slab allowed subcompartment gases to freely communicate with the dome, but most of the debris dispersed from the cavity was trapped beneath the slab.

The concrete slab was placed at distances of $1 \mathrm{~m}, 2 \mathrm{~m}$, and $8 \mathrm{~m}$ above the cavity exit in various tests. The $8 \mathrm{~m}$ position represented an essentially open Surtsey vessel without any intervening subcompartment structure. DCH interactions were most efficient in this open geometry. The efficiency of DCH interactions was not strongly dependent on variations in slab positions between $1 \mathrm{~m}$ and $2 \mathrm{~m}$. These tests provided experimental evidence that DCH interactions were largely dominated by cavity phenomena and that subcompartment mitigation of DCH loads was important.

The tests were conducted with RPV holes equivalent to sizes between $0.4 \mathrm{~m}$ and $0.8 \mathrm{~m}$ at full scale. DCH loads were found to be very weakly dependent on hole sizes over this range.

\section{B.4.6 SNL WC Tests}

The SNL water cavity (WC) tests were conducted by SNL in the Surtsey facility and included a 1:10 scale mockup of the Zion reactor cavity (Allen et al. 1992a, 1992b). Subcompartment structures were not modeled. Counterpart experiments (WC-1 and WC-2) were conducted with and without small levels of water in the cavity. DCH loads were insensitive to 
the addition of condensate levels of water in the cavity and some additional hydrogen was produced. Additional counterpart experiments (WC-1 and WC-3) showed that DCH loads were insensitive to variations in RPV hole size over the range $0.4 \mathrm{~m}$ to $1.0 \mathrm{~m}$ full-scale equivalent, although some additional hydrogen was produced with the larger hole.

\section{B.4.7 SNL IET-Surry Tests}

These tests were conducted by SNL in the 1:5.75 scale containment technology test facility (Blanchat et al. 1994). Scaled Surry cavity and subcompartment structures were modeled. Tests were conducted with fully prototypic air-steam-hydrogen atmospheres. DCH-produced hydrogen burned as a jet when it vented to the upper dome. Autoignition (i.e., sudden volumetric combustion of all preexisting hydrogen in the containment atmosphere) was not observed despite a measured (bulk) dome temperature of $1100 \mathrm{~K}$. However, hydrogen combustion over a longer time scale was observed. One proposed explanation (Pilch et al. 1994) for the lack of autoignition is that stratification and separation of hot combustion products (from burning jet) and the preexisting atmosphere prevented combustion on the time scale of peak containment pressurization. Enhanced pressurization in SNL IET-11 was attributed to significant debris dispersal through an annular gap around the RPV, which was simulated in this test, and to enhanced hydrogen combustion.

\section{B.4.8 FAI DCH Tests}

These tests were conducted in a 1:20 scale Zion geometry (Henry et al. 1991). Iron thermite at a temperature of about $2400 \mathrm{~K}$ was used to represent the core debris. The tests were performed with grossly overscaled melt mass to account for the greater propensity for debris to freeze on structure walls in scaled experiments.

Four experiments comprised the test matrix. The first three were performed with nitrogen and the fourth with steam as the pressurizing medium. The experiments included tests with a dry reactor cavity, a thin layer of water $(-1 \mathrm{~cm})$ in the cavity, and half-filled cavity. Water was on the simulated lower compartment floor for all tests.

The mitigative nature of subcompartment structures was clearly demonstrated in the experiments. Virtually no direct heating of the atmosphere was seen in the tests (less than 3 
percent efficient). The major pressurization mechanism observed was rapid steam generation from dynamic interactions between the molten debris and water within the reactor cavity and on the lower compartment floor.

\section{B.5 Separate-Effects Tests}

DCH separate-effects tests have been conducted at Purdue University to study the detailed mechanisms of debris entrainment in a reactor cavity and of trapping in a subcompartment (Ishii et al. 1993). The separate-effects tests are carefully designed simulation experiments using water-air and woods metal-air in a 1/10 linear scale model of the Zion-like geometry. Water or woods metal is used to simulate molten core material and air is used to simulate steam in a high-pressure melt ejection (HPME) event. The combination of water-air and woods metal-air as working fluid gives a unique database over broad parametric ranges that can be used with the integral-effects test (SNL/ANL) results to develop reliable mechanistic models and correlations for debris transport in the cavity and subcompartment and into the containment upper dome which could be used by CONTAIN.

The choice of the 1/10 linear scale model for the cavity and subcompartment was based on two considerations. The first was the relation of the prototype scale of the existing standard database for liquid entrainment and droplet size. Since most of the annular flow data were taken in a system having a hydraulic diameter around 2 to $3 \mathrm{~cm}$, the scale ratio to the prototype is about $1 / 100$. The present $1 / 10$ linear scale model increases the scale ratio by a factor of 10 . The property scale base can be significantly broadened by using water as well as the woods metal, which has hydrodynamic properties very similar to those of molten corium. When the existing models are improved by the use of these data, the scaling reliability will increase significantly. The second consideration is a scale relation to the integral-test database. The most extensive integral-test data were obtained by SNL in the $1 / 10$-scale Surtsey facility. Thus, using the same linear scale, the separate-effect results can be compared directly with those for the integral tests.

The air-water simulation experiments have been completed. Experiments performed included break flow that was scaled to a final ablated hole diameter of $0.35 \mathrm{~m}$ in the reactor pressure vessel lower head. The liquid film transport mechanism, entrainment process and subcompartment trapping mechanism have been measured by hot film probes, resistivity-based 
film thickness probes, pitot tubes, isokinetic droplet sampling probes, and several pressure transducers. It was observed that the entrainment process was rather rapid $(\sim 0.2)$ and about half of the liquid that remained in the cavity at the time of gas blowdown was entrained as small droplets. The rest of the liquid was transported out as a liquid film. Prior to the gas discharge, about 15 percent of the liquid came out by its own inertia. Thus, approximately 46 percent of the liquid became droplets in the cavity. The volume median droplet size was in the range of 0.2 to $0.6 \mathrm{~mm}$, depending on the location and time. Approximately 3 percent of the water discharged into the cavity was transported to the upper dome section through the seal table room holes and exhaust holes. If heat transfer and chemical effects are taken into account, the fraction transported to the upper dome section is comparable to those observed in the SNL IET-1R test (Allen et al. 1992c). The rest of the liquid was initially deflected into horizontal directions by the bottom of the seal table room. The impingement and flow diversion into the horizontal plane was very effective in trapping the liquid in the subcompartment. After this impingement and flow diversion, smaller droplets were lifted up by the continuous gas flow and carried over to the dome section. However, this process was limited to very small droplets. Most of the liquid subsequently fell on the floor of the subcompartment and formed a thick film.

\section{B.6 References}

Allen, M.D. et al. (1990). A Demonstration Experiment of Steam-Driven, High-Pressure Melt Ejection: The HIPS-10S Test, NUREG/CR-5373, SAND89-1135, Sandia National Laboratories, Albuquerque, NM.

Allen, M.D. et al. (1991a). Experimental Results of Direct Containment Heating by HighPressure Melt Ejection into the Surtsey Vessel: The DCH-3 and DCH-4 Tests, SAND90-2138, Sandia National Laboratories, Albuquerque, NM.

Allen, M.D. et al. (1991b). Experiments to Investigate the Effect of Flight Path on Direct Containment Heating (DCH) in the Surtsey Test Facility: The Limited Flight Path (LFP) Tests, NUREG/CR-5728, SAND91-1105, Sandia National Laboratories, Albuquerque, NM.

Allen, M.D. et al. (1992a). Experiments to Investigate the Effect of Water in the Cavity on Direct Containment Heating (DCH) in the Surtsey Test Facility - The WC-1 and WC-2 Tests, SAND91-1173, Sandia National Laboratories, Albuquerque, NM.

Allen, M.D. et al. (1992b). Experimental Results of Tests to Investigate the Effects of Hole Diameter Resulting from Bottom Head Failure on Direct Containment Heating (DCH) in the Surtsey Test Facility - The WC-1 and WC-3 Tests, SAND91-2153, Sandia National Laboratories, Albuquerque, NM. 
Allen, M.D. et al. (1992c). Experiments to Investigate the Effects of 1:10 Scale Zion Structures on Direct Containment Heating (DCH) in the Surtsey Test Facility: The IET-1 and IET-1R Tests, SAND92-0255, Sandia National Laboratories, Albuquerque, NM.

Allen, M.D. et al. (1992d). The Third Integral Effects Test (IET-3) in the Surtsey Test Facility, SAND92-0166, Sandia National Laboratories, Albuquerque, NM.

Allen, M.D. et al. (1992e). The Effects of Condensate Levels of Water on Direct Containment Heating (DCH) in Zion-Like Geometry: The Fourth Integral Effects Test (IET-4) Conducted in the Surtsey Test Facility, SAND92-1241, Sandia National Laboratories, Albuquerque, NM.

Allen, M.D. et al. (1992f). Experimental Results of an Integral Effects Test in a Zion-Like Geometry to Investigate the Effects of a Classically Inert Atmosphere on Direct Containment Heating: The IET-5 Experiment, SAND92-1623, Sandia National Laboratories, Albuquerque, NM.

Allen, M.D. et al. (1992g). An Integral Effects Test in a Zion-Like Geometry to Investigate the Effects of Preexisting Hydrogen on Direct Containment Heating in the Surtsey Test Facility - The IET-6 Experiment, SAND92-1802, Sandia National Laboratories, Albuquerque, NM.

Allen, M.D. et al. (1992h). An Integral Effects Test to Investigate the Effects of Condensate Levels of Water and Preexisting Hydrogen on Direct Containment Heating in the Surtsey Test Facility - The IET-7 Experiment, SAND92-2021, Sandia National Laboratories, Albuquerque, NM.

Allen, M.D. et al. (1993). Experiments to Investigate the Effects of Fuel/Coolant Interactions on Direct Containment Heating: The IET-8A and IET-8B Experiments, SAND92-2849, Sandia National Laboratories, Albuquerque, NM.

Allen, M.D. et al. (1994a). Experimental Results of Integral Effects Tests with Zion-Like Structures to Investigate Direct Containment Heating, NUREG/CR-6044, SAND93-1049, Sandia National Laboratories, Albuquerque, NM.

Allen, M.D. et al. (1994b). Test Results on Direct Containment Heating by High-Pressure Melt Ejection into the Surtsey Vessel: The TDS Test Series, SAND91-1208, Sandia National Laboratories, Albuquerque, NM.

Binder, J.L. et al. (1992a). Quick Look Data Report on the Integral Effects Test $1 R$ in the Corexit Facility at Argonne National Laboratory, draft for review, Argonne National Laboratory, Argonne, IL.

Binder, J.L. et al. (1992b). Quick Look Data Report on the Integral Effects Test 1RR in the Corexit Facility at Argonne National Laboratory, draft for review, Argonne National Laboratory, Argonne, IL. 
Binder, J.L. et al. (1992c). Quick Look Data Report on the Integral Effects Test-3 in the Corexit Facility at Argonne National Laboratory, draft for review, Argonne National Laboratory, Argonne, IL.

Binder, J.L. et al. (1992d). Quick Look Data Report on the Integral Effects Test-6 in the Corexit Facility at Argonne National Laboratory, draft for review, Argonne National Laboratory, Argonne, IL.

Binder, J.L. et al. (1992e). Quick Look Data Report on the Integral Effects Test-7 in the Corexit Facility at Argonne National Laboratory, draft for review, Argonne National Laboratory, Argonne, IL.

Binder, J.L. et al. (1992f). Quick Look Data Report on the Integral Effects Test-8 in the Corexit Facility at Argonne National Laboratory, draft for review, Argonne National Laboratory, Argonne IL.

Binder, J.L. et al. (1994). Direct Containment Heating Integral Effects Tests at 1/40 Scale in Zion Nuclear Power Plant Geometry, NUREG/CR-6168, ANL-94/18, Argonne National Laboratory, A Argonne, IL.

Blanchat, T.K. et al. (1994). Experiments to Investigate Direct Containment Heating Phenomena with Scaled Models of the Surry Nuclear Power Plant, NUREG/CR-6152, SAND932519, Sandia National Laboratories, Albuquerque, NM.

Chun, M.H. et al. (1991). "A Parametric Study of the High Pressure Melt Ejection from Two Different Scale Reactor Cavity Models," Int. Con. Heat Mass Trans., Vol. 18, pp. 619-628.

Fauske and Associates (1985). Technical Support for Issue Resolution, IDCOR, Technical Report 85.2, Fauske and Associates, Inc., Burr Ridge, IL.

Henry, R.E. et al. (1991). "Direct Containment Heating Experiments in a Zion-Like Geometry," 26th National Heat Transfer Conference, AIChE Symposium Series 283, Vol. 89, p. 86-98, Minneapolis, MN.

Ishii, M. et al. (1993). Separate Effects Experiments on Phenomena of Direct Containment Heating - Air-Water Simulation Experiments in Zion Geometry, PU NE-93/1, Purdue University, West Lafayette, IN.

Kim, M. et al. (1992). "Experimental Study on Direct Containment Heating Phenomena," in ANS Winter Meeting, Chicago, $\Pi$.

Macbeth, R.W., and R. Trenberth (1987). Experimental Modelling of Core Debris Dispersion from the Vault Under a PWR Pressure Vessel - Part 1. "Preliminary Experimental Results," AEEW-R1888, UK Atomic Energy Authority, AEE Winfrith, UK. 
Macbeth, R.W. et al. (1988). Experimental Modelling of Core Debris Dispersion from the Vault Under PWR Pressure Vessel - Part 3. "Results of Varying the Size Scaling Factor of the Model Use," AEEW-R2426, UK Atomic Energy Authority, AEE Winfrith, UK.

Pilch, M., and M.D. Allen (1991). A Scaling Methodology for Direct Containment Heating with Application to the Design and Specification of an Experiment Program, SAND91-2784, Sandia National Laboratories, Albuquerque, NM.

Pilch, M., and R.O. Griffith (1992). Gas Blowthrough and Flow Quality Correlations for Use in the Analysis of High Pressure Melt Ejection (HPME) Events, SAND91-2322, Sandia National Laboratories, Albuquerque, NM.

Pilch, M., and W.W. Tarbell (1985). High Pressure Ejection of Melt from a Reactor Pressure Vessel: The Discharge Phase, NUREG/CR-4383, SAND85-0012, Sandia National Laboratories, Albuquerque, NM.

Pilch, M. et al. (1988). The Influence of Selected Containment Structures on Debris Dispersal and Transport Following High Pressure Melt Ejection from the Reactor Vessel, NUREG/CR4914, SAND87-0940, Sandia National Laboratories, Albuquerque, NM.

Pilch, M. et al. (1994). The Probability of Containment Failure by Direct Containment Heating in Zion, NUREG/CR-6075, SAND93-1535, Sandia National Laboratories, Albuquerque, NM.

Rose, P.W. (1987). Experimental Modeling of Core Debris Dispersion from the Vault Under a PWR Pressure Vessel - Part 2. Results of Including the Instrument Tubes Support Structure in the Experiment, AEEW-R2143, UK Atomic Energy Authority, AEE Winfrith, UK.

Sharon, A. et al. (1992). "Direct Containment Heating Experiments for the CE Owners Group," Proc. 20th Water Reactor Safety Meeting, Bethesda, MD.

Spencer, B.W. et al. (1982). Sweepout Thresholds in Reactor Cavity Interactions, ANL/LWR/SAF 82-1, Argonne National Laboratory, Argonne, IL.

Spencer, B.W. et al. (1983a). "Phenomenological Investigations of Cavity Interactions Following Postulated Vessel Meltthrough," Proceedings of the International Meeting on Thermal Nuclear Reactor Safety, Chicago, IL, 2, NUREG/CR-0027, U.S. Nuclear Regulatory Commission, Washington, DC, p. 923.

Spencer, B.W. et al. (1983b). Hydrodynamics Aspects of Ex-Vessel Debris Dispersal in ZionType Containment Design, ANL/LWR/SAF 83-1, Argonne National Laboratory, Argonne, IL.

Spencer, B.W. et al. (1983c). "Corium/Water Dispersal Phenomena in Ex-Vessel Cavity Interactions," Proceedings of the International Meeting on Light Water Reactor Severe Accident Evaluation, Cambridge, MA, 2, American Nuclear Society, La Grange Park, IL, p. 15.5-1. 
Spencer, B.W. et al. (1984). Hydrodynamic Sweepout Thresholds in BWR Mk III Lower Drywell Interactions, ANL/LWR/SAF 84-1, Argonne National Laboratory, Argonne, IL.

Spencer, B.W. et al. (1987). Hydrodynamics and Heat Transfer Aspects of Corium/Water Interactions, EPRI-NP-5127, Electric Power Research Institute, Palo Alto, CA.

Spencer, B.W. et al. (1988). Results of EPRI/ANL DCH Investigations and Model Development, International ENS/ANS Conference on Thermal Reactor Safety, Vol. 5, p. 314, Avignon, France.

Tarbell, W.W. et al. (1983). "High Pressure Melt Ejection," in Proc. Eleventh Water Reactor Safety Mtg., Vol. 3, Gaithersburg, MD.

Tarbell, W.W. et al. (1987). Results from the DCH-1 Experiment, NUREG/CR-4871, SAND862483, Sandia National Laboratories, Albuquerque, NM.

Tarbell, W.W. et al. (1988). DCH-2: Results from the Second Experiment Performed in the Surtsey Direct Heating Test Facility, NUREG/CR-4917, SAND87-0976, Sandia National Laboratories, Albuquerque, NM.

Tarbell, W.W. et al. (1991). Pressurized Melt Ejection Into Water Pools, NUREG/CR-3916, SAND84-1531, Sandia National Laboratories, Albuquerque, NM.

Technical Program Group (1991). An Integrated Structure and Scaling Methodology for Severe Accident Technical Issue Resolution, NUREG/CR-5809, EGG-2659, EG\&G Idaho, Inc., Idaho Falls, ID.

Tutu, N.K. et al. (1988a). Debris Dispersal from Reactor Cavities During High Pressure Melt Ejection Accident Scenarios, NUREG/CR-5146, BNL-NUREG-52147, Brookhaven National Laboratory, Upton, NY.

Tutu, N.K. et al. (1988b). "Low Pressure Cutoff for Melt Dispersal from Reactor Cavities," Fourth Proc. of Nuclear Thermal Hydraulics, 29-37.

Tutu, N.K. (1990). Melt Dispersal Characteristics of the Watts Bar Cavity, Technical Report A-3024, Brookhaven National Laboratory, Upton, NY.

Tutu, N.K., and T. Ginsberg (1990). "The Results of Melt Dispersal Experiments with Surry and Zion Cavity Models," Letter Report, Brookhaven National Laboratory, NY.

ZPSS (1981). Zion Probabilistic Safety Study, Commonwealth Edison Co., Chicago, IL. 
Table B.1 Survey of DCH-relevant experiments

\begin{tabular}{||c|c|c|c|c||}
\hline Experiment Series & $\begin{array}{c}\text { Number } \\
\text { of Tests }\end{array}$ & $\begin{array}{c}\text { Nominal } \\
\text { Scale }\end{array}$ & $\begin{array}{c}\text { Cavity } \\
\text { Type }\end{array}$ & Water \\
\hline \hline $\begin{array}{c}\text { SNL/DCH } \\
\text { (Tarbell et al. 1987, 1988; } \\
\text { Allen et al. 1991a) }\end{array}$ & 4 & $1: 10$ & Zion & None \\
\hline $\begin{array}{c}\text { SNL/TDS } \\
\text { (Allen et al. 1994b) }\end{array}$ & 7 & $1: 10$ & Surry & None \\
\hline $\begin{array}{c}\text { SNL/LFP } \\
\text { (Allen et al. 1991b) }\end{array}$ & 6 & $1: 10$ & Surry & None \\
\hline $\begin{array}{c}\text { SNL/WC } \\
\text { (Allen et al. 1992a, 1992b) }\end{array}$ & 3 & $1: 10$ & Zion & $\begin{array}{c}\text { None } \\
\text { Cavity }\end{array}$ \\
\hline $\begin{array}{c}\text { SNL/IET-Zion } \\
\text { (Allen et al. 1992c, 1992d, } \\
\text { 1992e, 1992f, 1992g, 1992h, } \\
\text { 1993a, 1994a) }\end{array}$ & 9 & $1: 10$ & Zion & $\begin{array}{c}\text { Cavity } \\
\text { Cavity/Basement }\end{array}$ \\
\hline $\begin{array}{c}\text { SNL/IET-Surry } \\
\text { (Blanchat et al. 1994) }\end{array}$ & 3 & $1: 5.75$ & Surry & $\begin{array}{c}\text { None } \\
\text { Cavity/Basement }\end{array}$ \\
\hline $\begin{array}{c}\text { ANL/CWTI } \\
\text { (Spencer et al. 1987) }\end{array}$ & 5 & $1: 30$ & Zion- & Cavity/Basement \\
\hline $\begin{array}{c}\text { ANL/IET } \\
\text { (Binder et al. 1992a, 1992b, } \\
\text { 1992c, 1992d, 1992e, 1992f) }\end{array}$ & 6 & $1: 40$ & Zion & $\begin{array}{c}\text { None } \\
\text { Cavity }\end{array}$ \\
\hline $\begin{array}{c}\text { ANL/U } \\
\text { (Binder et al. 1993a, 1993b) }\end{array}$ & 3 & $1: 40$ & Zion & None \\
\hline $\begin{array}{c}\text { FAI/DCH } \\
\text { (Henry et al. 1991) }\end{array}$ & 4 & $1: 20$ & Zion & $\begin{array}{c}\text { Basement } \\
\text { Cavity/Basement }\end{array}$ \\
\hline
\end{tabular}


Table B.1 (continued) Survey of DCH-relevant experiments

\begin{tabular}{|c|c|c|c|c|c|}
\hline $\begin{array}{l}\text { Experiment } \\
\text { Series }\end{array}$ & $\begin{array}{l}\text { Driving } \\
\text { Gas }\end{array}$ & $\begin{array}{c}\text { Driving } \\
\text { Pressure } \\
\text { (MPa) }\end{array}$ & $\begin{array}{l}\text { Melt Mass } \\
\quad(\mathrm{kg})\end{array}$ & Melt Composition & $\begin{array}{c}\text { Hole } \\
\text { Size }\end{array}$ \\
\hline SNL/DCH & $\mathrm{N}_{2}$ & $2.6-6.7$ & 20,80 & $\mathrm{Fe} / \mathrm{Al}_{2} \mathrm{O}_{3}$ & 0.06 \\
\hline SNL/TDS & $\mathrm{H}_{2} \mathrm{O}$ & $3.7-4.0$ & 80 & $\mathrm{Fe} / \mathrm{Al}_{2} \mathrm{O}_{3} / \mathrm{Cr}$ & 0.065 \\
\hline SNL/LFP & $\mathrm{H}_{2} \mathrm{O}$ & $2.5-3.6$ & 50,80 & $\mathrm{Fe} / \mathrm{Al}_{2} \mathrm{O}_{3} / \mathrm{Cr}$ & $0.04-0.09$ \\
\hline SNL/WC & $\mathrm{H}_{2} \mathrm{O}$ & $3.8-4.6$ & 50 & $\mathrm{Fe} / \mathrm{Al}_{2} \mathrm{O}_{3} / \mathrm{Cr}$ & $0.04-0.10$ \\
\hline $\begin{array}{c}\text { SNL/IET } \\
\text { Zion }\end{array}$ & $\mathrm{H}_{2} \mathrm{O}$ & $5.9-7.1$ & 43 & $\mathrm{Fe} / \mathrm{Al}_{2} \mathrm{O}_{3} / \mathrm{Cr}$ & 0.04 \\
\hline $\begin{array}{c}\text { SNL/IET } \\
\text { Surry }\end{array}$ & $\mathrm{H}_{2} \mathrm{O}$ & 12 & 158 & $\mathrm{Fe} / \mathrm{Al}_{2} \mathrm{O}_{3} / \mathrm{Cr}$ & $\begin{array}{l}0.07- \\
0.098\end{array}$ \\
\hline ANL/CWTI & $\mathrm{N}_{2}$ & $4.7-5.0$ & 4.1 & $\mathrm{UO}_{2} / \mathrm{ZrO}_{2} / \mathrm{SS}$ & 0.13 \\
\hline ANL/IET & $\mathrm{H}_{2} \mathrm{O}$ & $5.7-6.7$ & $0.72,0.82$ & $\mathrm{Fe} / \mathrm{Al}_{2} \mathrm{O}_{3} / \mathrm{Cr}$ & 0.011 \\
\hline $\mathrm{ANL} / \mathrm{U}$ & $\mathrm{H}_{2} \mathrm{O}$ & $3.0-6.0$ & 1.13 & $\mathrm{UO}_{2} / \mathrm{Zr} / \mathrm{ZrO}_{2} / \mathrm{SS}$ & 0.011 \\
\hline FAI/DCH & $\mathrm{N}_{2}, \mathrm{H}_{2} \mathrm{O}$ & $2.4-3.2$ & 20 & $\mathrm{Fe} / \mathrm{Al}_{2} \mathrm{O}_{3}$ & 0.025 \\
\hline
\end{tabular}


Table B.1 (continued) Survey of DCH-relevant experiments

\begin{tabular}{|c|c|c|c|c|}
\hline $\begin{array}{l}\text { Experiment } \\
\text { Series }\end{array}$ & $\begin{array}{c}\text { Containment } \\
\text { Pressure } \\
\text { (MPa) }\end{array}$ & $\begin{array}{l}\text { Annular } \\
\text { Gap Around } \\
\text { RPV }\end{array}$ & $\begin{array}{l}\text { Atmosphere } \\
\text { Composition }\end{array}$ & $\begin{array}{l}\text { Containment } \\
\text { Structures }\end{array}$ \\
\hline SNL/DCH & 0.08 & no & Air, Ar & Open Containment \\
\hline SNL/TDS & $0.09-0.23$ & no & Air, Ar & Open Containment \\
\hline SNL/LFP & 0.16 & no & $\mathrm{Ar}$ & $\begin{array}{c}\text { Compartmentalized } \\
\text { by Slab }\end{array}$ \\
\hline SNL/WC & 0.16 & no & $\mathrm{Ar}$ & Essentially Open \\
\hline $\begin{array}{l}\text { SNL/IET } \\
\text { Zion }\end{array}$ & 0.2 & no & $\begin{array}{c}\mathrm{N}_{2}, \mathrm{~N}_{2} / \mathrm{Air} \\
\mathrm{N}_{2} / \mathrm{Air} / \mathrm{H}_{2}, \\
\mathrm{CO}_{2} / \mathrm{Air} / \mathrm{H}_{2} \\
\end{array}$ & $\begin{array}{c}\text { Zion } \\
\text { Subcompartment } \\
\text { Structures } \\
\end{array}$ \\
\hline $\begin{array}{l}\text { SNL/IET } \\
\text { Surry }\end{array}$ & $0.13-0.19$ & $\begin{array}{c}\text { no } \\
\text { partial } \\
\text { insulation }\end{array}$ & $\mathrm{Air} / \mathrm{H}_{2} \mathrm{O} / \mathrm{H}_{2}$ & $\begin{array}{c}\text { Surry } \\
\text { Subcompartment } \\
\text { Structures } \\
\end{array}$ \\
\hline ANL/CWTI & 0.1 & no & $\mathrm{Ar}$ & $\begin{array}{c}\text { Compartmentalized } \\
\text { by Baffle }\end{array}$ \\
\hline ANL/IET & 0.2 & no & $\begin{array}{c}\mathrm{N}_{2}, \mathrm{~N}_{2} / \mathrm{Air}, \\
\mathrm{N}_{2} / \mathrm{Air} / \mathrm{H}_{2}, \\
\mathrm{H}_{2} \mathrm{O} / \mathrm{Air} / \mathrm{H}_{2} \\
\end{array}$ & $\begin{array}{c}\text { Zion } \\
\text { Subcompartment } \\
\text { Structures } \\
\end{array}$ \\
\hline $\mathrm{ANL} / \mathrm{U}$ & 0.2 & no & $\mathrm{N}_{2} / \mathrm{Air} / \mathrm{H}_{2}$ & $\begin{array}{c}\text { Zion } \\
\begin{array}{c}\text { Subcompartment } \\
\text { Structures }\end{array} \\
\end{array}$ \\
\hline FAI/DCH & 0.1 & no & $\mathrm{N}_{2}$ & $\begin{array}{c}\text { Zion (Like) } \\
\text { Subcompartment } \\
\text { Structures }\end{array}$ \\
\hline
\end{tabular}




\title{
APPENDIX C Tools for Quantification of DCH Containment Loads
}

\author{
Kenneth D. Bergeron and Martin M. Pilch \\ Sandia National Laboratories
}

This section summarizes NRC-sponsored analytical tools and calculational methodologies for quantifying containment loads in DCH events. The complex phenomena of containment pressurization during a DCH event have resulted in the development of a variety of containment analysis tools. These methodologies quantify containment loads by representing DCH at various levels of detail, ranging from simple adiabatic equilibrium methods to modeling the physics associated with individual droplets. The tools used to calculate DCH loads are listed in Table C.1, which indicates the intended application and several pertinent references for each tool. This appendix gives a brief description of each of the codes that can be used to calculate DCH loads. Each section has a description of the basic approach taken in the code to model DCH. The references in Table C.1 give more complete information.

In the DCH resolution process, it is anticipated that the two-cell equilibrium (TCE) model will be the workhorse tool used to compute DCH loads because it is simple, fast running, and has been well validated against an extensive experimental database. If more detailed calculations are required, it is anticipated that CONTAIN, the NRC's best-estimate code for containment analyses, will be used.

\section{C.1 Two-Cell Equilibrium Model}

The TCE model is an extension of early single-cell equilibrium models to account for the major effects of containment compartmentalization, which airborne debris from mixing efficiently with the entire atmosphere by confining the bulk of the debris to the subcompartment of the containment. Processes contributing to $\mathrm{DCH}$ loads include RCS blowdown, oxidation of the metallic components of debris with steam, the exchange of debris thermal energy with the blowdown gases or the containment atmosphere and the combustion of DCH-produced hydrogen and some hydrogen preexisting in the containment atmosphere prior to vessel failure.

The TCE model divides the containment into two compartments: one for the cavity and subcompartments and one for the containment upper dome. DCH-governing phenomena (debris- 
gas heat transfer and debris oxidation) are assumed to proceed independently to equilibrium in the two volumes. Therefore, the calculated loads are equal to the sum of the energy given up in the two compartments. The debris ejected from the RPV and dispersed from the cavity is partitioned between the subcompartment and dome to account for flow paths where the debris is carried to the containment upper dome without interacting significantly with the subcompartment, e.g., through the RPV annular gap. Debris dispersed into the subcompartment equilibrates predominantly with blowdown steam that is coherent with the dispersal process, while debris dispersed to the dome equilibrates predominantly with the dome atmosphere.

DCH-produced hydrogen can burn as a hot hydrogen jet as it vents to the upper dome. Preexisting hydrogen in the containment atmosphere can burn as a deflagration (if the appropriate conditions exist) or as an autoignition event if DCH heats the atmosphere sufficiently. The energy released from possible deflagrations contributes to enhanced DCH loads only if the combustion rate exceeds the heat transfer rate to structures.

TCE avoids predicting overly conservative loads by taking into account mitigating processes. This includes (1) accounting for the limited amount of hydrogen combustion that occurs on DCH time scales, (2) confining most of the debris dispersed from the cavity to the subcompartment, and (3) limiting the amount of water and blowdown steam participating in DCH (called the coherence ratio). The TCE model provides models for the coherence ratio, the fraction of debris transported to the dome, and the extent of hydrogen combustion on DCH time scales.

Calculations of loads in DCH experiments with the TCE model have been very encouraging (Pilch et al. 1994) (see Figure C.1). These validation results, together with the simplicity of use of the TCE model, have resulted in the selection of this model as the workhorse analytical tool in applying the $\mathrm{DCH}$ resolution process to the Zion and Surry plants.

\section{C.2 Convection-Limited Containment Heating (CLCH) Model}

The CLCH model takes an approach to quantifying DCH loads similar to that taken by the TCE model. Like TCE, the CLCH model divides the containment into two compartments, and treats the phenomena governing DCH loading in these compartments independently. The major feature mitigating DCH loads is the implicit assumption that debris is quickly trapped in the subcompartment. CLCH considers a flow process in which the melt comes to thermal and 
chemical equilibrium as it becomes entrained and swept out of the cavity by the portion of the blowdown steam that is coherent with the dispersal process. This rate-limiting process is similar to the coherent steam argument of the TCE. DCH-produced hydrogen is assumed to transport to the dome, where it burns as a diffusion flame. Combustion of preexisting hydrogen can occur as an autoignition event if DCH heats the dome sufficiently. Heat losses to structures are not considered.

\section{C.3 CONTAIN Code}

The CONTAIN code (Murata et al., 1989) has for many years played an important role in a variety of the NRC's programs addressing DCH. The earliest studies (Bergeron et al., 1986, Williams et al. 1987) combined CONTAIN's mechanistic models for gas flow and heat transfer between the atmosphere and structures with rather simplistic and parametric treatments of DCH phenomena. As the research program has yielded better understanding, the models in CONTAIN have been improved, generally becoming more mechanistic. However, key phenomena remain uncertain, and as a result, the current version of CONTAIN (i.e., the one used in Appendix $G$ of this report) offers the analyst a variety of modeling options for the most uncertain phenomena. A brief review of the evolution of CONTAIN DCH models is provided in the introduction to Appendix $\mathrm{G}$, along with a comparison of models and calculations between CONTAIN and TCE. A detailed discussion of the CONTAIN DCH models is provided in Washington (1994). Here only the basic concepts are summarized.

CONTAIN allows the analyst to subdivide the containment into any number of nodes or cells, each of which consists of a well-mixed repository of gases (the atmosphere) as well a number of solid heat transfer structures which exchange heat with the atmosphere through an appropriate array. of heat transfer correlations. The cell atmospheres are arranged in a userspecified network of flow paths which allow pressure-driven gas flow. Cells can also contain a liquid pool, and the user can specify flow paths between pools as well (though this option is seldom used for DCH calculations). When conditions in the cell atmospheres satisfy certain criteria, combustion of hydrogen can occur, either as a global deflagration or as a diffusion flame at the entrance to a cell.

The key element of DCH calculations is to treat the suspended molten debris as a field of uniformly dispersed particles in the atmosphere, transferring heat through appropriate heat 
transfer correlations and reacting chemically with oxygen and steam in the atmosphere, with corresponding mass transfer correlations. Debris is injected into the atmosphere via userspecified, time-dependent tables, which may specify a number of different debris particle sizes. Debris in the atmosphere can flow from one cell to another, with the debris velocity relative to the gas flow velocity controlled by user-specified slip factors.

Debris is removed from the atmosphere by trapping models, a variety of which are provided for the user's choice. The high degree of uncertainty in phenomena involving deentrainment of molten debris particles from the atmosphere is reflected in the range of user-selected models. The most simple of these is a user-specified residence time. A slightly less arbitrary option is the gravitational fall time (GFT) model, which sets the residence time equal to the time such a particle would take to fall the height of the cell. Another simple model is the time-of-firstimpact (TFI) trapping model, which is based on the concept that the debris is deentrained on the first heat transfer structure it encounters on entering the cell. For situations in which reentrainment is an important process, another model is available that combines a time-of-flight ballistic treatment with a reentrainment model based on a Kutateladze correlation for entrainment of liquid films into a shear gas flow (this option is abbreviated TOF-KU).

Chemical reactions in the atmosphere and the particles are very important to $\mathrm{DCH}$, and are also subject to significant uncertainties. As with trapping, CONTAIN offers a range of modeling options, allowing the user to explore the effects of different assumptions within the range of physical uncertainties. The rate of oxidation of metallic debris species by either steam or oxygen in the atmosphere is limited by both droplet-side and gas-side diffusion at the surface of debris particles. Another option allows the user to specify that the debris can mediate the recombination of hydrogen and oxygen in the atmosphere, even when conditions are not appropriate for bulk combustion. Finally, these chemical interactions are not limited to airborne debris, since there may be considerable exposure of the surface area of trapped or pooled molten debris to atmospheric gases or blowdown steam. Again, the user specifies the extent of these interactions through input to the code.

The wide variety of modeling options that are available to the user is valuable to the analyst wishing to explore the full range of uncertainty in phenomena. However, considerable experience has been obtained through sensitivity studies and comparison of the code against experiments (e.g., see Figure C-2). Out of this experience has evolved a "CONTAIN DCH 
analysis methodology" that embodies a much narrower range of code options, such as specific model choices and parameters that have been found to give good agreement with experiments (Williams et al., 1994). This methodology is discussed in more detail in Appendix G.

\section{C.4 References}

Bergeron, K.D. et al. (1986). "Development and Applications of the Interim Direct Containment Heating Model for the CONTAIN Computer Code," Transactions of the 14th Water Reactor Safety Information Meeting, Gaithersburg, MD.

Gido, R.G. et al. (1991). PWR Dry Containment Parametric Studies, NUREG/CR-5630, SAND90-2339, Sandia National Laboratories, Albuquerque, NM.

Gido, R.G. et al. (1992). "Burn Modeling Improvements for the CONTAIN Code, Change Document 96, Update C110T," Dept. 6429, Sandia National Laboratories, Albuquerque, NM.

Kmetyk, L.N. (1993). MELCOR 1.8.2 Assessment: IET Direct Containment Heating Tests, SAND93-1475, Sandia National Laboratories, Albuquerque, NM.

Kmetyk, L.N. (1994). MELCOR 1.8.2 Assessment: Surry PWR TMLB' (with a DCH Study), SAND93-1899, Sandia National Laboratories, Albuquerque, NM.

Marx, K.O. (1989). "A Computer Model for the Transport and Chemical Reaction of Debris in Direct Containment Heating Experiments," Nucl. Science \& Eng., p. 102.

Murata, K.K. (1992). "C1105 Code Change Document," Dept. 6429, April 1992; Attachment: K.E. Washington, "The CONTAIN DCH Trapping Model," Sandia National Laboratories, Albuquerque, NM.

Murata, K.K. et al. (1989). User's Manual for CONTAIN 1.1, A Computer Code for Severe Nuclear Reactor Accident Containment Analysis, NUREG/CR-5026, SAND87-2309, Sandia National Laboratories, Albuquerque, NM.

Pilch, M. (1992a). "Adiabatic Equilibrium Models for Direct Containment Heating," Proceedings of the Nineteenth Water Reactor Safety Information.Meeting, NUREG/CR-0119, US Nuclear Regulatory Commission, Washington, DC.

Pilch, M. (1992b). "Kinetic Limitations to Adiabatic Equilibrium Models for Direct Containment Heating," 28th ASME National Heat Transfer Conference, Vol. 88, No. 288.

Pilch, M., and R.O. Griffith (1992). Gas Blowthrough and Flow Quality Correlations for Use in the Analysis of High Pressure Melt Ejection (HPME) Events, SAND91-2322, Sandia National Laboratories, Albuquerque, NM. 
Pilch et al. (1994). The Probability of Containment Failure by Direct Containment Heating in Zion, NUREG/CR-6075, SAND93-1535, Sandia National Laboratories, Albuquerque, NM.

Summers, R.M. (1995). MELCOR Reference Manual, NUREG/CR-6119, SAND93-2185, Sandia National Laboratories, Albuquerque, NM.

Sweet, D.W. et al. (1991). Further Development of the KIVA-DCH Code for the Analyses of the Transport and Chemical Reaction of Molten Debris on Direct Containment Heating Experiments, SAND90-2535, Sandia National Laboratories, Albuquerque, NM.

Tarbell, W.W. et al. (1988). "Direct Containment Heating and Aerosol Generation During High Pressure Melt Ejection Experiments," in Proceedings of the ANS/ENS Winter Meeting, T.M. Overson, Washington, DC.

Theofanous, T.G., and H. Yan (1993). "The Prediction of Direct Containment Heating," Proceedings of the National Heat Transfer Conference, Atlanta, GA.

Washington, K.E. (1993). "C110U Code Change Document: Description of the Direct Containment Heating Model in the CONTAIN Code," Dept. 6429, Sandia National Laboratories, Albuquerque, NM.

Washington, K.E. (1994). Direct Containment Heating Models in the CONTAIN Code, SAND94-1073, Sandia National Laboratories, Albuquerque, NM.

Washington, K.E., and R.O. Griffith (1990). "CONTAIN Direct Containment Heating User's Manual and Reference Manual Change Document," (C1100 and CNOP Code Change Document) Dept. 6429, Sandia National Laboratories, Albuquerque, NM.

Williams, D.C. (1991). "DHEAT2: A Computer Code for Adiabatic Analyses of Hydrogen Burns, Direct Containment Heating, and Metal Oxidation Events," Internal Memorandum, Sandia National Laboratories, Albuquerque, NM.

Williams, D.C. (1992). "Posttest CONTAIN Calculations for the First Integral Effects Experiment (IET-1) at the Surtsey DCH Facility," (Draft) Letter Report transmitted with letter from D.C. Williams to A. Notafrancesco.

Williams, D.C., and J.J. Gregory (1990). Mitigation of Direct Containment Heating and Hydrogen Combustion Events in Ice Condenser Plants, NUREG/CR-5586, SAND90-1102, Sandia National Laboratories, Albuquerque, NM.

Williams, D.C., and D.L.Y. Louie (1988). "CONTAIN Analyses of Direct Containment Heating Events in the Surry Plant," Proceedings of the ANS/ENS Winter Meeting, Thermal Hydraulics Division, Washington, DC. 
Williams, D.C. et al. (1987). Containment Loads Due to Direct Containment Heating and Associated Hydrogen Behavior: Analysis and Calculations with the CONTAIN Code, NUREG/CR-4896, SAND87-0633, Sandia National Laboratories, Albuquerque, NM.

Williams, D.C. et al. (1994). Assessment of the CONTAIN Direct Containment Heating (DCH) Model, SAND94-1174, Sandia National Laboratories, Albuquerque, NM. 
Table C.1 Summary of major NRC-developed DCH analysis methodologies and codes

\begin{tabular}{|c|c|c|c|}
\hline $\begin{array}{c}\text { DCH Analysis } \\
\text { Methodologies/Codes }\end{array}$ & Intended Applications & Model/Code References & Analysis References \\
\hline DHEAT2 & Bound loads & (Williams 1991) & \\
\hline 1-Cell Equilibrium & $\begin{array}{l}\text { Bound loads } \\
\text { Scaling }\end{array}$ & (Pilch 1992a) & (Pilch 1992a) \\
\hline $\begin{array}{l}\text { 2-Cell } \\
\text { - Equilibrium* } \\
\text { - Kinetic }\end{array}$ & $\begin{array}{l}\text { Approximate loads } \\
\text { Scaling } \\
\text { Experiment analysis } \\
\text { Extrapolation }\end{array}$ & $\begin{array}{c}\text { (Pilch 1992b) } \\
\text { (Pilch et al. 1994) }\end{array}$ & (Pilch et al. 1994) \\
\hline $\begin{array}{l}\text { Convection Limited } \\
\text { Containment } \\
\text { Heating }^{*}\end{array}$ & $\begin{array}{l}\text { Approximate loads } \\
\text { Experiment analysis } \\
\text { Extrapolation }\end{array}$ & $\begin{array}{c}\text { (Pilch et al. 1994) } \\
\text { (Theofanous and Yan 1993) }\end{array}$ & $\begin{array}{c}\text { (Pilch et al. 1994) } \\
\text { (Theofanous and Yan 1993) }\end{array}$ \\
\hline $\begin{array}{l}\text { CONTAIN } \\
-1.12 \text { w/ CORDE } \\
-1.12 \mathrm{Multifield}^{*} \\
-1.2 \mathrm{TBD}^{*}\end{array}$ & $\begin{array}{l}\text { Best-estimate loads } \\
\text { Experiment analysis } \\
\text { Extrapolation } \\
\text { Phenomenon sensitivity }\end{array}$ & $\begin{array}{l}\text { (Pilch and Griffith 1992) } \\
\text { (Bergeron et al. 1986) } \\
\text { (Washington and Griffith 1990) } \\
\text { (Murata 1992) } \\
\text { (Gido et al. 1992) } \\
\text { (Washington) }\end{array}$ & $\begin{array}{c}\text { (Bergeron et al. 1986) } \\
\text { (Williams et al. 1987) } \\
\text { (Williams and Louie 1988) } \\
\text { (Williams and Gregory 1990) } \\
\text { (Gido et al. 1991) } \\
\text { (Williams 1992) }\end{array}$ \\
\hline MELCOR* & $\begin{array}{l}\text { Approximate loads } \\
\text { Parametric sensitivity }\end{array}$ & (Summers 1995) & $\begin{array}{l}\text { (Summers 1995) } \\
\text { (Kmetyk 1993) } \\
\text { (Kmetyk 1994) }\end{array}$ \\
\hline KIVA-DCH & $\begin{array}{l}\text { Experiment analysis } \\
\text { Phenomenon sensitivity }\end{array}$ & $\begin{array}{c}\text { (Marx 1989) } \\
\text { (Sweet et al. 1991) }\end{array}$ & $\begin{array}{l}\text { (Tarbell et al. 1988) } \\
\text { (Marx 1989) }\end{array}$ \\
\hline
\end{tabular}

"Currently active code available to support resolution of the DCH issue. 


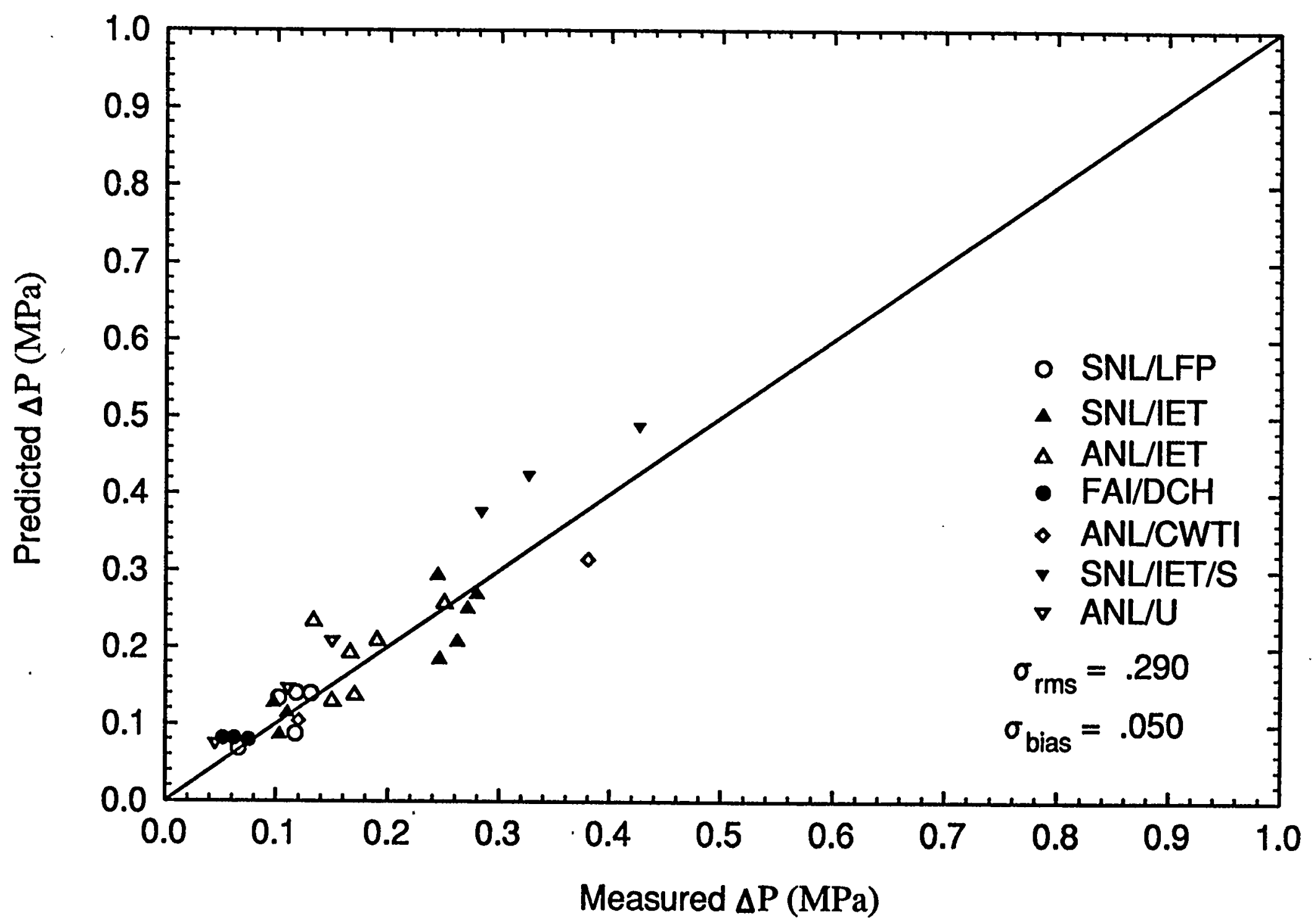

Figure C.1. Experimental validation of TCE model.

C-9 

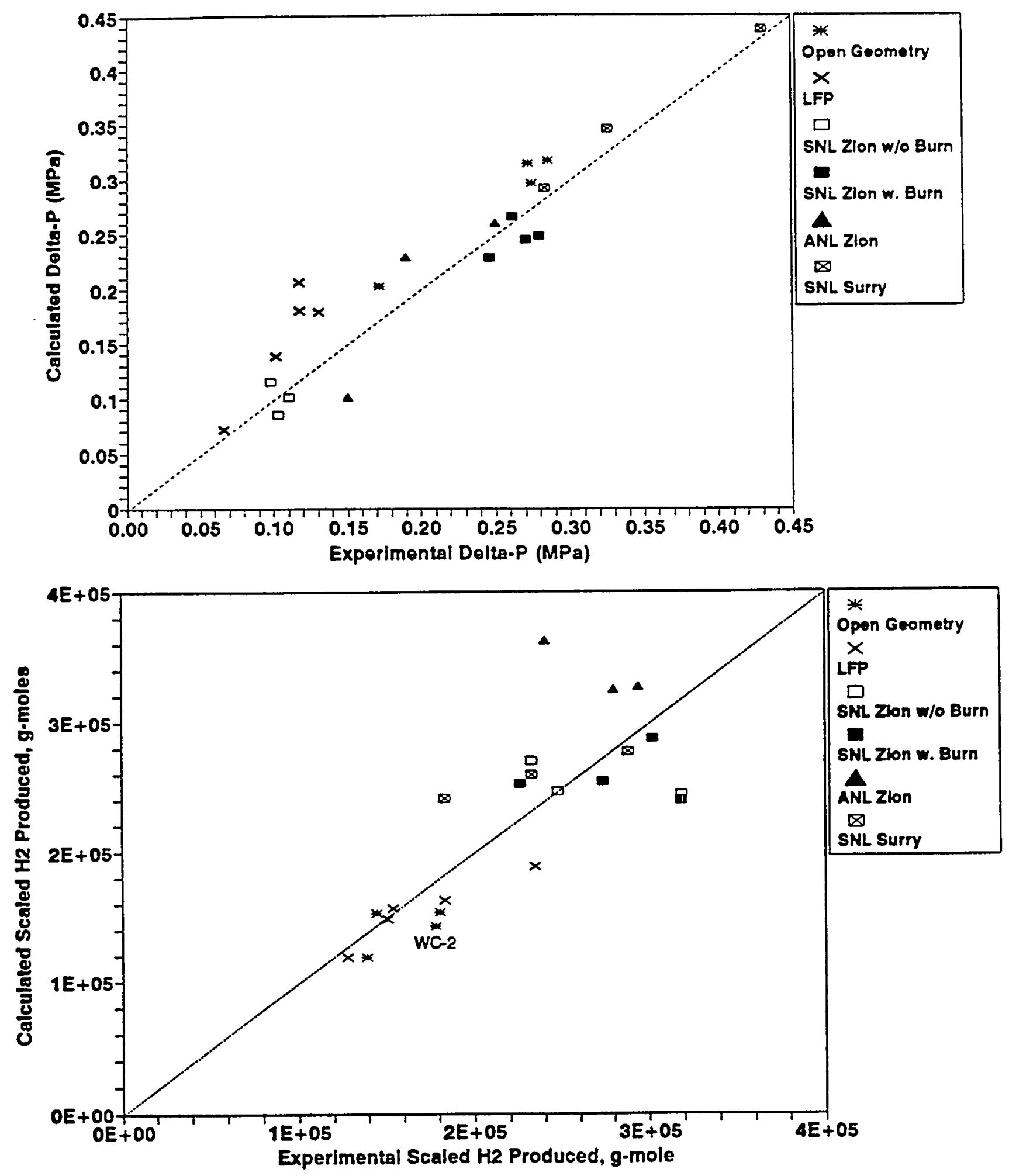

Figure C.2. CONTAIN predictions versus experimental results for (a) $\Delta \mathbf{P}$, and (b) scaled $\mathrm{H}_{2}$ production for the standard input prescription, which models nonairborne debris interactions in both the cavity and in the subcompartments (Case 1). 


\title{
APPENDIX D \\ CONTAIN Calculations and Hydrogen \\ Combustion Analyses for the Surry Plant
}

\author{
Eden L. Tadios and Douglas W. Stamps \\ Sandia National Laboratories
}

\section{D.1 Introduction}

A case of a postulated station blackout in the Surry nuclear power plant was investigated with the CONTAIN, Version 1.12AB (CONTAIN, 1993) code using liquid water, steam and noncondensible (hydrogen and nitrogen) sources obtained from Idaho National Engineering Laboratory (INEL) (Quick and Knudson 1995, Appendix E). The SCDAP/RELAP5 (SR5) code was used to predict the source rates. The scenario (Case 1) simulates the sequence of events after the loss of all AC power in the Surry PWR (pressurized water reactor). The sequence of events for the SR5 calculations is summarized in Table D.1.

In the postulated scenario, gases and liquid are released from two power operated relief valves (PORVs), a hot leg failure, and seal leaks from all three reactor coolant pumps (RCPs). RCP seal leaks are associated with the loss of seal cooling water flow that would accompany the loss of AC power. The initial seal leaks were introduced at the time the reactor scrammed. To simulate failures that could develop with two-phase flow across the seal faces, the seal leak rates were increased from $21 \mathrm{gpm}$ to $480 \mathrm{gpm}$ per RCP when saturated conditions were reached at the RCPs. Details of the postulated accident are discussed in Appendix E.

Sources (liquid water, steam, hydrogen and nitrogen) from the PORV are released to the pressure relief tank room, and the hot leg break and RCP seal leaks release the gases and liquid into the steam generator room (SGR). From each source location, with some exceptions, the discharge consists of liquid water, steam, hydrogen and nitrogen (nitrogen originates from the accumulator). No noncondensible gases are released from the PORV.

The objective of the CONTAIN calculations are to provide initial conditions at vessel failure (defined at 36705 seconds in the SR5 calculations) for the DCH Issue resolution and to provide insight into the potential of hydrogen combustion within the containment. 


\section{D.2 Nodalization and Initial Conditions}

For the present analysis, an existing Surry plant model (Williams, 1988) was used as a starting point. The model nodalized the containment into 17 cells as shown in Figure D.1. Cells that are not in the plane of view or have been combined with another cell (e.g. Cell 9) are not shown in Figure D.1 The containment dome, which includes the operating decks, is defined as Cell 1. Cell 2 represents the reactor pressure vessel (RPV), which is inactive in the present calculations and is treated as a dummy cell. The crane wall annulus is composed of Cells 3 and 12. The upper part of the annulus is subdivided into Cells 10 and 13, while Cells 11 and 14 make up the lower volume of the annulus. The cavity and instrument tunnel volumes are represented by Cell 4, while the containment basement is modeled as Cell 5 . The steam generator room is nodalized into three computational cells: Cells 6,7 and 17. The pressure relief tank room where the PORV sources are released is modeled as Cell 8 . Cell 9 previously represented the instrument room, but its volume is now included in Cell 4. Although Cells 2 and 9 are left intact (purely for convenience) in the input data, these cells are decoupled from the code calculations in the present analysis. Cells 15 and 16 model the pressurizer cubicle and the residual heat removal cubicle, respectively. The nodalization is summarized in Table D.2. With the exception of the dummy cells (Cells 2 and 9), the remaining cells in the containment have the same initial conditions and are listed in Table D.3 (Williams, 1988).

\section{D.3 Description of Calculations}

A set of source tables were generated for the CONTAIN input using data from the SR5 calculations (Appendix E). An input data table was developed for each constituent at each of the source locations, and each table consists of mass flow rates and temperatures or enthalpies as functions of time. As stated earlier, most of the sources consisted of liquid water, steam, and noncondensibles (hydrogen and nitrogen). PORV sources only consist of liquid and steam, no noncondensibles. For DCH (direct containment heating) purposes and the present analysis, only steam and hydrogen will be discussed. Temperature profiles and mass flow rates of the steam and hydrogen sources are shown in Figures D.2-D.4, in which RCP1 was arbitrarily chosen to represent the RCP leaks.

In the CONTAIN model, the hot leg break sources and RCP leaks were released into the SGR, while the PORV sources were introduced in the pressure relief tank room. The sources 
from the pressure relief tank room subsequently flow into the SGR and annulus, among other computational cells. From the SGR, flow paths are established to the annulus, dome and other compartments. The three RCP seal leaks are nearly identical and one RCP leak source was arbitrarily placed in each of the three SGR computational cells. The choice of the hot leg break source location among the three SGR computational cells was also arbitrary. Because of the complexity of the hydrogen combustion issues, CONTAIN was run with the burn model disabled, but hydrogen combustion analyses were later performed using both SR5 and CONTAIN predictions.

\section{D.4 Results}

Using the sources from the SR5 calculations, the CONTAIN results for the containment's cavity, SGR, annulus and dome are shown in Figures D.5 - D.13. The peak pressures and temperatures are directly correlated to the release of gases and liquid from the individual source locations. The effects of the PORV cycling is most evident in the SGR between $7000-9000$ seconds where the gas mole fractions rapidly oscillate (Figure D.8). The oscillatory behavior is also reflected in the containment pressure as well as the cell temperatures but to lesser magnitudes.

The low flow leaks from the RCP, located in the SGR, are introduced at the start of the problem and are later increased to $480 \mathrm{gpm}$ per RCP at 7638 seconds, at which time the containment pressure and temperature begin to build up. The accumulator injection is indicated by the rise of hydrogen concentration at about 12000 seconds (Figure D.8). The hot leg break is indicated by the next major peak in the containment pressure and cell temperatures at about 23000 seconds. The effects of the hot leg break are most pronounced in the SGR atmosphere in terms of temperature and gas mole fractions (Figures D.8 and D.9)

The containment pressure peaked at $0.230 \mathrm{MPa}$ (Figure D.5) at about 24100 seconds, immediately following the hot leg failure due to creep rupture. The cavity temperature peaked at about $379 \mathrm{~K}$ after the hot leg fails, as shown in Figure D.7. The SGR experienced higher temperatures than the cavity due largely to the vented gases from the hot leg failure located in this volume. The SGR temperature reached a high of about $743 \mathrm{~K}$ (Figure D.9). As shown in Figure D.11, the annulus initially reached a maximum of about $383 \mathrm{~K}$ during the PORV cycling and after the hot leg break, the temperature reaches approximately $406 \mathrm{~K}$. In the dome, the 
temperature profile follows a similar trend as the other cells, with a maximum of $450 \mathrm{~K}$, shown in Figure D.13. The initial drop in the cell temperatures (by as much as $8 \mathrm{C}$ ) at the onset of the event is probably due to the introduction of low enthalpy liquid from the RCP leaks. The low enthalpy liquid consequently removes energy from the atmosphere and lowers its temperature.

At lower head failure (at 36705 seconds), the containment pressure is at about $0.148 \mathrm{MPa}$. The corresponding temperatures in the computational cells ranged from $357 \mathrm{~K}$ to $370 \mathrm{~K}$.

Concentrations of gases within the containment are shown in Figures D.6, D.8, D.10 and D.12. The hydrogen inventory in the containment begin to build up after the accumulator injection at about 12000 seconds. The hydrogen concentration reached its highest concentration within the containment in the cavity at about 8.4 percent after vessel failure. After the hot leg break releases steam and liquid into the SGR, the steam concentration rises to a maximum of about 8.9 percent in the SGR, but drops to as low as 3.7 percent in the cavity after the vessel fails.

\section{D.5 Discussion of Hydrogen Combustion Potential}

Case 1 was analyzed using the INEL sources of gases entering the containment and CONTAIN predictions of the containment conditions to determine the amount of hydrogen that could be consumed exclusive of the $\mathrm{DCH}$ event. Because Case 1 was a station blackout scenario, no ignition sources were considered available except for autoigniting jets. It was assumed that no hydrogen would burn until a jet autoignited. Once a jet autoignited, a deflagration could be initiated in the source compartment and subsequent compartments if flammability limits and propagation limits were satisfied. The autoigniting jet may continue to burn as a diffusion flame even if the jet temperature drops below the autoignition temperature if diffusion flame stability criteria are met. The total amount of hydrogen consumed, however, was estimated by including only the amount of hydrogen that burned during the time the jets were autoigniting and any deflagrations that were initiated in the containment due to the autoigniting jets. The additional hydrogen that may have been consumed if stable diffusion flames existed is beyond the scope of this analysis. 
The criteria used to determine when the jets .would autoignite were based on the data of Zabetakis (1956). It should be noted that Zabetakis' data are for hydrogen-steam jets while Case 1 involved hydrogen-steam-nitrogen jets. The authors are not aware of autoignition data for jets having compositions of Case 1. Zabetakis' data are shown in Figure D.14. His data extend to 74 percent steam ( 26 percent hydrogen). It can be seen from this figure that the jet autoignition temperature rises rapidly for jets with low concentrations of hydrogen. The composition of many of the jets analyzed for this case were in regions where the data are sparse and the uncertainty is large. The impact of this uncertainty will be noted during the discussion of the potential autoignition of the jet released from the third reactor coolant pump.

Jet autoignition was determined by cross-plotting the hydrogen volume concentration of the jet at each release location against the gas temperature. The mass fractions of the sources shown in Figures D.2-D.4 were converted into mole fractions. These results are shown in Figures D.15-D.21. The release locations in this case include the PORV, hot-leg break, and three seal leaks from the RCPs in Case 1. The autoignition temperature for different jet hydrogen concentrations was overlaid on the plots. For example, any jet having a temperature lower than $947 \mathrm{~K}$ will not autoignite regardless of jet composition. A jet with 38 percent hydrogen will autoignite when the jet temperature exceeds $1006 \mathrm{~K}$. The times at which the jets would autoignite were estimated by graphical analysis of Figures D.15-D.21. The analysis of individual source locations will be discussed next.

No autoignition occurred in the PORV because no hydrogen was released, and even if it were, the jet temperature never exceeded the autoignition temperature as shown in Figure D.15. The jets did not autoignite in the first two reactor coolant pumps because the jet temperature never exceeded the autoignition temperature as shown in Figures D.16-D.17. In the third RCP, high jet temperatures were predicted between approximately 12560 seconds and 12600 seconds as shown in Figures D.18-D.19. The jet hydrogen mole fractions were low during this time and were generally between $27-40$ percent. In this concentration range only two data points are available from Zabetakis' data and jet autoignition temperatures for concentrations other than the data were estimated by linear extrapolation. Based on this method of estimating autoignition temperatures, the jet temperatures were always below the autoignition temperatures. However, at 12590 seconds, the difference was only $6 \mathrm{~K}$. Different methods of interpolating the data can yield lower autoignition temperatures. Also this difference is small relative to the uncertainty in the data. For example, at lower temperatures the uncertainty was as much as approximately 
$40 \mathrm{~K}$ because of the influence of jet velocities. Given these two sources of uncertainty, the autoignition of the jet released from the third RCP cannot be precluded. If the jet did autoignite, the jet temperature was not predicted to remain at elevated temperatures for very long and an insignificant amount of hydrogen would be consumed from the autoigniting jet. This does not consider the amount of hydrogen that may continue to be consumed if the diffusion flame were stable. Even though little hydrogen would be consumed in the jet per se, the autoigniting jet becomes an ignition source for the premixed gases in the containment. This point will be discussed later. In general, the temperature of the jet from the hot leg is below the autoignition temperature except for a time period between 26600 seconds and 27400 seconds. During that time, the jet temperature exceeded the autoignition temperature during six brief times. The first time autoignition occurred was at 26637 seconds and is a possible ignition source for the premixed gases in the containment.

The total amount of hydrogen consumed in the autoigniting jet from the hot leg was estimated by multiplying the average mass flow rate of hydrogen during the time period from 26600 seconds to 27400 seconds by the total time the jet autoignited. It was estimated that approximately $6 \mathrm{~kg}$ of hydrogen was consumed in the jet. This amount of hydrogen represents approximately 1.5 percent of the total hydrogen that flowed into the containment. As discussed earlier, even if the jet from the third RCP autoignited, the total amount of hydrogen that would have been consumed would be negligible because the jet autoignition time was very short.

If the jet from the third RCP autoignited at 12590 seconds, combustion would occur in the steam generator rooms. The other rooms in the containment would not be flammable at that time. In the source room, the hydrogen, oxygen, and steam concentrations were approximately 10.7 percent, 8.5 percent, and 48.0 percent, respectively, at 12590 seconds. This mixture is combustible according to the Whiteshell data (Kumar, 1985). Combustion could then propagate into the other steam generator rooms, but not into other compartments of the containment. Based on the correlations used in the CONTAIN code (CONTAIN, 1993), the combustion completeness of a deflagration would vary between approximately 20-60 percent in the steam generator rooms. It should be noted that the steam concentrations in the steam generator rooms were beyond the conditions in the database and that it was necessary to extrapolate the CONTAIN correlation to estimate the combustion completeness. The total hydrogen consumed was estimated to be approximately 6 percent of the $217 \mathrm{~kg}$ of hydrogen that had been released into the containment at that time. 
If the jet from the third RCP did not autoignite, combustion would be initiated in the steam generator rooms when the hot leg jet autoignited at 26637 seconds. Most of the rooms had between 5.7-6.2 percent hydrogen, 8-9 percent oxygen, and 46-52 percent steam except for one steam generator room which had slightly more hydrogen at approximately 7.8 percent. The mixture was flammable in the steam generator room in which the jet from the hot leg autoignited. Several other rooms in the lower part of the containment also contained flammable mixtures although propagation criteria may not have been satisfied for the burn to propagate in all of these rooms. For example, combustion probably would not have propagated in rooms below the steam generator room because the downward propagation criterion was not satisfied. It may also be possible that the flame would not have propagated in other rooms because the horizontal propagation criteria may not have been satisfied. It would not be expected that the burn would propagate into the dome because the dome mixture is just below the flammability limits. According to Kumar's data, the flammability limits for 51.8 percent steam is $\mathbf{5 . 7 2}$ percent hydrogen. The dome had only 5.66 percent hydrogen and 51.8 percent steam. The premixed combustion analysis assumed no burns occurred in the dome, cavity or basement. The remaining rooms with flammable mixtures have approximately 6.2 percent hydrogen and 47 percent steam. Based on the CONTAIN correlation, the combustion completeness was approximately 18 percent. Assuming the flame propagated both upward and horizontally, the total hydrogen burned was estimated to be approximately $9 \mathrm{~kg}$ of hydrogen. By 26637 seconds, approximately $335 \mathrm{~kg}$ of hydrogen had been released into the containment. It was estimated that approximately 3 percent of the hydrogen in the containment would be consumed. These estimates were based on the assumption that the jet from the third RCP did not autoignite at 12590 seconds. If the RCP jet autoignited at that time and some of the hydrogen was consumed from premixed combustion, it is still possible that a second combustion event would occur at 26637 seconds when the hot leg jet autoignited. In either case, however, the combustion completeness would be low.

\section{D.6 Conclusions}

For DCH purposes, the dome conditions are most important in the analysis of containment integrity. The CONTAIN simulations show that the highest load on the containment with a dome pressure of $0.230 \mathrm{MPa}$, due to high flow rate of steam released from the RCPs. High temperatures occur in the subvolumes of the containment (i.e., steam generator room and annulus) but are only moderately high in the dome, reaching $450 \mathrm{~K}$. At the time of vessel 
breach, the containment pressure was at about $0.148 \mathrm{MPa}$ while the compartment temperatures ranged from 357 to $370 \mathrm{~K}$.

Hydrogen combustion analyses were performed using the results from SCDAP/RELAP5 and CONTAIN analyses. The results of the analyses indicated that autoignition would occur in the hot leg and possibly in the third reactor coolant pump. Autoignition would not occur in the PORV or other reactor coolant pumps because the jet temperatures were below the autoignition temperature. The amount of hydrogen consumed in the autoigniting jet from the hot leg was approximately 1.5 percent of the total hydrogen released into the containment. Because the autoignition time would be brief, a negligible amount of hydrogen would be consumed if the jet from the third reactor coolant pump autoignited.

If the third reactor coolant pump jet autoignited at approximately 12590 seconds, combustion would occur in the steam generator rooms. Approximately 6 percent of the premixed hydrogen in the containment at that time would be consumed. If the third reactor coolant pump did not autoignite, then combustion in containment would be initiated at 26637 seconds when the hot leg jet autoignited. Combustion would occur in several of the rooms in the lower part of the containment but not in the dome. It is estimated that 3 percent of the premixed hydrogen in the containment at that time would be consumed. Even if combustion occurred at 12590 seconds because of an autoigniting jet at the third reactor coolant pump, a second burn would likely occur at 26637 seconds when the hot leg jet autoignited.

\section{D.7 References}

CONTAIN 1.2 Code Manual, (1993). "A Computer Code For Severe Accident Analysis," Prepared for the U.S. Nuclear Regulatory Commission, Draft for Review, Sandia National Laboratories, Albuquerque, NM.

Kumar, R.K., (1985). "Flammability Limits of Hydrogen-Oxyget-Diluent Mixtures," Journal of Fire Sciences, V. 3, pp. 245-262.

Williams, D.C. and Louie, D.Y., (1988). "CONTAIN Analyses of Direct Containment Heating Events in the Surry Plant," ANS Thermal Hydraulics Division Proceedings of the ANS/ENS International Meeting, Washington, D.C.

Zabetakis, M.G., (1956). "Research on the Combustion and Explosion Hazards of Hydrogen-Water Vapor-Air Mixtures," Bureau of Mines Final Report, AECU-3327. 
Table D.1 SCDAP/RELAP5 calculations sequence of events (Quick and Knudson, Appendix E)

\begin{tabular}{||l|c||}
\hline \multicolumn{1}{|c|}{ Event } & $\begin{array}{c}\text { Case 1 Time of } \\
\text { Event (sec) }\end{array}$ \\
\hline \hline TMLB' initiation & 0 \\
\hline $\begin{array}{l}\text { Introduction of seal leaks of 21 gpm per RCP, leak diameters }= \\
\text { 0.00331 m }\end{array}$ & 0 \\
\hline Steam generators dryout (pressurizer/non-pressurizer loops) & $4850 / 5020$ \\
\hline Onset of pressurizer PORV cycling & 6020 \\
\hline $\begin{array}{l}\text { RCP saturation; seal leaks increased to 480 gpm per RCP; leak } \\
\text { diameters = 0.0190m) }\end{array}$ & 7638 \\
\hline End of full loop (liquid) natural circulation & 7692 \\
\hline Collapsed liquid level falls below the top of fuel rods & 8783 \\
\hline End of pressurizer PORV cycling & 8980 \\
\hline $\begin{array}{l}\text { Vapor in the core exit begins to superheat; hot leg countercurrent } \\
\text { circulation begins }\end{array}$ & 8900 \\
\hline Collapsed liquid level falls below the bottom of the fuel rods & 10372 \\
\hline Pressurizer drains & 10830 \\
\hline Onset of fuel oxidation & 10980 \\
\hline First heatup to molten fuel temperatures; in the first channel & 12213 \\
\hline Accumulator injection begins & 12362 \\
\hline First fuel rod fragmentation; in the second channel & 13780 \\
\hline Pressurizer loop hot leg nozzle fails by creep rupture & 22975 \\
\hline Hot leg break initiated; break diameter = 0.150m & 22975 \\
\hline $\begin{array}{l}\text { Accumulators empty; injection ends with collapsed liquid level } \\
\text { 0.22 m below top of fuel rods }\end{array}$ & 23200 \\
\hline $\begin{array}{l}\text { Second core dryout; collapsed liquid level falls below the bottom of } \\
\text { the fuel rods }\end{array}$ & 24056 \\
\hline 79 kg Ag-In-Cd melts and slumps into lower head & 27649 \\
\hline 1209 kg Ag-In-Cd melts and slumps into lower head & 28775 \\
\hline
\end{tabular}


Table D.1 SCDAP/RELAP5 calculations sequence of events (Quick and Knudson, Appendix E)

\begin{tabular}{||l|c||}
\hline \multicolumn{1}{|c|}{ Event } & $\begin{array}{c}\text { Case 1 Time of } \\
\text { Event (sec) }\end{array}$ \\
\hline \hline $201 \mathrm{~kg} \mathrm{Ag}-\mathrm{In}-\mathrm{Cd}$ melts and slumps into lower head & 28900 \\
\hline $267 \mathrm{~kg} \mathrm{Ag}-\mathrm{In}-\mathrm{Cd}$ melts and slumps into lower head & 29595 \\
\hline $50 \mathrm{~kg} \mathrm{Ag}-\mathrm{In}-\mathrm{Cd}$ melts and slumps into lower head & 31350 \\
\hline $117 \mathrm{~kg} \mathrm{Ag}-\mathrm{In}-\mathrm{Cd}$ melts and slumps into lower head & 32725 \\
\hline Core slumping into lower head; 58.648 kg UO2, 14966 kg ZrO2 & 32406 \\
\hline $\begin{array}{l}\text { Lower head failure; by creep rupture } ~ \\
\text { bottom surface of the head }\end{array}$ & 36705 \\
\hline End of calculation & 37705 \\
\hline
\end{tabular}


Table D.2 Surry plant nodalization (Williams 1988)

\begin{tabular}{|c|l|c|}
\hline $\begin{array}{c}\text { Cell } \\
\text { Number }\end{array}$ & \multicolumn{1}{|c|}{ Description } & $\begin{array}{c}\text { Cell Volume } \\
\left(\mathrm{m}^{3}\right)\end{array}$ \\
\hline \hline Cell 1 & Dome & 1820.405 \\
\hline Cell 2 & RPV (dummy cell) & \\
\hline Cell 3 & Crane wall annulus \#1 & 2302.613 \\
\hline Cell 4 & Cavity and instrument tunnel & 290.0 \\
\hline Cell 5 & Basement and upper hoist volumes & 7527.0 \\
\hline Cell 6 & Steam generator Room C & 1326.191 \\
\hline Cell 7 & Steam generator Room B & 1147.653 \\
\hline Cell 8 & Pressure relief tank room & 477.337 \\
\hline Cell 9 & Instrument room (dummy cell) & \\
\hline Cell 10 & Upper annulus \#1 and instrument control room & 1820.405 \\
\hline Cell 11 & Lower annulus \#1 & 1074.851 \\
\hline Cell 12 & Crane wall annulus \#2 & 2302.613 \\
\hline Cell 13 & Upper annulus \#2 and upper hoist volume & 2164.342 \\
\hline Cell 14 & Lower annulus \#2 & 1074.851 \\
\hline Cell 15 & Pressurizer cubicle & 841.973 \\
\hline Cell 16 & Residual heat removal cubicle & 437.977 \\
\hline Cell 17 & Steam generator Room A & 1199.587 \\
\hline
\end{tabular}

Table D.3 Initial conditions (Williams 1988)

\begin{tabular}{||l|l|l||}
\hline \multicolumn{1}{|c|}{ Cell } & \multicolumn{1}{|c|}{ Initial Conditions } & \multicolumn{1}{|c|}{$\begin{array}{c}\text { Initial Inventory } \\
\text { (mole fraction) }\end{array}$} \\
\hline \hline All cells & $\mathrm{T}=311.0 \mathrm{~K}$ & $\mathrm{~N}_{2}=0.75525$ \\
(except cells 2 \& 9) & $\mathrm{P}=68.94 \mathrm{kPa}$ & $\begin{array}{l}\mathrm{O}_{2}=0.19475 \\
\end{array}$ \\
& & $\begin{array}{l}\mathrm{H}_{2}=0.0 \\
\mathrm{H}_{2} \mathrm{O} \text { (steam) }=0.05\end{array}$ \\
\hline
\end{tabular}




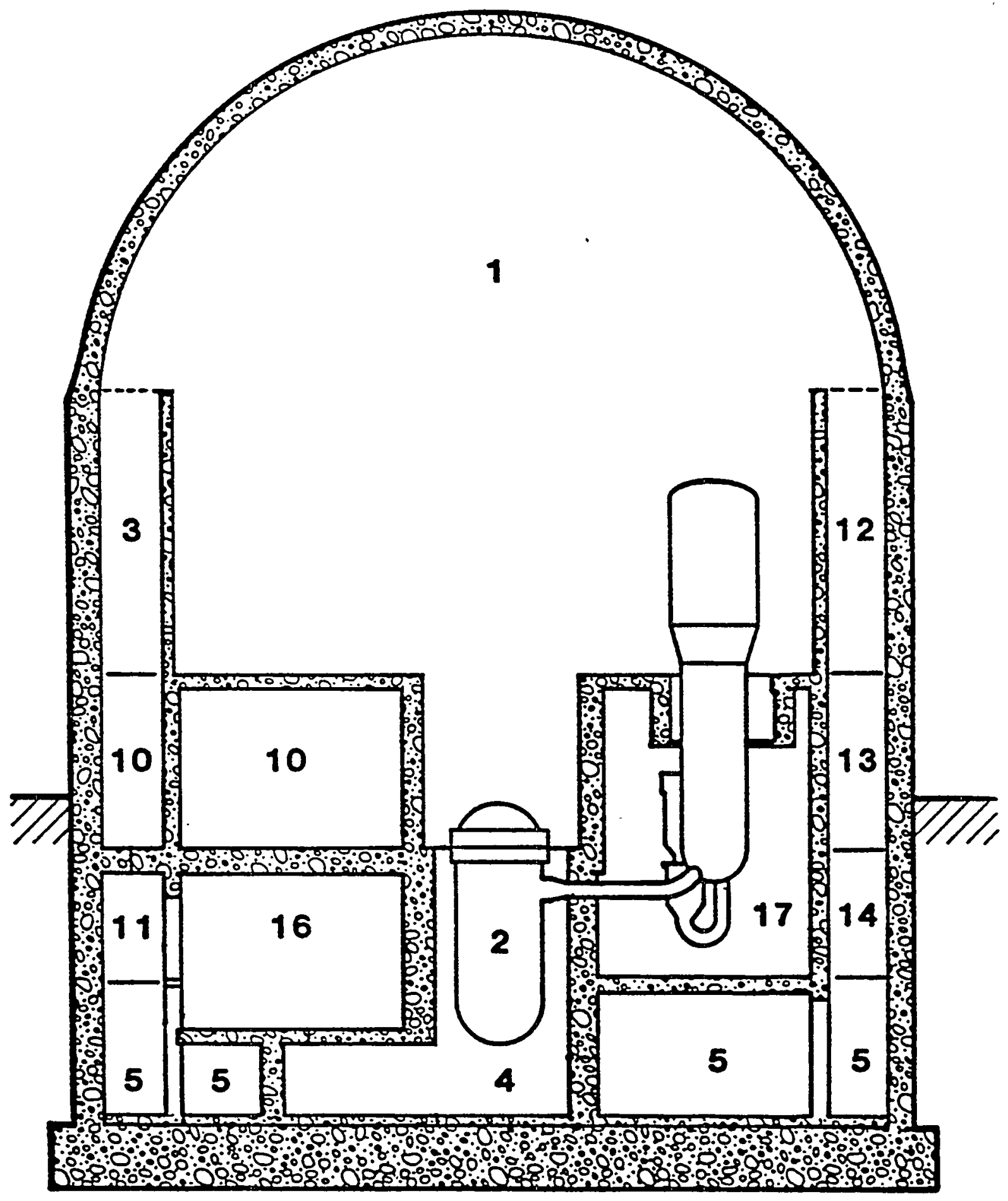

Figure D.1 Schematic of Containment Design and Nodalization for Surry Power Plant (Williams, 1988) 


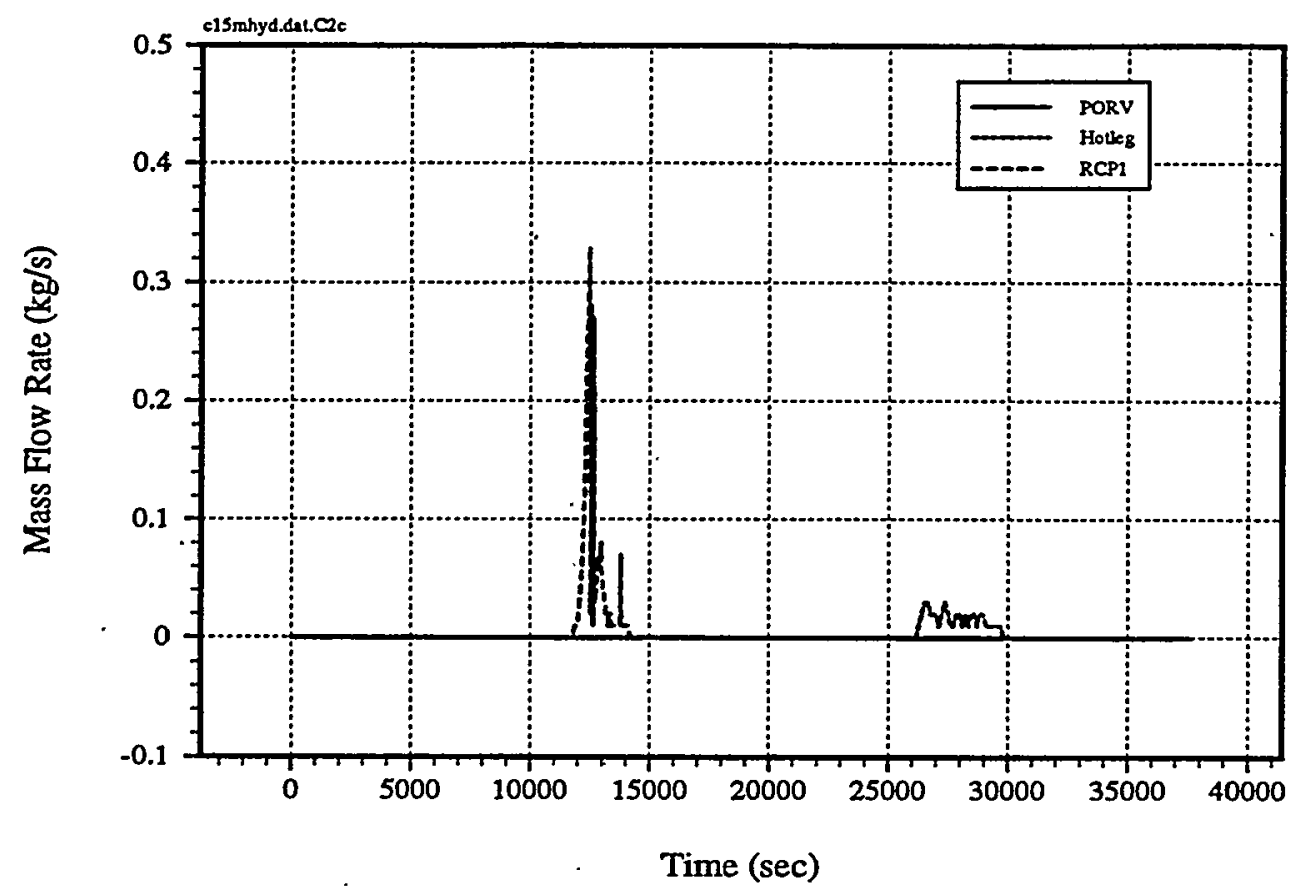

Figure D.2 Hydrogen Source Flow Rates

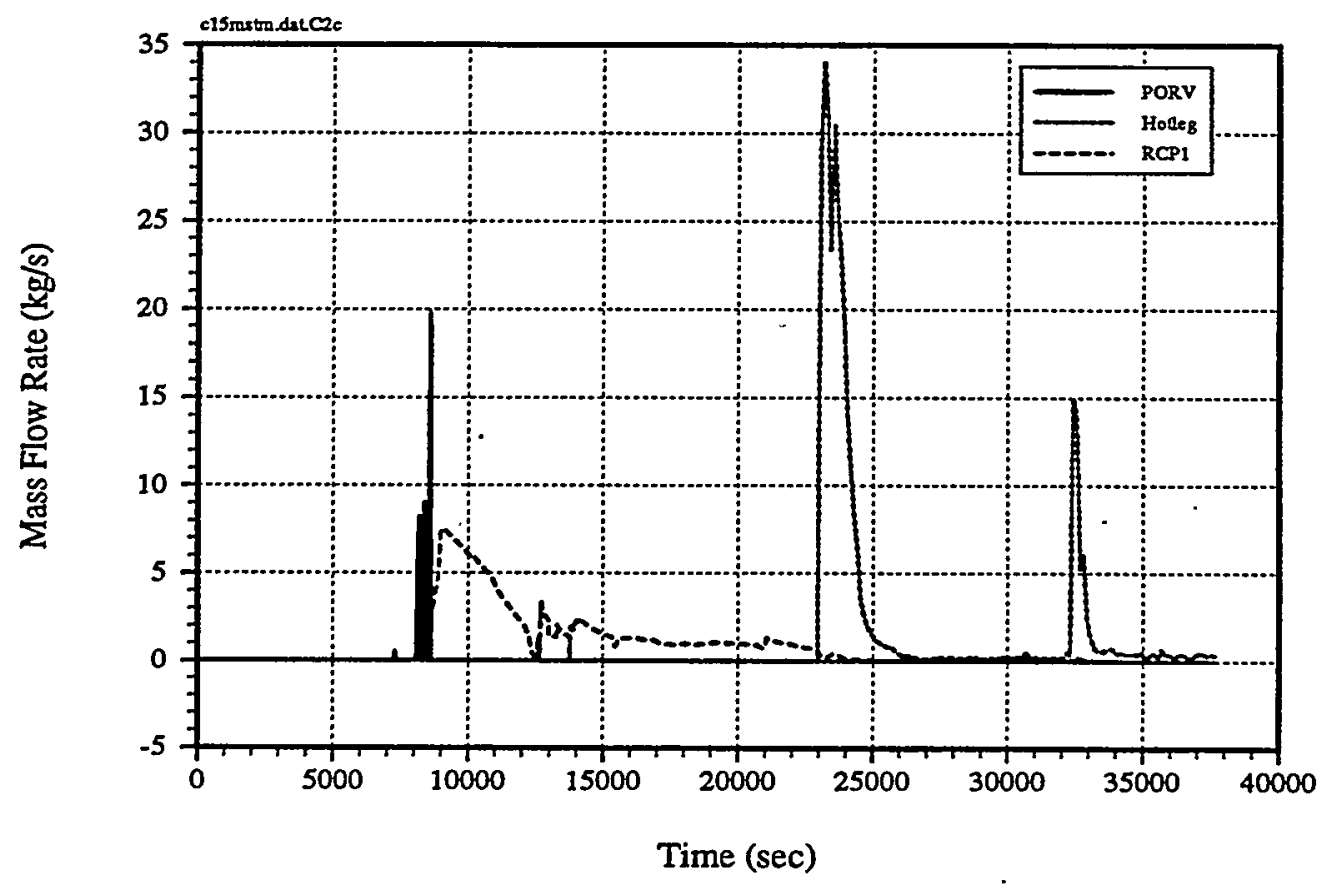

Figure D.3 Steam Source Flow Rates

D-13 


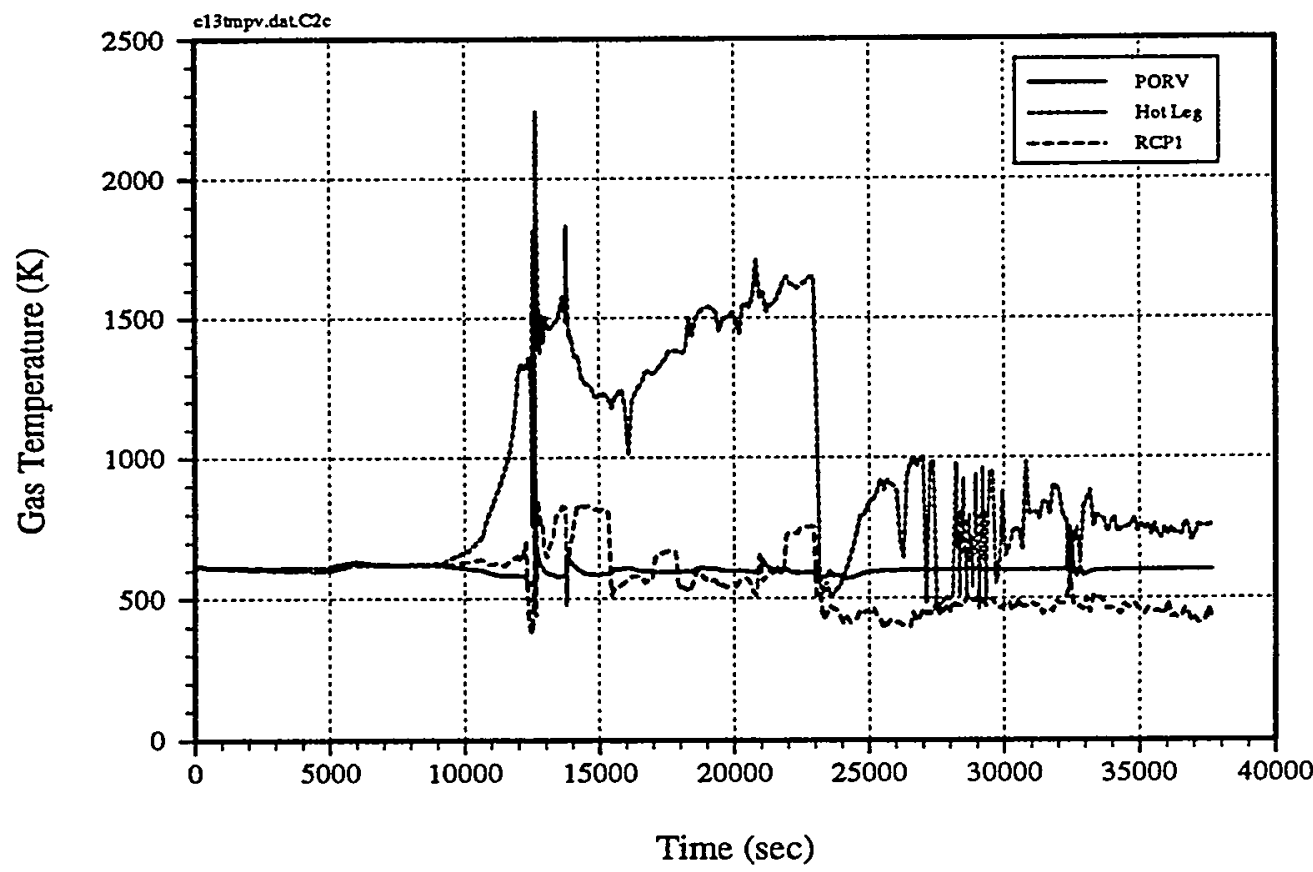

Figure D.4 Gas Temperature at Source Locations

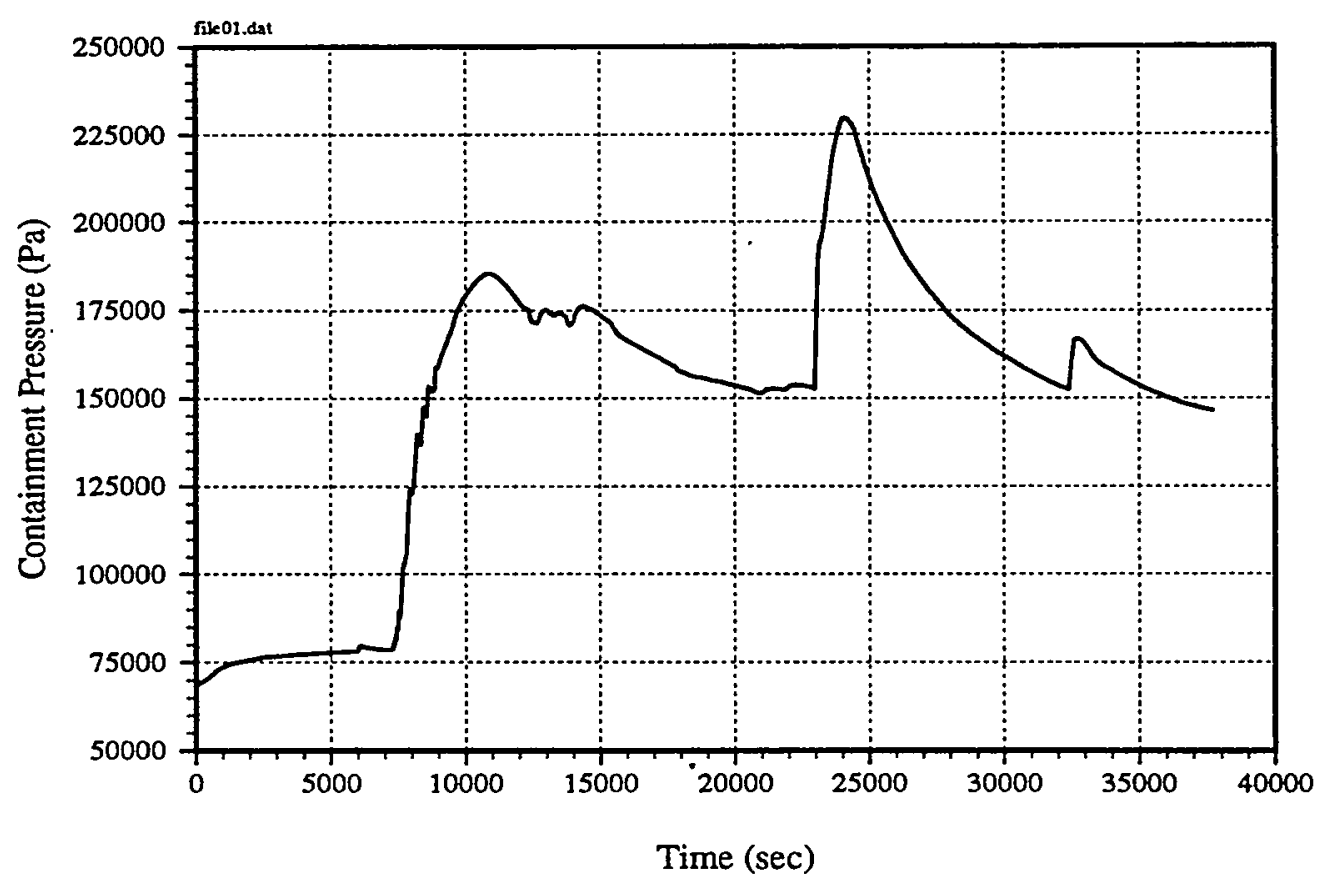

Figure D.5 Containment Pressure 


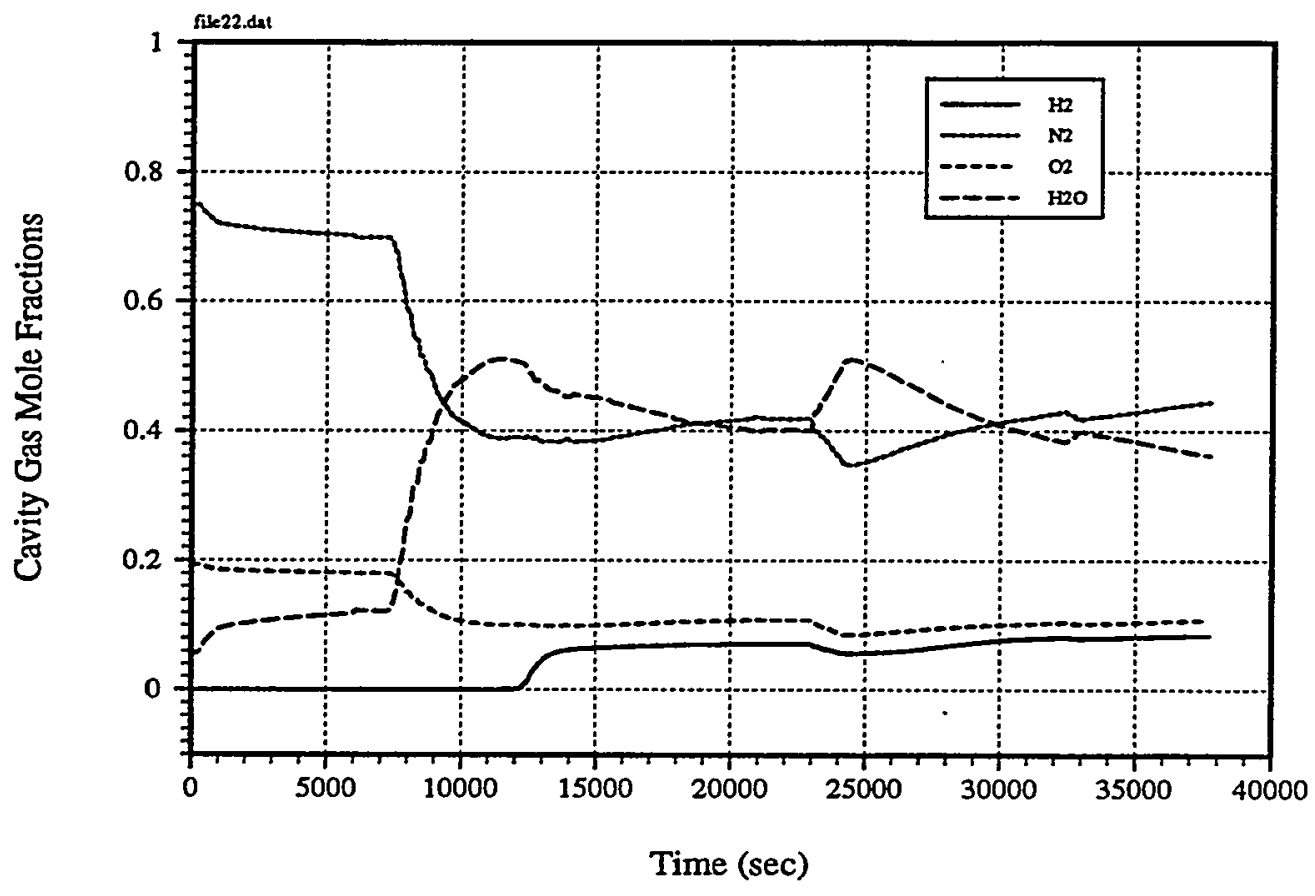

Figure D.6 Cavity Gas Mole Fractions

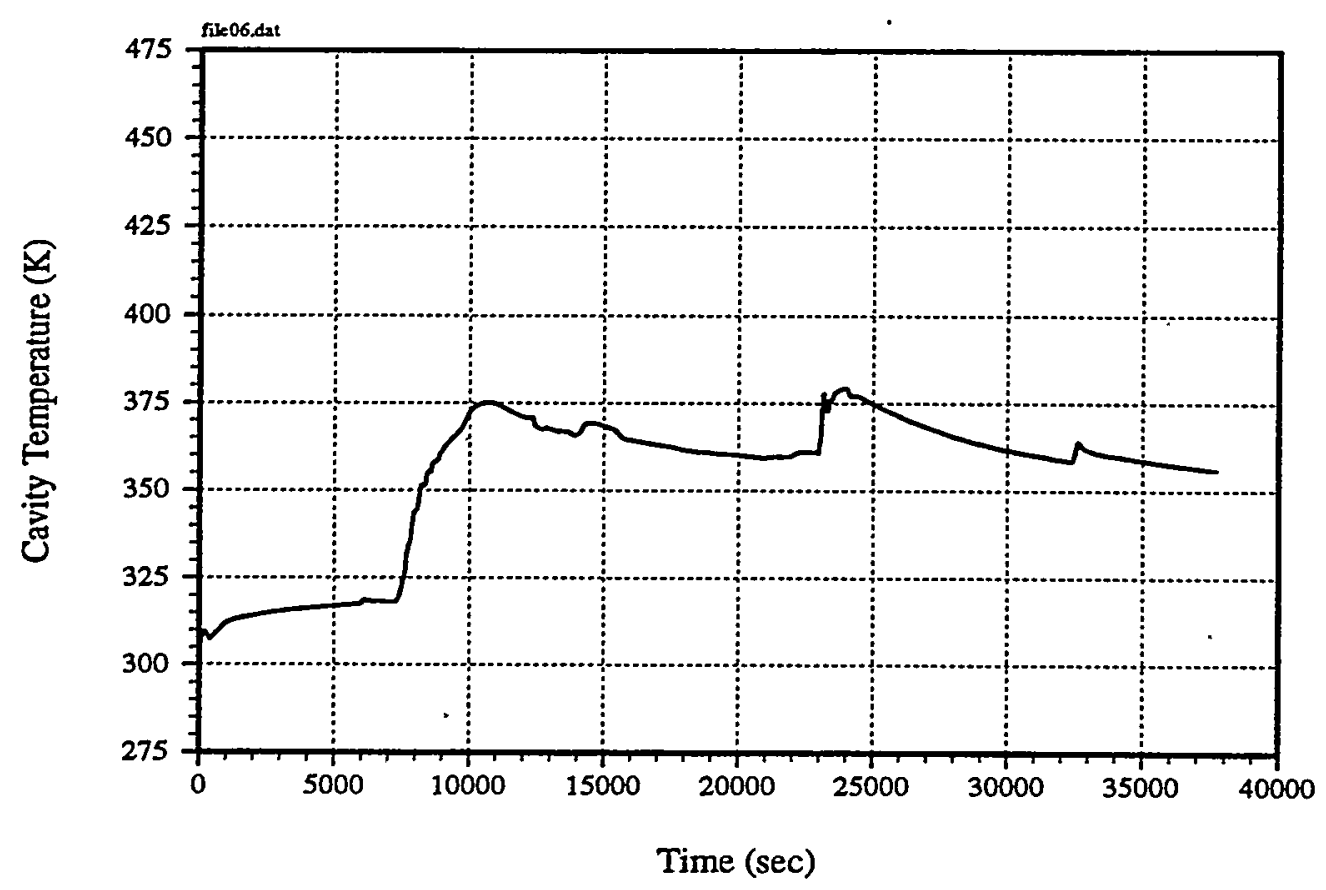

Figure D.7 Cavity Gas Temperature 


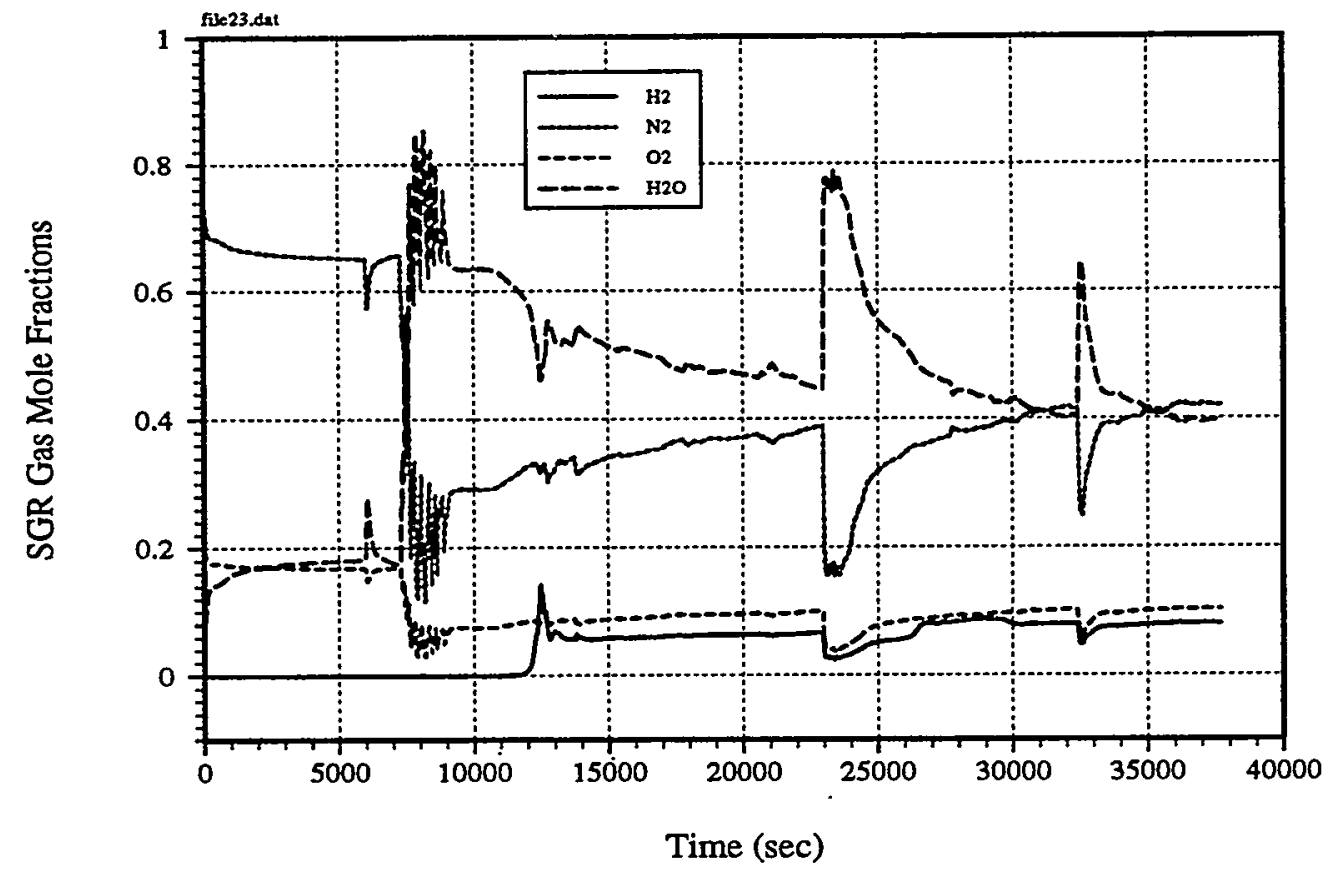

Figure D.8 Steam Generator Room Gas Mole Fractions

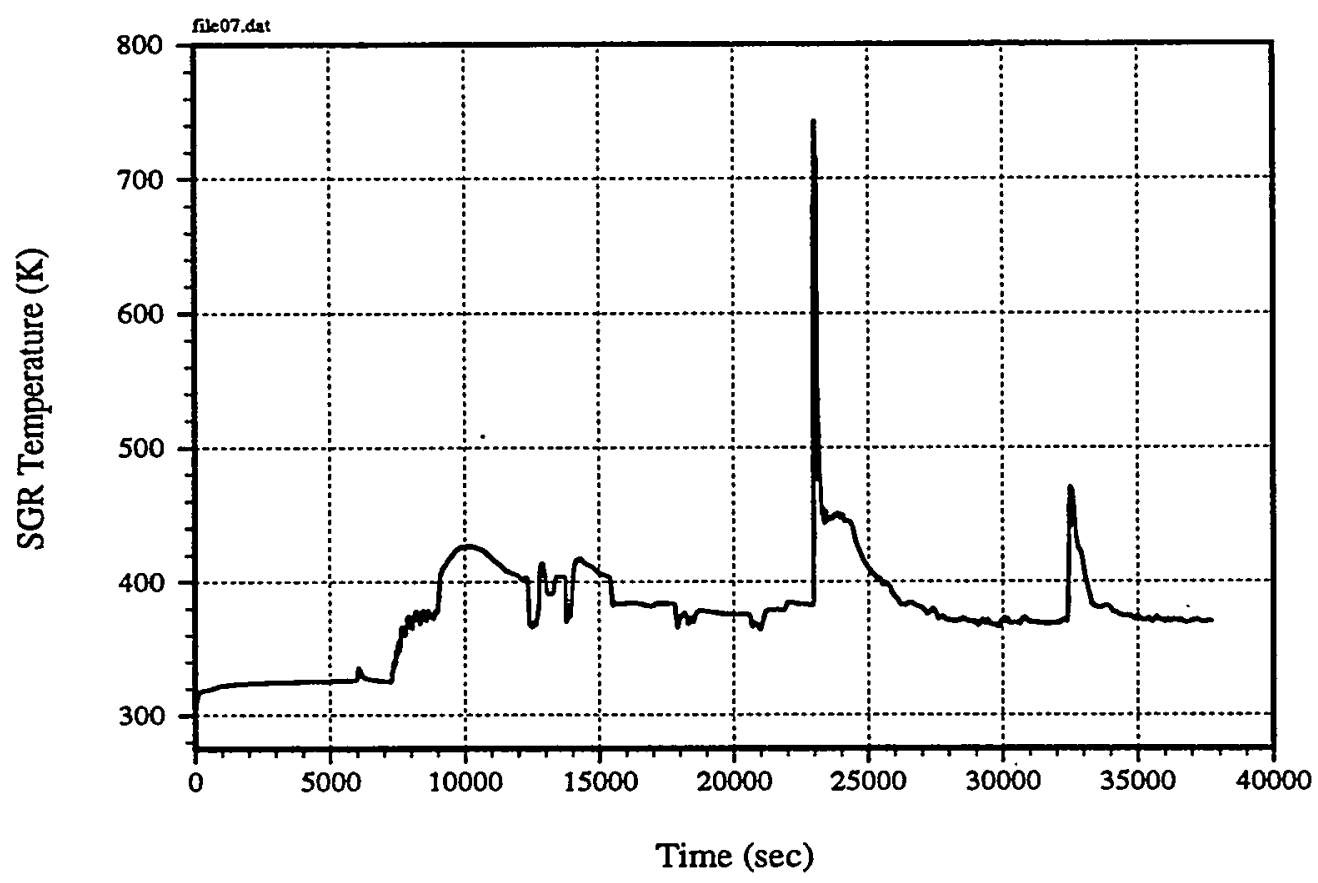

Figure D.9 Steam Generator Room Gas Temperature 


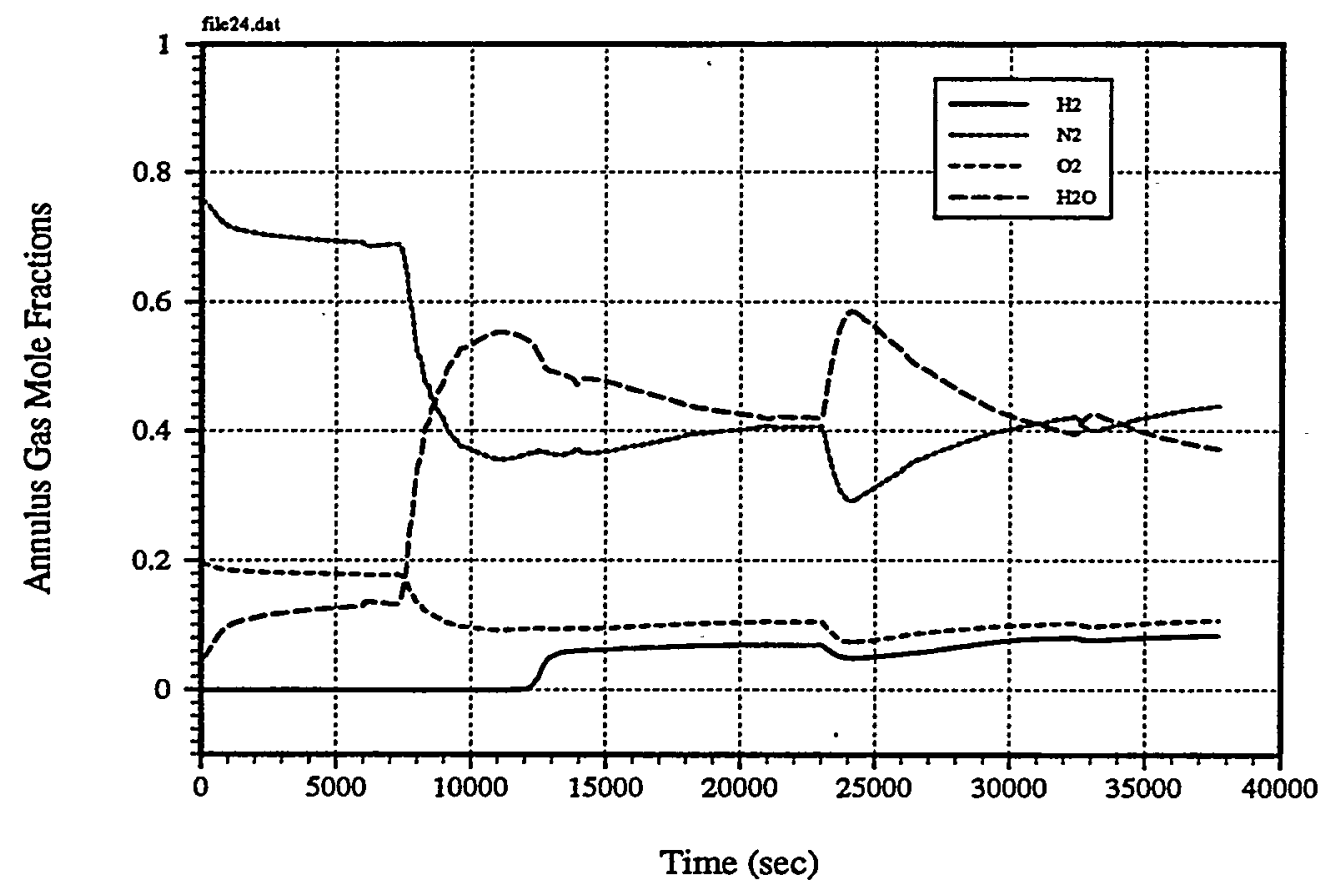

Figure D.10 Annulus Gas Mole Fractions

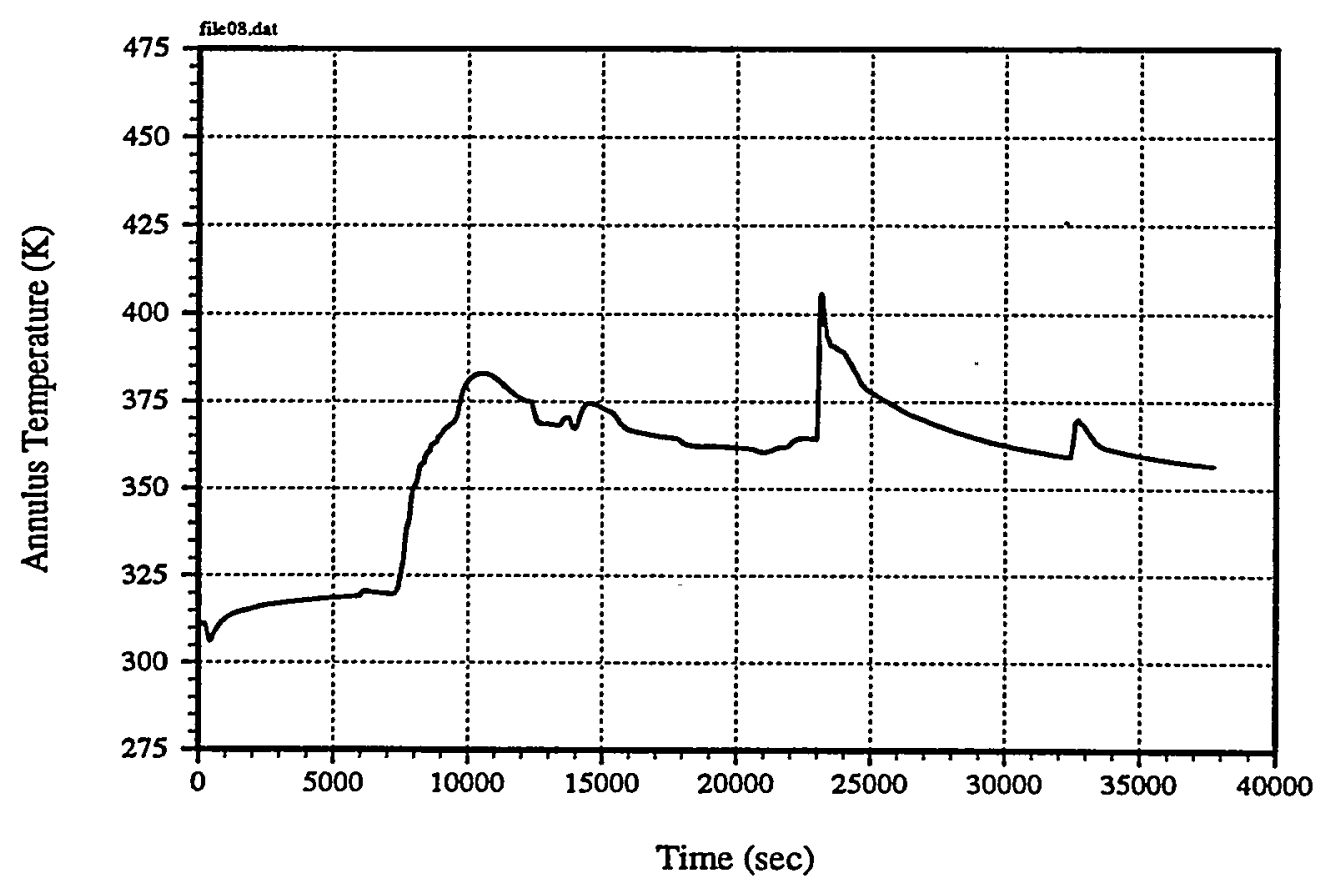

Figure D.11 Annulus Gas Temperature 


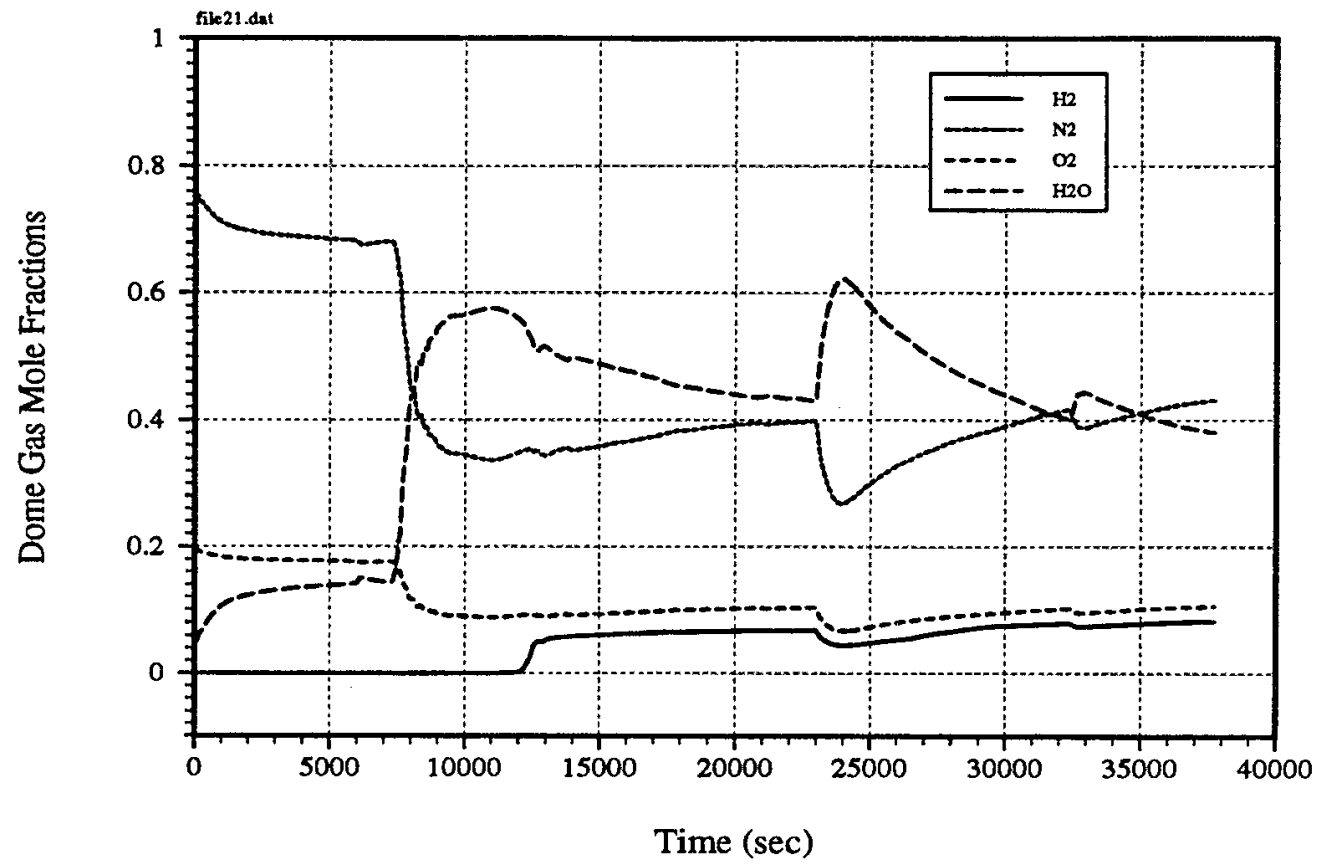

Figure D.12 Dome Gas Mole Fractions

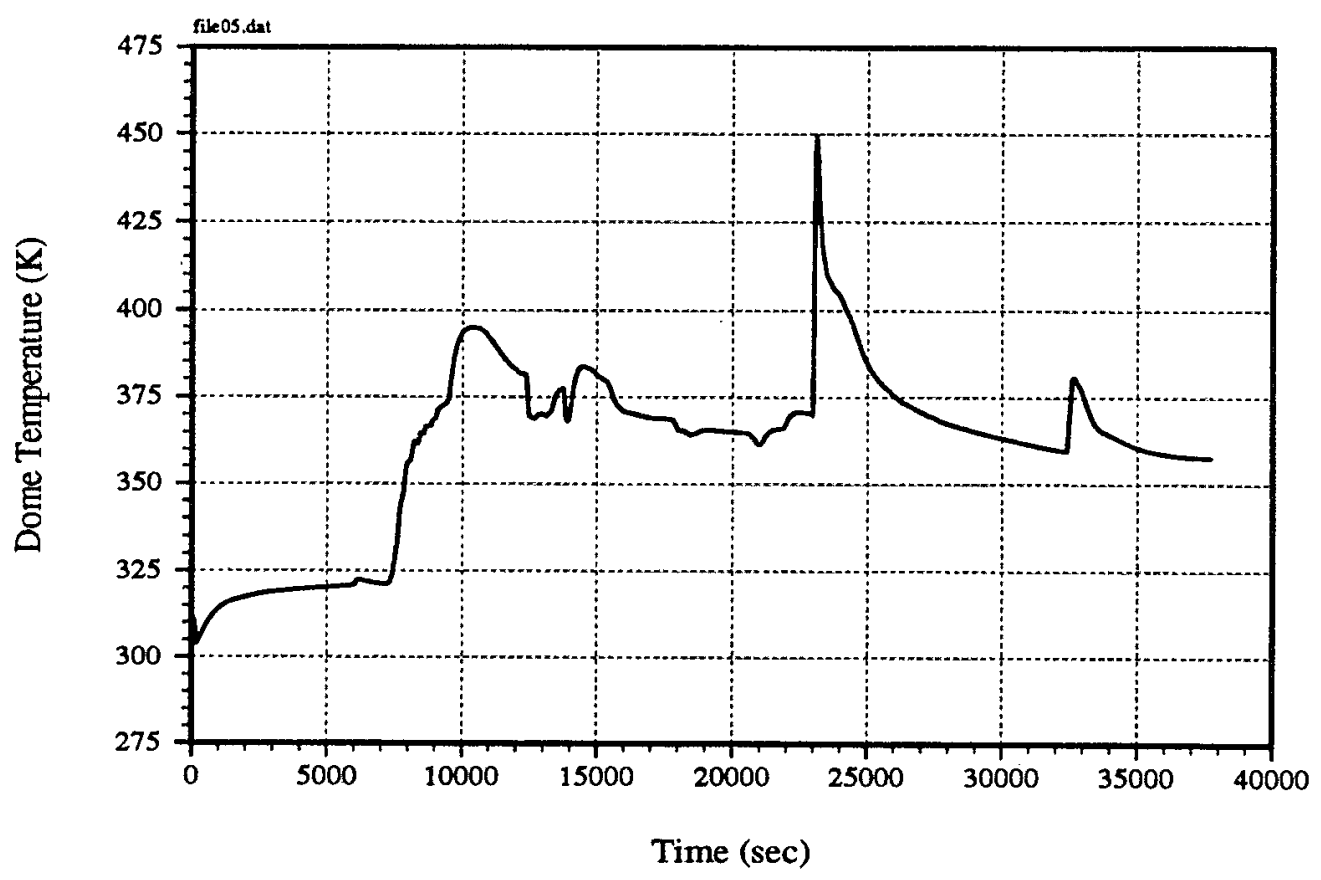

Figure D.13 Dome Gas Temperature 


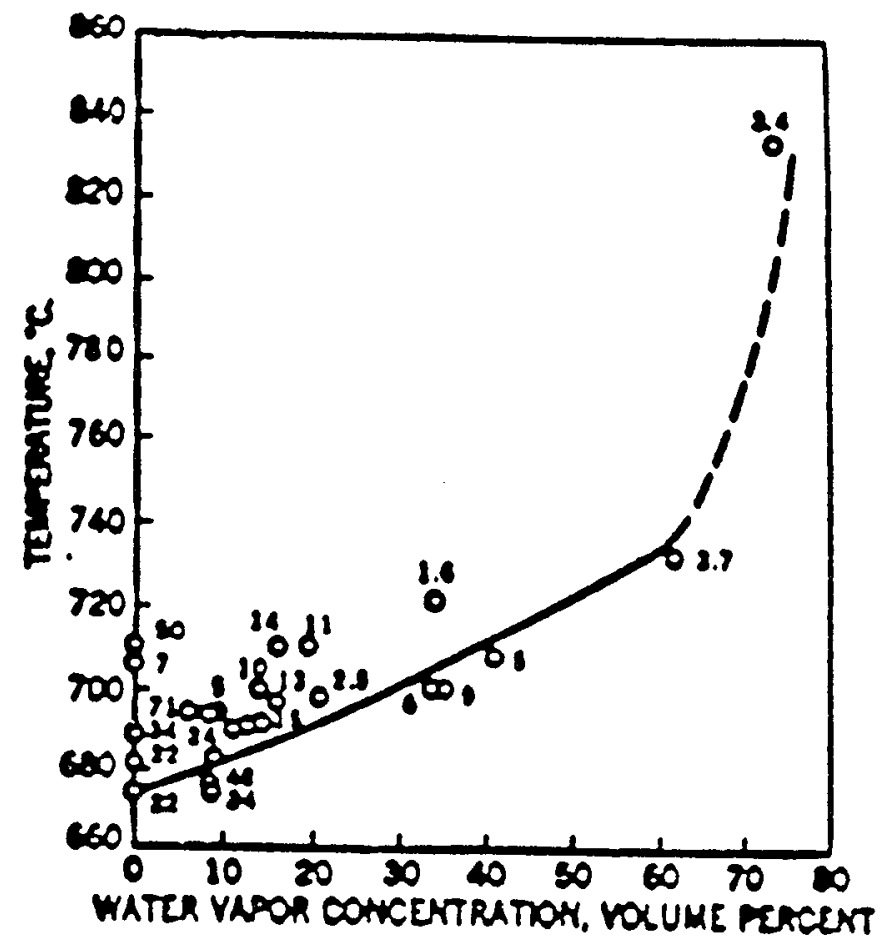

Figure D.14 Autoignition Temperature Data for Hydrogen-Steam Jets (Zabetakis, 1956)

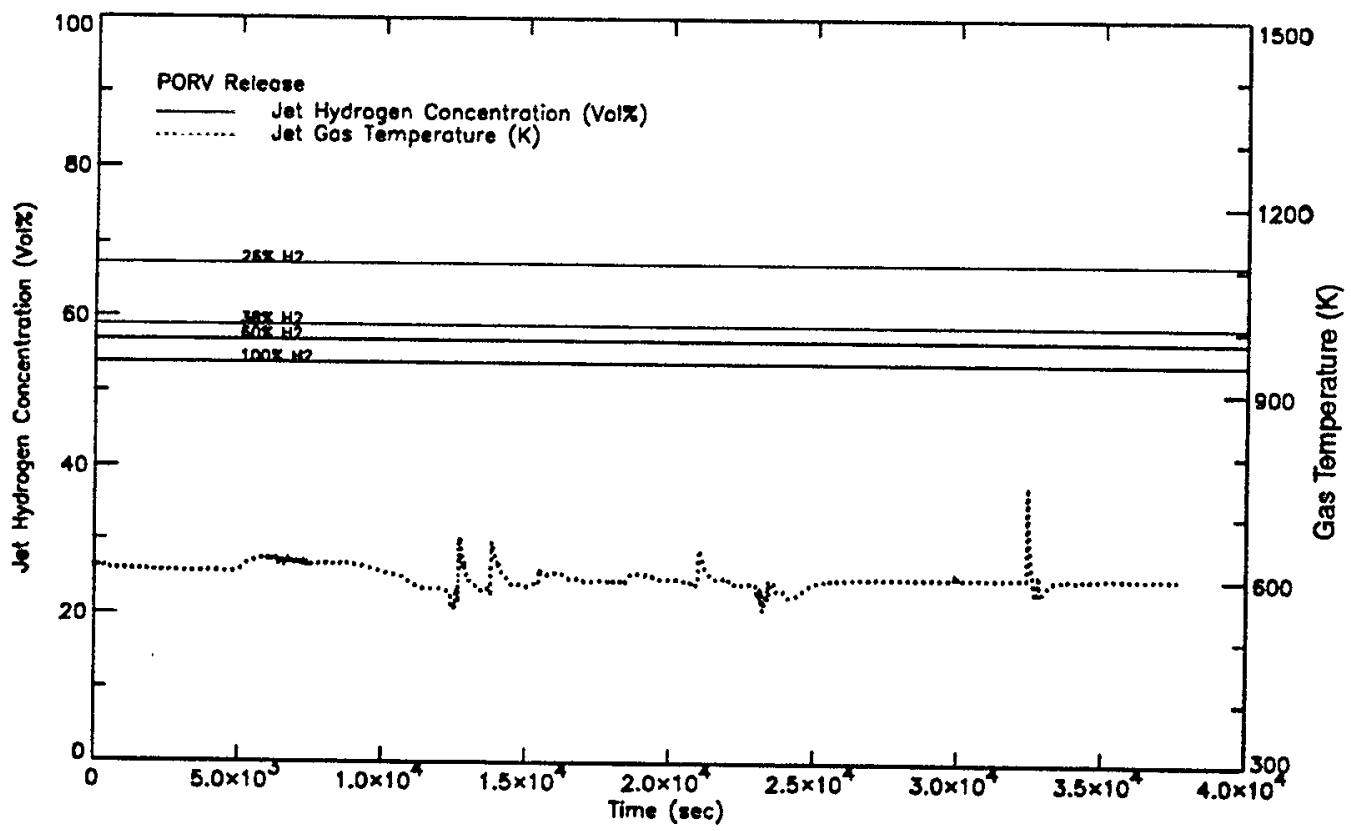

Figure D.15 Jet Hydrogen Concentration and Temperature of the Gases Released from the PORV 


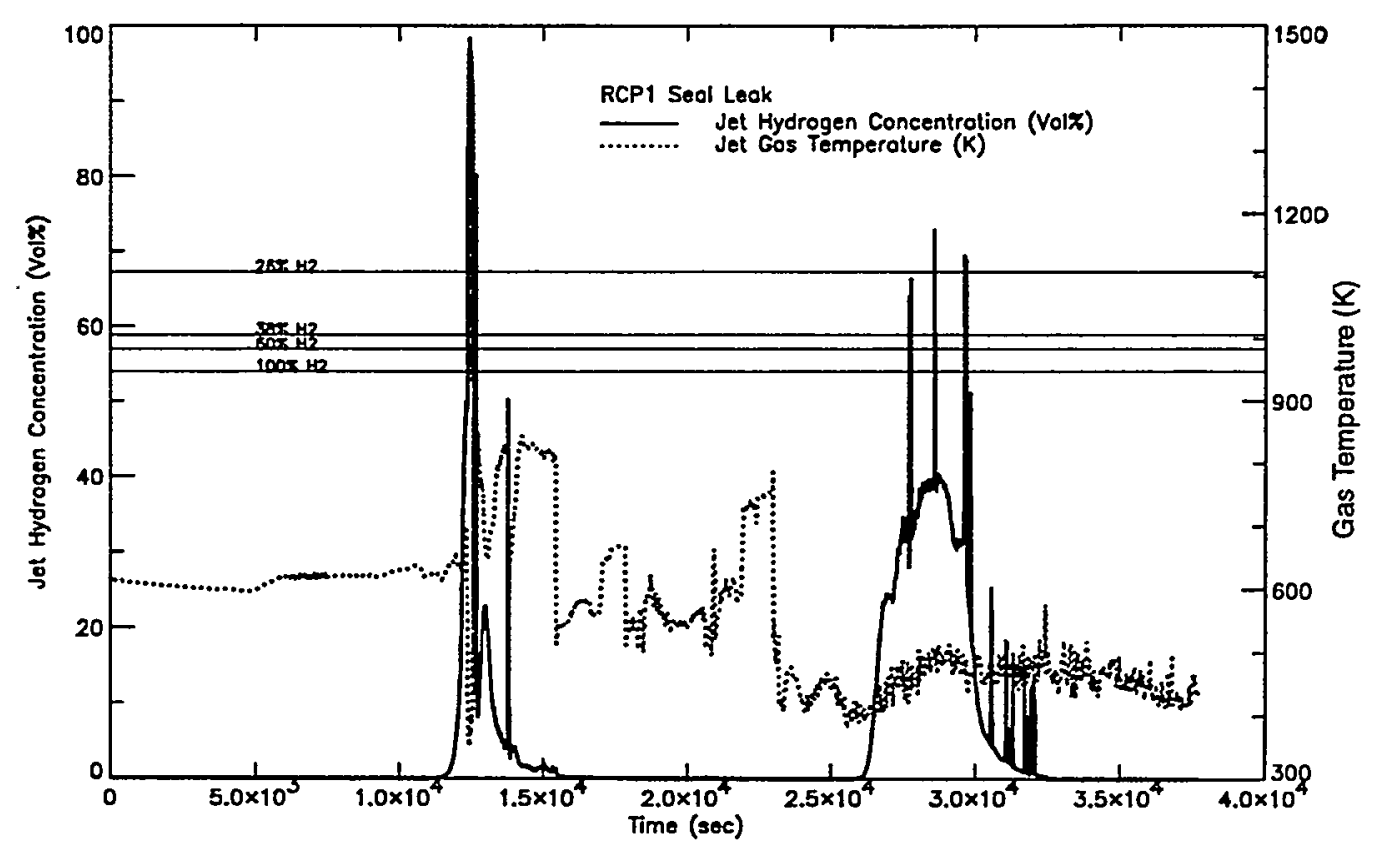

Figure D.16 Jet Hydrogen Concentration and Temperature of the Gases Released from the Reactor Coolant Pump 1 Seal Leak

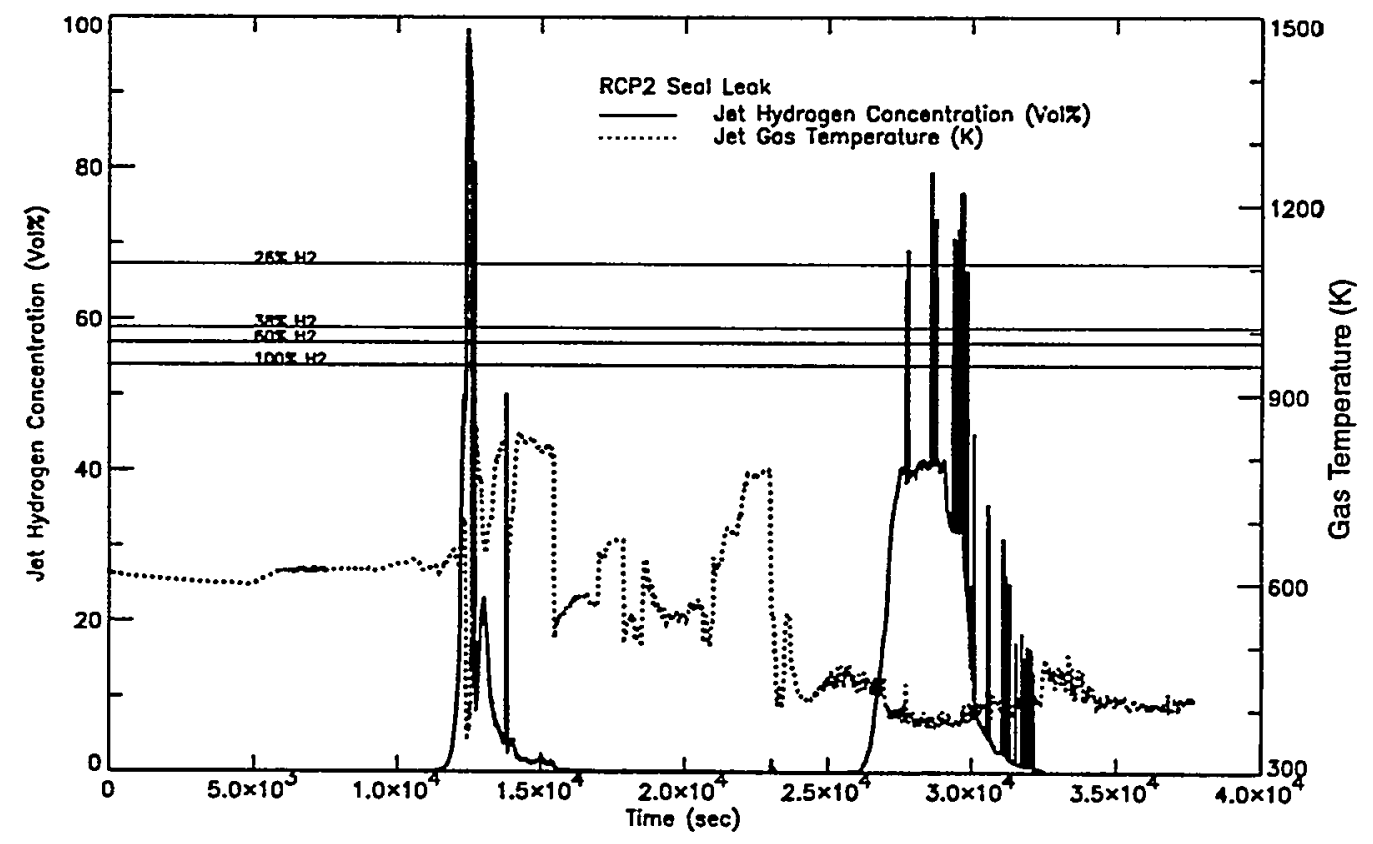

Figure D.17 Jet Hydrogen Concentration and Temperature of the Gases Released from the Reactor Coolant Pump 2 Seal Leak 


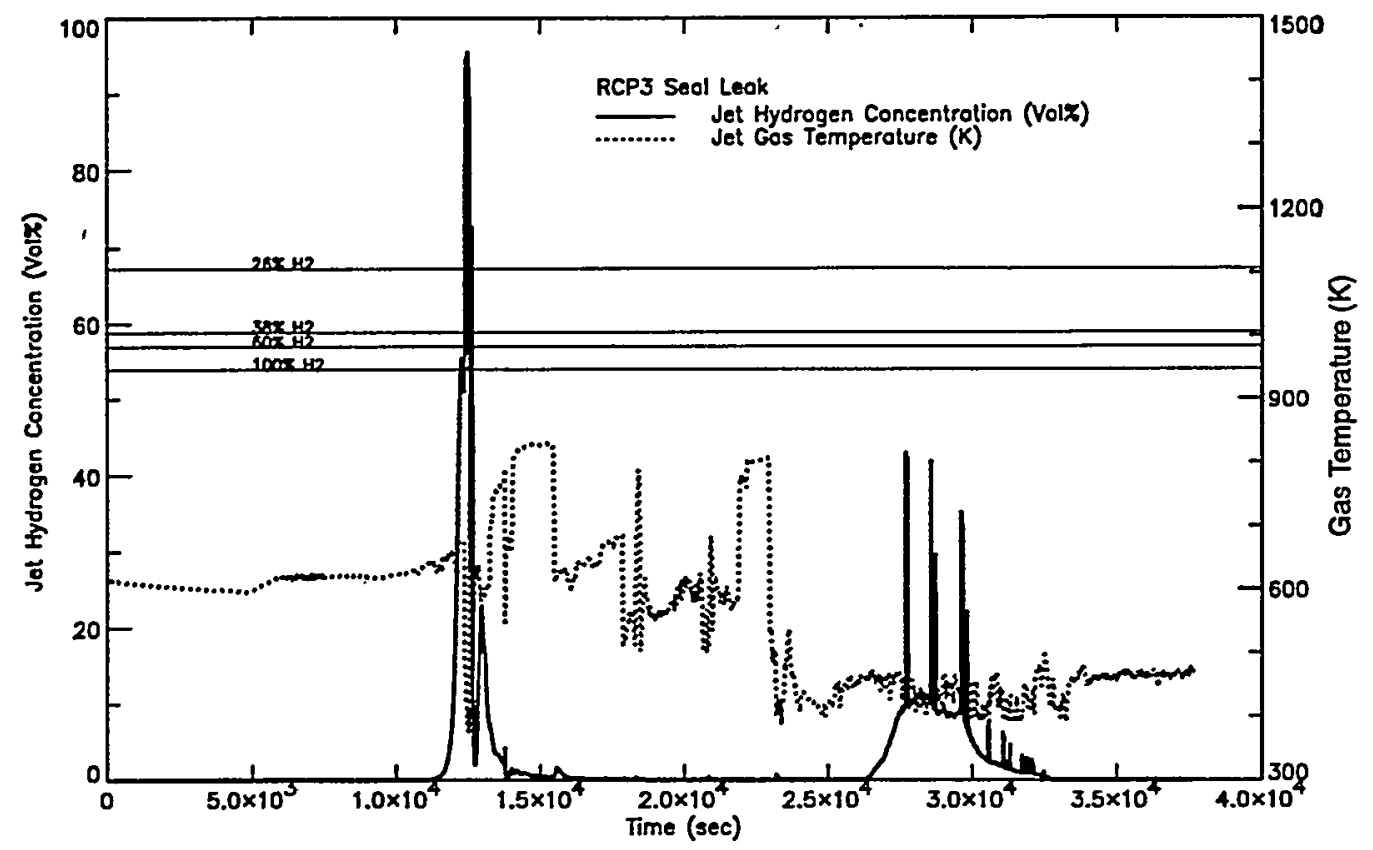

Figure D.18 Jet Hydrogen Concentration and Temperature of the Gases Released from the Reactor Coolant Pump 3 Seal Leak

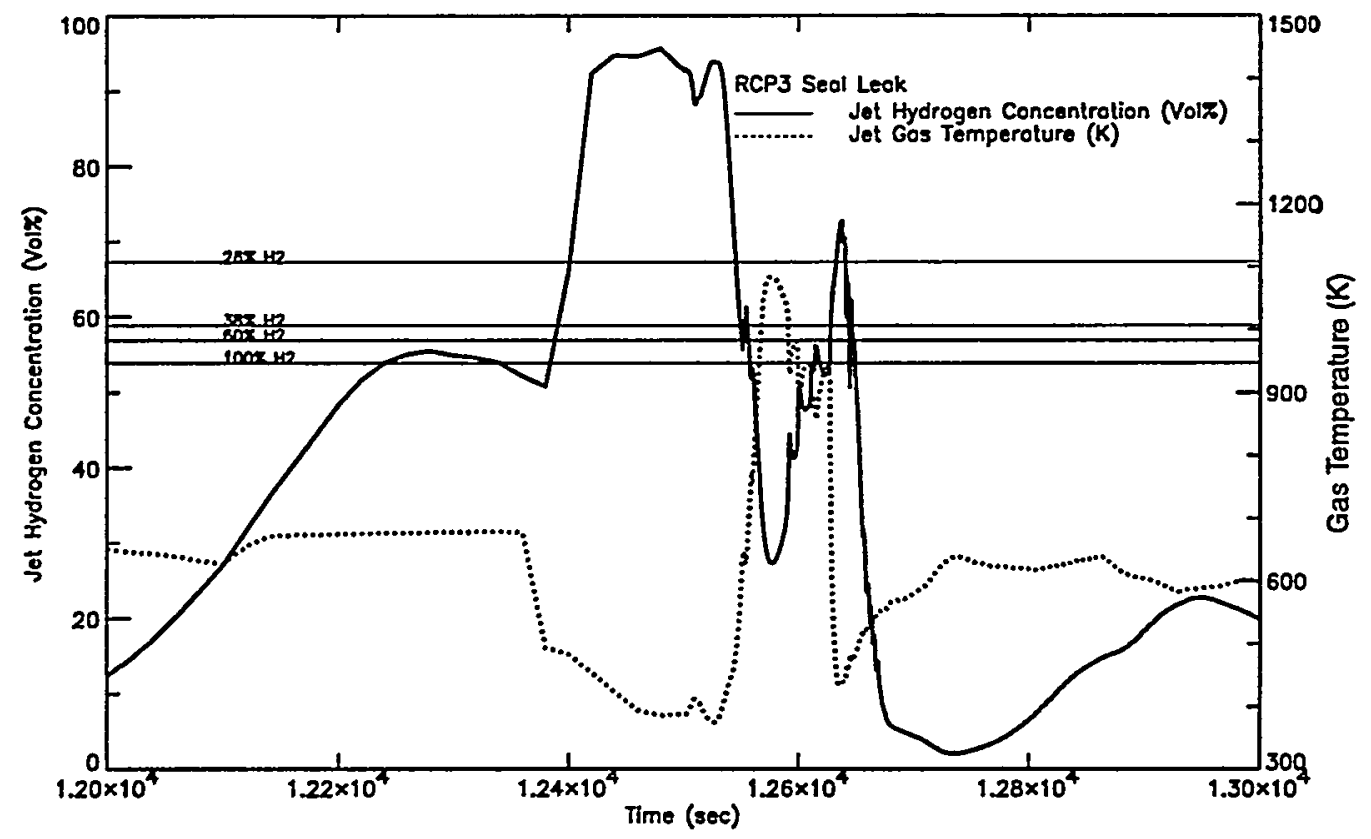

Figure D.19 Jet Hydrogen Concentration and Temperature of the Gases Released from the Reactor Coolant Pump 3 Seal Leak 


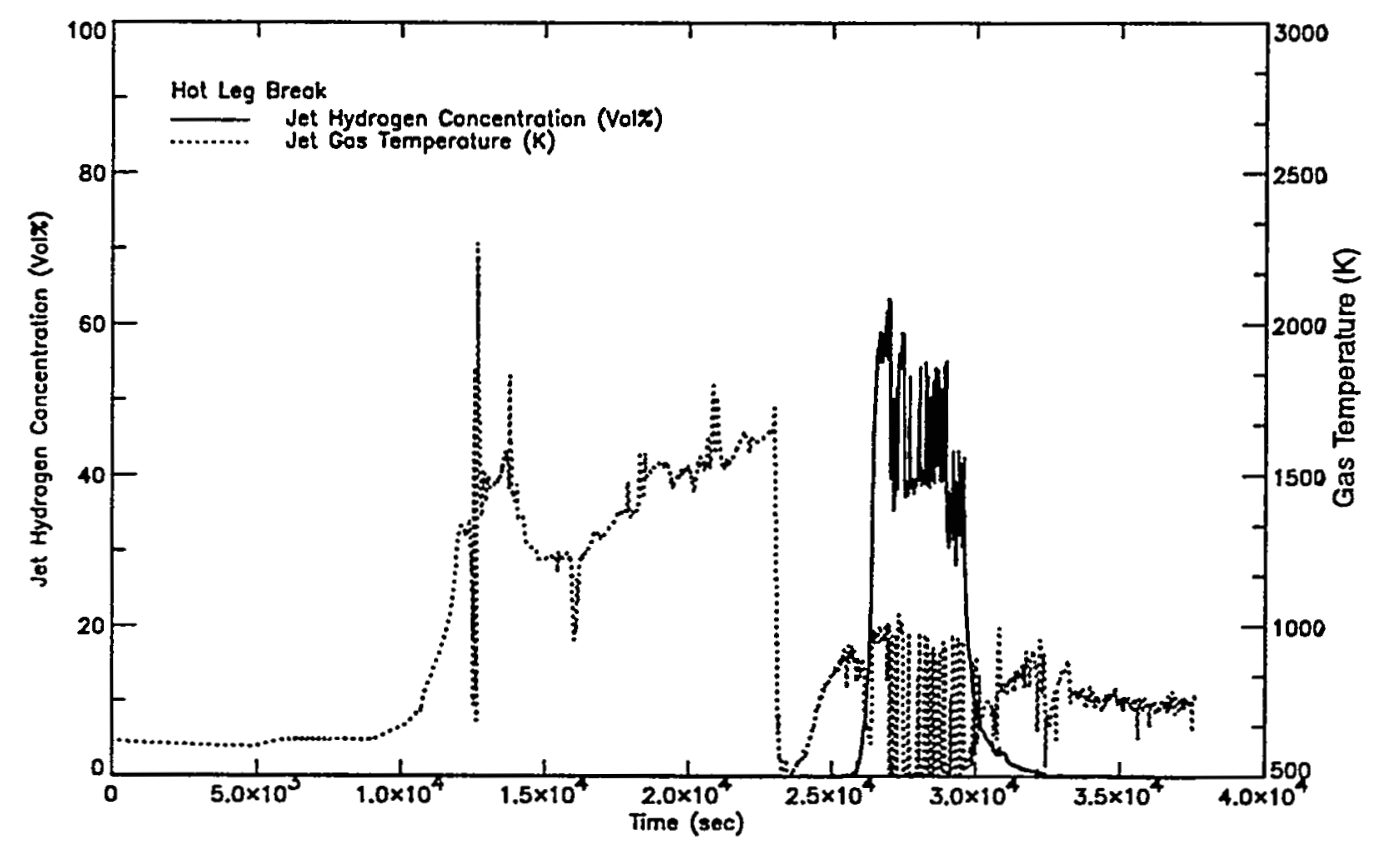

Figure D.20 Jet Hydrogen Concentration and Temperature of the Gases Hot Leg Break

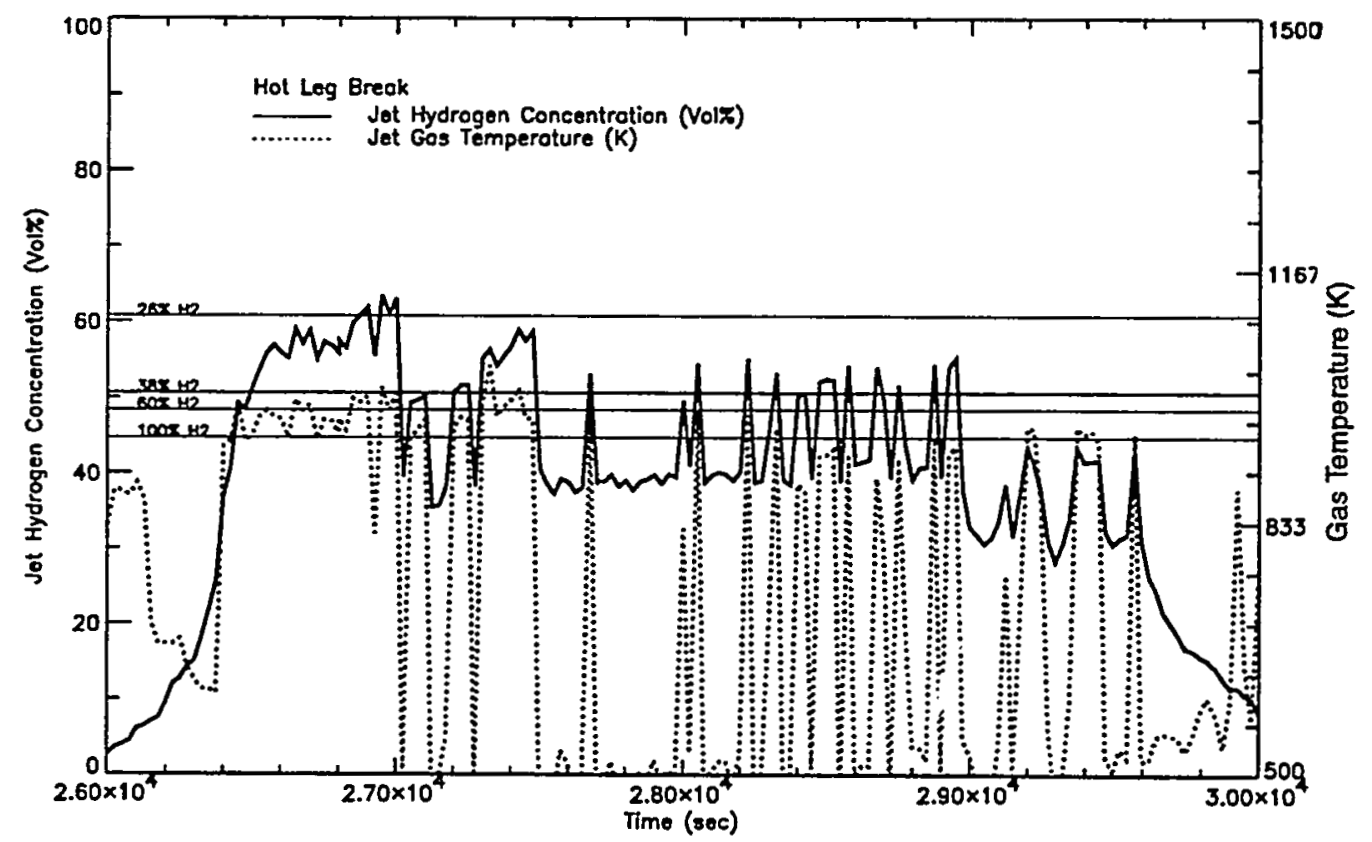

Figure D.21 Jet Hydrogen Concentration and Temperature of the Gases Hot Leg Break 


\title{
APPENDIX E \\ A SCDAP/RELAP5 ANALYSIS SUPPORTING DCH ISSUE RESOLUTION FOR THE SURRY PWR
}

\author{
K. S. Quick and D. L. Knudson \\ Idaho National Engineering Laboratory
}

\section{E.1 INTRODUCTION}

Molten core materials could be ejected into the containment building by a high pressure RCS (reactor coolant system) following reactor vessel failure during certain severe accidents. A rapid rise in containment temperature and pressure, or $\mathrm{DCH}$ (direct containment heating), could result from that HPME (high pressure melt ejection). In an extreme case, the pressurization associated with DCH could lead to containment failure. The potential for such a failure has driven a number of DCH-related studies, including this analysis to support resolution of the issue for the Surry PWR (pressurized water reactor). The support provided centers on a 'best-estimate' SCDAP/RELAP5 (Allison 1993) analysis of core damage progression and the behavior of the RCS during a station blackout without recovery and without operator actions.

A station blackout was considered because core damage and melting could occur, providing a potential for DCH that may or may not develop in many other postulated reactor accidents. Furthermore, it was assumed that the extent of core melting without recovery and without operator actions will reasonably bound conditions that could develop as a result of any other accident.

Analysis of RCS behavior was important because experimental results have indicated that natural circulation flows can develop without operator actions (Stewart 1986 and Stewart 1992). Those flows can redistribute core decay energy, which can lead to creep rupture failures in exvessel pressure boundaries (Bayless 1988 and Knudson 1993). [The surge line, the hot leg nozzles, the SG (steam generator) tubes, and the pressurizer PORVs (power operated relief valves) are the most vulnerable boundaries in the Surry PWR.] Depressurization through an accident-induced failure of the RCS pressure boundary prior to lower head failure could prevent or mitigate the severity of the HPME, and thereby reduce any associated threat to containment integrity. 
And finally, an analysis of core damage progression was needed to determine melt mass, melt composition, melt temperature, and related data that can be used to develop initial conditions that contribute to containment loads. The analysis was performed using a realistic SCDAP/RELAP5 model to provide the best estimate of potential HPME conditions. A separate study of the results (and other appropriate information) is planned to determine if DCH is or is not expected to cause containment failure in the Surry PWR.

A detailed description of the SCDAP/RELAP5 model and the specific calculation performed is provided in Section E.2. SCDAP/RELAP5 results are given in Section E.3 while associated conclusions are summarized in Section E.4. Section E.5 contains a list of references.

\section{E.2 SCDAP/RELAP5 ANALYSIS}

The best-estimate SCDAP/RELAP5 analysis of a station blackout (without recovery and without operator actions) in the Surry PWR is described in this section. The Surry PWR is a Westinghouse-designed nuclear power station with a rated thermal power of $2441 \mathrm{MW}_{\mathrm{t}}$. The core consists of $15715 \times 15$ fuel assemblies with an active fuel height of approximately $3.66 \mathrm{~m}$. There are three primary coolant loops. Each loop contains a U-tube SG, a RCP (reactor coolant pump), and associated piping. A single pressurizer is attached to the hot leg piping in one of the three loops. Two PORVs, with a combined capacity of $45.1 \mathrm{~kg} / \mathrm{s}$, can be used to relieve excess RCS pressure from the top of the pressurizer. One accumulator, with $29,100 \mathrm{~kg}$ of borated water at $322 \mathrm{~K}$, is attached to each cold leg. The accumulators, which are initially pressurized to $4.24 \mathrm{MPa}$ by a nitrogen cover gas, are the only operational part of the ECCS (emergency core cooling system) during a station blackout. A large, dry, subatmospheric containment building surrounds the reactor systems.

The specific station blackout sequence considered is designated TMLB'. This sequence is initiated by the loss of offsite power. Onsite AC (alternating current) power is also unavailable because the diesel generators fail to start or fail to supply power. Decay heat removal cannot be maintained in the long term because there is no $\mathrm{AC}$ power for the electrical pumps and the steam driven auxiliary feedwater pumps also fail to supply water. When the TMLB' sequence begins, power is lost to the control rod drives and pumps. A reactor scram follows, with coastdown of the main feedwater pumps and RCPs. Feedwater is quickly reduced to zero as the main feedwater valves close. The turbine stop valves close and the pressure in the SGs increase until the relief (or dump) valves open. SG pressures are maintained between the opening and closing pressures of 
the relief valves thereafter. Water in the secondaries is completely vaporized as heat is transferred from the RCS to the SGs. Once water in the secondaries is depleted, the SGs no longer remove significant amounts of heat. Core decay energy then heats the RCS, resulting in system pressurization controlled by cycling pressurizer PORVs. The RCS pressure can also be influenced by RCP seal leaks, which could develop following the loss of seal cooling associated with the loss of AC power. After the RCS saturates, a high pressure boiloff begins, ultimately leading to core uncovery and heatup. Without recovery of power or equipment, the transient proceeds to severe core damage and melting.

SCDAP/RELAP5 is an integrated computer code designed for reactor accident analysis. It can be used to simulate a very wide variety of system transients of interest in reactor safety, but it is specifically designed to calculate RCS behavior during severe accidents. SCDAP/RELAP5 was developed by incorporating coding from SCDAP (Berna 1984), TRAP/MELT (Jordan 1985), and COUPLE (Lemmon 1980) into RELAP5 (Allison 1990). SCDAP provides coding for simulation of the reactor core, including logic for oxidation, hydrogen generation, ballooning and rupture of the fuel rod cladding, fission product release, fuel and cladding liquefaction, flow and freezing of liquefied core materials, and associated geometry changes. TRAP/MELT allows simulation of fission product transport and deposition, including aerosol agglomeration, deposition, evaporation, condensation, and the chemisorption of vapors by stainless steel. COUPLE provides coding for two-dimensional, finite-element heat conduction/convection calculations at user specified locations. Such detailed thermal simulation is typically used to represent molten regions in the core and/or lower head. And finally, RELAP5 contains coding to allow simulation of fluid behavior throughout the system, as well as the thermal behavior of structures outside the core, based on a one-dimensional, two-fluid, nonequilibrium, six-equation hydrodynamic representation. Feedbacks between all parts of the code have been developed to allow an integral analysis capability. The user can then provide model input to activate those parts of the code necessary to simulate the problem of interest.

The SCDAP/RELAP5 transient calculation completed in this analysis includes a seal leak rate of $480 \mathrm{gpm}$ per RCP. The calculation required the use of (1) RELAP5 to simulate thermalhydraulics and heat transfer affecting the plant structural mass; (2) SCDAP to simulate core components during degradation, melt, and relocation to the lower reactor vessel head; and (3) COUPLE to represent the lower head during thermal attack by relocated core materials. Generic input for each of those modules is described in Sections E.2.1, E.2.2, and E.2.3, respectively. Input necessary to establish the transient calculation is discussed in Section E.2.4. And finally, 
steady state conditions (developed as a starting point for the transient calculation) are described in Section E.2.5.

Before those sections are given, it should be noted that Release B of MOD3.1, with updates, was used to complete this analysis. The updates included (1) logic to allow user-defined relocation of in-vessel stainless steel into an in-core molten pool or the lower head (as appropriate), (2) logic to allow user control of core relocation to the lower head based on crust stability on the core periphery, and (3) minor error corrections that have been added to subsequent versions.

\section{E.2.1 RELAP5 Input}

RELAP5 input was used to develop a model to represent the thermal-hydraulics of the reactor vessel, all three primary coolant loops, the pressurizer, all three SGs, and selected parts of the secondary systems. The corresponding nodalization for the reactor vessel is shown in Figure E.1. As indicated, five parallel flow channels (with cross connections) extend from the lower plenum through the core to the upper reactor vessel head. If the appropriate conditions exist, this nodalization will allow development of in-vessel natural circulation. Core components, which will be discussed in detail in Section E.2.2, are represented by the shaded regions. Heat structures, which are represented by those areas filled with slanted lines, were included to simulate the structural mass of the reactor vessel walls, the core barrel and baffle, the thermal shield, the upper and lower core plates, and other structures in the upper and lower plena. The external surfaces of all structures were assumed to be adiabatic, with the exception of the lower reactor vessel head as discussed in Section E.2.3.

Modeling provisions were made to monitor the temperature of upper plenum stainless steel structures in this analysis. If a given structure temperature reached the melting point, that structure was relocated to the in-core molten pool (if one existed) or to the lower head through user-defined slumping input. (As previously indicated, user-defined slumping input was added to Release B of SCDAP/RELAP5/MOD3.1 for this analysis.) In addition, a modeling approximation was developed to account for thin (cross-section) stainless steel structures in the lower head that would be expected to melt as a result of being submerged in relocated core materials. Specifically, it was estimated that there is about $7.8 \mathrm{mt}$ of thin stainless steel in the lower head of the Surry PWR. An assumption that the thin steel was a linear function of height (between the bottom of the lower head and the bottom of the core) and the depth of relocated debris was used to estimate the 
amount of thin stainless steel that would be expected to melt. The appropriate mass was then added to the lower head debris through the user-defined slumping input.

A junction connecting the top of the downcomer (Component 102) to the upper plenum (Component 172) at the hot leg elevation is shown in Figure E.1. This junction represents a small leak path associated with clearances between the hot leg nozzles (which are welded to the reactor vessel wall) and the internal hot leg piping (which is welded to the core barrel). The resulting gap in the hot leg piping, which allows some flow to bypass the core, is a design requirement to allow removal of the core internals.

Nodalizations of the primary coolant loop containing the pressurizer are shown in Figures E.2 and E.3. With the exception of the pressurizer and associated surge line piping, similar nodalizations were included in the model to separately represent the other two primary coolant loops in the Surry PWR.

As indicated in Figures E.2 and E.3, both fluid volumes and heat structures were included to represent the primary coolant loop piping, the pressurizer and associated surge line, and the SG with associated relief valves. Without AC power, accumulators are the only part of the ECCS that required simulation. The SG main feedwater system and associated piping were only needed to establish steady-state conditions prior to transient initiation. Auxiliary feedwater systems were not modeled because they are not operational in the subject transient. The external surfaces of all heat structures were assumed to be adiabatic. Relative elevations for the reactor vessel and primary coolant loop models (referenced to the bottom of the lower head) are listed in Table E.1.

Model input was included to track the potential for creep rupture failures in the surge line, hot leg nozzles, and SG tubes. Consistent with the best-estimate approach of this analysis, a break was introduced at the appropriate location in the RCS pressure boundary if rupture was predicted. However, the break size was assumed to be constant at $0.01769 \mathrm{~m}^{2}$ regardless of where the rupture occurred. That break size was derived from a previous Surry study where creep rupture failure was estimated to result in a break that was approximately $32.3 \%$ of the surge line flow area (Bayless 1988). The constant break area used was calculated by applying that fraction to the Surry surge line flow area of $0.05477 \mathrm{~m}^{2}$. Obviously, this flow area would be too large to represent creep rupture failure of a SG tube. However, scoping calculations indicated that SG tube failures will not occur prior to lower head failure. Other uncertainties associated with this simplification, 
which will be discussed in Section E.3.1, are not expected to be significant with respect to resolution of the DCH issue for the Surry PWR.

A single valve was used to represent both pressurizer PORVs in the Surry PWR. The valve was appropriately sized to provide the combined flow capacity of the PORVs. Similarly, a single valve was used to represent all three pressurizer SRVs (safety relief valves), although the SRVs were not challenged in this analysis. It was assumed that plant air and battery power were sufficient to operate the PORVs throughout the transient. Furthermore, the potential for other PORV failure modes was not considered.

Valves were also used to allow simulation of RCP seal leaks. As indicated in Figures E.2 and E.3, leaks were modeled at the discharge elevation of each RCP. (SCDAP/RELAP5 allows only one connection to a pump outlet. However, the inlet of the connected pipe is hydraulically equivalent to the RCP outlet in the code.) The relationship between transient time and valve flow areas used to model seal leakage in this analysis is described in Section E.2.4.

RCP seal leaks, discharges from the pressurizer, and break flows (if creep rupture occurs) were directed into a component representing the Surry containment (see Figures E.2 and E.3). Component input included the total containment volume and estimates of the total mass of concrete and steel. However, the calculated containment pressure was expected to be high (by as much as a factor of 2) since there was no attempt to model the containment in detail. Detailed modeling was not justified because flows from the RCS will be choked most of the time in the calculation and because a separate (detailed) analysis is planned to provide a full evaluation of containment response.

The nodalization shown in Figure E.2 was used in conjunction with the reactor vessel nodalization from TMLB' initiation to the onset of core heatup. (In this analysis, the onset of core heatup was assumed to correspond to a core exit superheat of at least $2.78 \mathrm{~K}$ coincident with a void fraction of at least 0.95 .) During this portion of the transient, full loop natural circulation of subcooled and saturated liquid can develop. As the core heats the primary coolant toward saturation, however, voids begin to form and collect in the top of the SG U-tubes. When that occurs, full loop natural circulation of liquid is interrupted.

At the onset of core heatup, Figure E.2 nodalization was replaced by Figure E.3 nodalization. This substitution provided flow paths needed to allow simulation of hot leg 
countercurrent natural circulation. Hot leg countercurrent natural circulation became possible after saturated liquid in the hot legs flashed and/or drained to the vessel. At that time, temperature gradients from the core to the SG U-tubes can drive steam flow along the top half of the hot leg (Components 400, 402, and 404), through a portion of the SG U-tubes (Component 408), and back to the vessel through a cooler portion of the SG U-tubes and the lower half of the hot leg (Components 409 and 430, respectively). (It should be noted that the nodalization shown in Figure E.3 will also support development of full loop natural circulation of steam if RCP loop seals clear.)

Development of the hot leg countercurrent flow model was based on a previouslydeveloped Surry model (Bayless 1988) and Westinghouse experimental data (Stewart 1992) as follows. Flow areas (which are dependent on hot leg and SG tube splits) and loss coefficients controlling countercurrent flow were extracted directly from the Surry model and incorporated into a new Surry input deck (which is compatible with the current code version). That was justified because the previous Surry model was developed to match loop heat transfer based on experimental data.

Specifically, flow areas and loss coefficients were adjusted in the previous analysis so that a total of $29.4 \%$ of the energy generated in the core would be transferred to the three primary coolant loops in the Surry PWR during a fixed time period following the onset of countercurrent natural circulation. However, the energy transferred to the loops was found to be lower when the current version of SCDAP/RELAP5 (i.e., MOD3.1) was used with new Surry model. In other words, changes in SCDAP/RELAP5 (from 1988 to the present) resulted in reduced countercurrent heat transfer. A detailed investigation was not conducted, however, it appeared that recent changes in the correlation used in the code to calculate heat transfer in tube bundles (i.e., the SGs) could be a factor in the observed reduction. An appropriate model adjustment was required to match the experimental data on loop heat transfer rates in order to perform a best-estimate analysis.

The adjustment process was completed by altering loss coefficients used in the nodalization shown in Figure E.3. [Flow areas associated with dividing the hot leg and assigning $35 \%$ of the SG tubes for hot flow were not changed (Bayless 1988)]. Loss coefficient alterations were made to establish loop heat transfer (as discussed above) and to refine flow patterns consistent with experimental data. Specifically, data indicated that hot and cold mixing fractions should be approximately 0.87 (Stewart 1992). (The hot mixing fraction is the fraction of hot leg 
flow entering the SG inlet plenum that is mixed with plenum steam before entering the tubes. Conversely, the cold mixing fraction is the fraction of tube flow entering the SG inlet plenum that is mixed with plenum steam before returning to the vessel through the bottom half of the hot leg.) The data also indicated that the recirculation ratio should be about 1.9 (Stewart 1992). (The recirculation ratio is the SG tube flow divided by the hot leg flow. A ratio greater than one indicates that SG tube-to-plenum-to-SG tube recirculation is larger than the flow entering the SG inlet plenum from the hot leg).

A trial-and-error method was required to complete the adjustment process. The process was considered complete when heat transfer, mixing fractions, and recirculation ratios in all three primary coolant loops were in reasonable agreement with target values. A comparison of the target values with the final model calculation is given in Table E.2 as evidence that an acceptable adjustment was made. Loss coefficients from the final iteration were then used in this analysis.

A horizontal section of the surge line in the Surry PWR connects to the centerline of the hot leg pipe. That orientation required a surge line split to represent potential countercurrent flow in a fashion similar to the rest of the loop piping (as indicated in Figure E.3). The normal connections for the split nodalization are the connection between the top of the hot leg and the top of the surge line and the connection between the bottom of the hot leg and the bottom of the surge line. In addition to the normal connections, connections were provided so that the bottom of the hot leg can communicate with the top of the surge line and the top of the hot leg can communicate with the bottom of the surge line. Those connections, which are illustrated in Figure E.4, include two valves (Components 463 and 465) and two sections of pipe (Component 462 and 464) to compensate for centerline-to-centerline elevation differences between the hot leg pipe halves and surge line pipe halves. The valves were configured to open and close with the pressurizer PORV, providing a best-estimate approach for modeling the surge line response as follows.

The valves prevent hot to cold (top to bottom) communication when the PORV is closed, which allows development of countercurrent flow in the horizontal section of the surge line. When the PORV opens, the valves open allowing both hot and cold flow streams to be drawn into both halves of the surge line, as one would expect. In addition, any undrained pressurizer liquid can only flow toward the reactor vessel through the bottom halves of the surge line and hot leg. Interface drag prevents liquid draining when the PORV is open and the valves (realistically) prevent liquid from getting into the top half of the hot leg pipe when the PORV is closed. 


\section{E.2.2 SCDAP Input}

Two criteria were used to establish the five flow channels shown in Figure E.1. The first (and most important) consideration was to split the core so that similarly powered fuel assemblies could be grouped together. Splitting the core into channels with similar flow areas was a secondary consideration. Cross sections of the resulting five channel model are shown in Figures E.5 and E.6. [Data needed for developing the split and the balance of the SCDAP input was largely based on the UFSAR (Updated Final Safety Assessment Report) for the Surry PWR.]

The $15 \times 15$ assemblies in each flow channel contain 204 fuel rods and a total of 21 lattice positions for control rods and instrument tubes. The fuel rods have a $\mathrm{Zr}$ clad and an active $\left(\mathrm{UO}_{2}\right)$ length of approximately $3.66 \mathrm{~m}$. An initial fuel rod pressure of $5.29 \mathrm{MPa}$ was assumed. The control rod material is Ag-In-Cd in the ratio of 80-15-5. Control rods are clad with stainless steel and are configured for insertion into $\mathrm{Zr}$ guide tubes. With only $48 \mathrm{CRAs}$ (control rod assemblies), about $69.4 \%$ of the control rod guide tubes in the Surry PWR are empty.

A SCDAP fuel rod component was required in each channel to represent the fuel rods. Based on a previously developed approach (Knudson 1993), a SCDAP control rod component was used in the outer four channels to represent the control rods, empty control rod guide tubes, and instrument tubes. The center channel contains only empty guide tubes which were represented by a SCDAP water rod component. Therefore, the core model was composed of a total of 10 SCDAP components. Ten axial nodes were assigned to each component consistent with the hydrodynamic nodalization shown in Figure E.1.

The SCDAP/RELAP5 implementation of a 1979 ANS (American Nuclear Society) Standard was used to calculate core decay heat. Specifically, ANS 79-3 with three fissile isotopes $\left({ }^{235} \mathrm{U},{ }^{238} \mathrm{U}\right.$, and $\left.{ }^{239} \mathrm{Pu}\right)$ and a $2 \mathrm{yr}$ average burnup was assumed. A chopped-cosine axial power profile was also used. A peak-to-average power ratio of 1.154 in the third axial node characterized that profile. (Data defining the radial power profile was provided in Figure E.5.)

SCDAP input is required to define certain core damage parameters. The values used in this analysis are listed in Table E.3. The following outlines the logic used to establish the values.

Debris formation during core degradation results in flow restrictions, which will affect core heatup. Until fully mechanistic models are developed, the user must specify the flow area to 
be applied in core regions where cohesive debris has formed. Any input from 0 to $100 \%$ of the nominal flow area can be specified. However, the current version of the code will set the debris flow area to zero for all inputs of $10 \%$ or less. It was clear that an input greater than $10 \%$ was needed since a flow area of zero corresponds to coplanar blockage, which has not been observed in tests performed to date. Unfortunately, there is no other basis for setting the input at this time. However, selecting large values will tend to delay core heating and melting, which could be nonconservative with respect to the potential for HPME and DCH. Therefore, the minimum flow area through cohesive debris was set to $11 \%$ of the nominal flow area as indicated in Table E.3. Although that value is on the low end of the expected range, there is insufficient data to justify larger values without the risk of generating non-defensible results.

Relocation of the core to the lower head cannot occur until melt develops and/or spreads to the core periphery in the current version of the code. There are then two options for controlling relocation. In the first option, a simple model is used to estimate the thermal stability of a peripheral oxide crust. Relocation occurs when the crust is estimated to melt. In the second option, relocation occurs as soon as the melt reaches the periphery. (Those options are considered an interim solution until a mechanistic crust failure model is completed.) The second option was used because an early relocation could occur, which could affect the potential for HPME.

Debris-to-coolant heat transfer is either on or off in the current version of SCDAP/RELAP5. Debris quenching occurs with the heat transfer turned on, up to the limit imposed by the amount of water available in the lower head. The potential for pressurization associated with quenching was of interest in this analysis because of the corresponding implications on HPME and the DCH issue. On that basis, heat transfer was turned on as indicated in Table E.3.

\section{E.2.3 COUPLE Input}

The COUPLE representation of the reactor vessel lower head is shown in Figure E.7. The axisymetric mesh includes a total of 320 nodes with 285 elements. Two elements were used to represent the thickness of the carbon steel portion of the lower head, with an adjoining single element representing the stainless steel liner. (Because the liner is very thin, the elements representing it appear to be a heavy line in the figure.) Remaining elements were initially filled with primary coolant, which can boil and/or be displaced as debris relocates from the core. 
Heat transfer from relocated debris to the lower head will be affected by the debris roughness and any gases that become trapped between the debris and the vessel wall. A layer of zero-width elements was aligned with the inner surface of the lower head to provide a way to simulate that contact resistance. A constant coefficient of $500 \mathrm{~W} / \mathrm{m}^{2}-\mathrm{K}$ was used to represent the heat transfer across that gap in all calculations. Code-calculated convection heat transfer to the containment atmosphere was modeled on the external surface of the lower head.

\section{E.2.4 Transient Calculation}

The SCDAP/RELAP5 transient calculation completed in this analysis included RCP seal leakage. (As previously discussed, best-estimate input was used to develop the rest of the model.) Under normal operating conditions, high pressure systems provide cooling water flow to the seals to offset a design leak rate of approximately $3 \mathrm{gpm}$ per RCP. However, the loss of all AC power results in a loss of seal cooling water. Without cooling water, leak rates increase as RCP seal temperatures increase. Leak rates of $21 \mathrm{gpm}$ per RCP have been calculated for intact RCP seals subjected to normal RCS temperatures and pressures (Boardman 1985).

Leak rates will be higher if one or more of the three seal stages in a Westinghouse RCP fail. The primary factors affecting seal behavior during a TMLB' sequence are high temperature survivability and the potential for hydraulic instability under two-phase flow conditions (Ruger 1989). Unfortunately, the prediction of failure of any particular seal stage (which leads to a particular leak rate) is not straightforward. For that reason, a panel of experts was assembled to make a probabilistic determination of RCP leak rates in Westinghouse PWRs for use in completing NUREG-1150 (Wheeler 1989). The panel concluded that the maximum leak rate (with a low probability) was $480 \mathrm{gpm}$ per RCP. Based on results from the experts, a leak rate of $21 \mathrm{gpm}$ per RCP was introduced at TMLB' initiation in this analysis to represent leakage associated with the loss of seal cooling. The maximum leak rate of $480 \mathrm{gpm}$ per RCP was then introduced at the time saturated conditions were reached at the pumps.

\section{E.2.5 Steady State}

Steady state initialization of the SCDAP/RELAP5 model was required to provide a starting point for the transient calculation. Initialization involved bringing the model to a stable state representing full power operation of the Surry PWR. Initialization was considered acceptable when calculated conditions and published operating conditions (from the Surry 
UFSAR) were in reasonable agreement. A comparison of selected parameters is provided in Table E.4 as evidence that an appropriate initialization was achieved.

\section{E.3 RESULTS}

A best-estimate SCDAP/RELAP5 analysis of a TMLB' transient in the Surry PWR with a seal leak rate of $480 \mathrm{gpm}$ per RCP was completed. The sequence of events for this case is listed in Table E.5 while DCH related-parameters are given in Table E.6. The tables provide quantitative information that may be helpful in conjunction with the following transient description.

The reactor scrammed and RCPs tripped due to the loss of AC power at TMLB' initiation (at $0 \mathrm{~s}$ ). Seal leaks of $21 \mathrm{gpm}$ per RCP were introduced at that time to simulate leakage associated with the loss of seal cooling that would accompany the loss of AC power. An initial RCS pressure reduction occurred because boiling on the SG secondary side was sufficient to remove core decay heat and cool the RCS. However, the SG heat sinks were not sustainable without feedwater. As a result, the RCS pressure began to increase following SG dryout (at 4800-5000 s). The pressure increase terminated at the pressurizer PORV opening set point, which was reached at $6020 \mathrm{~s}$ as indicated in Figure E.8. A gradual RCS heatup and boiloff followed where PORV cycling providing pressure control between 15.8 and $16.3 \mathrm{MPa}$.

Saturated conditions were reached at the RCPs at $7638 \mathrm{~s}$. Seal leaks were increased to $480 \mathrm{gpm}$ per RCP at that time to simulate failures that could develop with two-phase flow across the seal faces. That rate corresponds to the maximum leakage that would be expected if all seal stages in a Westinghouse RCP failed (Boardman 1985 and Wheeler 1989).

Core decay heat was transported to the SGs by full loop natural circulation of liquid until $7692 \mathrm{~s}$. By that time, vapor generated in the core had collected in the top of the SG U-tubes, preventing further liquid circulation. Energy dissipated through RCP seal leaks exceeded core decay heat by $8980 \mathrm{~s}$. As a result, the RCS pressure dropped below the PORV set point, which ended further PORV cycling as indicated in Figure E.8. The pressure reduction resulting from RCP seal leak flows persisted until the initial accumulator pressure of $4.24 \mathrm{MPa}$ (and the associated injection) was reached at $12362 \mathrm{~s}$.

As indicated in Figure E.9, the first core uncovery began at $8783 \mathrm{~s}$ and was complete by $10372 \mathrm{~s}$ as a result of boiling and venting through the RCP seals. By $8900 \mathrm{~s}$, voiding in the SG 
tubes and hot legs allowed development of hot leg countercurrent natural circulation. Heat transfer to the ex-vessel piping by the countercurrent flow produced a heatup and an associated creep rupture failure of the hot leg in the pressurizer loop at $22975 \mathrm{~s}$ as indicated in Figure E.10. (It is important to note that SG tubes were not predicted to fail at any time during this calculation since they remained relatively cool as indicated in Figure E.10).

A $0.150 \mathrm{~m}$ diameter break was introduced at the time of hot leg failure, allowing further RCS pressure reduction and injection of the remaining accumulator inventory. The accumulators emptied at $23200 \mathrm{~s}$, with a core collapsed liquid level $\sim 0.22 \mathrm{~m}$ below the top of the fuel rods. A second heatup and boiloff at low RCS pressure followed, with a second (and final) core uncovery completed at $24056 \mathrm{~s}$ as indicated in Figure E.9.

The first formation of an in-core molten pool occurred as a result of heating to ceramic melt conditions at $12213 \mathrm{~s}$. However, accumulator injewere immediately relocated to the lower headctions (starting at $12362 \mathrm{~s}$ ) delayed further melting until $27649 \mathrm{~s}$, when control rod absorber materials began to melt and relocate to the lower head. Core melting followed since accumulators (the only cooling water source) emptied by $23200 \mathrm{~s}$. The melt spread both axially and radially until the pool reached the core periphery at $32406 \mathrm{~s}$. At that time, the contents of the in-core molten pool (58 $648 \mathrm{~kg}$ of $\mathrm{UO}_{2}, 14966 \mathrm{~kg}$ of $\mathrm{ZrO}_{2}$ ) was relocated to the lower head over a $60 \mathrm{~s}$ time period, resulting in a final debris depth of about $1.36 \mathrm{~m}$ as indicated in Figure E.11. (Note that some debris had accumulated from prior relocations of control rod materials.) It was estimated that $5420 \mathrm{~kg}$ of thin cross-section lower plenum stainless steel would be submerged by the relocated core materials. Therefore, that steel was added to the lower head debris bed assuming that it would melt as a result of being submerged. Following the first core relocation to the lower head, a second relocation of molten materials $\left(4976 \mathrm{~kg}\right.$ of $\mathrm{UO}_{2}$ and $1170 \mathrm{~kg}$ of $\left.\mathrm{ZrO}_{2}\right)$ took place at $36260 \mathrm{~s}$.

Partial quenching of the debris was calculated during the relocations. However, quenching was limited by the amount of water available in the lower head. The amount of water was limited because some of it was vaporized, some of it was displaced by relocating debris, and some of the water was pushed out of the lower head by the pressurization associated with the vapor generation. Consequently, the debris was only cooled from $2873 \mathrm{~K}$ to about $2560 \mathrm{~K}$ during relocation as indicated in Figure E.12. A gradual heatup of the debris then followed as indicated in the figure. Once quenching was complete, the remaining coolant settled on top of the lower head debris and heatup of the lower head began. A corresponding failure of the lower head as a 
result of creep rupture was predicted at $36780 \mathrm{~s}$. The failure location was approximately $0.66 \mathrm{~m}$ above the bottom of the inside surface of the lower head.

The RCS pressure at the time of failure was about $0.16 \mathrm{MPa}$ with the water inventory shown in Figure E.13. A total of $383.6 \mathrm{~kg}$ of hydrogen was produced through oxidation of about $54 \%$ of the in-core $\mathrm{Zr}$ as indicated in Figure E.14. All of the generated hydrogen was ultimately vented into containment, primarily through RCP seal leaks as indicated in Figure E.15. Molten material relocation after $32406 \mathrm{~s}$ was not predicted.

\section{E.3.1 Uncertainties}

Numerous uncertainties arise when any detailed analysis is performed with a complex computer code like SCDAP/RELAP5. In this case, there are uncertainties that could impact the predicted melt mass, melt composition, and other results that could be used to establish DCH initial conditions for the Surry PWR. There are also uncertainties that could impact the potential for HPME through their influence on the timing of predicted RCS pressure boundary failures. However, only uncertainties falling into the second category are discussed here because SCDAP/RELAP5 results indicate that HPME will not occur in the Surry PWR during the subject TMLB' sequence. Since HPME is not predicted to occur, the melt mass and other DCH initial conditions are inconsequential. On the other hand, any uncertainties that could alter conclusions relative to the potential for HPME in the Surry PWR merit further discussion as outlined below.

It was recognized that hot leg countercurrent natural circulation would control ex-vessel heating and the timing of ex-vessel failures before this analysis began. Therefore, a significant effort was focused on development of a best-estimate model of countercurrent natural circulation in the Surry PWR (within time and budget constraints). The resulting model closely correlates with previous SCDAP/RELAP5 analyses and available experimental data. Results using that model indicate that the hot leg will fail $9431 \mathrm{~s}$ before relocation into the lower head begins and $13730 \mathrm{~s}$ before the lower head would fail in the sequence considered. Those margins will increase if heat transfer by hot leg countercurrent natural circulation was underpredicted and conversely, the margins will decrease if the heat transfer was overpredicted. Because experimental data is limited, there is also a possibility that the heat transfer was overpredicted to the point where lower head failure would actually occur before a hot leg (or other ex-vessel) failure. However, the potential for that result appears to be very unlikely based on the current understanding of hot leg countercurrent natural circulation. 
The current version of SCDAP/RELAP5 does not allow relocation of the core into the lower head until melt develops and spreads to the core periphery. This restriction appears to be reasonable based on preliminary hand calculations indicating that stresses are much higher (and therefore, failure is more likely) in side wall crusts of an in-core crucible than in bottom crusts of the same thickness (personal communication with S. A. Chavez, Idaho National Engineering Laboratory, Idaho Falls, ID). Furthermore, natural circulation within the molten pool should result in relatively thin side wall crusts, providing an additional factor favoring side failure before bottom failure. However, there is no known experimental or analytical verification supporting this code feature. Therefore, some uncertainty in the results of this analysis must be acknowledged. Although it is expected to be unlikely, an early bottom crust failure could allow core relocation with a potential for lower head failure before ex-vessel failure.

There are two options in the current version of SCDAP/RELAP5 for controlling relocation to the lower head once melt is established on the core periphery. The option allowing relocation as soon as melt reaches the periphery was used in this analysis. That approach neglects the potential relocation delay that could occur as a result of side wall crust stability. However, accounting for side wall crust stability did not appear necessary since hot leg failure was predicted well ahead of core relocation (and associated lower head failure).

A constant coefficient of $500 \mathrm{~W} / \mathrm{m}^{2}-\mathrm{K}$ was used to represent debris/vessel heat transfer in this analysis. However, there is a considerable amount of uncertainty in this parameter, primarily because the surface roughness at the debris/vessel interface in severe reactor accidents has not been characterized. It is important to note that this uncertainty is not critical with respect to the potential for HPME in this analysis since hot leg failure was predicted to occur $9431 \mathrm{~s}$ before relocation. In other words, an infinite coefficient, which would have led to an almost instantaneous failure of the lower head, could have been used without changing the results relative to the potential for HPME.

The current version of SCDAP/RELAP5 provides two options for heat transfer between debris and coolant during core relocation into the lower head. In the first option, debris is relocated without heat transfer, providing the potential for a relatively early lower head failure. Relocating debris is quenched in the second option, within limits imposed by the amount of - coolant available in the lower head. The second option was used in this analysis because the potential for repressurization associated with debris quenching was considered the best estimate while the first option is biased to accelerate lower head failure. However, the results indicate that 
either option could have been used without impact on the potential for HPME. Specifically, a relatively early lower head failure would not alter conclusions relative to the potential for HPME because hot leg failure was predicted well ahead of core relocation. In addition, the potential for HPME was not affected by any repressurization because there was a relatively small amount of water available for quenching (as a result of a hot leg break) and because there was sufficient time to vent excess vapor and reduce RCS pressures before failure of the lower head.

Creep rupture failure of the hot leg was predicted in the TMLB' sequence considered in this analysis. A corresponding hot leg break was introduced at the predicted failure time, consistent with the best-estimate nature of this calculation. However, a constant break flow area of $0.01769 \mathrm{~m}^{2}$ was used based on a previous estimate for creep rupture of the Surry surge line. Although one would expect a larger break flow area to develop in the hot leg (since it is larger than the surge line), a more rigorous evaluation of breaks resulting from creep rupture was avoided by using that break flow area. Furthermore, it is clear that this simplification had no adverse impact on the results of this analysis since the break area was large enough to allow rapid and complete depressurization of the RCS. A slightly faster depressurization associated with the use of a larger (and perhaps, more defensible) break flow area would be insignificant, given the predicted margin of $13730 \mathrm{~s}$ between hot leg and lower head failures.

Uncertainties in the prediction of ex-vessel creep rupture are believed to be relatively small because rupture depends on natural convection heating and the corresponding creep damage response, which are experimentally based. Unfortunately, there are numerous (and potentially large) uncertainties in the simulation of core melt progression leading to melt relocation and lower head failure, primarily because there is a lack of experimental data for thorough validation of the late phase core damage models. However, those uncertainties are not expected to be large enough to offset the large predicted margin between hot leg and lower head failures. In other words, the uncertainties are not expected to change the respective ordering of the RCS pressure boundary failures.

\section{E.4 CONCLUSIONS}

A best-estimate SCDAP/RELAP5 analysis of the Surry PWR during a TMLB' sequence without recovery and without operator actions was completed. The analysis was designed to evaluate the behavior of the RCS and the progression of core damage with seal leaks of $480 \mathrm{gpm}$ per RCP. Conclusions developed on the basis of this analysis are presented below. 
Natural circulation of steam (and steam flow associated with pressurizer PORV cycling) will induce creep rupture failures in the hot leg piping before failure of the lower head.

Hot leg countercurrent natural circulation of steam will be established in the Surry PWR after the SG tubes and the hot legs are voided. Decay energy is transferred from the core to structures in the primary coolant loops by that flow. Steam flows associated with PORV cycling will also transfer heat to the loop structures until RCS pressures are reduced by the RCP seal leaks. As a result, the hot leg will be heated to the point of creep rupture failure before failure of the lower head.

The RCS will depressurize through the hot leg failure before the lower head fails.

The hot leg break that develops as a result of creep rupture will allow a rapid depressurization of the RCS. As the pressure drops, all available accumulator inventories will be injected into the core. Some RCS repressurization can occur during the injection, depending on the amount of accumulator water available and the condition of the core. However, any excess steam will be vented through the hot leg break, allowing complete depressurization of the RCS to the containment pressure long before the lower head fails.

HPME is unlikely in the Surry PWR during a station blackout with seal leaks of 480 gpm per $R C P$.

The SCDAP/RELAP5 results for the TMLB' sequence considered indicates that the margin between RCS depressurization (through the hot leg break) and lower head failure is large. Although uncertainties in the results were identified, the uncertainties do not appear to provide support for any condition where the lower head could fail before failure of the hot leg. Since hot leg failure and complete RCS depressurization is expected, HPME in the Surry PWR during the sequence considered appears to be unlikely.

Conditions in the lower head at the time of failure will be characterized by a low $R C S$ pressure and a relatively large oxidic melt mass.

The RCS pressure will be at (or very near) the containment pressure at the time of lower head failure as a result of a (relatively early) hot leg failure. The total oxidic debris $\left(\mathrm{UO}_{2}\right.$ plus 
$\mathrm{ZrO}_{2}$ ) in the lower head will be about $74 \mathrm{mt}$. However, a fraction of that debris will be solidified as heat is transferred from the melt to the lower head. Therefore, the molten mass of oxidic debris (available for ejection into the containment building) will be somewhat lower.

The conclusions of this analysis are specific to the Surry PWR but should be applicable to Surry-like PWRs.

This analysis was based on a best-estimate SCDAP/RELAP5 model to determine the Surry PWR response during a specific TMLB' sequence. Therefore, the results and conclusions of this analysis are specific to the Surry PWR. However, the results and conclusions of this analysis should be applicable to other three loop Westinghouse PWRs with similar geometries and core powers.

\section{E.5 REFERENCES}

- Allison, C. M., et al. (1990). RELAP5/MOD3 Code Manual, NUREG/CR-5535, EGG-2596 (Draft), Volumes 1-4, Idaho National Engineering Laboratory, Idaho Falls, ID.

- Allison, C. M., et al. (1993). SCDAP/RELAP5/MOD3.l Code Manuals, Volumes 1-5, NUREG/CR-6150, EGG-2720, Idaho National Engineering Laboratory, Idaho Falls, ID.

- Bayless, P. D. (1988). Analyses of Natural Circulation During a Surry Station Blackout Using SCDAPIRELAP5, NUREG/CR-5214, EGG-2547, Idaho National Engineering Laboratory, Idaho Falls, ID.

- Berna, G. A., et al. (1984). SCDAP/MOD1/V0: A Computer Code for the Analysis of LWR Vessel Behavior During Severe Accident Transients, IS-SAAM-83-002, Revision 1, Idaho National Engineering Laboratory, Idaho Falls, ID.

- Boardman, T., et al. (1985). Leak Rate Analysis of the Westinghouse Reactor Coolant Pump, NUREG/CR-4294, 85-ETEC-DRF-1714, Rockwell International Corporation, Canoga Park, CA.

- Jordan, H., et al. (1985). TRAP-MELT2 User's Manual, NUREG/C'R-4205, BMI-2124, Battelle Memorial Institute, Columbus, $\mathrm{OH}$.

- Knudson, D. L., and C. A. Dobbe (1993). Assessment of the Potential for High Pressure Melt Ejection Resulting from a Surry Station Blackout Transient, NUREG/CR-5949, EGG-2689, Idaho National Engineering Laboratory, Idaho Falls, ID. 
- Lemmon, E. C. (1980). COUPLE/FLUID: A Two-Dimensional Finite Element Thermal Conduction and Advection Code, EGG-ISD-SCD-80-1, Idaho National Engineering Laboratory, Idaho Falls, ID.

- Ruger, C. J., et al. (1989). Technical Findings Related to Generic Issue 23: Reactor Coolant Pump Seal Failure, NUREG/CR-4948, BNL-NUREG-521444, Brookhaven National Laboratory, Upton, NY.

- Stewart, W. A., et al. (1986). "Experiments on Natural Circulation Flows in Steam Generators During Severe Accidents", Proceedings of the International ANS/ENS Topical Meeting on Thermal Reactor Safety, American Nuclear Society, San Diego, CA.

- Stewart, W. A., et al. (1992). Natural Circulation Experiments for PWR High Pressure Accidents, EPRI Project No. RP2177-5 Final Report, Westinghouse Electric Corporation, Pittsburgh, PA.

-Wheeler, T. A., et al. (1989). Analysis of Core Damage Frequency From Internal Events: Expert Judgement Elicitation, NUREG/CR-4550, SAND86-2084, Volume 2, Sandia National Laboratories, Albuquerque, NM. 
Table E.1.

SCDAP/RELAP5 model elevations relative to the lower reactor vessel head

\begin{tabular}{||l|c|}
\hline Location & Relative Elevation (m) \\
\hline Inside surface of the bottom of the lower head (reference) & 0 \\
\hline Bottom of the active core & 3.064 \\
\hline Top of the active core & 6.722 \\
\hline Surge line (at the connection to the hot leg piping) & 8.089 \\
\hline Hot leg nozzle & 8.089 \\
\hline RCP seal leak & 8.089 \\
\hline Pressurizer PORV & 23.13 \\
\hline Pressurizer SRV & 23.13 \\
\hline
\end{tabular}

Table E.2.

Comparison of countercurrent flow parameters with values calculated by SCDAP/RELAP5

\begin{tabular}{|l|c|c||}
\hline \hline Parameter & Target Value & Calculated Value \\
\hline Fraction of core energy absorbed by all primary coolant loops & $0.29^{\mathrm{a}}$ & 0.29 \\
\hline Hot mixing fraction (range: $0.85-0.89$ ) & $0.87^{\mathrm{b}}$ & $0.87^{\mathrm{c}}$ \\
\hline Cold mixing fraction (range: $0.85-0.89$ ) & $0.87^{\mathrm{b}}$ & $0.87^{\mathrm{c}}$ \\
\hline Recirculation ratio (range: 1.7-2.2) & $1.9^{\mathrm{b}}$ & $1.9^{\mathrm{c}}$ \\
\hline $\begin{array}{l}\text { a. Derived from a previous SCDAP/RELAP5 analysis of hot leg countercurrent natural circulation (Bayless 1988). } \\
\text { b. Derived from experiments conducted by Westinghouse (Stewart 1992). } \\
\text { c. Represents an average for the three primary coolant loops in the Surry PWR. }\end{array}$ \\
\hline
\end{tabular}


Table E.3.

SCDAP core damage input

\begin{tabular}{|l|c|}
\hline Parameter & Value \\
\hline Minimum cohesive debris flow area & $11 \%$ of nominal \\
\hline Early relocation (relocation to lower head when melt spreads to core periphery) & yes \\
\hline Molten pool relocation time interval & $60 \mathrm{~s}$ \\
\hline Debris-to-coolant heat transfer during core relocation to the lower head & yes \\
\hline
\end{tabular}

Table E.4.

Surry UFSAR steady state parameters compared to values calculated by SCDAP/RELAP5

\begin{tabular}{||l|c|c||}
\hline \hline Parameter & UFSAR Value & Calculated Value \\
\hline Reactor power $(\mathrm{MW})$ & 2441 & 2441 \\
\hline Pressurizer pressure $(\mathrm{MPa})$ & 15.5 & 15.5 \\
\hline Pressurizer liquid level $(\mathrm{m})$ & 6.62 & 6.62 \\
\hline Coolant flow per loop $(\mathrm{kg} / \mathrm{s})$ & 4230 & 4229 \\
\hline Cold leg temperature $(\mathrm{K})$ & 557.0 & 557.0 \\
\hline Hot leg temperature $(\mathrm{K})$ & 591.9 & 591.7 \\
\hline SG pressure $(\mathrm{MPa})$ & 5.41 & 5.40 \\
\hline Feedwater flow per $\mathrm{SG}(\mathrm{kg} / \mathrm{s})$ & 441.8 & 443.5 \\
\hline Liquid mass in each SG $(\mathrm{kg})$ & 44000 & 43999 \\
\hline
\end{tabular}


Table E.5.

Sequence of events

\begin{tabular}{|c|c|}
\hline Event & Time (s) \\
\hline TMLB' initiation & 0 \\
\hline Introduction of seal leaks of $21 \mathrm{gpm}$ per RCP; leak diameters $=0.00331 \mathrm{~m}$ & 0 \\
\hline Steam generators dryout (pressurizer/non-pressurizer loops) & $4850 / 5020$ \\
\hline Onset of pressurizer PORV cycling & 6020 \\
\hline RCP saturation; seal leaks increased to $480 \mathrm{gpm}$ per RCP; leak diameters $=0.0190 \mathrm{~m}$ & 7638 \\
\hline End of full loop (liquid) natural circulation & 7692 \\
\hline Collapsed liquid level falls below the top of the fuel rods & 8783 \\
\hline End of pressurizer PORV cycling & 8980 \\
\hline Vapor in the core exit begins to superheat; hot leg countercurrent circulation begins & 8900 \\
\hline Collapsed liquid level falls below the bottom of the fuel rods & 10372 \\
\hline Pressurizer drains & 10830 \\
\hline Onset of fuel rod oxidation & 10980 \\
\hline First heatup to molten fuel temperatures; in first channel & 12213 \\
\hline Accumulator injection begins & 12362 \\
\hline First fuel rod fragmentation; in the second channel & 13780 \\
\hline Pressurizer loop hot leg nozzle fails by creep rupture & 22975 \\
\hline Hot leg break initiated; break diameter $=0.150 \mathrm{~m}$ & 22975 \\
\hline Accumulators empty; injection ends with collapsed liq level $\sim 0.22 \mathrm{~m}$ below top of fuel rods & 23200 \\
\hline Second core dryout; collapsed liquid level falls below the bottom of the fuel rods & 24056 \\
\hline $79 \mathrm{~kg} \mathrm{Ag}-\mathrm{In}-\mathrm{Cd}$ melts and slumps into lower head & 27649 \\
\hline $1209 \mathrm{~kg} \mathrm{Ag}$-In-Cd melts and slumps into lower head & 28775 \\
\hline $201 \mathrm{~kg} \mathrm{Ag-In-Cd} \mathrm{melts} \mathrm{and} \mathrm{slumps} \mathrm{into} \mathrm{lower} \mathrm{head}$ & 28900 \\
\hline $267 \mathrm{~kg} \mathrm{Ag}-\mathrm{In}-\mathrm{Cd}$ melts and slumps into lower head & 29595 \\
\hline $50 \mathrm{~kg} \mathrm{Ag}$-In-Cd melts and slumps into lower head & 31350 \\
\hline $117 \mathrm{~kg} \mathrm{Ag}$-In-Cd melts and slumps into lower head & 32725 \\
\hline Core slumping into lower head; $58648 \mathrm{~kg} \mathrm{UO}_{2}, 14966 \mathrm{~kg} \mathrm{~kg} \mathrm{ZrO} 2$ & 32406 \\
\hline $5420 \mathrm{~kg}$ of submerged 'thin' stainless steel added to lower head debris & 32466 \\
\hline
\end{tabular}


Table E.5.

Sequence of events (continued)

\begin{tabular}{|l|c|}
\hline Event & Time (s) \\
\hline Second core relocation into lower head; $4976 \mathrm{~kg} \mathrm{UO}_{2}, 1170 \mathrm{~kg} \mathrm{ZrO}$ & \\
\hline Lower head failure; by creep rupture $\sim 0.66 \mathrm{~m}_{2}$ above the inside bottom surface of the head & 36260 \\
\hline End of calculation & 37780 \\
\hline
\end{tabular}


Table E.6.

DCH parameters at selected times

\begin{tabular}{|c|c|c|c|}
\hline$\overline{\text { Parameter }}$ & $@ 32406 s^{a}$ & @36780s & @ $37780 \mathrm{~s}^{\mathrm{c}}$ \\
\hline Lower head pressure (MPa) & 0.1702 & 0.1699 & 0.1700 \\
\hline Lower head liquid temperature $(\mathrm{K})$ & 387 & 388 & 388 \\
\hline Containment pressure (MPa) & 0.1563 & 0.1603 & 0.1608 \\
\hline Containment vapor temperature $(\mathrm{K})$ & 336 & 340 & 341 \\
\hline Mass of in-vessel liquid (kg) & 16412 & 11154 & 10890 \\
\hline Integrated $\mathrm{H}_{2}$ generated $(\mathrm{kg})$ & 383.6 & 383.6 & 383.6 \\
\hline Integrated $\mathrm{H}_{2}$ flow into containment $(\mathrm{kg})$ & 383.6 & 383.6 & 383.6 \\
\hline Lower head debris ${ }^{\mathrm{d}}$ : Ag-In-Cd (kg) & 1923 & 1923 & 1923 \\
\hline Stainless steel $(\mathrm{kg})$ & 5420 & 5420 & 5420 \\
\hline $\mathrm{UO}_{2}(\mathrm{~kg})$ & 58648 & 58648 & $63624^{e}$ \\
\hline $\mathrm{Zr}(\mathrm{kg})$ & 0 & 0 & 0 \\
\hline $\mathrm{ZrO}_{2}(\mathrm{~kg})$ & 14966 & 14966 & $16136^{\mathrm{e}}$ \\
\hline Maximum temperature (K) & 2873 & 3443 & $3653^{f}$ \\
\hline Average molten temperature $(\mathrm{K})$ & 2873 & 3232 & 3303 \\
\hline Molten fraction & $0.91^{\mathrm{g}}$ & 0.65 & 0.70 \\
\hline \multicolumn{4}{|c|}{$\begin{array}{l}\text { a. Corresponding to the time that the first major core relocation into the lower head began. } \\
\text { b. Corresponding to the time of lower head failure. } \\
\text { c. Corresponding to the end of the calculation. } \\
\text { d. Includes } 1923 \mathrm{~kg} \text { of } \mathrm{Ag} \text {-In-Cd from earlier relocations and } 5420 \mathrm{~kg} \text { of thin cross-section steel in the lower plenum that would } \\
\text { be expected to melt as a result of being submerged by core materials. } \\
\text { e. Includes } 4976 \mathrm{~kg} \mathrm{UO} \mathrm{O}_{2} \text { amd } 1170 \mathrm{~kg} \text { of } \mathrm{ZrO}_{2} \text { that relocate between lower head failure and the end of the calculation. } \\
\text { f. This temperature reflects the non-physical condition associated with retaining the melt in the lower head when it should have } \\
\text { relocated to containment. } \\
\text { g. The fraction is estimated to be } 0.91 \text { because earlier relocations }(1923 \mathrm{~kg} \mathrm{Ag}) \text { were quenched and } 5420 \mathrm{~kg} \text { of lower plenum SS } \\
\text { was assumed to be added at the lower plenum temperature. }\end{array}$} \\
\hline
\end{tabular}




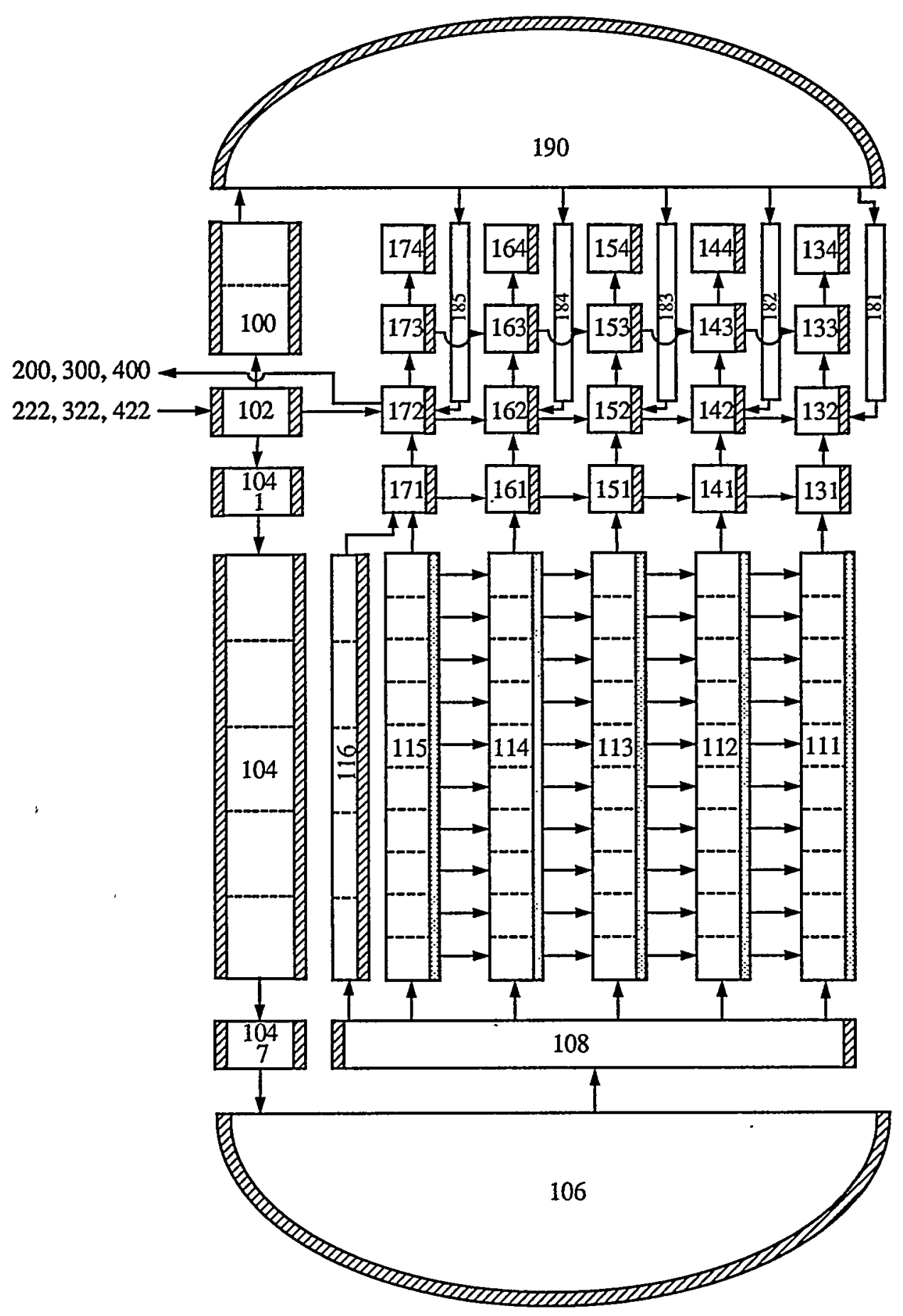

Figure E.1. Surry reactor vessel nodalization with provisions for in-vessel natural circulation. 


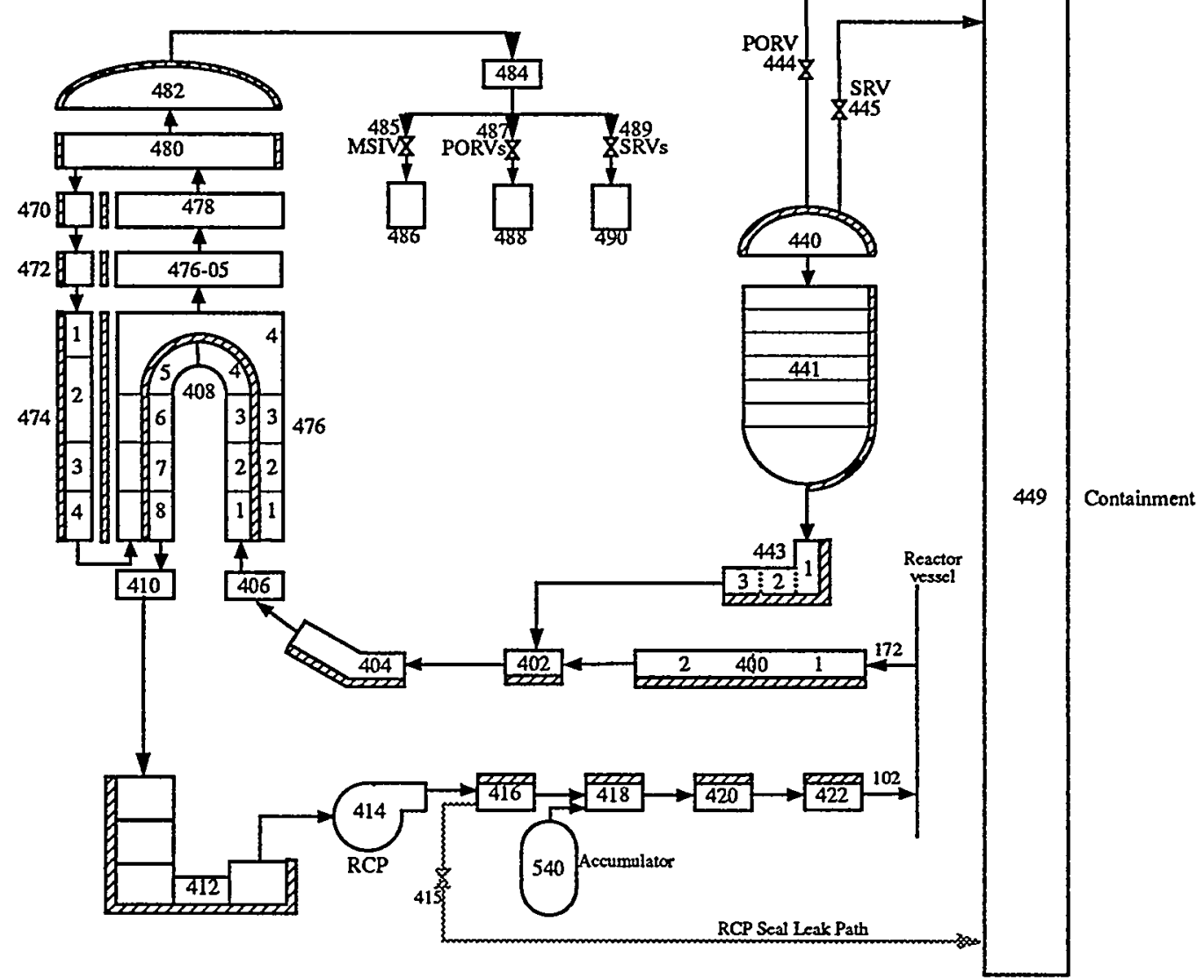

Figure E.2. Pressurizer coolant loop nodalization for the Surry PWR without provisions for hot leg countercurrent natural circulation. 


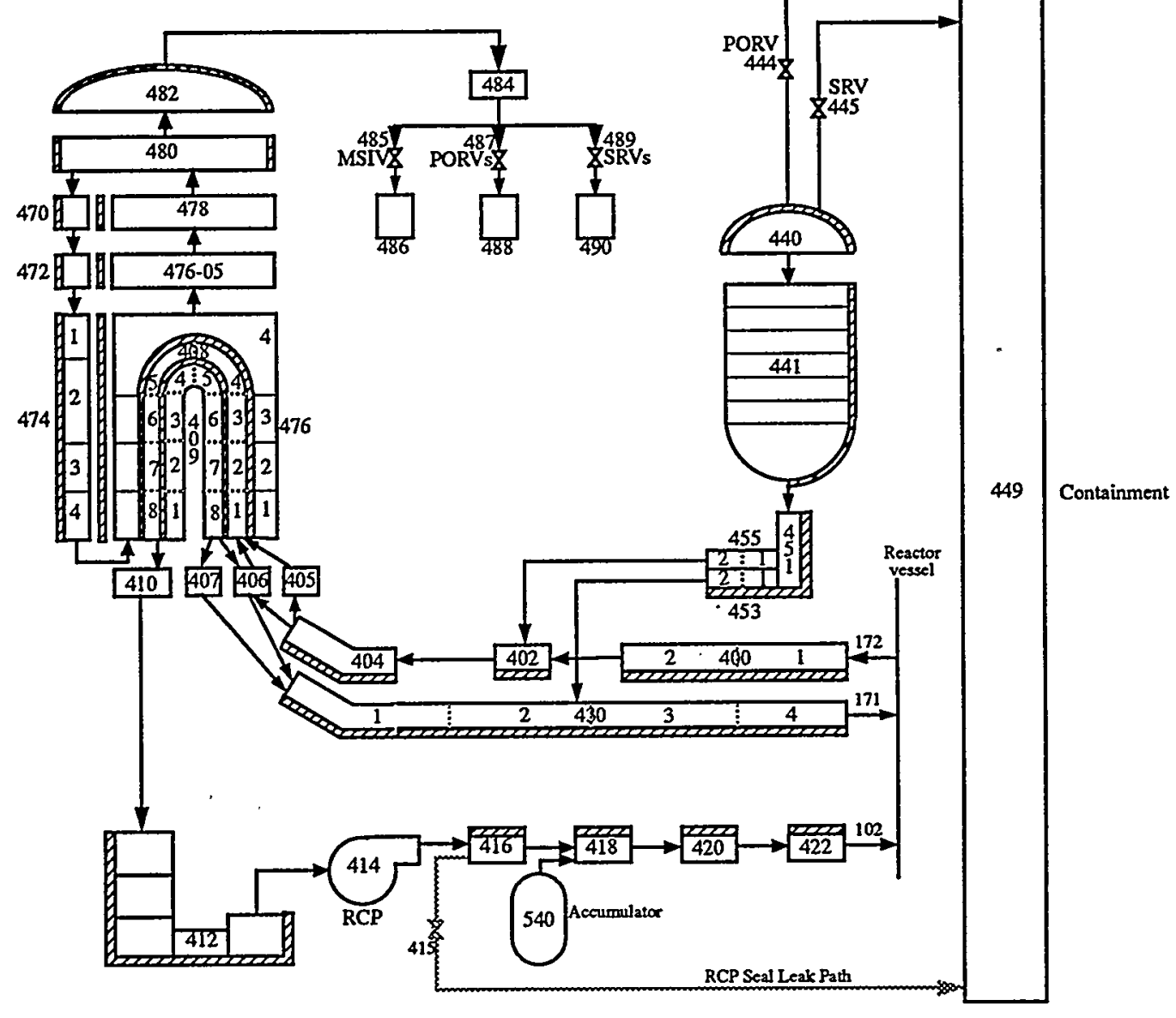

Figure E.3. Pressurizer coolant loop nodalization for the Surry PWR with provisions for hot leg countercurrent natural circulation. 


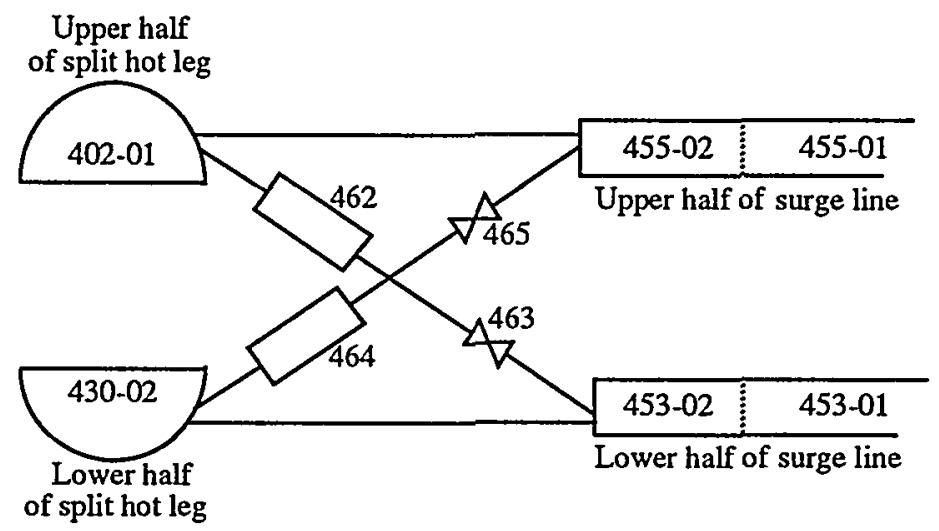

Figure E.4. Nodalization detail showing the surge line connection to the split hot leg.

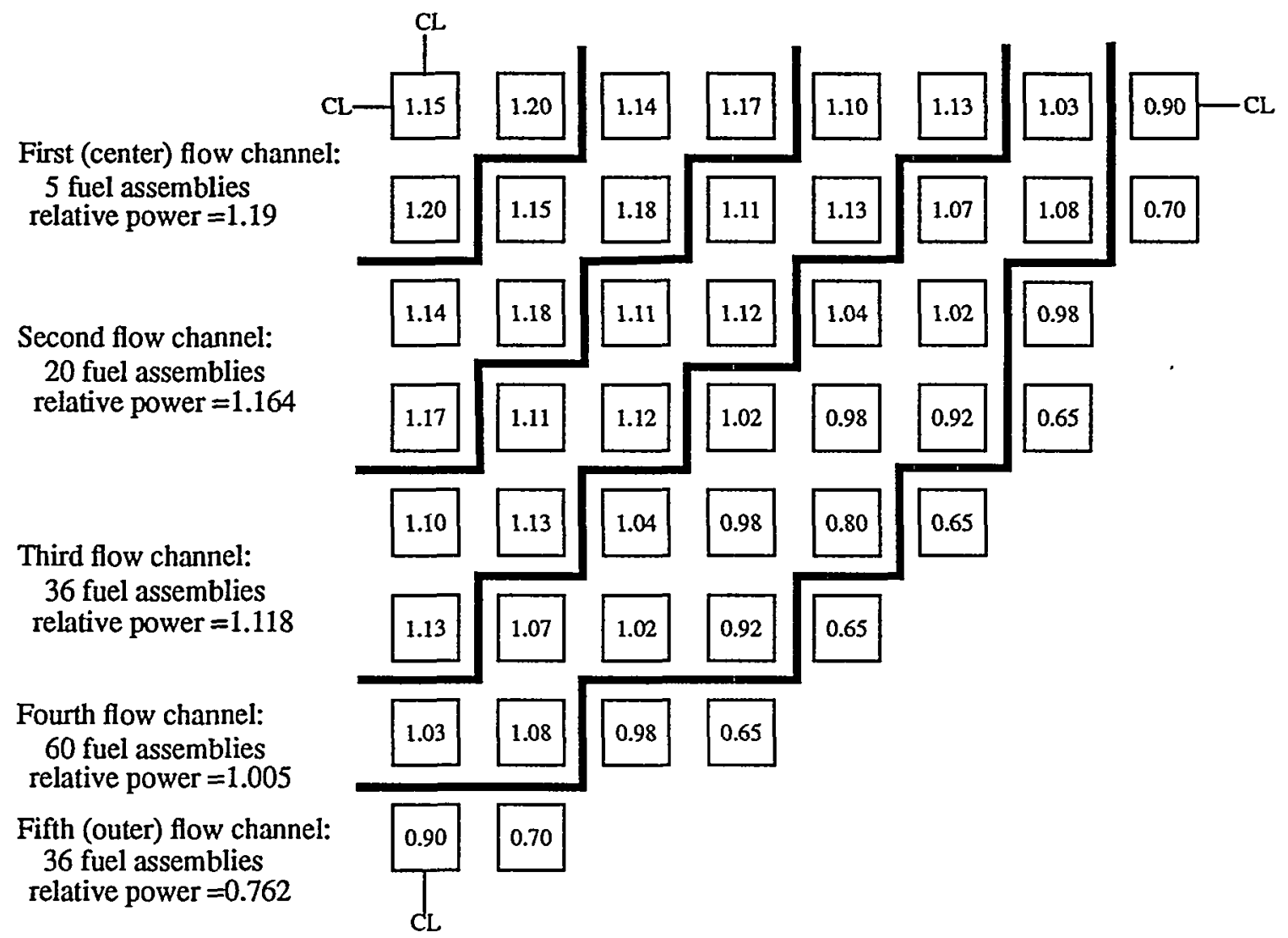

Figure E.5. Cross section of the five channel core with assembly and channel relative power levels. 


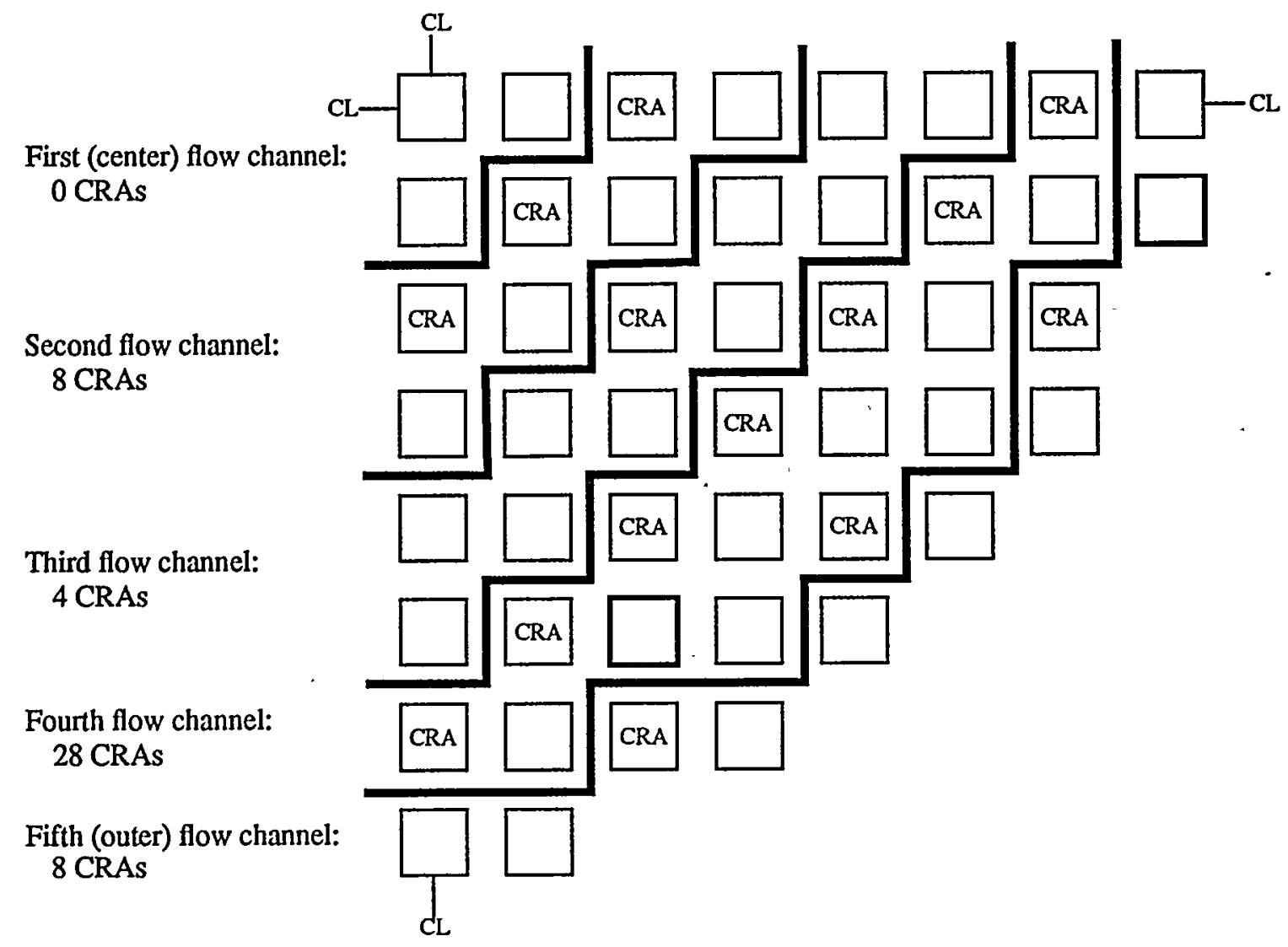

Figure E.6. Cross section of the five channel core with CRA (control rod assembly) locations. 


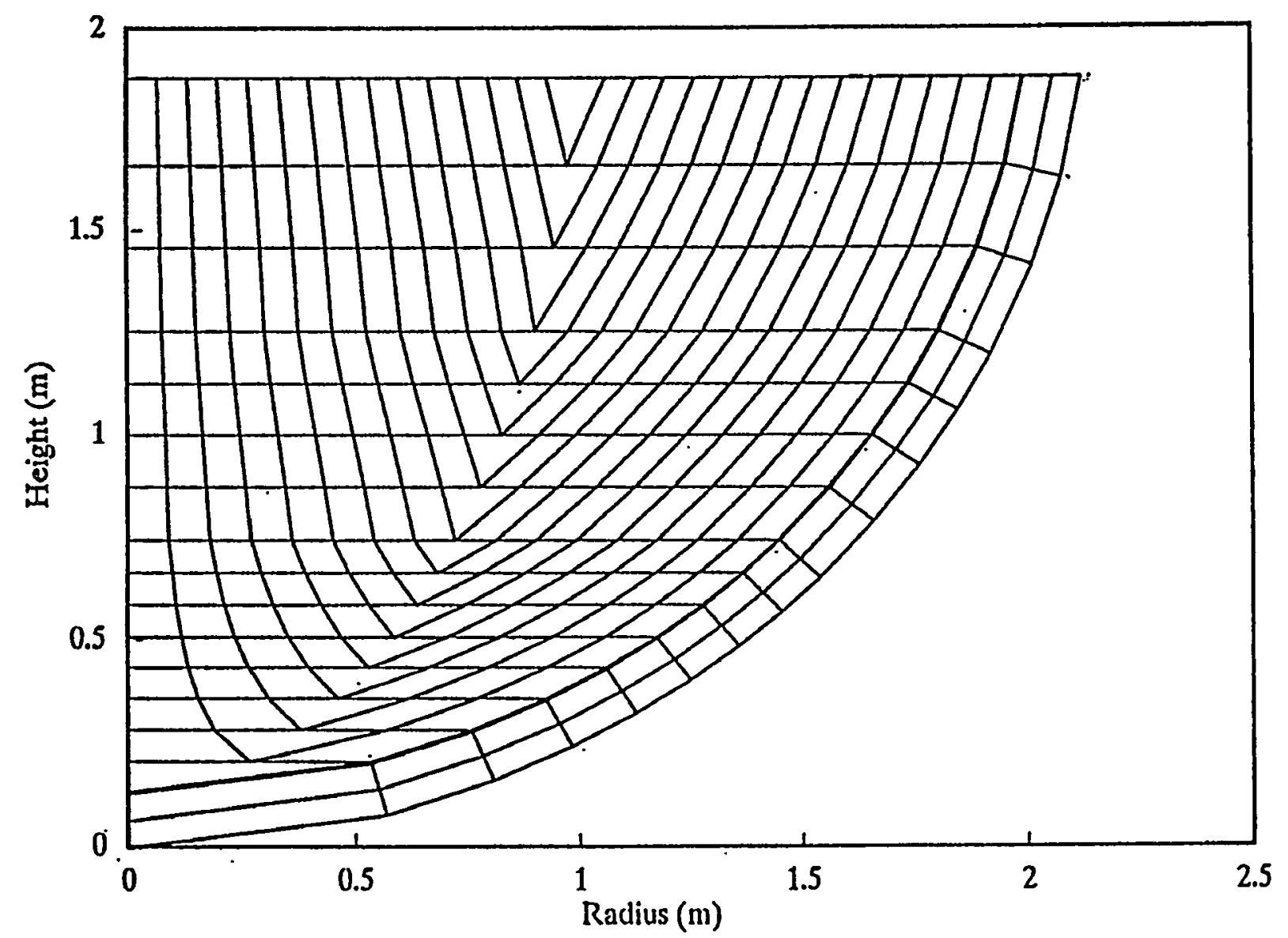

Figure E.7. COUPLE mesh representing the lower reactor vessel head of the Surry PWR. 


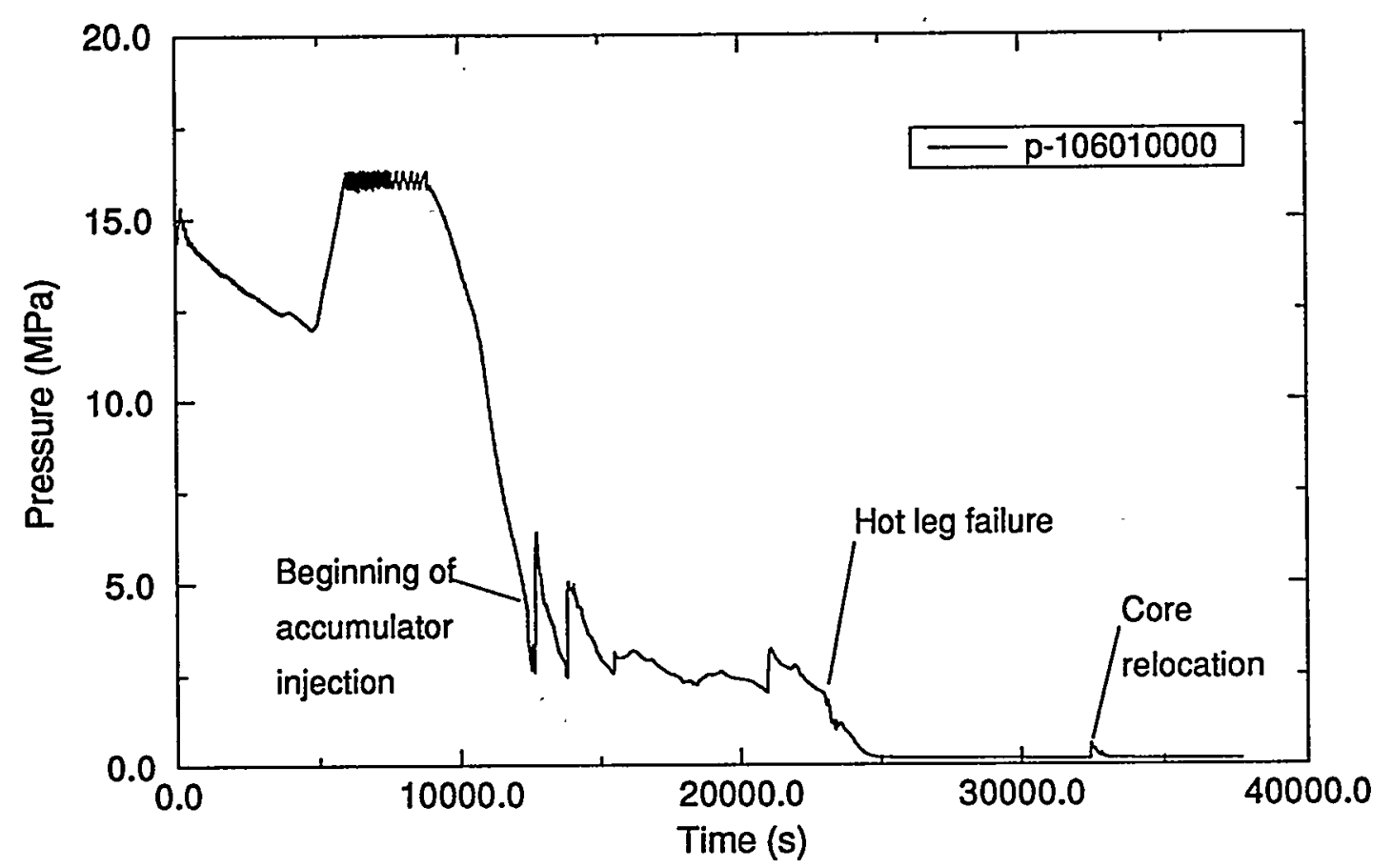

Figure E.8. Pressure in the reactor vessel lower head.

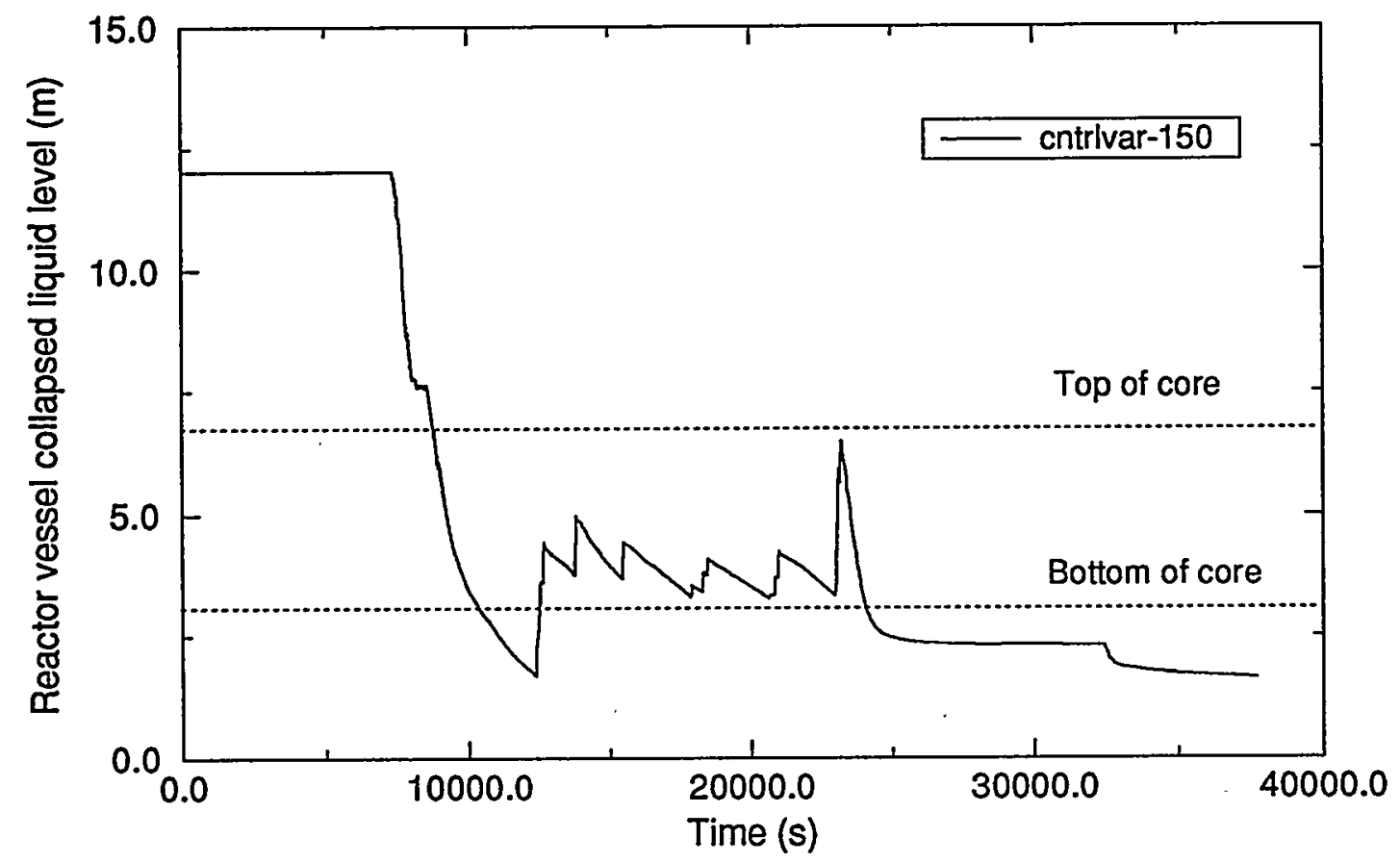

Figure E.9. Reactor vessel collapsed liquid level. 


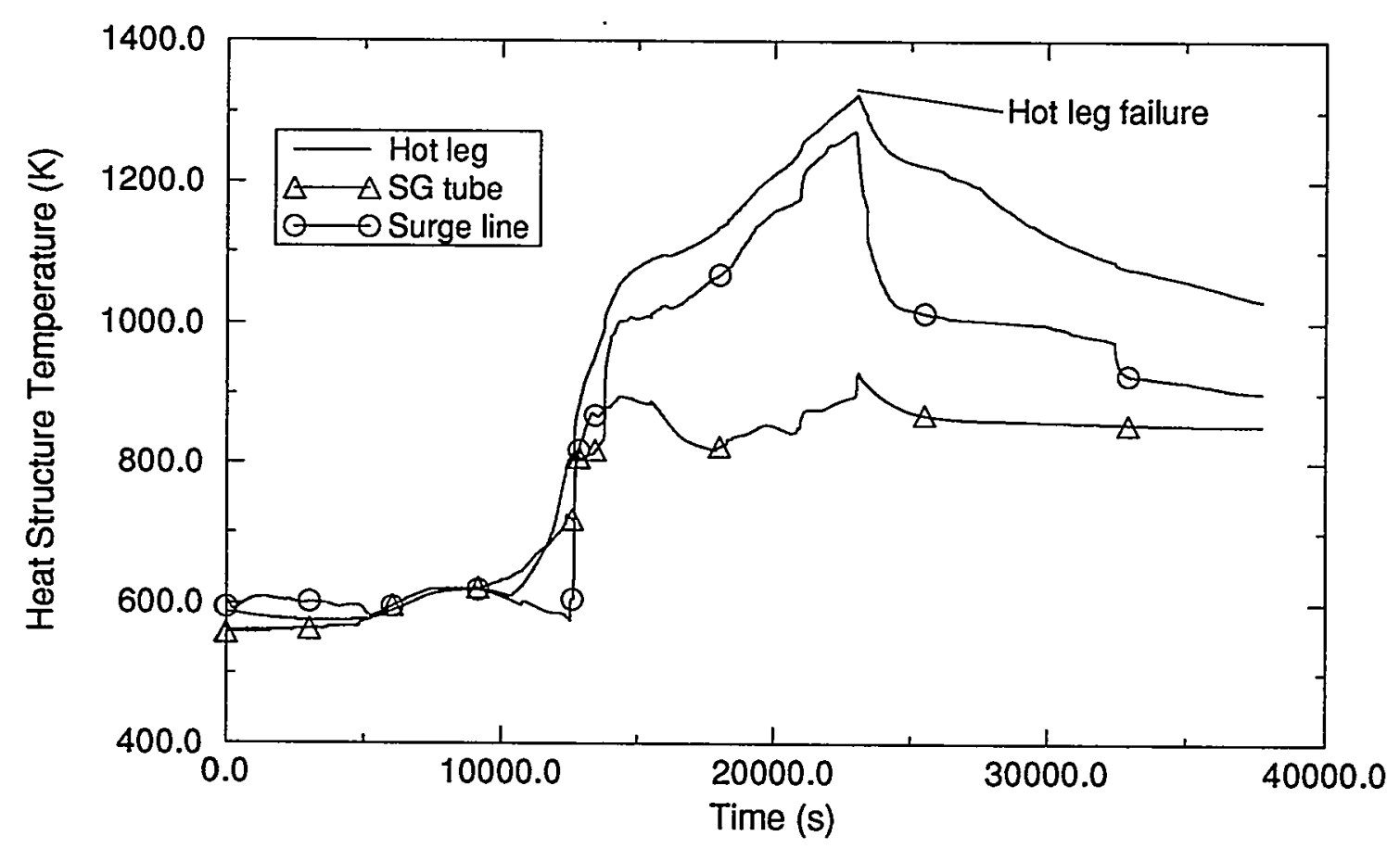

Figure E.10. Volume-averaged temperatures of pressurizer loop piping.

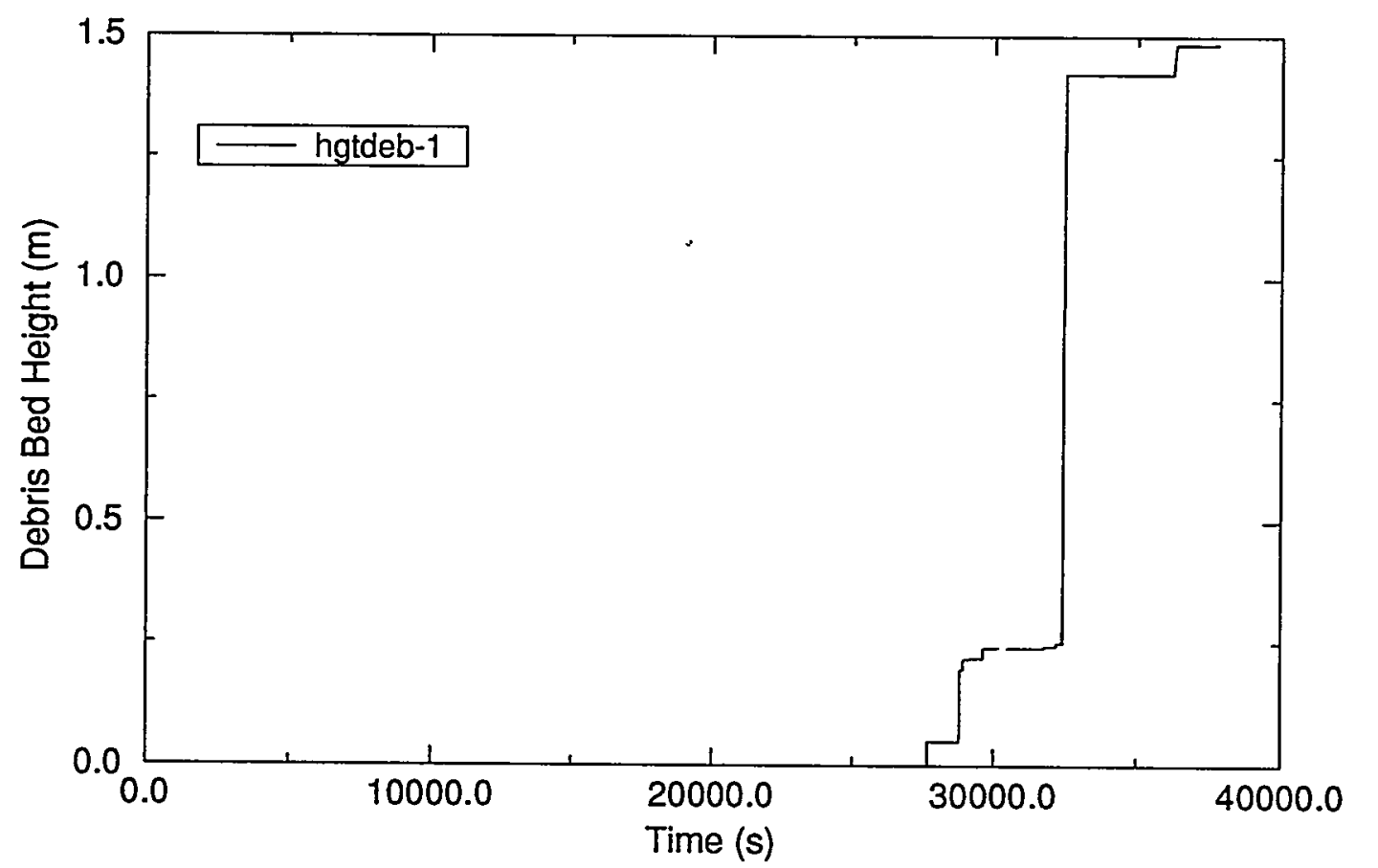

Figure E.11. Lower head debris depth (referenced to the bottom inside surface of the head). 


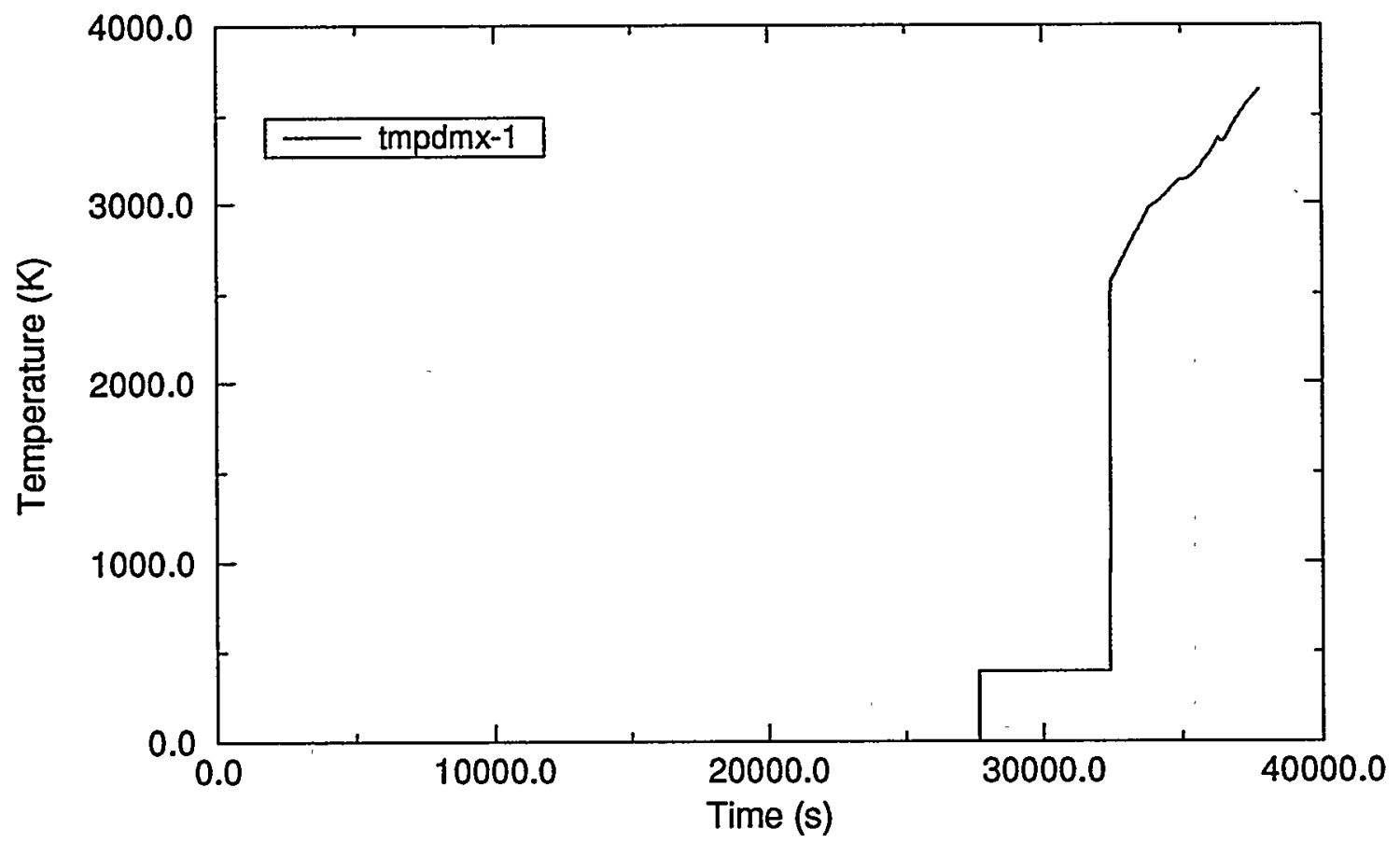

Figure E.12. Lower head maximum debris temperature.

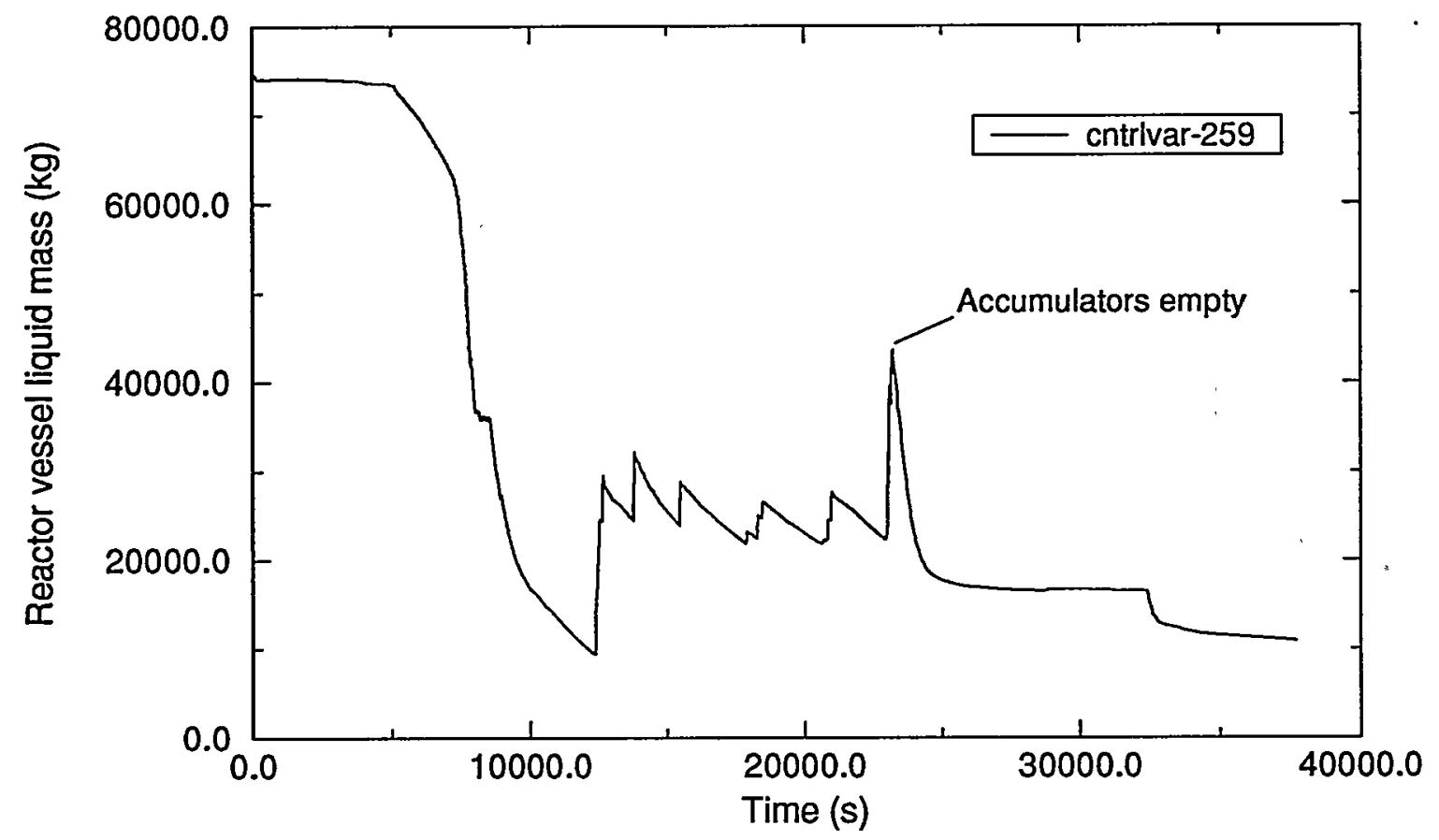

Figure E.13. Mass of liquid in the reactor vessel. 


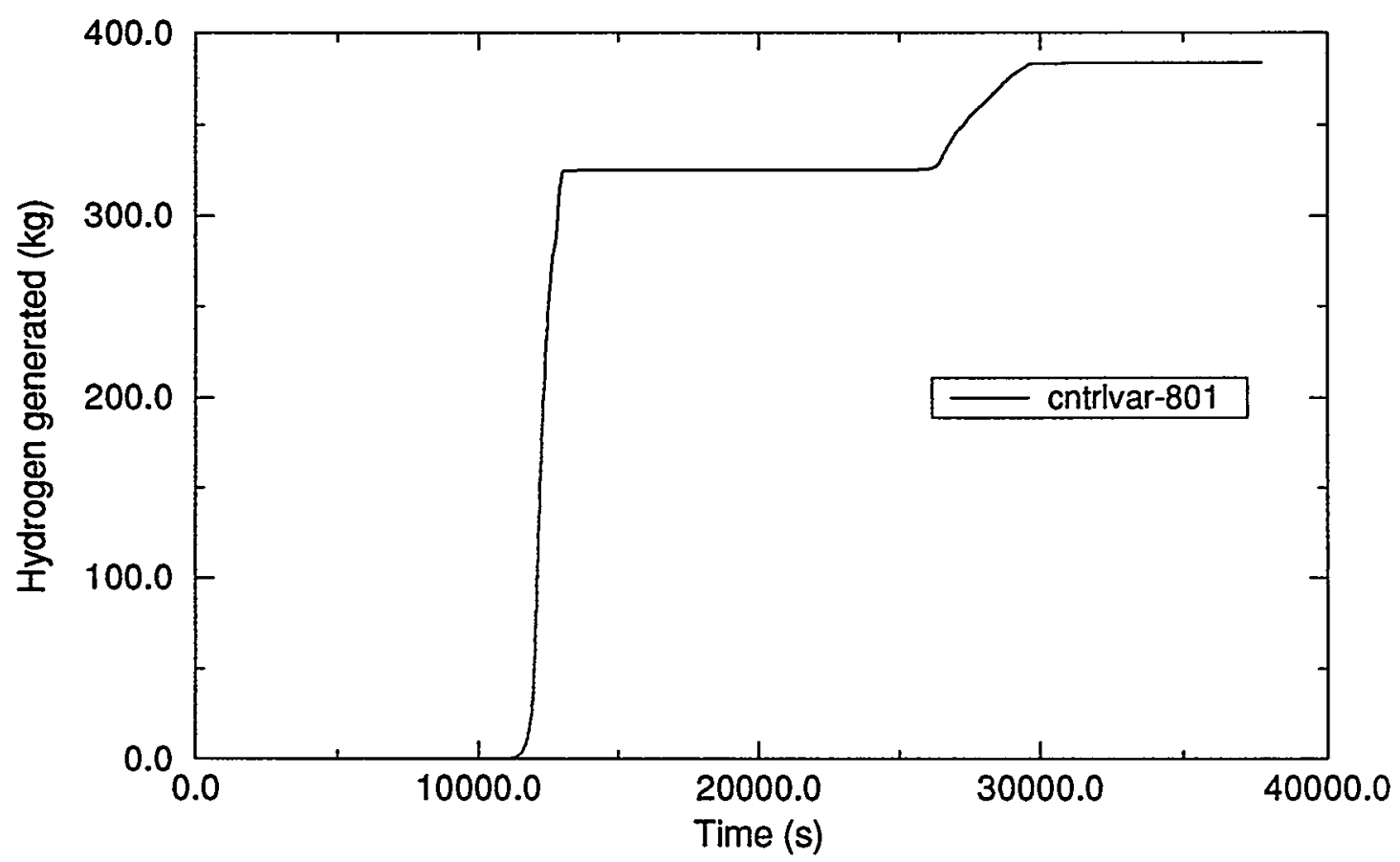

Figure E.14. Total hydrogen generated.

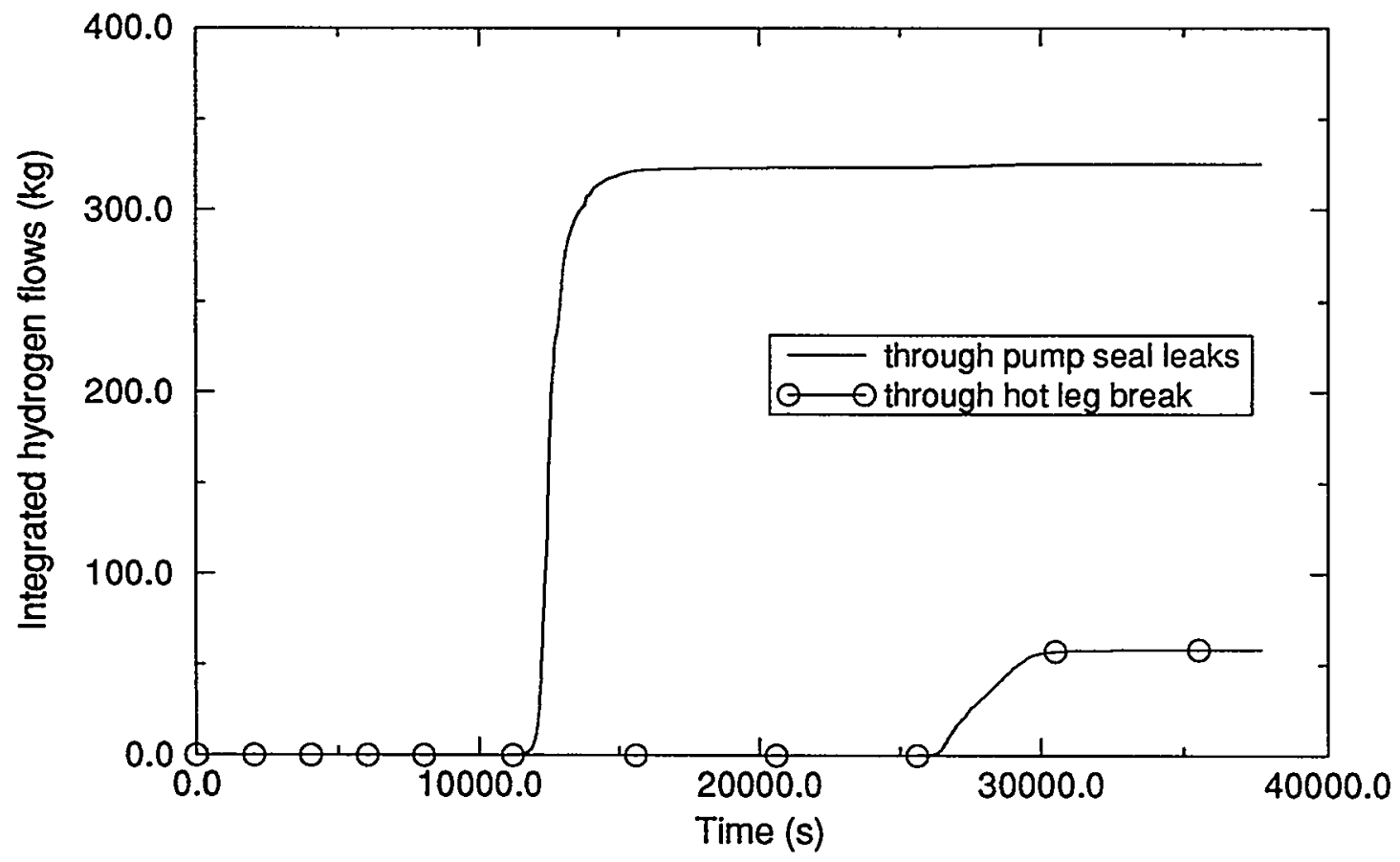

Figure E.15. Total hydrogen vented to containment. 


\section{ACRONYMS}

AC altemating current

ANS American Nuclear Society

CRA control rod assembly

DCH direct containment heating

ECCS emergency core cooling system

HPME high pressure melt ejection

PORV power operated relief valves

PWR pressurized water reactor

RCP reactor coolant pump

RCS reactor coolant system

SG steam generator

SRV safety relief valve

UFSAR Updated Final Safety Analysis Report 


\section{APPENDIX F \\ Likelihood of DCH}

\section{F.1 Introduction}

A necessary condition for DCH is that the reactor pressure vessel (RPV) fails while the reactor coolant system (RCS) is still at elevated pressure. The main body of this report addresses DCH when high pressure sequences exist. This appendix addresses the likelihood that the RPV will fail while the RCS is still at pressures high enough to lead to a potential direct containment heating threat. Section F.2 provides an overview of relevant issues and research programs. Section F. 3 provides a specific application to the Surry plant using methodologies similar to those developed for NUREG-1150. As part of this application, existing SCDAP/RELAP5 calculations were used to assess whether accident-induced failure of the RCS would lead to rapid RCS depressurization before bottom head failure. Where possible, parallel insights are brought in from the Surry IPE. Conclusions are summarized in Section F.4.

\section{F.2 Overview of NRC-Sponsored Research}

\section{F.2.1 Probability of High-Pressure Sequences}

The NRC has, sponsored many probabilistic risk assessments (PRAs), beginning with the Reactor Safety Study, that have identified the most probable core melt sequences. The more recent PRAs, NUREG-1150 in particular, have identified which of these core damage sequences will be at high pressure when the core uncovers. Summary core damage sequence information is provided for the Surry plant in Section F.3.1

The dominant core damage sequences are plant-specific, so the NUREG-1150 results cannot be generalized to cover all plants. In fact, the Accident Sequence Evaluation Program (ASEP) investigated the feasibility of extending plant-specific PRAs to other plants and concluded that this would not be possible because there are too many plant-specific considerations that affect the frequencies of various sequences. The individual plant examinations (IPEs) have been completed for all plants and they provide information on the most probable core damage sequences. However, the IPEs may not indicate the pressure at core uncovery for the various 
sequences (e.g., the relative contribution of various pump leak rates to the overall sequence frequencies).

Although plant-specific core damage sequence information is not available for all plants, the past PRAs indicate that there are a limited number of sequences that would be expected to lead to vessel breach at high pressure. Stylized RCS pressure traces (capturing general trends of calculations) for some of the sequences that have been found important in PRAs are shown in Figure F.1. Station blackout sequences or sequences that progress similarly to station blackout sequences are normally the dominant high-pressure core damage sequences. Emergency core coolant (ECC), other than accumulators, is lost immediately in most of these sequences. In some cases (such as long-term station blackout), steam generator auxiliary feedwater is available for a limited time, but eventually fails. In other cases (such as short-term station blackout), auxiliary feedwater fails immediately. Further variations include pump seal loss-of-coolant accidents (LOCAs) and stuck-open power-operated relief valves (PORVs).

Most other nonrecovered core damage sequences that have been identified in the completed PRAs would be expected to reach low pressure either before core damage begins or between the onset of core damage and vessel breach (i.e., after core damage occurs yet before vessel breach). For example, large LOCA sequences reach low pressure before core damage occurs. Smaller LOCAs may be at elevated pressure before core damage, but only very small LOCAs are not expected to be at low pressure before vessel breach. Possibilities for such very small LOCAs include pump seal failure, which is included as one of the variations of station blackout sequences. Anticipated transient without scram (ATWS) sequences would normally be at high pressure when core damage begins, but at the plants studied to date, the operator would be expected to depressurize the system before vessel breach. For plants without depressurization capability, the ATWS sequences might proceed at high pressure, but the RCS response would be expected to be similar to the response during a station blackout sequence following core voiding.

Based on these considerations, the variations of station blackout cover the range of RCS responses predicted for the high-pressure core melt sequences from currently completed PRAs. However, the containment response also must be considered. The various sequences discussed in the previous two paragraphs would have approximately the same integral blowdown source to containment, but the timing could vary considerably. The timing differences would be 
bounded by the short-term and long-term station blackout sequence variations. Other sequences have been identified in PRAs that could have a greater impact on containment response, however. In some sequences, engineered safety features (ESFs) such as containment sprays or ECC might be operating, thus affecting containment response. For example, sequences with ECC initially operating but then failing in the recirculation mode would have a larger containment blowdown source, which would result in a higher containment steam concentration than sequences with immediate failure of ECC. Operation of containment sprays would also have a large impact on containment response by reducing containment pressure, temperature, and steam content. In NUREG-1150, such sequences were found to be small contributors to the internal events analysis, but could be more important at other plants, or when evaluating external events.

\section{F.2.2 Probability of High-Pressure Melt Ejection}

DCH risks could be reduced if the effects of HPME were prevented or mitigated through RCS depressurization before lower head failure. The factors that contribute to the probability of HPME are discussed in this section (based on the assumption that plant operators do not take actions to intentionally depressurize). Intentional RCS depressurization as a means to prevent or mitigate the effects of HPME is discussed in Section F.2.3. Factors that contribute to the probability of HPME include both depressurization and repressurization mechanisms as discussed below. The analysis of severe accident progression to evaluate the probability of HPME, including the depressurization and repressurization aspects, is also described.

Without operator actions, failure of the RCS pressure boundary is the only mechanism for depressurization. Vulnerable areas in the RCS pressure boundary include the pressurizer PORVs, the reactor coolant pump (RCP) seals, the surge line piping, the hot leg nozzles, and the steam generator tubes.

Primary system pressure will be controlled by pressurizer PORV cycling during severe reactor accidents without RCS leaks. There is a potential for PORV failures before core damage, as discussed in Section F.2.1, and an increased potential during protracted accident sequences since the valves are not normally designed for repeated cycling. As an accident progresses, fluid temperatures discharged through the PORVs will increase. PORV failures could also result from valve operation at temperatures above design conditions. At this point, 
data are not available to determine the mode of PORV failure. However, RCS depressurization could occur if the PORVs fail in an open or partially open position.

The loss of RCP seal cooling, resulting from a loss of ac power or a loss of component cooling water, would subject the pump seals to RCS fluid temperatures. Without failure of any of the seal stages in a Westinghouse RCP, seal leakage would increase from $3 \mathrm{gpm}$ to approximately $21 \mathrm{gpm}$ per RCP under those conditions (Boardman et al. 1985). Leak rates as high as $480 \mathrm{gpm}$ per RCP could occur if all three seal stages in a Westinghouse RCP subsequently failed (Boardman et al. 1985). Although other designs have not received the same attention as the Westinghouse RCPs, a potential for leaks as a result of severe reactor accident conditions is anticipated in all RCPs. Obviously, such leakage also provides a potential for RCS depressurization.

Without operator actions, natural circulation flows could develop and redistribute core decay heat in the RCS during severe reactor accidents. Full loop, in-vessel, and hot leg countercurrent natural circulation modes are possible. Experiments performed for Westinghouse-type pressurized water reactors (PWRs) (Stewart et al. 1986) indicate that hot leg countercurrent natural circulation flows could be expected in any PWR with U-tube steam generators. Recent experimental work (D. Marzo, 1993) shows that natural circulation paths can also be established in plants with once-through steam generators (OTSG) and suggest that failure of the RCS boundary may occur on a time scale comparable to plants with U-tube steam generators. Exvessel heating associated with natural circulation could lead to creep rupture failures in the RCS pressure boundary. The surge line, the hot leg nozzles, and the steam generator tubes appear to be the most vulnerable failure locations. (Flow to cycling PORVs during accidents without leaks would also contribute to the heating of the surge line and the hot leg nozzle in the pressurizer coolant loop.) A potential for RCS depressurization would occur if any point in the RCS pressure boundary were heated to a failure condition.

It should be noted that all potential RCS pressure boundary failures discussed in this study are influenced by the accident progression. If any one of the accident-induced failures occurs before failure of the lower head, there is a potential for preventing or mitigating the effects of HPME and DCH through RCS depressurization. 
The primary mechanisms for RCS repressurization include the effects of accumulator injection and the potential for debris-to-coolant heat transfer during molten relocation from the core to the lower head. It should be noted that ECC systems other than accumulators could also produce a repressurization. However, if other ECC systems are available early in the transient, the accident would not normally proceed to the point of HPME. The consideration of those conditions is of no interest on that basis. If the other ECC systems are not initially available, but are restored after core damage has begun, the melt progression might not be terminated. For these cases, the pressurization from the other ECC systems could be important.

Both mechanisms for repressurization are similar. Specifically, the mechanisms involve the generation of excess vapor that is not immediately removed from the RCS or condensed in cooler parts of the RCS. If the RCS is depressurized to the initial accumulator pressure, cold water will be injected. Heat transfer from the core to the injected water will generate some amount of vapor. The RCS will then repressurize to some point above the accumulator pressure, terminating the injection. (The injection process can be repeated if the RCS is depressurized through removal of the excess vapor. However, subsequent cycles occur at lower pressures since accumulator pressures decrease with each discharge into the RCS.) Sequences that lead to core melt could have some liquid inventory in the lower head and lower plenum at the time of core relocation. Interaction between the molten debris and that coolant could result in RCS repressurization through the rapid generation of a substantial amount of vapor. Note that either mechanism for repressurization could accelerate or contribute to failures in the heated RCS pressure boundary. These effects have been included in the HPME evaluations for this appendix.

Although the potential for HPME is a function of RCS depressurization and repressurization, there are many interrelated complexities in the progression of severe reactor accidents that influence the timing and magnitude of the depressurization and repressurization events. Those complexities include thermal-hydraulics and heat transfer through core heatup, ballooning and rupturing of the fuel rod cladding, oxidation, core quenching and fragmentation, the formation of in-core blockages, and the processes of melting and relocation of core materials. In severe reactor accidents without operator actions, thermal-hydraulics and heat transfer are established through natural circulation processes. Computer-based tools provide an effective method for analyzing these complexities. 
There are several computational tools currently available for analysis of the RCS response during severe reactor accidents (i.e., SCDAP/RELAP5, Allison et al. 1991; MELCOR, Summers et al. 1991; and MAAP, Fauske and Associates 1987). The MAAP code has been used extensively in the IPEs. However, the SCDAP/RELAP5 computer code provides the most mechanistic treatment of severe reactor accidents while others are designed for parametric studies. The SCDAP/RELAP5 code has an additional advantage in that it is the current code of choice for best-estimate NRC severe accident analyses. As a result, there are ongoing development and maintenance activities to enhance code capabilities and to help ensure code performance.

The computational tool must adequately simulate natural circulation processes because of its importance in severe reactor accidents without operator actions. Numerous natural circulation studies have been performed with various computer codes, as documented by Martinez et al. (1991). Those studies included assessments of natural circulation and decay heat redistribution in station blackout transients. The results indicate that core damage progression is coupled to the natural circulation flow patterns. Hot leg countercurrent flow is of particular interest with respect to the probability of HPME since it is an important mechanism in the development of RCS pressure boundary failures.

Bayless (1988) developed an approach for simulating hot leg countercurrent flow in the Surry PWR using SCDAP/RELAP5. The modeling approach evolved from low-pressure countercurrent flow experiments performed by Westinghouse (Stewart et al. 1986). The Westinghouse experiments were successfully simulated using the COMMIX computer code (ANL, 1985). The COMMTX model of the Westinghouse experiment was then scaled up to represent the high-pressure conditions of a PWR and SCDAP/RELAP5 was benchmarked against the COMMIX results. The SCDAP/RELAP5 modeling approach used to represent countercurrent flow in the Surry PWR was taken from that benchmark. An independent assessment of the resulting countercurrent flow model was performed using the MELCOR computer code (Martinez et al. 1991). The MELCOR natural circulation results were found to agree with those calculated with SCDAP/RELAP5. Pafford subsequently simulated highpressure Westinghouse natural circulation experiments with a SCDAP/RELAP5 model utilizing the Bayless modeling approach and obtained reasonable agreement with the data (Stewart et al. 1986). 
SCDAP/RELAP5 appears to be a reasonable computational tool for assessing the phenomena related to the probability of HPME based on its mechanistic nature and its capability to represent natural circulation. For that reason, analyses documented in this report were based on SCDAP/RELAP5. It should be noted that an independent peer review indicated that some of the SCDAP/RELAP5 models are not completely adequate for representing certain aspects of latephase core melt phenomena (Corradini et al. 1993). Since those limitations are primarily the result of a limited database for late-phase core melt progression in full-scale PWR geometries, other computer codes will have the same limitations. The uncertainties arising from the limitations were considered in the analyses contained in this appendix.

\section{F.2.3 Intentional RCS Depressurization}

Intentional depressurization of the RCS before vessel breach could be effective in eliminating or reducing HPME severity, which would eliminate or mitigate the effects of DCH and the potential for containment failure. Therefore, intentional RCS depressurization represents one possible plan of action to reduce the risks for those PWRs with a non-negligible potential for containment failure.

Within the context of this report, intentional RCS depressurization refers to a deliberate operator action to latch open pressurizer PORVs at some time during a severe reactor accident to avoid the potential for HPME. Intentional depressurization would only be proposed for core melt sequences that would be expected to progress to vessel breach. Furthermore, intentional depressurization would not be proposed in sequences where cooling water is available to establish feed-and-bleed operations. Experimental and analytical results indicate that core heatup can be effectively arrested by implementing feed-and-bleed on either the primary or secondary side of the RCS (Shimeck et al. 1982; Loomis and Cozzuol 1988). Obviously, intentional depressurization could not be employed without backfits in plants without PORVs (i.e., certain CE PWRs).

Because of the potential risk reduction benefits, intentional RCS depressurization has been a subject of international interest for a number of years (OECD 1989). The NRC initiated a program in the mid-1980s at the Idaho National Engineering Laboratory (INEL) to study intentional depressurization. The INEL project was originally established as an analytical investigation using SCDAP/RELAP5. The project was subsequently expanded to encompass all 
facets of the process, including human factors considerations, the performance of instrumentation and required equipment under accident conditions, and PRA insights.

The impact of PORV opening times with respect to intentional depressurization of the Surry PWR during a station blackout transient was initially evaluated using SCDAP/RELAP5 (Hanson et al. 1990). An early depressurization was considered where PORVs were assumed to be opened at the time of steam generator dryout. In addition, late depressurization was evaluated where PORVs were assumed to be opened at the time core exit temperature reached $922 \mathrm{~K}$. That temperature indicates that the core is uncovering and that fuel damage is imminent. Both PORV opening times were found to effectively reduce the RCS pressure in the Surry PWR before lower head failure. However, early depressurization led to early and extensive core damage compared with late depressurization. It was concluded that late depressurization was preferred over early depressurization because core damage is reduced and because there is more time for accident recovery (through restoration of ac power, by securing firewater or other alternative cooling water sources, etc.).

Brownson (1991) developed an approach for extension of the Surry late depressurization results to other PWRs operating in the United States. The approach involved grouping the PWRs, selecting a representative plant from each group for systematic evaluation, and then extending the evaluation results to the remaining PWRs in each group. However, uncertainties in the extension of results were identified that required detailed transient calculations. SCDAP/RELAP5 was used to complete the required late depressurization calculations for a Babcock \& Wilcox (B\&W) PWR, a CE PWR, and a 4-loop Westinghouse PWR (Brownson et al. 1993). Within documented constraints, the results indicated that intentional depressurization could eliminate the potential for HPME in 3- and 4-loop Westinghouse PWRs and mitigate the severity of HPME in B\&W and CE PWRs. The documented constraints include equipment operability and survivability issues and human factors considerations that would have to be addressed before intentional depressurization is implemented in any operating PWR.

\section{F.3 Application to Surry}

Figure F.2 summarizes our approach for estimating the probability of HPME. Many different accident sequences can lead to core damage. For simplicity, these are combined into seven plant damage states (PDSs), which characterize the condition of the plant at the onset of 
core damage. The PDSs are regroupings of the core damage accident sequences according to important characteristics that affect the subsequent accident progression and the source term. Section F.3.1 discusses the seven PDSs for Surry. The RCS pressure at vessel breach is a function of the PDS characteristics and core melt phenomena. Accident-induced RCS depressurization in Surry is the focus of Section F.3.2.

For each PDS, the RCS pressure at vessel breach can be grouped into one of four ranges. In this appendix, we carry this procedure through for two PDSs representing short-term and long-term station blackout accidents, respectively. Ideally, DCH load calculations could be performed for the unique conditions of each event that leads to vessel failure. This may be impractical; consequently, we were motivated to identify a small number of splinter scenarios that envelop the many possible damage states at vessel breach. Finally, the probabilities (conditional on core damage) for a given pressure range can be summed over all PDSs. This process can then be repeated for each pressure range. The summary results represent the probability of HPME given core damage. This process is discussed for Surry in Section F.3.3.

\section{F.3.1 Probability of High-Pressure Sequences in Surry}

This section provides perspectives on the frequencies of accidents with high RCS pressures at core uncovery. Note that the pressure at the time of core uncovery can be either higher or lower than the pressure at the time of vessel breach (i.e., either depressurization or repressurization is possible following core damage). These possibilities are discussed in Section F.2.1. The dominant PDSs from NUREG-1150 are described. This information feeds into the development of the three enveloping scenarios that are actually used in the DCH analyses.

The internal event core damage frequency estimates for Surry in NUREG/CR-1150 were:

$\begin{array}{ll}\text { Mean } & 4.01 \mathrm{E}-5 / \mathrm{yr} \\ 5 \text { percent Lower } & 6.75 \mathrm{E}-6 / \mathrm{yr} \\ \text { 95 percent Upper } & 1.31 \mathrm{E}-4 / \mathrm{yr}\end{array}$

These values represent reasonably low values for frequency estimates of internal-event core damage. Of concern here is the fraction of accidents that are expected to be at high pressure at the onset of core damage. In dividing the accident sequences into PDSs, a number of factors 
are considered. The first factor in delineating PDSs is the one of most concern (i.e., the status of the RCS at the onset of core damage). For Surry, the RCS status is divided into eight categories:

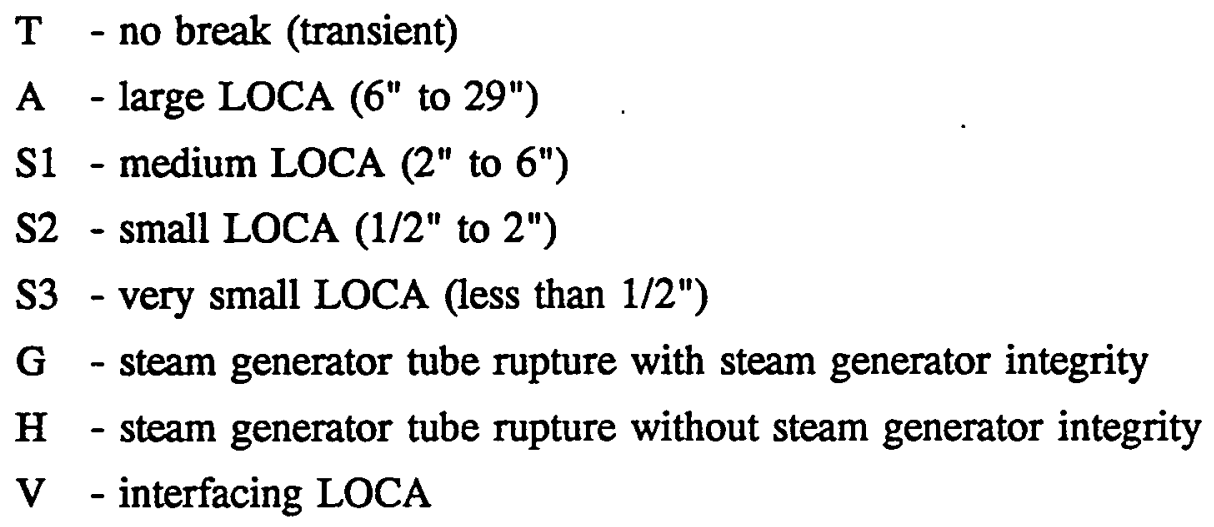

It is important to note that these categories do not correspond directly to the initiating event categories used in the core damage accident sequence analysis for Surry. For example, if an event begins as a transient, but results in the failure of a reactor coolant pump seal before core damage, it is categorized in the PDS analysis as a small break. To simplify the analysis, the many possible PDSs were combined into seven PDS groups. Within each group, four RCS pressure ranges were considered at the onset of core damage:

$$
\begin{array}{ll}
\text { System setpoint pressure } & -2500 \mathrm{psia}(17.2 \mathrm{MPa}) \\
\text { High pressure } & -600-2000 \mathrm{psia}(4.1 \mathrm{MPa}-13.8 \mathrm{MPa}) \\
\text { Intermediate pressure } & -200-600 \mathrm{psia}(1.4 \mathrm{MPa}-4.1 \mathrm{MPa}) \\
\text { Low pressure } & -<200 \mathrm{psia}(<1.4 \mathrm{MPa})
\end{array}
$$

In the discussions below, each of the seven PDS groups is described. Table F.1 contains the mean core damage frequency for each group and the fraction of accidents expected to occur within each of the four pressure ranges. Table F.2 compares the relative frequency for each PDS, with both NUREG-1150 and IPE results shown. Tables F.1 and F.2 show that station blackout accidents (both longterm and shortterm) are the dominant accidents proceeding to core uncovery while the RCS is still pressurized. 


\section{PDS Group 1 - Slow Blackout}

Group 1 is the most likely PDS group. This PDS consists of long-term station blackout sequences without any containment systems available. All of the sequences in this PDS are initiated by the loss of off-site power, followed by failure of on-site emergency ac power and successful operation of the turbine-driven portion of the auxiliary feedwater system. Core damage may occur in approximately 7 hours as a result of battery depletion (4 hours until battery depletion and an additional 3 hours until core uncovery) or sooner owing to loss of coolant through a reactor coolant pump seal LOCA or a stuck-open PORV. Any loss of RCS integrity prior to core damage involves no more than the equivalent of a small break LOCA. Source term code package calculations (STCP) indicate that the pressure would be intermediate or higher for these conditions.

\section{PDS Group 2 - Loss-of-Coolant Accidents}

PDS group 2 includes LOCAs of all sizes. A variety of emergency core cooling failures ultimately lead to core damage. Because RCS integrity is lost at the outset, none of the sequences proceed to core damage at the system setpoint or high pressure. Intermediate pressures can occur for the smaller breaks.

\section{PDS Group 3 - Short-Term Station Blackout}

Short-term station blackout events begin with a loss of off-site and on-site ac power, but proceed rapidly owing to the failure of turbine-driven auxiliary feedwater. All of these sequences at Surry proceed to core damage with the RCS intact and at the system setpoint pressure.

\section{PDS Group 4 - Event V}

Event $\mathrm{V}$ is an interfacing systems LOCA, involving failure of the boundary between highand low-pressure systems. The low-pressure system fails when it is exposed to the high RCS pressure, resulting in loss of coolant outside the containment boundary. Because of the relatively large piping involved, the accident will proceed at relatively low pressure. The DCH concern is minimal because the RCS pressure is low and the containment is already by-passed. 


\section{PDS Group 5 - Transients}

The transient group at Surry consists of accidents initiated by either a loss of main feedwater or the loss of a DC bus. This is followed by a loss of auxiliary feedwater and a failure to provide feed-and-bleed core cooling. Containment systems are successful in these accidents. At core uncovery, these accidents have an intact RCS at the system setpoint pressure.

\section{PDS Group 6 - ATWS}

Anticipated transients without scram events make up group 6. These are transient events with failure of both the automatic reactor protection system and the manual scram systems. The core power is estimated to be much higher than available heat removal (without the power conversion system), and rapid steaming and boiloff result. Even with the PORVs held open by the steaming, the reactor will proceed to core damage at or near the system setpoint pressure. After core uncovery, the power drops as the water level falls, so opening the PORVs can depressurize the RCS.

\section{PDS Group 7 - Steam Generator Tube Ruptures (SGTRs)}

PDS group 7 consists of SGTR accidents involving a single tube rupture, followed by failure of the operators to depressurize the RCS and prevent loss of coolant through the faulted steam generator (and outside containment). This accident may proceed at relatively high pressure (the tube break is small). However, the concern for DCH is lessened because the containment is already by-passed.

\section{F.3.2 Accident-Induced Reactor Coolant System Depressurization}

RCS depressurization before lower head failure could eliminate the potential for or reduce the severity of HPME during severe reactor accidents. The RCS of a PWR could be depressurized through accident-induced ex-vessel pressure boundary failures (see Section F.2.2) or as a result of deliberate operator actions (see Section F.2.3). An assessment of the potential for HPME in the Surry PWR with respect to accident-induced ex-vessel pressure boundary failures was recently completed (Knudson and Dobbe, 1993). Based on results from the assessment, it was concluded that there is a low probability for HPME in the Surry PWR during 
station blackout accidents that progress without recovery and without operator actions. The remainder of this section contains a summary of the assessment supporting that conclusion. Complete assessment details are provided in the reference.

\section{Assessment Approach and Scope}

The Surry assessment was limited to an evaluation of a station blackout scenario. The station blackout scenario was selected because it is expected to cover the possible range of RCS responses during the high-pressure melt sequences considered for this report (see Section F.2.1) and because it is the single largest contributor to the frequency of core damage for the Surry PWR (see Section F.3.1). The specific station blackout scenario considered was a TMLB' sequence, which was initiated by the loss of all ac power and a simultaneous loss of auxiliary feedwater. The potential effects of operator actions and accident recovery were not considered. The assessment was completed in two parts including (1) a detailed SCDAP/RELAP5/MOD3 analysis of the TMLB' sequence in the Surry PWR and (2) an evaluation of associated RCS depressurization-related probabilities.

Part one of the assessment consisted of a SCDAP/RELAP5/MOD3 analysis to quantify (1) the time and location of the initial RCS pressure boundary failure, (2) the associated RCS conditions at the time of the initial pressure boundary failure, and (3) the RCS conditions at the time of reactor vessel lower head failure. Plant modeling based on previous work (Bayless, 1988) was included to allow for the development of full-loop, in-vessel, and hot leg countercurrent natural circulation. Natural circulation flows provided a mechanism for the potential development of ex-vessel failures (in the surge line and hot leg piping, steam generator tubes, etc.).

Code calculations from accident initiation through the time of lower head failure were performed with and without hot leg countercurrent natural circulation, with and without RCP seal leakage, and with variations on some of the more important core damage progression parameters. Best-estimate parameters were used as inputs where there are data or where the effects of the parameters are well characterized. For core damage progression parameters with a high degree of uncertainty, values were selected to minimize the time to lower head failure, producing a conservative evaluation of the potential for HPME. 
The code calculations assumed that there was sufficient plant air and battery power to operate the PORVs throughout the transient. Furthermore, the potential for PORV failures that could result from repeated cycles at extreme temperatures was not considered. Simple structural models of the ex-vessel piping were included to track the potential for creep ruptures induced by the combined effects of elevated temperature and pressure assuming that all ex-vessel piping was free of structural defects and degradation. Any predicted ex-vessel failure was appropriately recorded although an associated RCS blowdown was not simulated. Instead, the code calculations were extended to lower head failure without RCS depressurization following induced failures, providing an approach for estimating the possible timing difference among all events.

Six different SCDAP/RELAP5/MOD3 calculations were performed in the first part of the assessment. In the base case, full-loop, in-vessel, and hot leg countercurrent natural circulation flows were considered. This case represents conditions that could develop following TMLB' initiation without operator actions. Hot leg countercurrent natural circulation was eliminated in case 2 to minimize the core heatup time by minimizing ex-vessel heat transfer. Case 2 was performed to evaluate the effects of hot leg countercurrent flow on the potential for HPME. Cases 3 through 6 were designed to account for all modes of natural circulation along with the potential effects of RCP seal leakage (the "old" O-ring materials are used in the Surry RCPs). In those cases, breaks providing initial leak rates of $21 \mathrm{gpm}$ per RCP were introduced at TMLB' initiation and larger break sizes were introduced at the time liquid in the RCPs reached saturated conditions. The initial leak rate (of $21 \mathrm{gpm}$ per RCP) represented leakage associated with the loss of seal cooling that would accompany the loss of ac power. Larger break sizes were introduced to represent the potential for failures associated with instabilities that could occur when the seals are exposed to high-temperature, two-phase fluid conditions. A continuous leak rate of $21 \mathrm{gpm}$ was not included in cases 1 and 2 because it would not be expected to significantly alter the results since the flow rate is only a small fraction of the PORV capacity.

In case 3, break sizes were increased when RCP liquid renched saturated conditions to provide initial leaks of $250 \mathrm{gpm}$ per RCP, representing the most probable leak rate (Wheeler et al. 1989). In case 4 , breaks were increased to provide initial leaks of $480 \mathrm{gpm}$ per RCP, representing the maximum leak rate corresponding to failure of all three seal stages in a Westinghouse RCP (Boardman et al. 1985). Case 5 was identical to case 3 with the exception of how heat transfer from molten materials was treated during relocation from the core to the lower head. In Case 3, molten materials were relocated from the core to the lower head without 
heat transfer. In Case 5, molten materials were assumed to quench during the relocation (up to the physical limit associated with the amount of water in the lower head). Results from cases 3 and 5 provide insight into the effects of debris cooling on the potential for HPME. Case 6 was identical to case 4 with the exception of the treatment of fuel cladding deformation. In case 4 , it was assumed that deformation was limited to 2 percent owing to an oxide buildup on the outer surface of the cladding prior to the onset of ballooning. The limit on cladding deformation was increased to 15 percent in case 6 to represent an upper bound on the average deformation that could be expected.

Probabilities of RCS depressurization-related issues were evaluated in part two of the assessment. The specific depressurization issues that were considered were identified through examination of the APET developed in NUREG-1150 (NRC, 1990). Specifically, the APET was examined to compile a list of those RCS depressurization-related issues that have the largest influence on the risks associated with HPME. The list included a surge line/hot leg failure issue and an RCS pressure at vessel breach issue that could be affected by the SCDAP/RELAP5/MOD3 analyses completed after NUREG-1150. Those issues can be expressed as follows:

1. What is the probability that the surge line or hot leg will fail and depressurize the RCS to a low pressure before lower head failure?

2. What are the probabilities of being at a low, intermediate, and high RCS pressure at the time of reactor vessel breach?

Similar to the treatment of DCH in NUREG-1150, low, intermediate, and high RCS pressures were taken to be pressures below $1.38 \mathrm{MPa}$, pressures between 1.38 and $6.89 \mathrm{MPa}$, and pressures above $6.89 \mathrm{MPa}$, respectively. In NUREG-1150, the transition between high and intermediate pressure ranges was set at $4.1 \mathrm{MPa}$ (vs $6.89 \mathrm{MPa}$ here) to address concerns related to the timing of accumulator injection. For our purposes here, using $6.89 \mathrm{MPa}$ is more appropriate because it gives a more uniform spread among the pressure ranges. It was assumed that HPME would not occur at low RCS pressures.

The approach used to evaluate the issue probabilities was closely patterned after the expert elicitation method used in NUREG-1150. In general, the issues were first decomposed 
(separated) into parts that were easier to evaluate; endpoint probabilities were established for each part; a distribution was assumed between the endpoints; and the resulting distributions were recombined to arrive at a probability for the issue. However, establishing the endpoint probabilities was the key to the process. Although current SCDAP/RELAP5/MOD3 results were used as a basis, the endpoints were not simply derived from the results. Instead, an attempt was made to capture the potential uncertainties in the results with the endpoints. In some cases, engineering judgments were made to assess the magnitude of the potential uncertainties. In other cases, potential uncertainties were addressed by completing sensitivity calculations using SCDAP/RELAP5/MOD3.

\section{Assessment Results}

The SCDAP/RELAP5/MOD3 results listed in Table F.3 summarize the predicted response of the Surry PWR for all calculations performed in the first part of the assessment. Base case results indicate that natural circulation of steam and steam flow through the cycling pressurizer PORVs can induce creep rupture failures in the surge line and hot leg piping before failure of the lower head (assuming the RCS is not depressurized by leaks). Without leaks, the RCS pressure is maintained by pressurizer PORV cycling as shown in Figure F.3. During each valve cycle, energy is transferred from the core to the surge line and hot leg piping. Hot leg countercurrent natural circulation is established between PORV cycles, which also transfers core decay heat to the hot legs. However, the surge line is heated to a failure condition before the hot legs because it is relatively thin. Tube failures would not be expected at the temperatures predicted at the time of hot leg failure because the circulating steam loses a significant amount of energy before reaching the steam generators, leaving the tubes relatively cool, as shown in Figure F.4. The predicted steam generator tube temperatures could increase if steam generator tube leakage was included. Previous studies indicate that the RCS pressure could be reduced from the PORV set point pressure to a value below $1.38 \mathrm{MPa}$ before the predicted lower head failure through either a surge line or hot leg breach (Bayless, 1988).

Case 2 results indicate that surge line and hot leg failures can be expected before the lower head fails even if hot leg countercurrent natural circulation is not established (assuming the RCS is not depressurized by leaks). Hot leg countercurrent natural circulation provides an effective mechanism for transferring core decay heat to the ex-vessel piping. If that heat sink is eliminated, heatup of the core and in-vessel structures will accelerate with corresponding 
increases in steam temperatures. Under those conditions, however, the surge line and hot leg will also be exposed to higher temperatures during each PORV cycle, which leads to surge line and hot leg creep ruptures before lower head failure. Without hot leg countercurrent natural circulation, steam generator tube failures would not occur since tube heating is minimal.

The RCS pressure is reduced below the pressurizer PORV set point by the seal leak rates considered in cases 3 through 6 . PORV cycling ends with that pressure reduction as shown for case 5 in Figure F.5. Although surge line heating decreases when PORV cycling ends, ex-vessel heating continues as a result of hot leg countercurrent flow. Results from cases 3 and 5 indicate that both surge line and hot leg failures would occur before lower head failure if the RCS pressure were reduced below the pressurizer PORV set point by seal leaks of $250 \mathrm{gpm}$ per RCP. Although the hot leg is relatively massive, it would be heated to a failure condition before the surge line because of the decrease in surge line heating and because the hot leg is exposed to the highest-temperature steam leaving the reactor vessel. RCS depressurization through either breach would occur before the lower head fails. Given that the steam generator tubes are free of defects, the results indicate that failure of the tubes would not be expected with leaks of 250 gpm per RCP.

SCDAP/RELAP5/MOD3 results for cases 4 and 6 indicate that a lower head failure would be the first breach of the RCS pressure boundary in the Surry PWR if RCP seals leak $480 \mathrm{gpm} / \mathrm{pump}$. The onset of core damage is accelerated by the higher leak rate. However, the higher RCP leak rate also depressurizes the RCS to allow earlier accumulator injection, which can delay further core degradation. The most important aspect associated with RCP seal leak rates, however, has to do with their effect on ex-vessel heating. The total core decay energy is split into the portion that is deposited in the vessel and ex-vessel structures by circulating steam and the portion that is dissipated through RCP seal leaks. The results indicate that seal leaks of $480 \mathrm{gpm}$ per RCP dissipate a relatively large fraction of core decay energy, leaving a relatively small fraction for ex-vessel heating. As indicated in Table F.3, ex-vessel failures occur before lower head failure with seal leaks of $250 \mathrm{gpm}$ per RCP while ex-vessel failures do not occur with leaks as high as $480 \mathrm{gpm}$ per RCP.

Transfer of debris and coolant heat during molten relocation from the core to the lower head can significantly delay vessel breach. Minimum and maximum debris-coolant heat transfer are the only options currently available in SCDAP/RELAP5/MOD3. With the minimum option, it 
is assumed that the debris relocates from the core to the lower head in a coherent stream without heat transfer, which results in a rapid lower head thermal attack. With the maximum option, it is assumed that the debris will break up as a result of interactions with water (and structures) in the lower plenum and lower head. The code then calculates a complete quench of the debris, up to the limit imposed by the amount of coolant available. A large RCS repressurization can result during quench, as indicated in Figure F.5. However, a thermal attack on the lower head is delayed until the debris reheats. Case 3 and 5 results indicate that the delay in lower head failure could be more than 1 hour in the Surry PWR.

Changes in deformation associated with ballooning of the fuel rod cladding can significantly change the progression of core damage and the time to lower head failure. The core flow resistance in case 6 was relatively high, with a ballooning deformation limit of 15 percent. As a result, the core was reflooded from the top down by an accumulator injection that was forced through the core by-pass. A boiloff was then required before the core could reach molten temperatures. The accumulators were essentially emptied during the reflood, which eliminated the possibility of effective cooling during the subsequent reheating. A relatively large relocation of approximately $44,370 \mathrm{~kg}$ of molten $\mathrm{UO}_{2}$ occurred as a result. With deformation limit of 2 percent in case 4 , periodic accumulator injection provided only partial cooling of the core hot spots. However, the partial cooling occurred over a prolonged period and was sufficient to delay relocation, which consisted of about $12,940 \mathrm{~kg}$ of molten $\mathrm{UO}_{2}$. The delay in relocation produced a corresponding delay in lower head failure of 43.2 minutes (compared with the higher deformation case).

The SCDAP/RELAP5/MOD3 calculations were reviewed to identify potential uncertainties that could affect the predicted response of the Surry PWR. The review focused on uncertainties that could affect the timing of the RCS pressure boundary failures since that timing is critical in this assessment of the potential for HPME.

Uncertainties in (1) the current oxidation models in the code, (2) the core decay power, (3) the initial steam generator liquid inventory, and (4) the nature and rate of core damage progression, tend to accelerate or delay both ex-vessel failures and lower head failures. For example, the current version of SCDAP/RELAP5/MOD3 only calculates oxidation of the zircaloy cladding of in-core components, which is terminated as soon as rodlike geometry is lost. As a result, the rate of core heatup could be underpredicted in the current calculations since the 
oxidation reactions are exothermic. If core heatup is underpredicted, core and circulating steam temperatures will be underpredicted. Therefore, the timing of both lower head and ex-vessel failures could be delayed by the current treatment of oxidation in the code. A more detailed treatment of oxidation would be expected to accelerate both lower head and ex-vessel failure times without a significant change in the relative timing between the events.

Uncertainties in the following conditions tend to change the time of ex-vessel failures relative to the time of lower head failure:

1. The treatment of in-core crust heat transfer;

2. The flow and heat transfer characteristics of a degraded core, particularly during accumulator injections;

3. Natural circulation flow and heat transfer; and

4. The effects of repressurization resulting from vapor produced during accumulator injection and during molten relocation to the lower head.

For example, if the heat transfer from the molten pool to the in-core crust is overpredicted, relocation and lower head failure could be earlier than expected relative to predicted ex-vessel failures.

Sensitivity calculations were performed and engineering judgment was used in an attempt to account for the potential effects of the uncertainties in the SCDAP/RELAP5/MOD3 calculations. The results of that effort are reflected in the probabilities listed in Tables F.4 and F.5 for the following scenarios:

1. TMLB' sequences without RCP seal leaks (at full system pressure);

2. TMLB' sequences with seal leaks of $250 \mathrm{gpm}$ per RCP;

3. TMLB' sequences with seal leaks of $480 \mathrm{gpm}$ per RCP; and 
4. TMLB' sequences with stuck-open or latched-open PORVs.

Probabilities for scenarios (1) through (3) were generally based on SCDAP/RELAP5/MOD3 results completed in the first part of the assessment. Specifically, scenario (1) was based on results from the base case and case 2; scenario (2) was based on results from cases 3 and 5; and scenario (3) was based on results from cases 4 and 6. A SCDAP/RELAP5/MOD3 analysis of intentional depressurization of the Surry PWR (Brownson et al. 1993) was used to establish probabilities for scenario (4). The probabilities listed in Table F.4 account for potential uncertainties that could affect the timing of accident-induced failures as well as estimates of RCS depressurization that could follow ex-vessel failures. Uncertainties in temperatures, pressures, and relocation mechanisms were identified that could affect the calculated time of both vessel and ex-vessel failures. Variations on those parameters were considered in order to establish a possible failure window around each calculated failure time. The ex-vessel failure windows were shifted to account for the time required for RCS depressurization to $1.38 \mathrm{MPa}$. Probabilities for an ex-vessel failure with depressurization before lower head failure were then determined by comparing the appropriate failure windows. The probabilities listed in Table F.5 include potentials for repressurizing (as a result of accumulator injections and/or debris and coolant heat transfer); however, potentials for accident induced RCS failures were not considered. As a result, the probabilities listed in Table F.5 define the RCS pressure at the time of lower head failure for those cases that are not depressurized through accident-induced exvessel failures. Those probabilities were determined by overlaying the potential RCS pressure response onto the accident-induced failure window. Complete details associated with the development of all RCS depressurization probabilities have been documented in Knudson and Dobbe (1993).

\section{Summary}

In the calculations representing scenarios (1), (2), and (4), natural circulation of steam and steam flow through the PORVs led to surge line and/or hot leg failures before lower head failures without operator actions. After accounting for uncertainties in the calculated results, it was concluded that there was a high probability for being at a low RCS pressure at the time of lower head failure as a result of accident-induced ex-vessel failures. Specifically, probabilities for a surge line or hot leg failure with RCS depressurization below $1.38 \mathrm{MPa}$ 
before lower head failure were assigned values of $0.98,0.98$, and 1.0 , given the occurrence of scenarios (1), (2), and (4), respectively.

Accident-induced RCS failures were not calculated before lower head failures in the cases representing scenario (3). For that reason, a probability of 0.0 was assigned to the surge line and hot leg failure issue. However, the probability of being at or below $1.38 \mathrm{MPa}$ at the time of lower head failure (without an ex-vessel failure) was estimated to be 0.47 . In addition, the probability of seal leaks as large as $480 \mathrm{gpm}$ per RCP is very low (Wheeler et al. 1989). In other words, conditions associated with scenario (3) are unlikely and if they occurred, there would be a reasonable probability for being at low pressure as a result of seal leakage. Therefore, there is a low probability for HPME in the Surry PWR during station blackout accidents that progress without recovery and without operator actions based on those considerations for scenario (3) and the surge line and hot leg failure issue probabilities for scenarios (1), (2), and (4). A best-estimate SCDAP/RELAP5 calculation (Appendix E) for the $480 \mathrm{gpm} /$ pump scenario was found to depressurize the RCS owing to hot leg failure, further reinforcing the conclusion. The probabilities in Table F.4 have not been updated to reflect this new information.

\section{F.3.3 HPME Probabilities for Surry}

Event trees (Figure F.6) were used to combine the individual probabilities for the induced RCS failures and depressurization that were developed in Section F.3.2, giving the probability of vessel breach occurring at various pressure levels for particular sequences. The long-term and short-term station blackout sequences that were identified in NUREG-1150 and described in Section F.3.1 were evaluated. The relative frequencies of long-term versus short-term station blackout sequences are taken from information listed in Table F.2.

The probabilities for hot leg and surge line failure are taken from Table F.4 for the shortterm station blackout accident. The intentionally biased SCDAP/RELAP5 calculations indicated that the reduced RCS pressure accompanying the 480-gpm/pump leak made hot leg and surge line failure unlikely, although best-estimate calculations (Appendix E) suggest otherwise. For this analysis, we conservatively assume that a 480 -gpm/pump seal leak will not lead to hot leg and surge line failure. 
For short-term station blackouts, the RCS pressure at vessel breach is taken from Table F.5. System setpoint pressures are realized only if the PORV does not fail open and if the hot leg or surge line does not fail.

SCDAP/RELAP5 calculations for the long-term station blackout were not performed, so it was necessary to draw on other sources of information. For long-term station blackout sequences without induced failures (stuck-open PORV or pump seal leak) before core damage, the analogous short-term station blackout probabilities were used. This approximation is justified because this variation of the long-term station blackout sequence should progress like the shortterm station blackout counterpart.

For long-term station blackout sequences with either a stuck-open PORV or pump seal leaks combined with steam generator depressurization before core damage, source term code package calculations for Surry indicate that the RCS pressure would be in the range of 5 - $8 \mathrm{MPa}$ during the period of core uncovery to core slump with a spike to nearly the system setpoint during core slump. Spontaneous failure of the hot leg has been observed at these RCS pressures in more recent SCDAP/RELAP5 calculations for short-term station blackouts in Surry (Knudson and Dobbe, 1993) and Zion (Appendix C in Pilch et al. 1994) if the hot leg is sufficiently hot. Hot leg failure in the long-term station blackout might also be expected because heating of the hot leg largely occurs during the $\mathrm{Zr}$ oxidation phase; however, STCP calculations cannot assess the likelihood of hot leg failure. Considering uncertainties in STCP predictions, we conservatively assume that there is only a 50 percent probability that the hot leg or surge line will fail after core damage for a pump seal leak initiated prior to core damage during a long-term station blackout accident. Uncertainties in these assessments are large, but they could be resolved with fully integrated SCDAP/RELAP5 calculations for the long-term station blackout accident.

For long-term station blackouts, the RCS, with a stuck-open PORV, is expected to be fully depressurized at vessel failure either because of the extended blowdown time or because the surge line fails. System setpoint pressures are realized only if the RCS does not vent (stuck PORV, pump seal leak, or hot leg and surge line failure) before the vessel fails. For a pump seal leak without hot leg and surge line failure, the probabilities of being in various pressure ranges are taken from Kelly (referenced in NUREG/CR-4551, Vol. 2, Part 6). Kelly considered uncertainties in RCS depressurization (following the core slump pressure spike) and timing 
uncertainties in lower head failure for situations where accumulators dump prior to core uncovery. The STCP predicts just such a situation for a long-term station blackout in Surry.

The probability of a vessel breach occurring at various pressure levels was calculated from the event tree in Figure F.6. The results for the long-term and short-term station blackout sequences are shown in Table F.6. The HPME probability for a long-term station blackout is more uncertain than for a short-term station blackout because we lack a fully integrated bestestimate calculation for the long-term station blackout. Table F.6 shows that the probability of HPME is 0.077 .

\section{F.4 Conclusions}

PRA studies show that station blackout accidents dominate those core damage accidents that have the potential of leading to high pressure melt ejection at Surry. The combined probability (for all station blackout events) that vessel breach will occur with the RCS exceeding $1.38 \mathrm{MPa}$ is $~ 0.077$. Consequently, the likelihood of HPME in Surry is low for those accidents without power recovery or operator intervention. For a short-term station blackout, there is a high likelihood that accident induced failure of the surge line or hot leg will occur as a result of the redistribution of energy from the core region to the components by natural circulation. Uncertainties are larger for a long-term station blackout because we lack a fully integrated bestestimate calculation. Uncertainty estimates in these probabilities are beyond the scope of this effort. The likelihood of HPME for accidents that proceed with power (e.g., TMI-II) or proceed to vessel breach following power recovery is also beyond the scope of the current effort.

\section{F.5 References}

Allison, C.M. et al. (1991). SCDAP/RELAP5/MOD3 Code Manual, NUREG/CR-5273, EGG2555 (Draft), Revision 2, Vols. 1-4, EG\&G Idaho, Inc., Idaho Falls, ID.

ANL (1985). COMMIX-1B: A Three-Dimensional Transient Single-Phase Computer Program for Thermal Hydraulic Analysis of Single and Multicomponent Systems, NUREG/CR-4348, ANL85-42, Argonne National Laboratory, Argonne, IL.

Bayless, P.D. (1988). Analyses of Natural Circulation During a Surry Station Blackout Transient Using SCDAP/RELAP5, NUREG/CR-5214, EGG-2547, EG\&G Idaho, Inc., Idaho Falls, ID. 
Boardman, T. et al. (1985). Leak Rate Analysis of the Westinghouse Reactor Cooling Pump, NUREG/CR-4294, 85-ETEC-DRF-1714.

Brownson, D.A. (1991). Extension of Surry Late Depressurization Strategy Results to Commercially Operating Pressurized Water Reactors, EGG-EAST-9717, EG\&G Idaho, Inc., Idaho Falls, ID.

Brownson, D.A. et al. (1993). Intentional Depressurization Accident Management Strategy for Pressurized Water Reactors, NUREG/CR-5937, EGG-2688, EG\&G Idaho, Inc., Idaho Falls, ID.

Corradini, M.L. et al. (1993). SCDAP/RELAP5 Independent Peer Review, LA-12481, Los Alamos National Laboratory, Los Alamos, NM.

Fauske and Associates, Inc., (FAI) (1987). User's Manual for the Module Accident Analysis Program (MAAP), Fauske and Associates, Inc., Burr Ridge, IL.

Hanson, D.J. et al. (1990). Depressurization as an Accident Management Strategy to Minimize the Consequences of Direct Containment Heating, NUREG/CR-5447, EGG-2574, EG\&G Idaho, Inc., Idaho Falls, ID.'

Knudson, D., and C. Dobbe (1993). Assessment of the Potential for High Pressure Melt Ejection Resulting from a Surry Station Blackout Transient, NUREG/CR-5949, EGG-2689, EG\&G Idaho, Inc., Idaho Falls, ID.

Loomis, G.G., and J.M. Cozzuol (1988). Decay Heat Removal Using Feed-and-Bleed for U.S. Pressurized Water Reactors, NUREG/CR-5072, EGG-2526, EG\&G Idaho, Inc., Idaho Falls, ID.

Martinez, G.M., et al. (1991). Independent Review of SCDAP/RELAP5 Natural Circulation Calculations, SAND91-2098, Sandia National Laboratories, Albuquerque, NM.

Nuclear Regulatory Commission (NRC) (1990). Severe Accident Risks: An Assessment for Five U.S. Nuclear Power Plants, NUREG-1150, U.S. Nuclear Regulatory Commission, Washington, DC.

OECD Nuclear Energy Agency (1989). Proceedings from the Specialist Meeting on Intentional Coolant System Depressurization, CSNI Report 158 (Restricted), Garching (FRG).

Pilch, M. et al. (1994). The Probability of Containment Failure by Direct Containment Heating in Zion, NUREG/CR-6075, SAND93-1535, Sandia National Laboratories, Albuquerque, NM.

Shimeck, D.J., et al. (1982). Analysis of Primary Feed-and-Bleed Cooling in PWR Systems, EGG-SEMI-6022. 
Stewart, W.A., A.T. Pieczynski, and V. Srinivas (1986). "Experiments on Natural Circulation Flows in Steam Generators During Severe Accidents, "Proceedings of the International ANS/ENS Topical Meeting on Thermal Reactor Safety, San Diego, CA.

Summers, R.M., et al. (1991). MELCOR 1.8.1: A Computer Code for Severe Nuclear Reactor Accident Source Term and Risk Assessment Analyses, NUREG/CR-5531, SAND90-0364, Sandia National Laboratories, Albuquerque, NM.

Wheeler, T.A., et al. (1989). Analysis of Core Damage Frequency from Internal Events: Expert Judgement Elicitation, NUREG/CR-4550, SAND86-2084, Vol. 2, Sandia National Laboratories, Albuquerque, NM. 
Table F.1 Summary of pressures for each Surry plant damage state

\begin{tabular}{|c|c|c|c|c|c|}
\hline PDS Group & $\begin{array}{l}\text { Mean Frequency } \\
\text { (per year) }\end{array}$ & $\begin{array}{c}\text { Fraction of } \\
\text { Accidents with } \\
\text { Core Uncovery } \\
\text { Occurring at } \\
\text { System Setpoint } \\
\text { Pressure } \\
\text { (2500 psia) }\end{array}$ & $\begin{array}{c}\text { Fraction of } \\
\text { Accidents with } \\
\text { Core Uncovery } \\
\text { Occurring at High } \\
\text { Pressure } \\
(600-2000 \text { psia) }\end{array}$ & $\begin{array}{c}\text { Fraction of } \\
\text { Accidents with } \\
\text { Core Uncovery } \\
\text { Occurring at } \\
\text { Intermediate } \\
\text { Pressure } \\
(200-600 \text { psia) }\end{array}$ & $\begin{array}{l}\text { Fraction of } \\
\text { Accidents with } \\
\text { Core Uncovery } \\
\text { Occurring at } \\
\text { Low Pressure } \\
\text { (<200 psia) }\end{array}$ \\
\hline $\begin{array}{l}\text { 1. Long-term } \\
\text { station blackout }\end{array}$ & $2.2 \mathrm{E}-5$ & 0.54 & 0.13 & 0.33 & 0.00 \\
\hline 2. LOCAs & $6.0 \mathrm{E}-6$ & 0.00 & 0.00 & 0.19 & 0.81 \\
\hline $\begin{array}{l}\text { 3. Short-term } \\
\text { station blackout }\end{array}$ & $5.4 E-6$ & 1.00 & 0.00 & 0.00 & 0.00 \\
\hline 4. Event V & $1.6 \mathrm{E}-6$ & - & -- & - & - \\
\hline 5. Transients & $2.1 \mathrm{E}-6$ & 1.00 & 0.00 & 0.00 & 0.00 \\
\hline 6. ATWS & $1.6 \mathrm{E}-6$ & 1.00 & 0.00 & 0.00 & 0.00 \\
\hline 7. SGTR & $1.8 \mathrm{E}-6$ & 0.00 & 1.00 & 0.00 & 0.00 \\
\hline
\end{tabular}


Table F.2 Relative contribution of each plant damage state to core damage frequency for internal events

\begin{tabular}{|c|c|c|c|c|}
\hline \multirow[b]{2}{*}{ PDS Group } & \multicolumn{2}{|c|}{ NUREG-1150 } & \multicolumn{2}{|c|}{ IPE } \\
\hline & $\begin{array}{c}\text { Mean Frequency } \\
\text { (per year) }\end{array}$ & Fraction of CDF & $\begin{array}{c}\text { Mean Frequency } \\
\text { (per year) }\end{array}$ & Fraction of $\mathrm{CDF}$ \\
\hline LOCA PDS-2 & $6.0 \times 10^{-6}$ & 0.150 & $2.17 \times 10^{-5}$ & 0.290 \\
\hline $\begin{array}{l}\text { Station Blackout } \\
\text { Short-term PDS-1 } \\
\text { Long-term PDS-3 } \\
\text { TOTAL }\end{array}$ & $\begin{array}{l}5.4 \times 10^{-6} \\
2.2 \times 10^{-5} \\
2.7 \times 10^{-5}\end{array}$ & $\begin{array}{l}0.133 \\
0.542 \\
0.675 \\
\end{array}$ & $3.21 \times 10^{-5}$ & 0.428 \\
\hline $\begin{array}{l}\text { Transients } \\
\text { Transients PDS-5 } \\
\text { ATWS PDS-6 } \\
\text { TOTAL }\end{array}$ & $\begin{array}{l}2.1 \times 10^{-6} \\
1.6 \times 10^{-6} \\
3.7 \times 10^{-6}\end{array}$ & $\begin{array}{l}0.052 \\
0.039 \\
0.091\end{array}$ & $9.14 \times 10^{-6}$ & 0.122 \\
\hline Event V PDS-4 & $1.6 \times 10^{-6}$ & 0.039 & $1.61 \times 10^{-6}$ & 0.021 \\
\hline SGTR PDS-7 & $1.8 \times 10^{-6}$ & 0.045 & $1.04 \times 10^{-5}$ & 0.139 \\
\hline $\mathrm{CDF}$ & $4.06 \times 10^{-5}$ & & $7.495 \times 10^{-5}$ & \\
\hline
\end{tabular}


Table F.3 Summary of Surry SCDAP/RELAP5/MOD3 results (in minutes)"

\begin{tabular}{lrrrrrr}
\hline \hline & \multicolumn{7}{c}{ Case } \\
\cline { 2 - 7 } Event & Base & 2 & 3 & 4 & 5 & 6 \\
\hline Core uncovery & 176.7 & 177.3 & 189.3 & 167.7 & 189.3 & 167.7 \\
First fuel clad failure & 235.5 & 206.0 & 220.5 & 197.3 & 220.5 & 205.2 \\
Surge line failure & 237.5 & 215.5 & 337.2 & $>463.3^{\mathrm{a}}$ & 337.2 & $>396.7^{\mathfrak{a}}$ \\
First hot leg failure & 258.3 & 234.3 & 334.8 & $>463.3^{\mathrm{b}}$ & 334.8 & $>396.7^{\mathrm{b}}$ \\
First fuel melting & 278.3 & 253.0 & 241.8 & 234.8 & 241.8 & 345.0 \\
First core relocation & 480.8 & 257.8 & 403.3 & 426.0 & 403.3 & 383.8 \\
Lower head failure & 482.0 & 260.1 & 405.7 & 433.0 & 479.6 & 389.8 \\
RCS pressure at lower head & 16.0 & 16.0 & 8.6 & 1.4 & 6.5 & 1.4 \\
failure (MPa) & & & & & & \\
\hline \hline
\end{tabular}

- Listed values do not include credit for depressurization that could occur through potential ex-vessel failures before lower head failure.

b A greater-than sign $(>)$ indicates that the event had not occurred by the end of the calculation at the indicated time.

Table F.4 Probabilities for a surge line or hot leg failure with RCS depressurization to 1.38 MPa (or less) before lower head failure given the occurrence of the specified scenarios for Surry

\begin{tabular}{lc}
\hline \hline Scenario & Probability \\
\hline 1. TMLB' sequences without RCP seal leaks & 0.98 \\
2. TMLB' sequences with seal leaks of $250 \mathrm{gpm}$ per RCP & 0.98 \\
3. TMLB' sequences with seal leaks of $480 \mathrm{gpm}$ per RCP & 0.0 \\
4. TMLB' sequences with stuck-open or latched-open PORVs & 1.0 \\
\hline \hline
\end{tabular}


Table F.5 Probabilities for being at low, intermediate, and high RCS pressure at the time of reactor vessel breach given the occurrence of the specified scenarios without accidentinduced RCS failures for Surry

\begin{tabular}{|c|c|c|c|}
\hline \multirow[b]{2}{*}{ Scenario } & \multicolumn{3}{|c|}{ Probability, at vessel breach, for } \\
\hline & $\begin{array}{c}\text { High RCS } \\
\text { Pressure } \\
\text { (> } 6.89 \mathrm{MPa})\end{array}$ & $\begin{array}{c}\text { Intermediate RCS } \\
\text { Pressure } \\
(1.38-6.89 \mathrm{MPa})\end{array}$ & $\begin{array}{c}\text { Low RCS } \\
\text { Pressure } \\
(<1.38 \mathrm{MPa}) \\
\end{array}$ \\
\hline $\begin{array}{l}\text { 1. TMLB' sequences without RCP seal } \\
\text { leaks }\end{array}$ & 1.0 & 0.0 & 0.0 \\
\hline $\begin{array}{l}\text { 2. TMLB' sequences with seal leaks of } \\
250 \mathrm{gpm} \text { per RCP }\end{array}$ & 0.21 & 0.75 & 0.04 \\
\hline $\begin{array}{l}\text { 3. TMLB' sequences with seal leaks of } \\
480 \mathrm{gpm} \text { per RCP }\end{array}$ & 0.13 & 0.40 & 0.47 \\
\hline $\begin{array}{l}\text { 4. TMLB' sequences'with stuck-open } \\
\text { or latched-open PORVs }\end{array}$ & 0.0 & 0.0 & 1.0 \\
\hline
\end{tabular}

Table F.6 HPME probabilities for Surry

\begin{tabular}{lccc}
\hline \hline & \multicolumn{2}{c}{ Probability of Vessel Breach in Pressure Range } \\
\cline { 2 - 4 } Pressure Range & $\begin{array}{c}\text { Long-term } \\
\text { Station Blackout }\end{array}$ & $\begin{array}{c}\text { Short-term } \\
\text { Station Blackout }\end{array}$ & $\begin{array}{c}\text { All-Station } \\
\text { Blackout }\end{array}$ \\
\hline System setpoint (16 MPa) & 0.00434 & 0.00066 & 0.00500 \\
High (6.89 - 16 MPa) & 0.01457 & 0.00033 & 0.01490 \\
Intermediate (1.38 - 6.89 MPa) & 0.05565 & 0.00113 & 0.05678 \\
Low ( < 1.38 MPa) & 0.72844 & 0.19488 & 0.92332 \\
\hline \hline
\end{tabular}




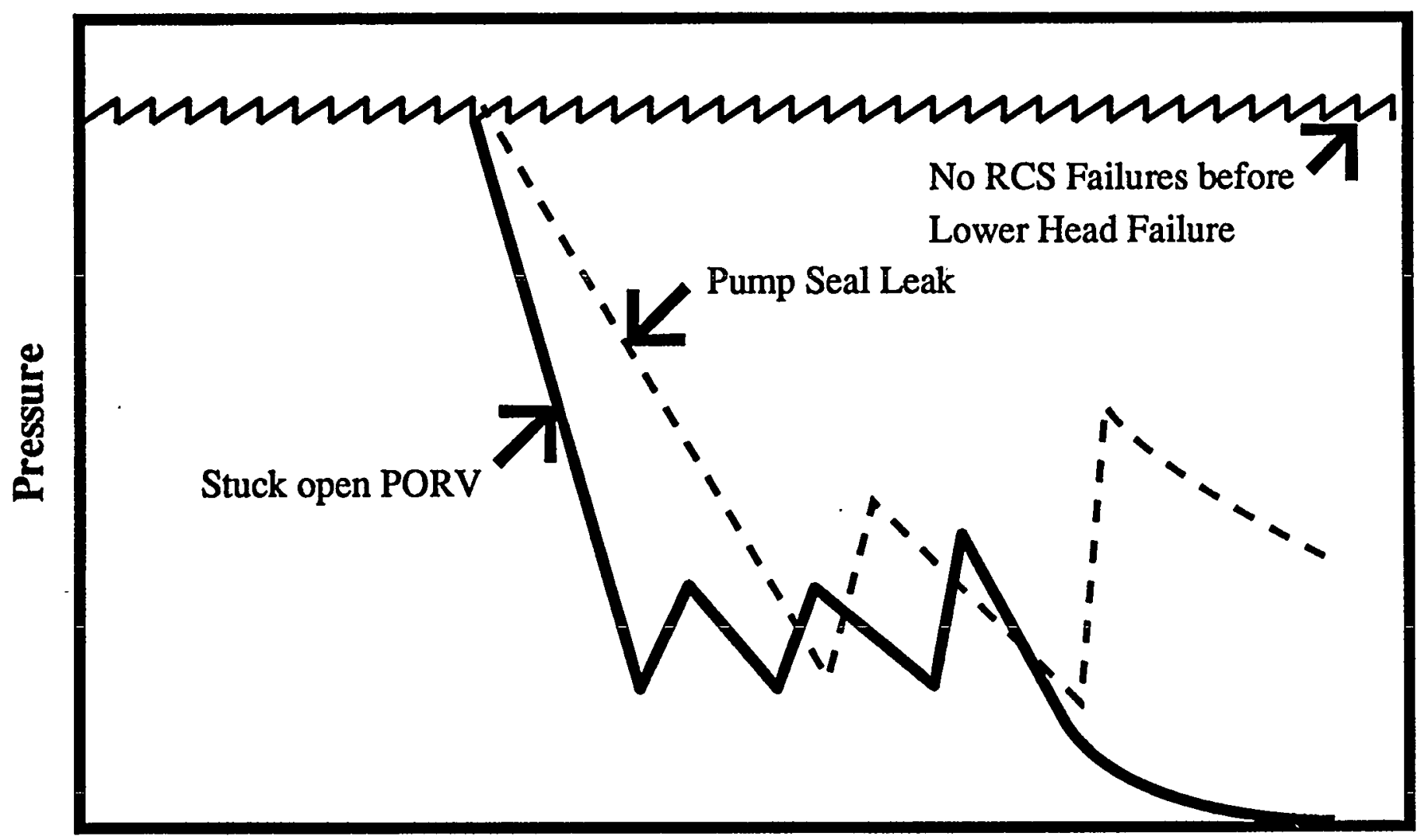

time/vessel failure time

Figure F.1. RCS pressure response for various sequences. 


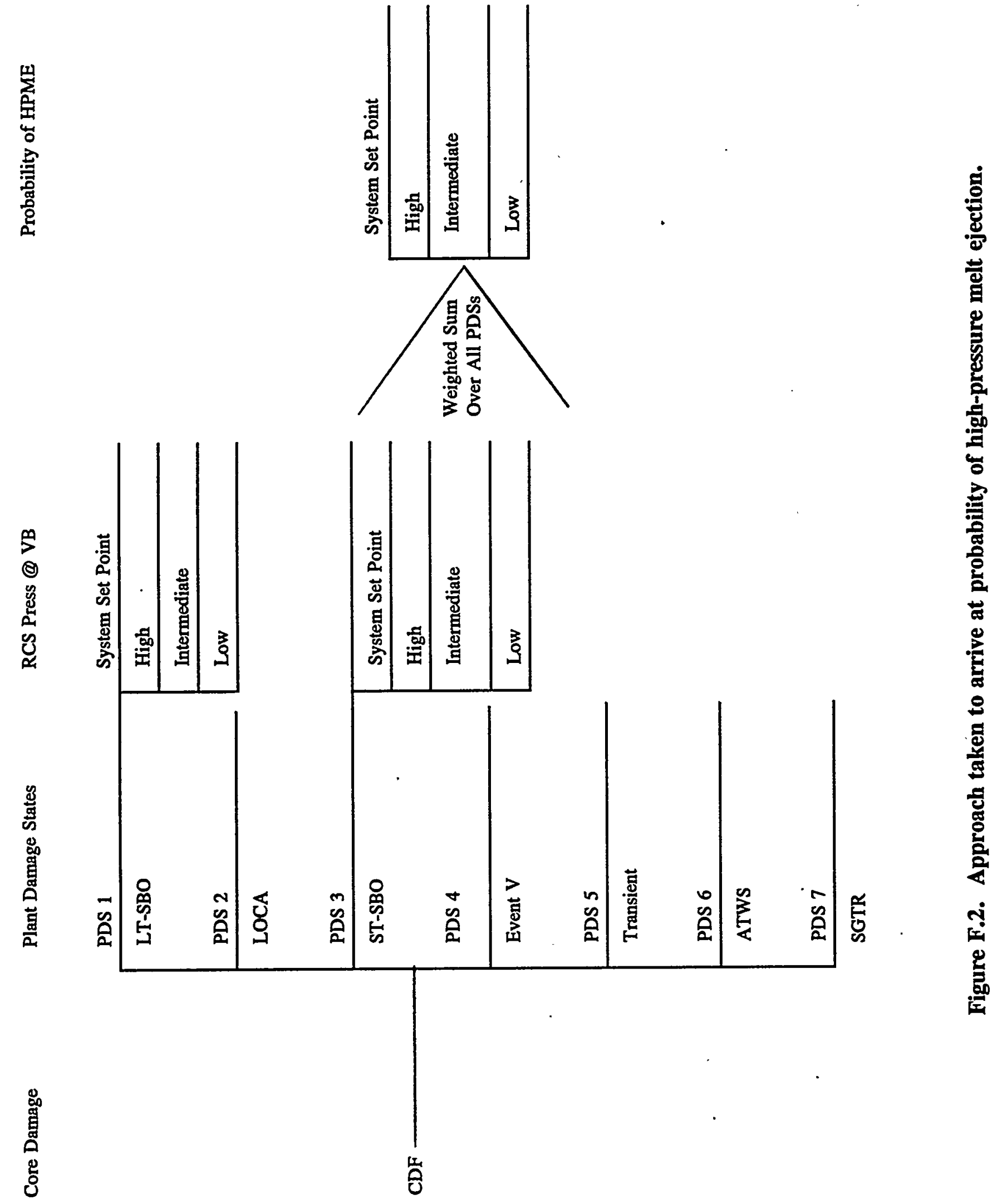




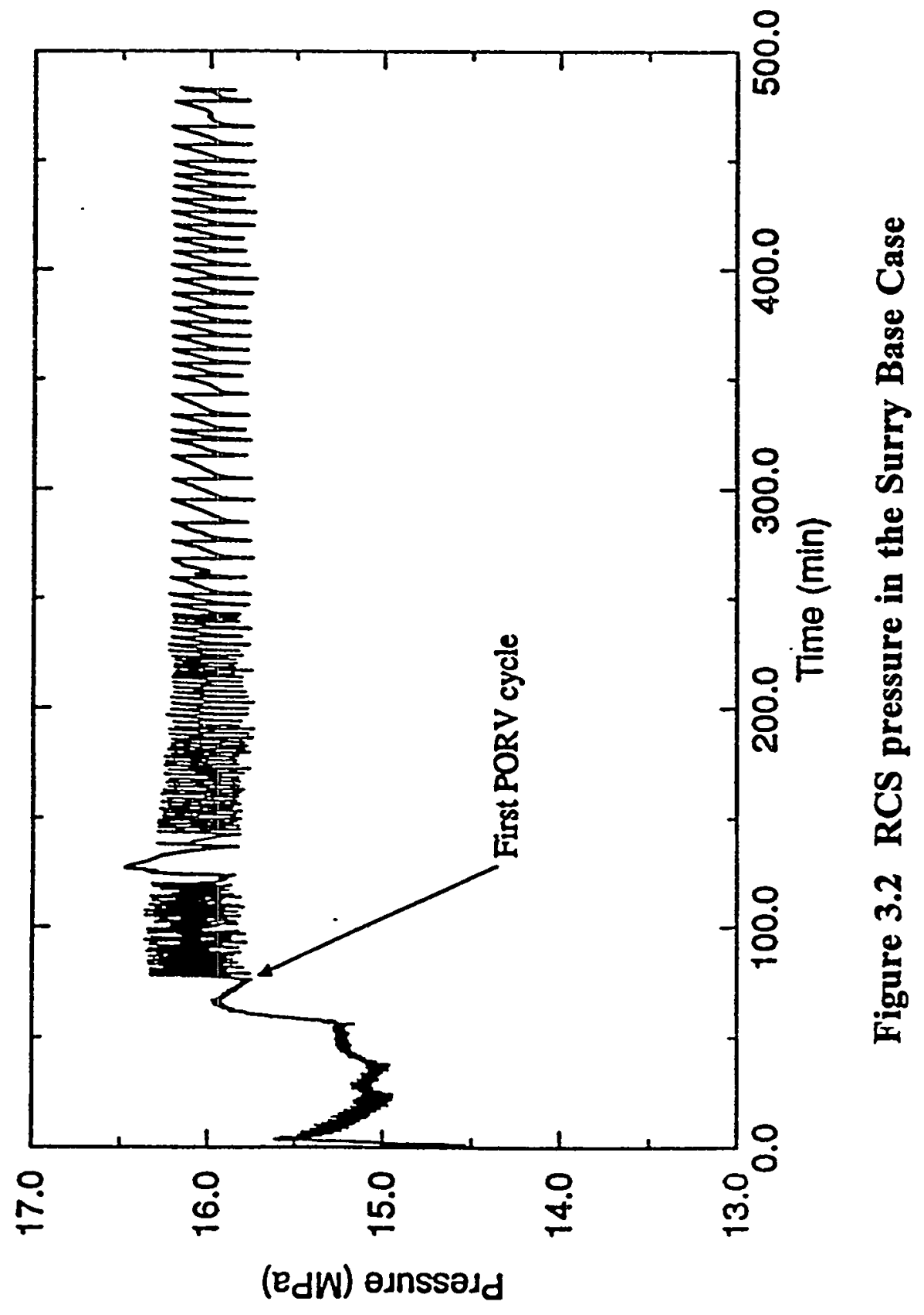

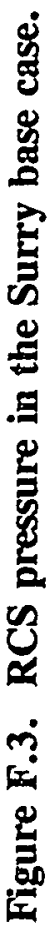




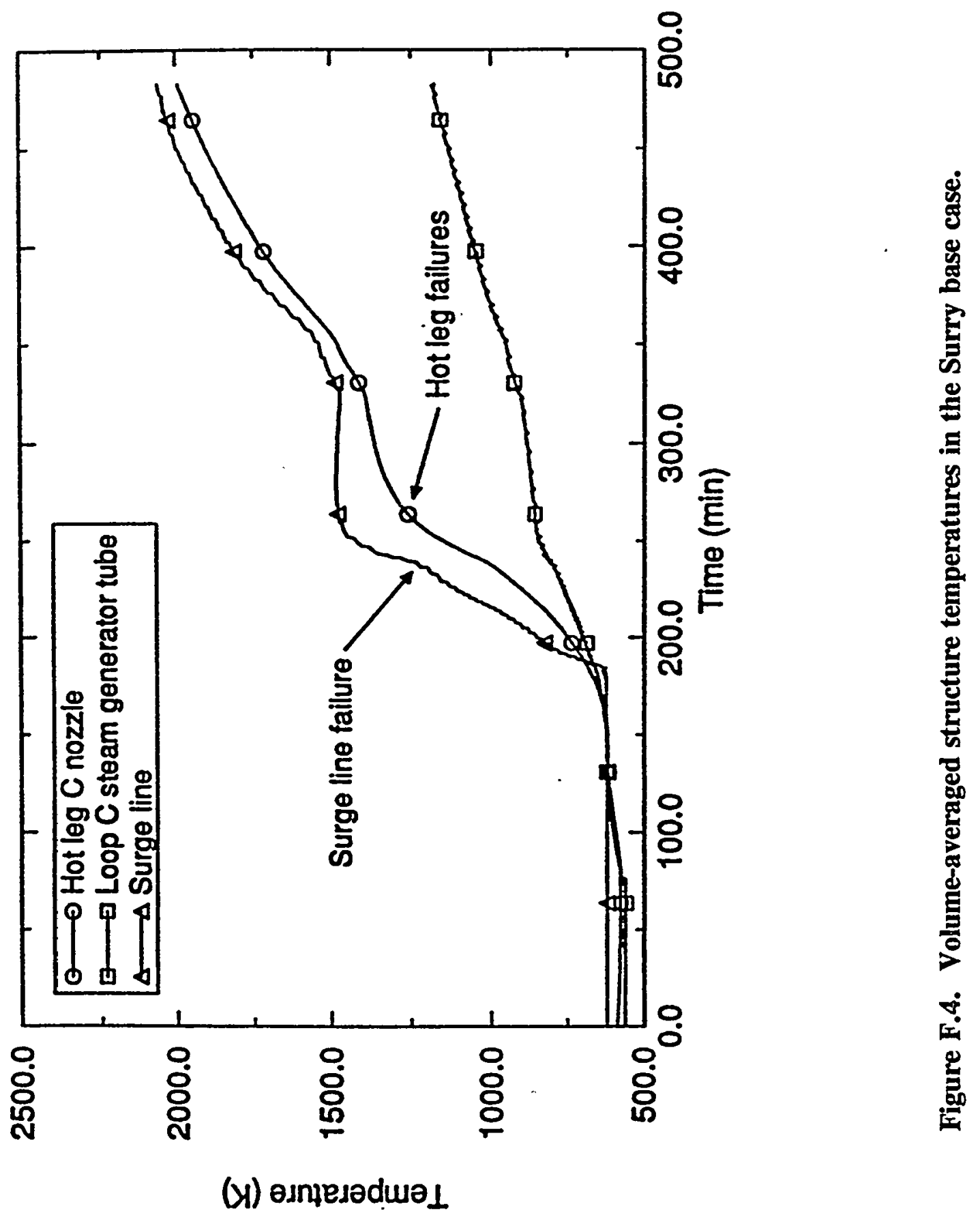




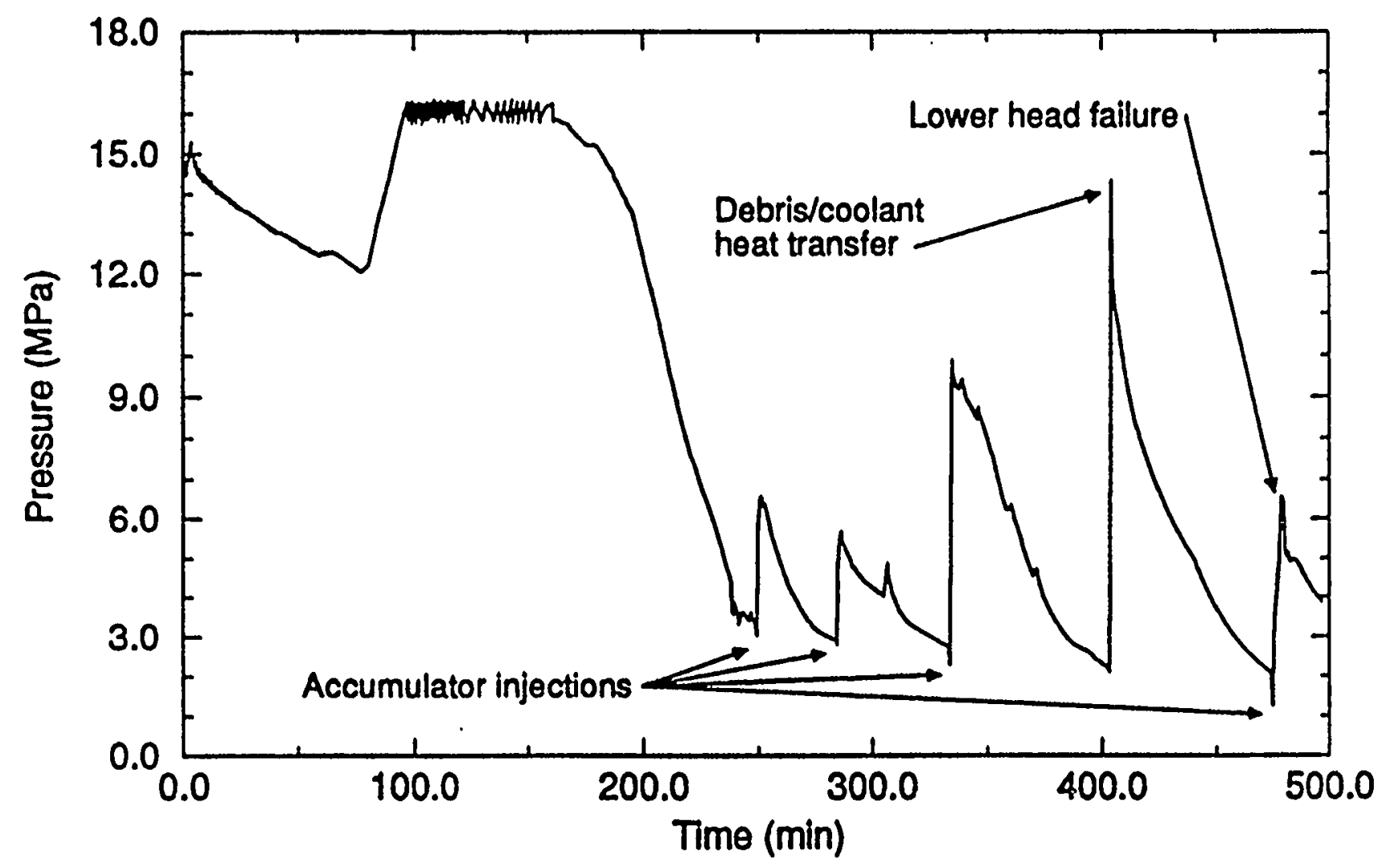

Figure F.5. RCS pressure in Surry case 5. 


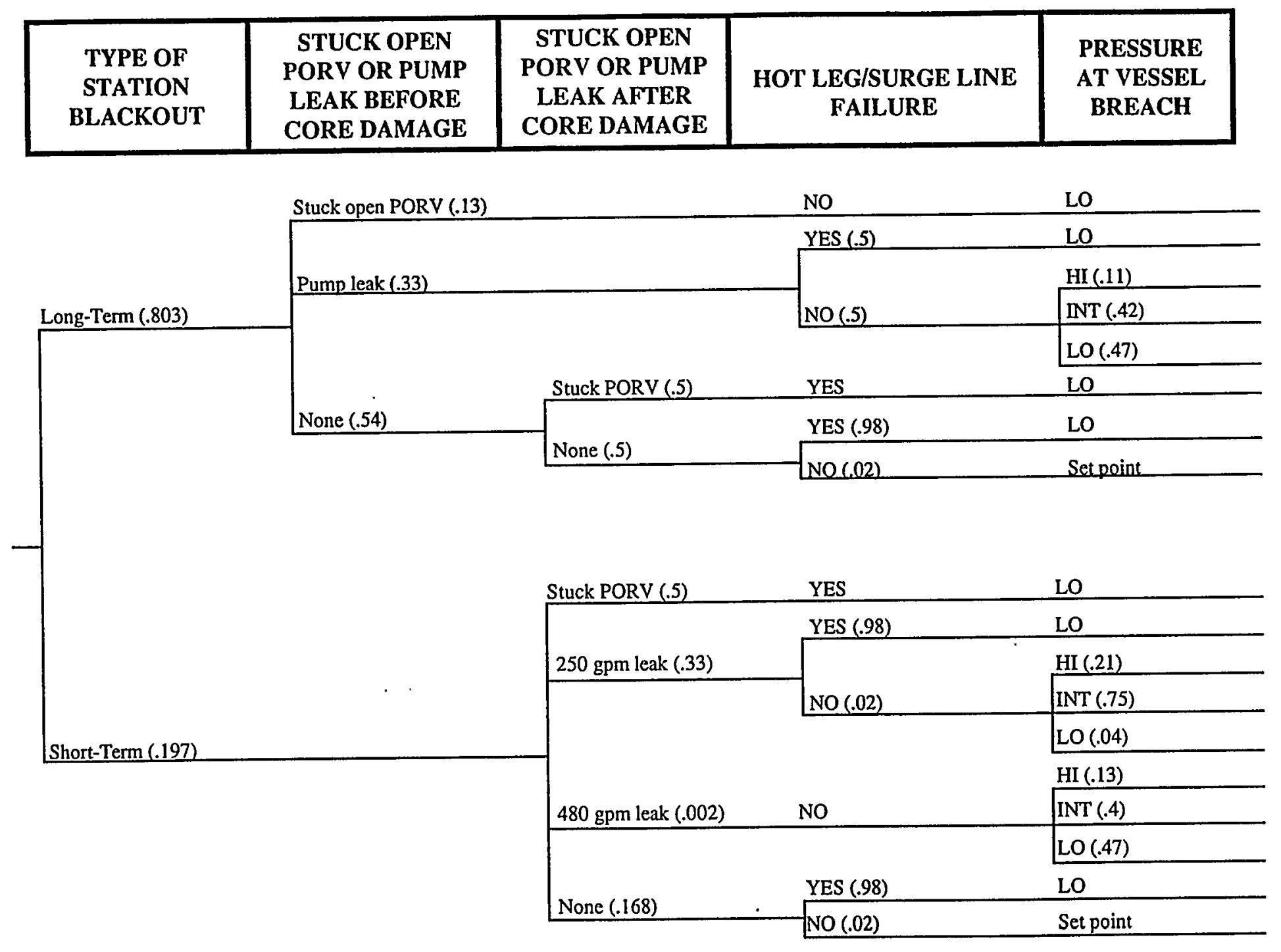

Figure F.6. Event tree for assessing HPME probability for Surry. 


\title{
APPENDIX G \\ Comparison of CONTAIN and TCE Calculations
}

\author{
Kenneth E. Washington and David S. Stuart \\ Sandia National Laboratories
}

\section{G.1 Introduction}

This appendix presents the results of nine series of CONTAIN code calculations used to model DCH loads for the Surry plant. Each series varies one or more of the basic CONTAIN modeling parameters, such as those controlling $\mathrm{H}_{2}$ ignition temperatures, heat losses to containment structures, debris settling, and participation of codispersed cavity water. The primary objective of this appendix is to compare the CONTAIN results with those obtained using the two-cell equilibrium (TCE) models assuming a similar set of initial and boundary conditions. Secondary objectives include assessing the sensitivity of the CONTAIN results to the parametric assumptions included in each of the nine series.

Three.specific cases have been selected for the CONTAIN/TCE comparisons (referred to here as V, Va, and VI). Initial conditions for these cases were selected near the upper end of the mass distributions for Scenarios V, Va, and VI described in Section 3 of the main body of the report. The first two cases are full-pressure cases (16 MPa), while the third is a partially depressurized ( $8 \mathrm{MPa})$ case. The nine sensitivity studies will be performed on each of the three cases (V, Va, and VI) for a total of 27 CONTAIN calculations.

Differences observed between the Surry loads and supporting results obtained using these two independently developed and validated models are discussed in this appendix, with special attention given to the cases where CONTAIN gives similar or greater loads than TCE. This comparison is important because both models have been favorably validated against the available DCH database, yet there are potentially important modeling differences. These differences are driven by differing underlying assumptions and interpretations of $\mathrm{DCH}$ phenomena and the experimental database. The purpose of the comparisons in this appendix is to quantitatively assess the impact of these differences. In particular, we will identify the extent to which TCE is conservative (relative to CONTAIN) for the selected cases.

The most significant difference between the two models is that CONTAIN explicitly includes transient models representing the competition of energy addition to and removal from the 
containment atmosphere, while TCE does not. In particular, the CONTAIN models include chemical reactions, heat and mass transfer, debris transport and trapping, and hydrogen combustion that compete with heat transfer to containment structures. On the other hand, TCE represents $\mathrm{DCH}$ using an equilibrium model, where only combustion of preexisting hydrogen is allowed to compete with heat losses to containment structures.

The nine series of CONTAIN sensitivity studies described in this appendix will explore conditions under which the TCE approximations lead to more and less conservative predictions than CONTAIN. In those instances where comparisons indicate TCE to be nonconservative relative to CONTAIN, physically based explanations will be sought and offered.

Section G.2 describes the CONTAIN DCH analysis methodology. It concludes with a summary of the lessons learned from the assessment activities that are applied to the CONTAIN Surry plant analyses. Section G.3 lists the parameter matrix used for the CONTAIN sensitivity studies. Section G.4 describes the CONTAIN results compared with TCE and the impact of those CONTAIN parameters varied for the sensitivity studies on containment loading. Section G.4, the final section, includes a discussion of insights from these comparisons.

\section{G.2 CONTAIN DCH Analysis Methodology}

The purpose of this section is to describe the methodology used in applying the CONTAIN $\mathrm{DCH}$ models to the quantification of DCH loads in the Surry plant. A brief overview of previous validation efforts and results is also included.

A detailed description of the DCH models available in CONTAIN is provided in Washington (1994) and a detailed assessment of the CONTAIN model against the DCH database is described in Williams et al. (1994). A short summary is given in Appendix C of this report.

The CONTAIN DCH analysis methodology consists of a fixed input prescription that evolved out of the assessment of CONTAIN against the available DCH experimental database. This evolution proceeded in the following four phases:

1. Early experiment analyses and plant calculations 
2. Assessment against high-temperature inert limited flight path (LFP) and water cavity (WC) data

3. Assessment against high-temperature chemically reactive integral-effects test (IET) data

4. Selection and assessment of entrainment correlations against cold simulant data and selected IET experiments

The first phase focused on the heat and mass transfer DCH models in CONTAIN. This phase spanned several prior years and included application of earlier versions of the CONTAIN $\mathrm{DCH}$ models. Many insights into the uncertainties in $\mathrm{DCH}$ were identified as a result of these early calculations (Williams, 1987a, 1987b; Williams and Louie, 1988; Gido et al., 1991; and Williams and Gregory, 1990). These insights motivated the development of several new models, such as drop size distributions, debris-gas slip flow, diffusion flame burning, volumetric hydrogen recombination, and improved models for trapping. Validation of these modeling improvements and new models were the focus of the LFP, WC, and IET assessment activities in the second and third phases.

An important feature of the second-phase assessment was that an approximation to the known experimental debris dispersal fraction and rate was used as input, an approach intended to remove some of the uncertainty about entrainment phenomena from the assessment process. A uniform input methodology for nonentrainment processes was developed during this effort and applied to all of the LFP and WC tests (Williams, 1992a). The calculated peak pressures and hydrogen generation compared favorably with the measured results. An important insight from the second phase of the model validation was support for the theory that debris in the cavity and immediate subcompartments interacts with blowdown steam to produce hydrogen (Williams, 1992b).

Minor refinements justified by the LFP and WC assessments were made to the analysis methodology (i.e., input prescription). The prescription was then applied to the assessment against the IET experimental database in the third phase. As in the LFP and WC cases, the IET calculations were performed using an approximation to the known experimental debris dispersal fraction and rate. Again, the results obtained were favorable; however, several uncertainties were identified in this work. Most notably it was observed for the Zion IET experiments that good agreement for $\Delta \mathrm{P}$ and hydrogen production is obtained either when water in the cavity is assumed to vaporize and interact with debris in the cavity, or when nondispersed debris in the 
cavity and subcompartments is assumed to react with blowdown steam. Unfortunately the existing database cannot be used to resolve which of these processes is dominant, or whether they are relatively equal. Therefore, if water is believed to be present in the cavity, the interaction of water with debris in the cavity should be considered as a sensitivity. The standard input prescription used here includes the interaction of nonairborne debris in the cavity and subcompartments with blowdown steam, but water in the cavity is not included because it is not part of the postulated accident conditions for this study.

The fourth phase involved assessment of models for debris discharge from the reactor pressure vessel (RPV) and entrainment from the cavity. Three entrainment models--WhaleyHewitt, Levy, and Tutu--were assessed against the large body of cold-simulant experimental data in stand-alone form in the first part of the fourth phase. This phase was then extended to apply these models embedded within the CONTAIN code to the IET- 9 and IET-10 experiments. The results of the cold simulant assessment are summarized in Williams (1992c). These efforts showed that the available correlations can be tuned (i.e., using a geometry-dependent cavity coefficient) to perform reasonably well for specific cold-simulant experimental series. However, the models require different cavity coefficients in order to obtain favorable comparisons across different geometries and experimental series. Further, when applied to the high-temperature IET-9 and IET-10 tests, the models require yet another cavity coefficient to obtain good agreement. On a more positive note, the predicted peak pressures using the Whaley-Hewitt and Levy models for IET-9 and IET-10 were not very sensitive to the predicted entrainment rates. This insensitivity is most likely attributable to the large dispersal fractions in the tests.

In the calculations presented here, dispersal fractions are assumed to be 100 percent for cases V and Va, and 85 percent for case VI to match the TCE calculations; therefore, the dispersal correlations are not needed. In addition, no attempt was made to use the CONTAIN models for debris entrainment fraction and rate. Instead, the TCE coherence ratio model was used as a stand-alone side calculation and the results translated into an equivalent entrainment rate for use in CONTAIN. The entrainment fractions were specified to match the fractions assumed in the TCE analysis as shown in Table G.1. For processes that are more completely understood, a standard analysis methodology for mechanistic models in the CONTAIN code was used. In particular, the models in CONTAIN for debris-gas heat transfer, chemistry, particle trapping, debris transport, and hydrogen transport and combustion were used. 
For the CONTAIN analyses described in the next section, the Surry containment was represented using a 16 cell nodalization plus a cell for the RCS to generate the gas blowdown. The input deck used in this study was adopted from the deck used in previous DCH and nonDCH containment load analyses (Williams et al., 1987a; Williams and Louie, 1988; Gido et al., 1991); therefore, it has been extensively checked for accuracy with respect to the Surry plant.

\section{G.3 The Sensitivity Study Parameter Matrix}

Three specific cases. (V, Va, and VI) were selected for the CONTAIN/TCE comparisons. These cases were selected near the upper end of the mass distributions described in Section 3 of the main body of the report. The first two cases are full-pressure scenarios (16 MPa), while the third case is a partially depressurized $(8 \mathrm{MPa})$ case. The second case is further characterized by a significantly higher initial mole fraction of $\mathrm{H}_{2}$ in the containment atmosphere because active containment cooling was assumed to condense steam from the containment atmosphere prior to vessel failure. The remaining initial and boundary conditions for the cases performed are given in Table G.1.

Nine variations of these scenarios were run with CONTAIN using various combinations of modeling options. Table G.2 summarizes the modeling assumptions included with each of the variations. Modeling options which differ from the base case are indicated with shading on the table.

\section{G.4 Discussion of Results}

For reference, a relatively complete list of results, along with the corresponding input parameters, is given in Table G.4. The remainder of this discussion will focus on key trends seen in the results.

\section{G.4.1 General Trends in the CONTAIN Results}

Figure G.1 shows all the peak pressure results, grouped by scenario. The peak pressures corresponding to those cases where temperatures exceeded the ignition temperatures for preexisting $\mathrm{H}_{2}$ are highlighted with $\mathrm{a} \otimes$ in the figure. Before examining the specific differences 
between the TCE and CONTAIN results, a review of the CONTAIN sensitivity studies leads to the following general conclusions:

1. The pressure results were primarily sensitive to switching off heat transfer (the last three on the right of each cluster), which typically added around 1 bar.

2. Cases in which preexisting hydrogen burned tended to give significantly higher pressures than corresponding cases when it did not. This threshold effect is characteristic of hydrogen combustion; in these runs, combustion of preexisting hydrogen occurred when the temperature of the atmosphere exceeded the user-specified SRTEMP, which ranged from 600 to $2000 \mathrm{~K}$. Because the adiabatic cases result in higher temperatures, they tended also to be the cases with combustion of preexisting hydrogen, a positive feedback effect that is somewhat artificial in these sensitivity studies (but that could qualitatively be accurate in some scenarios).

3. Other parameters or model choices did not have very large effects. These include the alternative gravitational fall time trapping model, turning off interactions between the atmosphere and nonairborne debris, introducing codispersed water, and the very small particle case (which was chosen to reproduce the thermal-chemical equilibrium assumptions in TCE).

\section{G.4.2 Comparison with TCE Results}

The TCE temperature and pressure results agree quite well with the nonadiabatic CONTAIN results for cases V and VI. For case Va, the TCE results lie somewhat between the CONTAIN adiabatic and nonadiabatic results.

Key results obtained using TCE and CONTAIN are shown in T'able G.3. This table includes the base case CONTAIN results and the results of two of the nine sensitivity studies. The first sensitivity study, Sens \#2, introduces additional conservatism by forcing preexisting hydrogen to burn at temperatures above $600 \mathrm{~K}$, as opposed to the $950 \mathrm{~K}$ base case. The purpose of this sensitivity study is to determine the magnitude of the effect of burning the preexisting hydrogen should it be allowed to burn and compete with heat loss mechanisms. This was done using CONTAIN rather than TCE because such a sensitivity with TCE would yield significantly higher 
loads of less utility because there is no competition from heat loss. The second sensitivity, Sens $\# 8$, is an adiabatic calculation using CONTAIN. In this calculation the burning of all preexisting hydrogen was disabled by setting SRTEMP $=2000 \mathrm{~K}$ to allow a more direct comparison with the CONTAIN and TCE base cases in which preexisting hydrogen did not burn. Transient CONTAIN pressure, temperature, and hydrogen combustion results are shown in Figures G.2 through G.4 for the base cases.

The first thing to note about the results shown in Table G.3 is that the base case predictions using CONTAIN and TCE are in very close agreement with each other for cases V and VI. This is partly because containment temperatures in the dome are sufficiently low that for these cases CONTAIN's detailed treatment of heat transfer gives results that are not significantly different than those for TCE. This is also due to the assumption in TCE that burning of preexisting hydrogen beyond $\mathrm{DCH}$ time scales can be neglected (this is approximately valid). The close agreement between the CONTAIN and TCE predicted loads for these cases is also supported by the essentially identical predictions for DCH-produced hydrogen and hydrogen burning on DCH time scales. The CONTAIN and TCE peak temperatures are also in good agreement with each other. Note that both models predict that containment temperatures are well below the assumed $950 \mathrm{~K}$ threshold for the burning of preexisting hydrogen.

The potential contribution of the burning of preexisting hydrogen is addressed in the Sens \#2 CONTAIN sensitivity cases. These sensitivities were performed because there is considerable uncertainty in the threshold temperature for preexisting hydrogen combustion. From more sophisticated chemical kinetics models, we in fact know that hydrogen recombination is not strictly a threshold phenomenon, and that it is a function of temperatures and concentration. Moreover, there remains significant uncertainty regarding the recombination of hydrogen under DCH conditions, where hot debris particles are present in the atmosphere. It has been hypothesized that under these conditions, even at temperatures below $950 \mathrm{~K}$, preexisting hydrogen may recombine rapidly enough to contribute to $\mathrm{DCH}$ loads. The recombination rate used in CONTAIN is sufficiently high (equivalent to $5 \mathrm{~m} / \mathrm{s}$ flame speed) to conservatively assess this effect. The results indicate that approximately an additional $0.1 \mathrm{MPa}$ would result if preexisting hydrogen burns. Because of the significant margin to the Surry containment failure pressure, preexisting hydrogen burning for these scenarios and this plant is not a major factor in determining whether containment failure occurs. 
The debris carryover results in Table G.3 show that the CONTAIN trapping models predict essentially the same amount of debris carryover as was assumed in the TCE analysis for the $16 \mathrm{MPa}$ cases. This result was obtained using the same prescription developed and applied to the validation of the trapping models against the DCH database (unlike the methodology for entrainment, nothing was done to the trapping or slip model input to force agreement with TCE). The agreement between the CONTAIN prediction and the TCE assumption indicates that the area ratio method used to make the TCE assumption is reasonable. This result is desirable because it allows us to compare other aspects of the modeling on an equal footing with the TCE model and therefore enables insights into the conservatism included to be more straightforwardly extracted. For the $8 \mathrm{MPa}$ case VI, CONTAIN predicted 12 percent carryover (based on melt mass at vessel failure) while TCE predicted 17.8 percent (same basis as CONTAIN). This result was somewhat expected because of the lower driving pressure in this case. This result also indicates that the 17.8 percent carryover prediction in TCE is in the conservative direction for the postulated conditions (this may not hold for other initial and boundary conditions).

The base case results for case Va in Table G.3 shows TCE to be significantly conservative relative to the base case CONTAIN results. This is explained by the fact that temperatures in the containment are sufficiently high that CONTAIN's more complete treatment of heat losses makes a significant difference in case Va. Both CONTAIN and TCE predict containment temperatures well above the $950 \mathrm{~K}$ threshold for preexisting hydrogen combustion. At these temperatures, the effect of CONTAIN's models for convection and radiation heat transfer in the dome and subcompartments diverges from the simpler TCE treatment, which only includes radiative heat losses in the dome. This difference translates into a difference in preexisting hydrogen burning before the peak load is reached. As shown in Table G.3, CONTAIN predicts $254 \mathrm{~kg}$ to burn on a DCH time scale, and TCE predicts $313 \mathrm{~kg}$. The importance of heat losses to containment structures is also shown by the Sens $\# 8$ results for all three cases. The loads increase by approximately $\sim 0.15-0.25 \mathrm{MPa}$ when heat losses are disabled. Approximately the same amount of hydrogen is burned in this problem on DCH time scales as in the TCE prediction. Beyond the DCH time scale in Sens \#8 for case Va, an additional $100 \mathrm{~kg}$ of hydrogen burns and contributes to the peak pressure in the CONTAIN result.

To summarize, for cases V and VI, the temperatures seen in the CONTAIN runs are not very high, and it is for this reason that the simplified treatment in TCE is capable of yielding results that are quite close to CONTAIN's (for V, the pressure from CONTAIN slightly exceeds 
that from TCE, while for VI, the converse is true). For case Va, where preexisting hydrogen burning results in a much higher temperature, the TCE-predicted pressure is significantly higher than the CONTAIN predictions, a result that is not surprising given the nonlinear nature of timedependent DCH phenomena, especially radiative heat transfer.

A major conclusion of this study is that, for the accident conditions, and for a broad range of sensitivity cases, the peak pressures predicted by both TCE and CONTAIN are well below the failure pressure for the Surry containment. The interactions occurring in DCH events are quite complex and the trends observed in this set of model comparisons might not extend to other accident conditions and/or other plants. However, these comparisons of two different computational models of DCH loading lend support to the notion that a basic understanding of the dominant processes involved in DCH has been achieved.

\section{G.5 References}

Gido, R.G. et al. (1991). PWR Dry Containment Parametric Studies, NUREG/CR-5630, SAND90-2339, Sandia National Laboratories, Albuquerque, NM.

Washington, K.E. (1994). Direct Containment Heating Models in the CONTAIN Code, SAND94-1073, Sandia National Laboratories, Albuquerque, NM.

Williams, D.C. (1992a). "Posttest CONTAIN Calculations for the First Integral Effects Experiment (IET-1) at the Surtsey DCH Facility" (draft), Letter Report, transmitted with letter from D.C. Williams to A. Notafrancesco, U.S. Nuclear Regulatory Commission, Washington, DC.

Williams, D.C. (1992b). "An Interpretation of the Results of Some Recent Direct Containment Heating (DCH) Experiments in the Surtsey Facility," SAND92-0442, in Proceedings of the NURETH-5 Conference, Salt Lake City, UT.

Williams, D.C. (1992c) letter report to the Accident Evaluation Branch of the U.S. Nuclear Regulatory Commission, Washington, DC.

Williams, D.C., and J.J. Gregory (1990). Mitigation of Direct Containment Heating and Hydrogen Combustion Events in Ice Condenser Plants, NUREG/CR-5586, SAND90-1102, Sandia National Laboratories, Albuquerque, NM.

Williams, D.C., and D.L.Y. Louie (1988). "CONTAIN Analyses of Direct Containment Heating Events in the Surry Plant," in Proceedings of the ANS/ENS Winter Meeting, Thermal Hydraulics Division, Washington, DC. 
Williams, D.C. et al. (1987a). Containment Loads Due to Direct Containment Heating and Associated Hydrogen Behavior: Analysis and Calculations with the CONTAIN Code. NUREG/CR-4896, SAND87-0633, Sandia National Laboratories, Albuquerque, NM.

Williams, D.C. et al. (1987b). "Integrated Phenomenological Analysis of Containment Response to Severe Core Damage Accidents," Progress in Nuclear Energy, Vol. 19, p. 69.

Williams, D.C. et al. (1994). Assessment of the CONTAIN Direct Containment Heating (DCH) Model, Sandia National Laboratories, Albuquerque, NM. 
Table G.1 DCH calculations for Surry initial and boundary conditions

\begin{tabular}{|c|c|c|c|}
\hline Case Number & V & $\mathrm{Va}$ & VI \\
\hline RCS pressure (MPa) & 16 & 16 & 8 \\
\hline RCS temperature $(\mathrm{K})$ & 700 & 700 & 1000 \\
\hline Debris temperature $(\mathrm{K})$ & 2800 & 2800 & 2800 \\
\hline RCS volume $\left(\mathrm{m}^{3}\right)$ & 238 & 238 & 238 \\
\hline Final hole size (m) & 0.44 & 0.44 & 0.47 \\
\hline $\mathrm{UO}_{2}(\mathrm{mt})$ & 30 & 30 & 55 \\
\hline $\mathrm{ZrO}_{2}(\mathrm{mt})$ & 3.3 & 3.3 & 5.9 \\
\hline $\mathrm{Zr}(\mathrm{mt})$ & 0.9 & 0.9 & 1.6 \\
\hline Steel (mt) & 1.8 & 1.8 & 2.3 \\
\hline Cavity dispersal fraction & $100 \%$ & $100 \%$ & $85 \%$ \\
\hline Containment initial pressure $(\mathrm{Pa})$ & 0.22 & $0.076^{*}$ & 0.22 \\
\hline Containment initial temperature $(\mathrm{K})$ & 400 & $314^{*}$ & 400 \\
\hline Initial mole fraction of air & 0.4 & 0.903 & 0.4 \\
\hline Initial mole fraction of steam & 0.557 & 0 & 0.557 \\
\hline Initial mole fraction of $\mathrm{H}_{2}$ & 0.043 & 0.097 & 0.043 \\
\hline Pilch coherence ratio & 0.6713 & 0.6713 & 1.6914 \\
\hline Entrainment time (s) & 4.77 & 4.77 & 6.92 \\
\hline
\end{tabular}

- These values differ slightly from those listed in Table 3.3 because these comparison calculations were performed before the initial conditions were frozen for Scenario Va. 
Table G.2 Base case and sensitivity study modeling assumptions."

\begin{tabular}{|c|c|c|c|c|c|c|c|c|}
\hline Case & $\begin{array}{l}\text { Heat Transfer } \\
\text { to Containment } \\
\text { Structures }\end{array}$ & $\begin{array}{c}\text { Ignition } \\
\text { Temperature for } \\
\text { Preexisting } \mathrm{H}_{2} \\
\text { (SRTEMP) }\end{array}$ & $\begin{array}{l}\text { Nonairborne } \\
\text { Debris } \\
\text { Interactions }\end{array}$ & $\begin{array}{l}\text { Debris } \\
\text { Particle } \\
\text { Sizes }\end{array}$ & $\begin{array}{l}\text { Diffusion Flame } \\
\text { Ignition } \\
\text { Temperature } \\
\text { (DFTEMP) }\end{array}$ & $\begin{array}{l}\text { Codispersed } \\
\text { Water }\end{array}$ & Trapping & $\begin{array}{c}\text { Characteristic } \\
\text { Dimension of } \\
\text { Nonairborne } \\
\text { Debris } \\
\text { Deposits } \\
\end{array}$ \\
\hline 1-Base & Yes & $950 \mathrm{~K}$ & $\overline{\text { Yes }}$ & Multiple & $400 \overline{\mathrm{K}}, 1000 \overline{\mathrm{K}}$ & $\overline{\text { No }}$ & TOF/KU & $\overline{0.063 \mathrm{~m}}$ \\
\hline 2 & Yes & $600 \mathrm{~K}$ & Yes & Multiple & $400 \mathrm{~K}, 1000 \mathrm{~K}$ & No & TOF/KU & $0.063 \mathrm{~m}$ \\
\hline$\overline{3}$ & Yes & $950 \mathrm{~K}$ & Yes & Multiple & $400 \mathrm{~K}, 1000 \mathrm{~K}$ & $\overline{\text { No }}$ & Gravitational & $0.063 \mathrm{~m}$ \\
\hline 4 & Yes & $950 \mathrm{~K}$ & : No : & Multiple & $400 \mathrm{~K}, 1000 \mathrm{~K}$ & No & TOF/KU & $0.063 \mathrm{~m}$ \\
\hline 5 & Yes & $950 \mathrm{~K}$ & Yes & Multiple & $400 \mathrm{~K}$ in all cells & YYes & TOF/KU & $0.063 \mathrm{~m}$ \\
\hline 6 & Yes & $950 \mathrm{~K}$ & Yes & Multiple & $400 \mathrm{~K}$ in all cells & १Yes\% & TOF/KU & $0.020 \mathrm{~m}$ \\
\hline 7 & No, adiabatic: & $950 \mathrm{~K}$ & $\overline{\text { Yes }}$ & Multiple & $400 \mathrm{~K}, 1000 \mathrm{~K}$ & No & TOF/KU & $0.063 \mathrm{~m}$ \\
\hline 8 & $\mathrm{No}_{\text {; }}$ adiabatic & $2000 \mathrm{~K}$ & Yes & Multiple & $400 \mathrm{~K}, 1000 \mathrm{~K}$ & No & TOF/KU & $0.063 \mathrm{~m}$ \\
\hline$\overline{9}$ & $\begin{array}{c}\text { No adiabatic } \\
\text { a } \\
\end{array}$ & $\begin{array}{l}\mathrm{V}-2000 \mathrm{~K} \\
\mathrm{~V}=950 \mathrm{~K} \\
\mathrm{VI}-2000 \mathrm{~K}\end{array}$ & औl & $\begin{array}{l}\text { Single, } \\
0.0005 \mathrm{~m} \\
\end{array}$ & $400 \mathrm{~K}, 1000 \mathrm{~K}$ & No & TOF/KU & $0.063 \mathrm{~m}$ \\
\hline
\end{tabular}

a Differences between sensitivity study parameters and those of the base case are shaded. 
Table G.3 Comparison of CONTAIN and TCE Surry DCH results

\begin{tabular}{|c|c|c|c|c|c|c|}
\hline Case & $\begin{array}{c}\text { Peak } \\
\text { Pressure } \\
\text { (MPa) }\end{array}$ & $\begin{array}{c}\text { Peak } \\
\text { Temp } \\
(\mathrm{K})\end{array}$ & $\begin{array}{l}\mathrm{H}_{2} \text { Prod. } \\
\text { (kg) }\end{array}$ & $\begin{array}{c}\text { Preexist. } \mathrm{H}_{2} \\
\text { Burn (kg) }\end{array}$ & $\begin{array}{c}\text { Total } \mathrm{H}_{2} \text { Burn } \\
(\mathrm{kg})^{\mathrm{a}}\end{array}$ & $\begin{array}{c}\text { Debris } \\
\text { Carryover } \\
\text { (\%) }\end{array}$ \\
\hline $\begin{array}{l}\text { Case V } \\
\text { TCE } \\
\text { CONTAIN } \\
\text { Sens \#2 } \\
\text { Sens \#8 }\end{array}$ & $\begin{array}{l}0.474 \\
0.486 \\
0.581 \\
0.614\end{array}$ & $\begin{array}{l}686 \\
689 \\
907 \\
904\end{array}$ & $\begin{array}{l}101 \\
104 \\
104 \\
104\end{array}$ & $\begin{array}{c}35 / \mathrm{NA} \\
38 / 54 \\
118 / 275 \\
23 / 23\end{array}$ & $\begin{array}{l}136 / \mathrm{NA} \\
142 / 158 \\
222 / 379 \\
127 / 127\end{array}$ & $\begin{array}{c}21 \\
20 \\
20 \\
205\end{array}$ \\
\hline $\begin{array}{l}\text { Case Va } \\
\text { TCE } \\
\text { CONTAIN } \\
\text { Sens \#2 } \\
\text { Sens \#8 }\end{array}$ & $\begin{array}{l}0.492 \\
0.366 \\
0.380 \\
0.558\end{array}$ & $\begin{array}{l}1279 \\
1230 \\
1255 \\
1528\end{array}$ & $\begin{array}{l}101 \\
104 \\
104 \\
104\end{array}$ & $\begin{array}{l}212 / \mathrm{NA} \\
150 / 263 \\
192 / 278 \\
101 / 195\end{array}$ & $\begin{array}{l}313 / \mathrm{NA} \\
254 / 367 \\
296 / 382 \\
205 / 299\end{array}$ & $\begin{array}{l}21 \\
20 \\
20 \\
20\end{array}$ \\
\hline $\begin{array}{l}\text { Case VI } \\
\text { TCE } \\
\text { CONTAIN } \\
\text { Sens \#2 } \\
\text { Sens \#8. }\end{array}$ & $\begin{array}{l}0.456 \\
0.458 \\
0.537 \\
0.653\end{array}$ & $\begin{array}{c}774 \\
705 \\
910 \\
1121\end{array}$ & $\begin{array}{l}121 \\
148 \\
148 \\
148\end{array}$ & $\begin{array}{c}42 / \mathrm{NA} \\
15 / 79 \\
69 / 269 \\
7 / 86\end{array}$ & $\begin{array}{l}162 / \mathrm{NA} \\
163 / 226 \\
217 / 417 \\
155 / 234\end{array}$ & $\begin{array}{c}17.8 \\
12 \\
12 \\
12\end{array}$ \\
\hline
\end{tabular}

a For the CONTAIN results, the first value is the amount burned after $5 \mathrm{~s}$ as an approximate measure of what is burned on DCH time scales, the second is total burned after $60 \mathrm{~s}$. The DCH time scale is estimated in TCE using a simple heat loss calculation (see Appendix $\mathrm{C}$ ). The values for preexisting hydrogen burned are nominal values based upon subtracting DCH-produced hydrogen from the total burned, i.e., as if all DCH-produced hydrogen always burned first; this is not always true in the CONTAIN model. 
Table G.4 CONTAIN DCH Surry analysis

\begin{tabular}{|c|c|c|c|c|}
\hline \multicolumn{5}{|c|}{$\begin{array}{l}\text { CONTAIN DCH Surry Analysis } \\
\text { in Support of the DCH Issue Resolution Effort }\end{array}$} \\
\hline Study & & Case V & Case Va & Case VI \\
\hline & PO RCS & 16 & $\overline{\overline{16}}$ & $\overline{8}$ \\
\hline & TO RCS & 700 & 700 & 1000 \\
\hline & Final hole size $(\mathrm{m})$ & 0.44 & 0.44 & 0.47 \\
\hline & $\mathrm{UO}_{2}(\mathrm{mt})$ & 30 & 30 & 55 \\
\hline & $\mathrm{ZrO}_{2}(\mathrm{mt})$ & 3.3 & 3.3 & 5.9 \\
\hline & $\mathrm{Zr}(\mathrm{mt})$ & 0.9 & 0.9 & 1.6 \\
\hline & Steel (mt) & 1.8 & 1.8 & 2.3 \\
\hline & Cavity dispersal fraction & $100 \%$ & $100 \%$ & $85 \%$ \\
\hline & $\overline{\mathrm{P} 0}$ containment $(\mathrm{Pa})$ & 0.22 & 0.07642 & 0.22 \\
\hline & To.containment (K) & 400 & 314 & 400 \\
\hline & Initial mole fraction of air & 0.4 & 0.903 & 0.4 \\
\hline & Initial mole fraction of steam & 0.557 & 0 & 0.557 \\
\hline & Initial mole fraction of $\mathrm{H}_{2}$ & $0 . \overline{043}$ & 0.097 & 0.043 \\
\hline & Pilch coherence ratio & 0.6713 & 0.6713 & 1.6914 \\
\hline & Entrainment time & 4.77 & 4.77 & 6.92 \\
\hline $\mathbf{1}$ & Base Case & & & \\
\hline & $\mathrm{P}_{\max }$ from $\overline{\mathrm{DCH}}(\mathrm{Pa})$ & 0.4858 & 0.3664 & 0.4578 \\
\hline & $\mathrm{T}_{\max }$ from $\mathrm{DCH}(\mathrm{K})$ & 689 & 1230 & 705 \\
\hline & Total run time (s) & 20.0 & 20.0 & 20.0 \\
\hline & Time to $\mathrm{P}_{\max }(\mathrm{s})$ & 5.4 & 8.0 & 6.8 \\
\hline & $\mathrm{H}_{2}$ burned @5s $(\mathrm{kg})$ & 141.75 & 253.58 & 163.47 \\
\hline & $\mathrm{H}_{2}$ burned @ $20 \mathrm{~s}(\mathrm{~kg})$ & 158.19 & 366.66 & 226.14 \\
\hline & $\mathrm{H}_{2}$ produced $@ 20 \mathrm{~s}(\mathrm{~kg})$ & 104.01 & 103.65 & 148.00 \\
\hline & Carryover fraction @ $20 \mathrm{~s}(\%)$ & $20.02 \%$ & $19.58 \%$ & $11.64 \%$ \\
\hline 2 & SRTEMP $=600 \mathrm{~K}$ & & & \\
\hline & $\mathrm{P}_{\max }$ from $\mathrm{DCH}(\mathrm{Pa})$ & 0.5814 & 0.3799 & 0.5372 \\
\hline & $T_{\max }$ from DCH (K) & 907 & 1255 & 910 \\
\hline & Total run time (s) & 20.0 & 20.0 & 20.0 \\
\hline & Time to $P_{\max }(s)$ & 12.0 & 5.0 & 10.5 \\
\hline & $\mathrm{H}_{2}$ burned@ $5 \mathrm{~s} \mathrm{(kg)}$ & 221.62 & 295.84 & 217.35 \\
\hline & $\mathrm{H}_{2}$ bumed @ $20 \mathrm{~s}(\mathrm{~kg})$ & 379.49 & 381.84 & 416.95 \\
\hline & $\mathrm{H}_{2}$ produced @20 s $(\mathrm{kg})$ & 104.06 & 103.77 & 147.77 \\
\hline & Carryover fraction@20s (\%) & $19.28 \%$ & $19.34 \%$ & $10.79 \%$ \\
\hline 3 & Gravitational fall & & & \\
\hline & $\mathrm{P}_{\max }$ from DCH (Pa) & 0.4852 & 0.3661 & 0.4574 \\
\hline & $T_{\max }$ from DCH $(\bar{K})$ & 684 & 1223 & 706 \\
\hline & Total run time (s) & 20.0 & 20.0 & 20.0 \\
\hline & Time to $\mathrm{P}_{\max }(\mathrm{s})$ & 5.2 & 8.0 & 6.6 \\
\hline & $\mathrm{H}_{2}$ bumed @ $9 \mathrm{~s}(\mathrm{~kg})$ & 141.47 & 252.07 & 162.74 \\
\hline & $\mathrm{H}_{2}$ burned @20 s (kg) & 157.18 & 365.13 & 224.10 \\
\hline & $\mathrm{H}_{2}$ produced@20s $(\mathrm{kg})$ & 104.02 & 103.75 & 148.02 \\
\hline & Carryover fraction@20s (\%) & $21.04 \%$ & $20.03 \%$ & $12.05 \%$ \\
\hline 4 & w/o nonairborne DI & & & \\
\hline & $\mathrm{P}_{\max }$ from $\mathrm{DCH}(\mathrm{Pa})$ & 0.4863 & 0.3633 & 0.5131 \\
\hline & $\mathrm{T}_{\max }$ from $\mathrm{DCH}(\mathrm{K})$ & 686 & 1223 & 1161 \\
\hline & Total run time (s) & 20.0 & 20.0 & 20.0 \\
\hline
\end{tabular}


Table G.4 CONTAIN DCH Surry analysis

\begin{tabular}{|c|c|c|c|c|}
\hline \multicolumn{5}{|c|}{$\begin{array}{l}\text { CONTAIN DCH Surry Analysis } \\
\text { in Support of the DCH Issue Resolution Effort }\end{array}$} \\
\hline \multirow[t]{6}{*}{ Study } & & Case V & Case Va & Case VI \\
\hline & Time to $P_{\max }(s)$ & 5.0 & $\overline{7.4}$ & 12.5 \\
\hline & $\mathrm{H}_{2}$ burned $@ 58(\mathrm{~kg})$ & 136.94 & 240.65 & 99.96 \\
\hline & $\mathrm{H}_{2}$ burned $@ 20 \mathrm{~s}(\mathrm{~kg})$ & 154.72 & 364.97 & 271.73 \\
\hline & $\mathrm{H}_{2}$ produced @ $20 \mathrm{~s}(\mathrm{~kg})$ & 104.31 & 103.61 & 130.93 \\
\hline & Carryover fraction @20 s (\%) & $20.67 \%$ & $20.17 \%$ & $30.98 \%$ \\
\hline \multirow[t]{9}{*}{5} & $5000 \mathrm{~kg}$ codispersed water, $\mathrm{DF}$ & & & \\
\hline & $\mathrm{P}_{\max }$ from $\mathrm{DCH}(\mathrm{Pa})$ & 0.4918 & 0.3607 & 0.5038 \\
\hline & $\mathrm{T}_{\max }$ from $\mathrm{DCH}(\mathrm{K})$ & 643 & 930 & 703 \\
\hline & Total run time (s) & 20.0 & 20.0 & 20.0 \\
\hline & Time to $\mathrm{P}_{\max }(\mathrm{g})$ & 6.6 & 5.2 & 5.8 \\
\hline & $\mathrm{H}_{2}$ burned $\otimes 5 \mathrm{~s}(\mathrm{~kg})$ & 127.78 & 207.56 & 190.76 \\
\hline & $\mathrm{H}_{2}$ burned $@ 20 \mathrm{~s}(\mathrm{~kg})$ & 153.82 & 242.01 & 244.35 \\
\hline & $\mathrm{H}_{2}$ produced $@ 20 \mathrm{~s}(\mathrm{~kg})$ & 101.11 & 102.17 & 153.65 \\
\hline & Carryover fraction @ $20 \mathrm{~s}(\%)$ & $20.18 \%$ & $20.58 \%$ & $11.76 \%$ \\
\hline & $5000 \mathrm{~kg}$ codispersed water, $\mathrm{DF}$ & $\dot{m}$ & & \\
\hline \multirow[t]{9}{*}{6} & & $2 \mathrm{~m}$ & & \\
\hline & $\mathrm{P}_{\max }$ from $\mathrm{DCH}(\mathrm{Pa})$ & 0.5128 & 0.4119 & 0.5186 \\
\hline & $T_{\max }$ from DCH (K) & 677 & 1206 & 730 \\
\hline & Total run time (s) & 20.0 & 20.0 & 20.0 \\
\hline & Time to $P_{\max }(\mathrm{s})$ & 8.0 & 8.8 & 5.0 \\
\hline & $\mathrm{H}_{2}$ burned $@ 5 \mathrm{~s}(\mathrm{~kg})$ & 157.05 & 280.67 & 214.09 \\
\hline & $\mathrm{H}_{2}$ burned $@ 20 \mathrm{~s}(\mathrm{~kg})$ & 176.48 & 375.43 & 247.96 \\
\hline & $\mathrm{H}_{2}$ produced @20 $(\mathrm{kg})$ & 103.28 & 103.80 & 152.40 \\
\hline & Carryover fraction @ 20s (\%) & $18.85 \%$ & $18.77 \%$ & $10.81 \%$ \\
\hline \multirow[t]{9}{*}{7} & Adiabatic & & & \\
\hline & $\mathrm{P}_{\max }$ from $\overline{\mathrm{DCH}}(\mathrm{Pa})$ & 0.7701 & 0.6051 & 0.7574 \\
\hline & $T_{\max }$.from DCH $(\mathrm{K})$ & 1164 & 1751 & 1313 \\
\hline & Total run time (s) & 80.0 & 80.0 & 59.5 \\
\hline & Time to $\mathrm{P}_{\max }(\mathrm{s})$ & 80.0 & 80.0 & 59.5 \\
\hline & $\mathrm{H}_{2}$ burned @ $5 \mathrm{~s}(\mathrm{~kg})$ & 142.53 & 268.45 & 165.25 \\
\hline & $\mathrm{H}_{2}$ burned@20 s (kg) & 384.83 & 387.10 & 428.74 \\
\hline & $\mathrm{H}_{2}$ produced @ $20 \mathrm{~s}(\mathrm{~kg})$ & 103.84 & 103.74 & 148.05 \\
\hline & Carryover fraction @ $20 \mathrm{~s}(\%)$ & $20.09 \%$ & $19.85 \%$ & $11.62 \%$ \\
\hline \multirow[t]{9}{*}{8} & Adiabatic, SRTEMP $=2000$ & & & \\
\hline & $P_{\max }$ from $\mathrm{DCH}(\mathrm{Pa})$ & 0.6135 & 0.5580 & 0.6533 \\
\hline & $\mathrm{T}_{\max }$ from DCH (K) & 904 & 1528 & 1121 \\
\hline & Total run time (s) & 80.0 & 80.0 & 80.0 \\
\hline & Time to $P_{\max }(s)$ & 80.0 & 80.0 & 80.0 \\
\hline & $\mathrm{H}_{2}$ bumed @ $5 \mathrm{~s} \mathrm{(kg)}$ & 126.98 & 204.51 & 154.59 \\
\hline & $\mathrm{H}_{2}$ bumed @ $20 \mathrm{~s}(\mathrm{~kg})$ & 126.98 & 298.70 & 234.09 \\
\hline & $\mathrm{H}_{2}$ produced @ $20 \mathrm{~s}(\mathrm{~kg})$ & 103.99 & 103.72 & 148.04 \\
\hline & Carryover fraction @ $20 \mathrm{~s}(\%)$ & $20.11 \%$ & $20.46 \%$ & $11.72 \%$ \\
\hline \multirow[t]{4}{*}{9} & Adiabatic, w/o nonairborne D & & & \\
\hline & SRTEMP (K) & 2000 & 950 & 2000 \\
\hline & $\mathrm{P}_{\max }$ from DCH (Pa) & 0.6385 & 0.6142 & 0.6569 \\
\hline & $\mathrm{T}_{\max }$ from DCH (K) & 947 & 1807 & 1136 \\
\hline
\end{tabular}


Table G.4 CONTAIN DCH Surry analysis

\begin{tabular}{|c|c|c|c|c|}
\hline \multicolumn{5}{|c|}{$\begin{array}{l}\text { CONTAIN DCH Surry Analysis } \\
\text { in Support of the DCH Issue Resolution Effort }\end{array}$} \\
\hline Study & & Case V & Case Va & Case VI \\
\hline & Total run time (s) & 80.0 & 67.5 & $\overline{80.0}$ \\
\hline & Time to $P_{\operatorname{mex}}(s)$ & 80.0 & 67.5 & 80.0 \\
\hline & $\mathrm{H}_{2}$ burned @ $98(\mathrm{~kg})$ & 127.74 & 271.26 & 117.83 \\
\hline & $\mathrm{H}_{2}$ bumed $@$ end of run $(\mathrm{kg})$ & 132.73 & 388.73 & 223.56 \\
\hline & $\mathrm{H}_{2}$ produced @ end of run $(\mathrm{kg})$ & 104.99 & 105.37 & 130.86 \\
\hline & Carryover fraction @ end of run (\%) & $21.14 \%$ & $20.75 \%$ & $12.27 \%$ \\
\hline
\end{tabular}




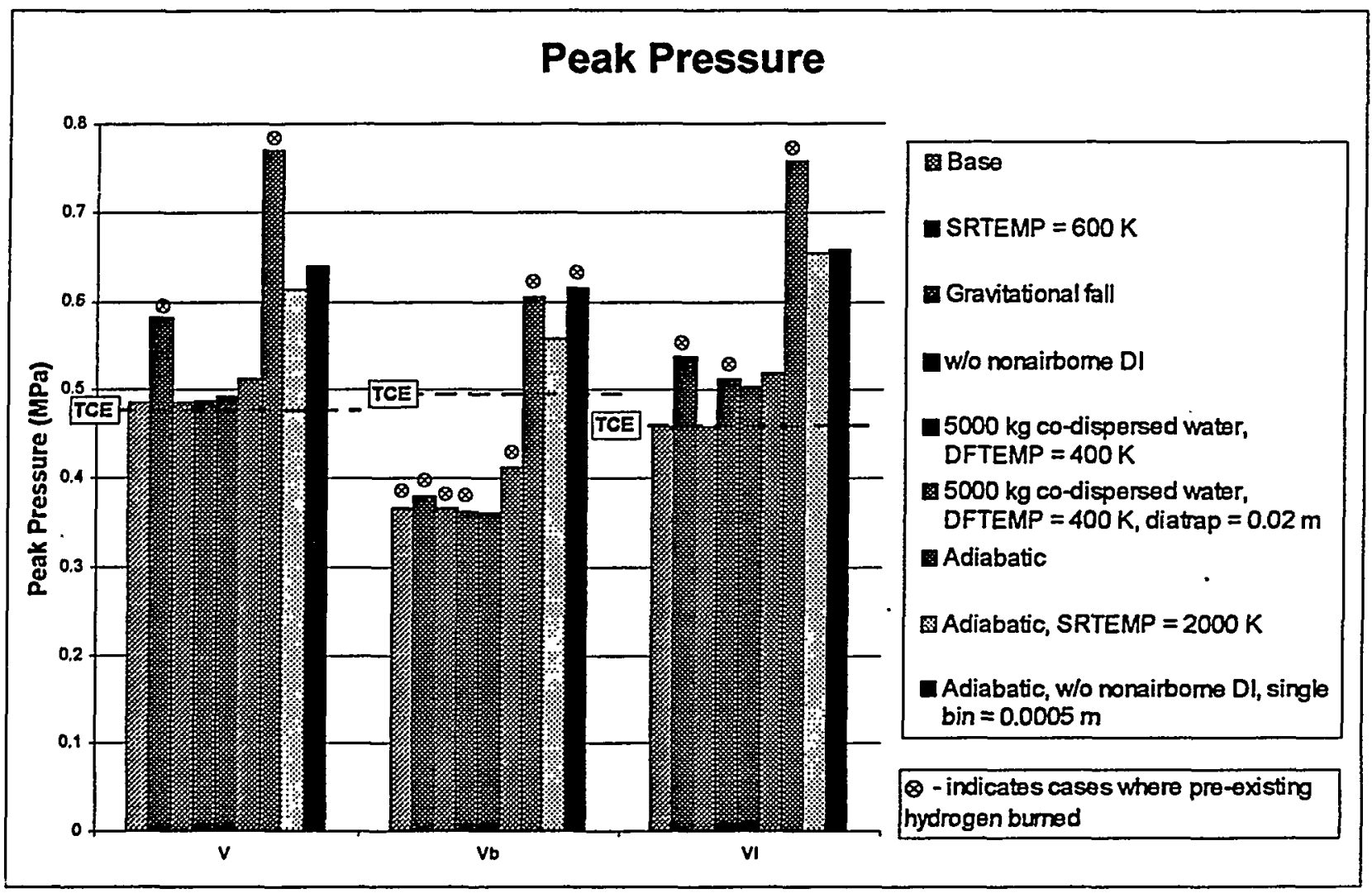

Figure G.1. Peak pressures from CONTAIN and TCE calculations of the Surry plant. 


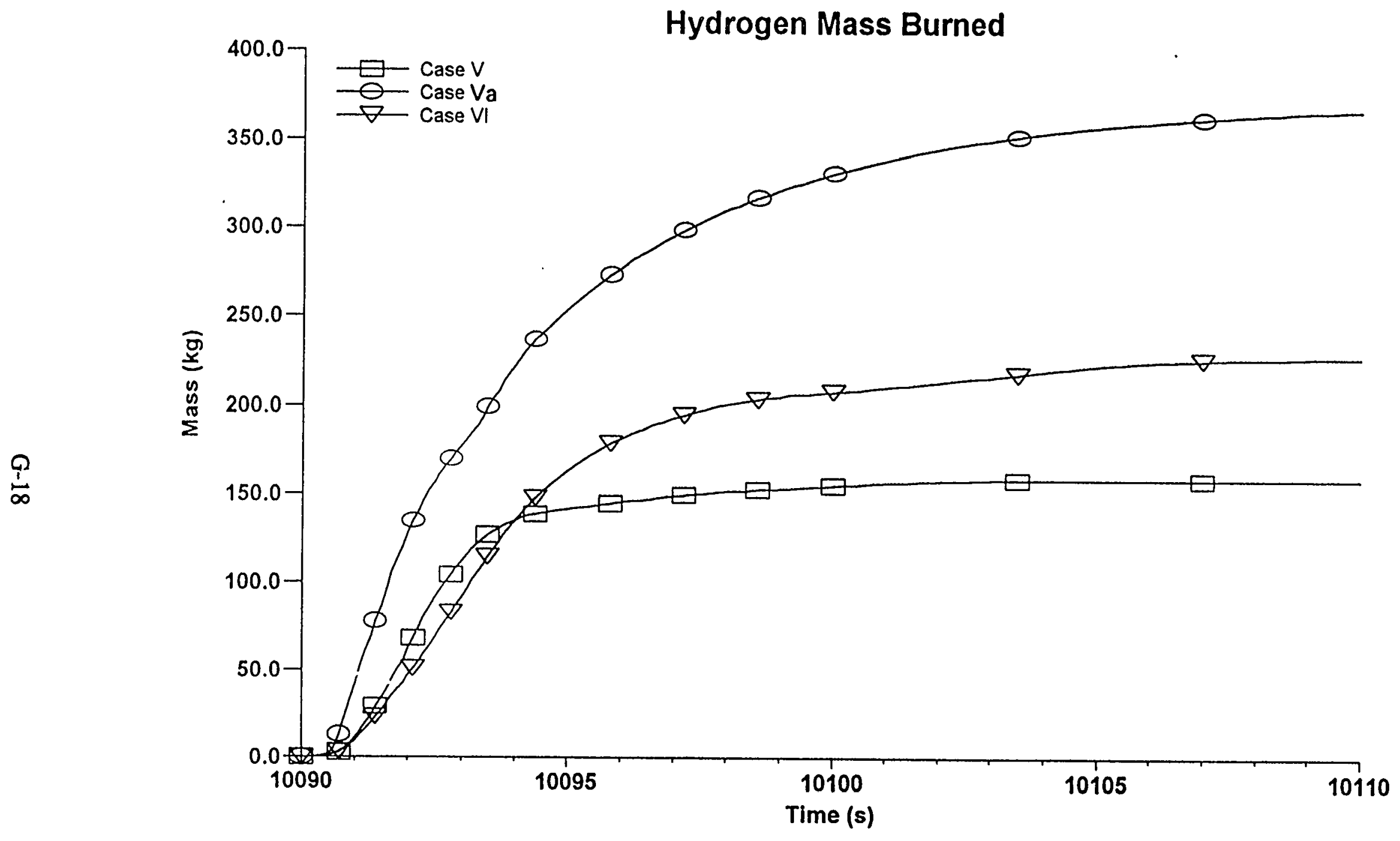

Figure G.2. CONTAIN results for hydrogen mass burned. 


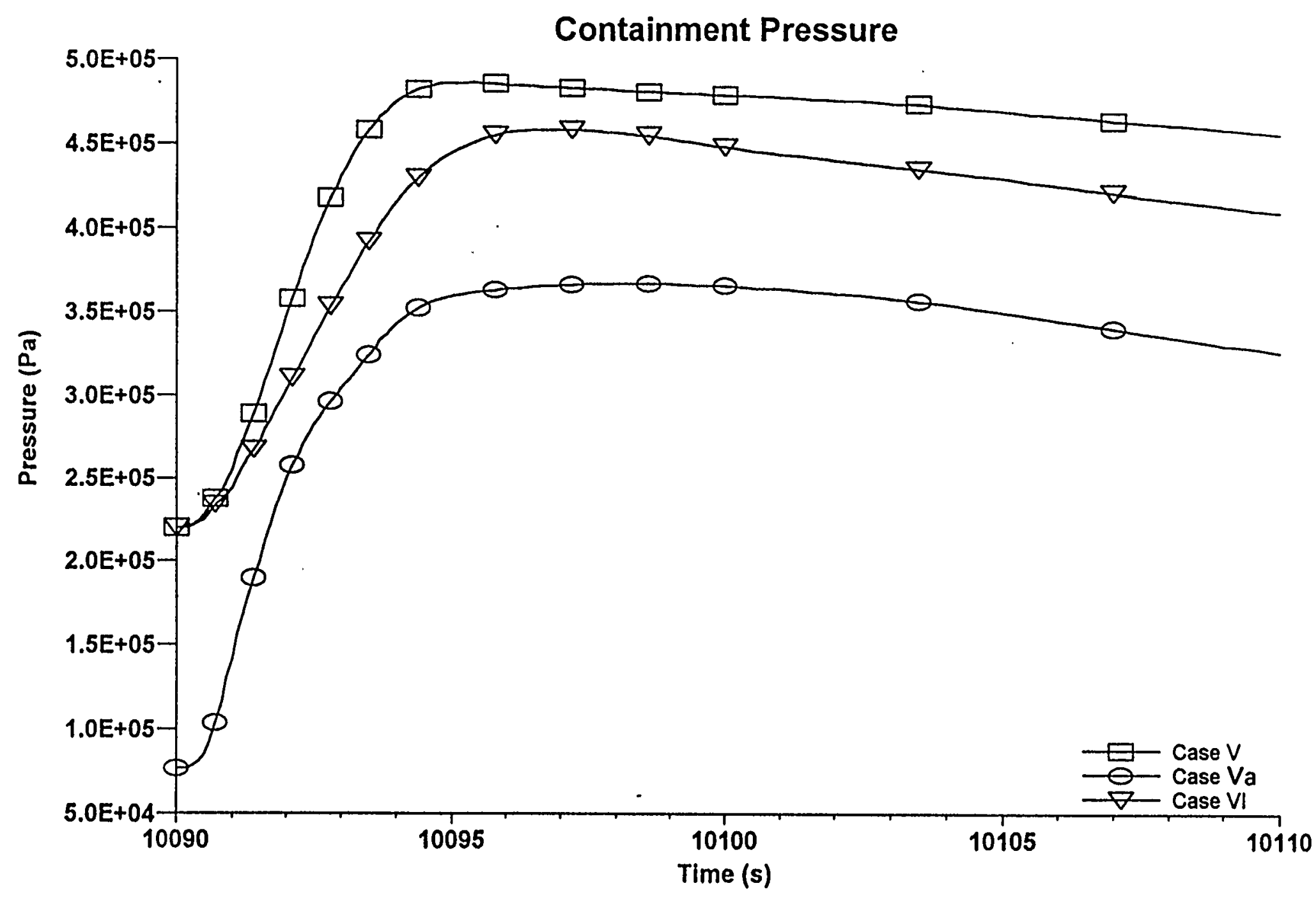

Figure G.3. CONTAIN results for containment pressure. 


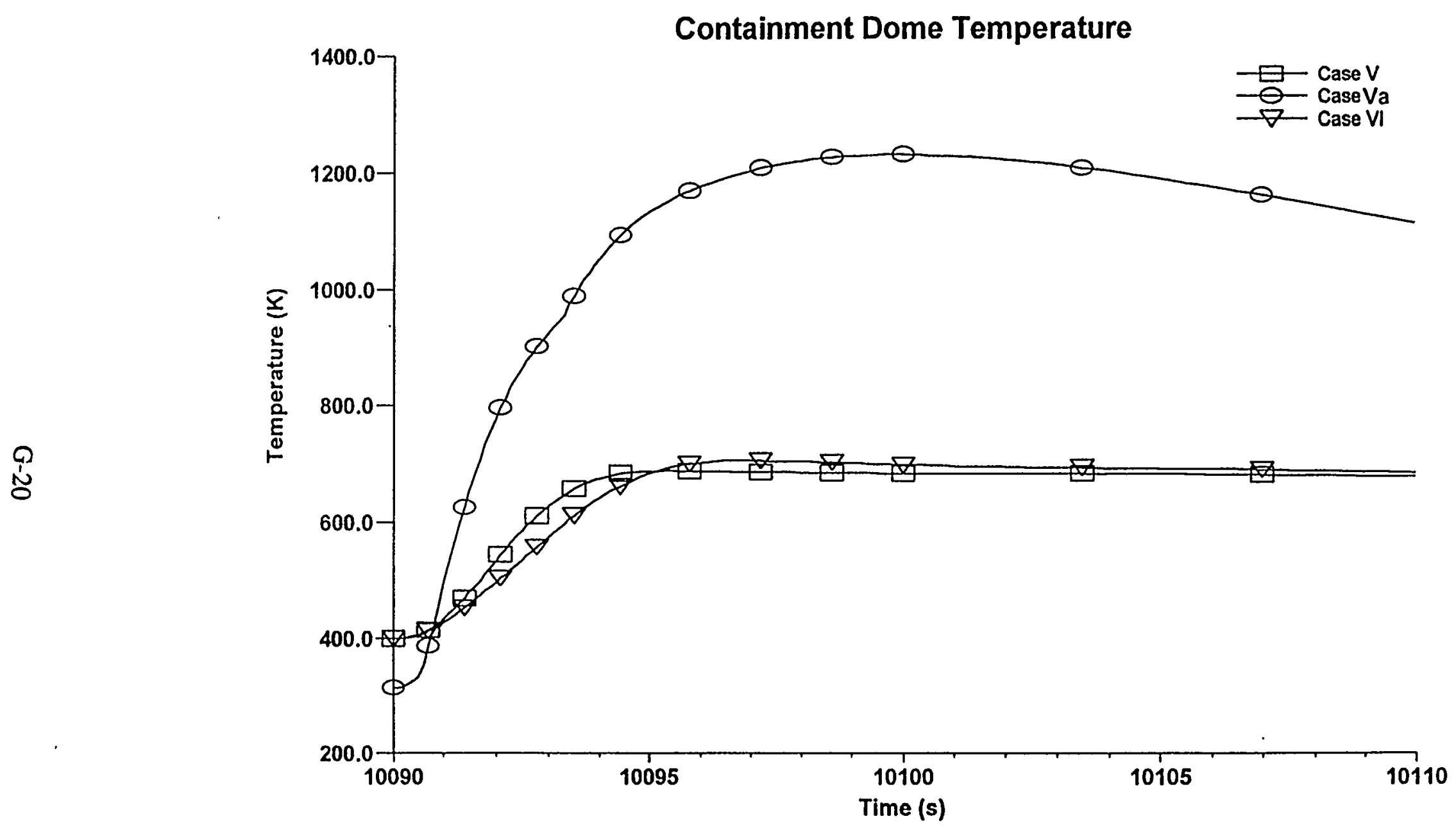

Figure G.4. CONTAIN results for containment dome temperatures. 
The Probability of Containment Failure by

Direct Containment Heating in Surry

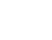

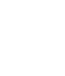

M.M. Pilch (SNL), M.D. Allen (SNL), B.W. Spencer (ANL),

K.D. Bergeron (SNL), K.S. Quick (INEL), D.L. Knudson (INEL),

E.L. Tadios (SNL) and D.W. Stamps (SNL)
8. PERFORMING ORGANIZATION - NAME AND ADDRESS III NAC, provide Division, Office or Region, U.S. Nuclear Rugulatery Commission, and mailing godress. If eontractor, Drovid name end moiling eodressil
Sandia National Laboratories
Idaho National Engineering Laboratory
Idaho Falls, ID 83415

Albuquerque, NM 87185-1137

\author{
Argonne National Laboratory \\ Argonne, IL
}

9. SPONSORING ORGANIZATION - NAME AND ADDRESS III NRC, type "Same as above": if contracior, provide NRC Division, Office or Region. U.S. Nuclear Regulatory Commission. und maillng eddress.)

Division of Systems Technology

Office of Nuclear Regulatory Research

U.S. Nuclear Regulatory Commission

Washington, DC 20555-0001

10. SUPPLEMENTARY NOTES

11. ABSTRACT (200 words or less)

This report uses the methodology and scenarios described in NUREG/CR-6075 and its supplement to address the direct containment heating (DCH) issue for the Surry nuclear power plant (NPP). Consistency of the initial distributions has been ensured by using insights from system-level codes, specifically SCDAP/RELAP5 and CONTAIN. The most usefu. Insights are that the reactor coolant system (RCS) pressure is low at vessel breach, metallic blockages in the core region do not melt and relocate into the lower plenum, and melting of upper plenum steel is correlated with hot leg failure. The SCDAP/RELAP5 output was used as input to CONTAIN to assess the containment conditions at vessel breach. The load evaluations for Surry showed no intersections of the load distributions with the containment strength distribution, and thus the DCH issue for Surry can be resolved based on containment loads alone. However, the likelihood of high RCS pressures at vessel breach was evaluated for Surry for a limited number or sequences. The probibility of RCS pressures greater than $1.38 \mathrm{MPa}$ for all station blackout scenarios without power recovery or operator intervention was found to be low (0.077). This probability could have been factored into the containment failure probability for Surry if there had been intersections of the load and strength distributions.

12. KEY WORDSIDESCR!PTORS (List words or phreses that will assist researchers in locating the report.)

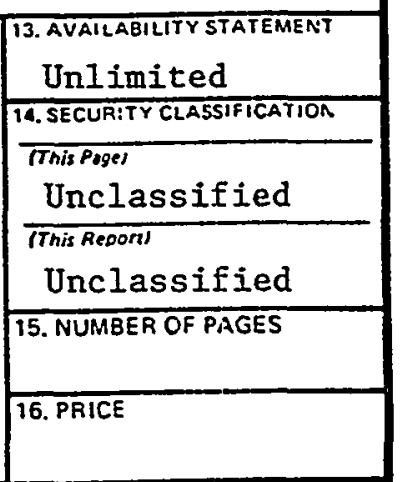

Direct Containment Heating (DCH)

high pressure melt ejection

probabilistic framework

Surry nuclear power plant

severe accident

containment failure probability

pressurized water reactor 